ANDRÉ SCHIAVON PEREZ ORTIGOSA

METODOLOGIA PARA A ANÁLISE ESTRUTURAL ESTÁTICA E DINÂMICA DE VENTILADORES CENTRÍFUGOS: EMPREGO DE MÉTODOS ANALÍTICOS E NUMÉRICOS

São Paulo

2012 
ANDRÉ SCHIAVON PEREZ ORTIGOSA

\section{METODOLOGIA PARA A ANÁLISE ESTRUTURAL ESTÁTICA E DINÂMICA DE VENTILADORES CENTRÍFUGOS: EMPREGO DE MÉTODOS ANALÍTICOS E NUMÉRICOS}

Dissertação apresentada à Escola Politécnica da Universidade de São Paulo para a obtenção do título de Mestre em Engenharia.

São Paulo 


\section{METODOLOGIA PARA A ANÁLISE ESTRUTURAL ESTÁTICA E DINÂMICA DE VENTILADORES CENTRÍFUGOS: EMPREGO DE MÉTODOS ANALÍTICOS E NUMÉRICOS}

Dissertação apresentada à Escola Politécnica da Universidade de São Paulo para a obtenção do título de Mestre em Engenharia.

Área de concentração:

Engenharia Mecânica

Orientador:

Prof. Dr. Demetrio Cornilios Zachariadis 
Autorizo a reprodução e divulgação total ou parcial deste trabalho, por qualquer meio convencional ou eletrônico, para fins de estudo e pesquisa, desde que citada a fonte.

Este exemplar foi revisado e alterado em relação à versão original, sob responsabilidade única do autor e com a anuência de seu orientador.

São Paulo, de setembro de 2012.

Assinatura do autor

Assinatura do orientador

FICHA CATALOGRÁFICA

Ortigosa, André Schiavon Perez

Metodologia para a análise estrutural estática e dinâmica de ventiladores centrífugos: emprego de métodos analíticos e numéricos / A.S.P. Ortigosa. -- ed.rev. -- São Paulo, 2012.

$161 \mathrm{p}$.

Dissertação (Mestrado) - Escola Politécnica da Universidade de São Paulo. Departamento de Engenharia Mecânica.

1. Método dos elementos finitos 2. Vibrações 3. Tensões 4. Dinâmica 5. Ventiladores I. Universidade de São Paulo. Escola Politécnica. Departamento de Engenharia Mecânica II. t. 
À Mila, meu amor.

Aos meus pais, Helenice e João Carlos, e aos meus irmãos, Leonardo e Lucas. 


\section{AGRADECIMENTOS}

Ao Prof. Dr. Demetrio Cornilios Zachariadis, que não só conduziu a pesquisa com competência e dedicação, mas que me encorajou sempre que precisei. Agradeço-o pela confiança, pelo respeito e pelos conhecimentos transmitidos ao longo da realização deste trabalho.

Ao José Roberto Mendes Morán, pela oportunidade e incentivo na realização do mestrado. Por ser inspiração e exemplo de profissional e de ser humano.

À Howden South America, por propiciar condições para que eu me dedicasse com a seriedade necessária à realização deste trabalho.

Aos colegas da Howden Technology, Samuel Orr, Ken Roberts, Colin Dunsmore e John Irons, pela generosidade com que transmitiram seus conhecimentos, sem os quais este trabalho não seria possível.

Ao meu primo Paulo José Schiavon Ara, pelos primeiros passos na busca por este sonho.

À minha família, pelo apoio constante. À minha mãe, Helenice, pelo amor permanente, pelo carinho e por me mostrar que eu nunca estarei só. Agradeço-a também pela revisão do texto da dissertação. Ao meu pai, João Carlos, não só pelo amor, mas por me ensinar que é preciso ser forte sempre. Aos meus irmãos, Leonardo e Lucas, por alegrarem a minha vida com as suas presenças.

À Mila, pelo amor incondicional, pelo apoio e incentivo ao longo destes anos, e, sobretudo, por proporcionar os momentos mais felizes da minha vida. 


\section{RESUMO}

A análise de tensões em impelidores de ventiladores centrífugos pelo método dos elementos finitos revela que seus componentes são altamente solicitados e sujeitos a campos de tensões complexos. Tradicionalmente, o projeto estrutural de impelidores centrífugos é realizado a partir do cálculo das tensões estáticas provenientes da força centrífuga, e o comportamento dinâmico do impelidor é frequentemente verificado através de estudos de vibrações livres frente ao conhecimento das fontes de excitação. Por tal abordagem não é realizada qualquer avaliação quanto aos níveis de tensões dinâmicas nos componentes do impelidor. Neste trabalho, contudo, a determinação das tensões dinâmicas é apresentada como uma importante ferramenta para avaliar a integridade estrutural de um impelidor centrífugo durante a sua operação. Para tanto, cálculos de resposta são realizados no rotor $\mathrm{e}$, isoladamente, no impelidor de um ventilador centrífugo, conduzindo a uma nova metodologia para a análise estrutural destes equipamentos através do método dos elementos finitos.

Palavras-chave: Ventiladores centrífugos. Impelidor. Tensões estáticas. Tensões dinâmicas. Método dos elementos finitos. 


\begin{abstract}
Stress analysis of centrifugal fan impellers through the finite element method reveals that its components are highly stressed and subjected to complex stress fields. Traditionally, the mechanical design of centrifugal impellers is performed from the study of the static stress levels due to the centrifugal force. The impeller dynamic behavior is evaluated through free vibration analysis and also with the knowledge of the main excitation sources. This approach does not consider any assessment on the dynamic response of the impeller components. In this work, however, the dynamic stress determination is presented as an important tool in order to evaluate the structural integrity of centrifugal fan impellers during its operation. For this purpose, frequency response analysis is performed on the rotor and, separately, on the centrifugal fan impeller, leading to a new methodology for structural analysis of these equipment through the finite element method.
\end{abstract}

Keywords: Centrifugal fans. Impeller. Static stresses. Dynamic stresses. Finite element method. 


\section{LISTA DE ILUSTRAÇÕES}

Figura 1.1 - Ventilador centrífugo com roda montada entre mancais (Disponível em: <http://www.howden.com>).

Figura 1.2- Rotor de um ventilador centrífugo de dupla-entrada (Disponível em: <http://www.howden.com>)

Figura 1.3 - Diagrama de Campbell para uma palheta de turbina. As linhas retas indicam as frequências de excitação, e as hipérboles as frequências naturais da palheta (IRRETIER, 1988). .29

Figura 1.4 - Efeito do enrijecimento centrífugo nos deslocamentos das extremidades das palhetas de uma turbina eólica (XIONG et al., 2010)

Figura 1.5 - Curvas S-N segundo a classificação da norma BS 7608 para algumas configurações de junções soldadas (MACDONALD e MADDOX, 2003).

Figura 1.6 - Regimes de fadiga de baixo ciclo e alto ciclo durante a operação do ventilador

Figura 2.1 - Disco sob o efeito da força centrífuga (BOHL, 1988).... 39

Figura 2.2 - Deformação do elemento do disco em estudo (BOHL, 1988) 40

Figura 2.3 - Representação do disco rotativo e esquematização da distribuição das tensões radiais e tangenciais devido à força centrífuga (BOHL, 1988).

Figura 2.4 - Disco rotativo submetido a esforços no furo central e na sua periferia (BOHL, 1988)

Figura 2.5 - Análise das forças em um elemento de palheta de ventilador centrífugo (BOHL, 1983).

Figura 2.6 - Dois possíveis modelos para o cálculo de tensões em palhetas de ventiladores centrífugos (BOHL, 1983).

Figura 2.7 - Modelo do impelidor de um ventilador centrífugo de dupla-entrada para a análise de tensões estáticas através do MEF.

Figura 2.8 - Indicação das regiões de alta tensão no disco lateral de um impelidor centrífugo, nas imediações das palhetas tipo aerofólio

Figura 2.9 - Efeito das soldas na resistência à fadiga (MADDOX, 2000). 
Figura 2.10 - Comparação entre as tensões radiais obtidas através de cálculos analíticos e do MEF para um disco rotativo.

Figura 2.11 - Comparação entre as tensões tangenciais obtidas através de cálculos analíticos e do MEF para um disco rotativo .56

Figura 2.12 - Tensões radiais obtidas através do cálculo pelo MEF........................56

Figura 2.13 - Tensões tangenciais obtidas através do cálculo pelo MEF ................57

Figura 2.14 - Ventilador de simples entrada modelado para o Exemplo 2................58

Figura 2.15 - Superfícies Z1 e Z2 consideradas pelo MD Nastran...........................58

Figura 2.16 - Tensões de von Mises no disco lateral $\left(\mathrm{N} / \mathrm{mm}^{2}\right)$ - superfície Z1..........59

Figura 2.17 - Tensões de von Mises no disco lateral $\left(\mathrm{N} / \mathrm{mm}^{2}\right)$ - superfície Z2.........59

Figura 2.18 - Tensões de von Mises no disco traseiro $\left(\mathrm{N} / \mathrm{mm}^{2}\right)$ - superfície $Z 1$........60

Figura 2.19 - Tensões de von Mises no disco traseiro $\left(\mathrm{N} / \mathrm{mm}^{2}\right)$ - superfície Z2.......60

Figura 2.20 - Tensões de von Mises na palheta $\left(\mathrm{N} / \mathrm{mm}^{2}\right)$ - superfície Z1 ................61

Figura 2.21 - Tensões de von Mises na palheta $\left(\mathrm{N} / \mathrm{mm}^{2}\right)$ - superfície Z2................61

Figura 2.22 - Tensões de von Mises no anel de entrada $\left(\mathrm{N} / \mathrm{mm}^{2}\right)$ - superfície Z1 ....62

Figura 2.23 - Tensões de von Mises no anel de entrada $\left(\mathrm{N} / \mathrm{mm}^{2}\right)$ - superfície Z2...62

Figura 2.24 - Tensões de von Mises no cone de rigidez $\left(\mathrm{N} / \mathrm{mm}^{2}\right)$ - superfície Z1 .....63

Figura 2.25 - Tensões de von Mises no cone de rigidez $\left(\mathrm{N} / \mathrm{mm}^{2}\right)$ - superfície Z2....63

Figura 2.26 - Exemplos de geometrias complexas em ventiladores centrífugos: (a) impelidor com palhetas do tipo aerofólio; (b) impelidor com disco recortado.

Figura 3.1- Modos de vibração de uma placa circular com a periferia engastada:

n é o número de diâmetros nodais e s é o número de círculos nodais (WEAVER; TIMOSHENKO; YOUNG, 1990).......................................70

Figura 3.2 - Primeiro modo diametral nodal.........................................................

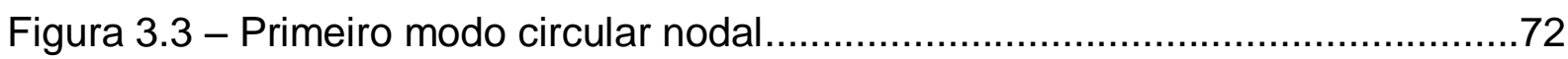

Figura 3.4 - Modo de duas linhas diametrais........................................................

Figura 3.5 - Modo diametral associado ao modo circular........................................73

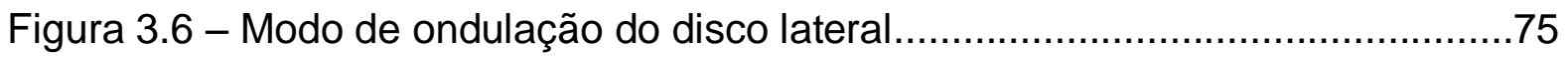

Figura 3.7 - Configuração da palheta estudada por Rao; Yu e Shiau (1999), representada através de uma placa rotativa........................................77

Figura 3.8 - Elemento de viga de Timoshenko e coordenadas de referência............80

Figura 3.9 - Desbalanceamento estático $\vec{U}_{\mathrm{e}}$ e dinâmico $\overrightarrow{\mathrm{U}}_{\mathrm{d}}$ no impelidor centrífugo 
Figura 3.10 - Translações e rotações na região do impelidor obtidas a partir do cálculo de resposta ao desbalanceamento estático no rotor completo

Figura 3.11 - Imposição dos movimentos de base no cubo do impelidor.

Figura 3.12 - Construção do modelo para a análise de resposta do impelidor, onde C é o nó central

Figura 3.13 - Detalhe do modelo do cubo após a expansão do modelo para o impelidor completo. Os movimentos de base são impostos em C

Figura 3.14 - Placa rotativa estudada nos testes, com a indicação de suas dimensões e propriedades

Figura 3.15 - Modelo de elementos finitos da placa rotativa .98

Figura 3.16 - Diagrama de Campbell para a placa rotativa .99

Figura 3.17 - Movimento de translação imposto à extremidade da placa 100

Figura 3.18 - Correspondência entre os deslocamentos de base e os deslocamentos obtidos na simulação para os nós da extremidade da placa.

Figura 3.19 - Tensões dinâmicas (componente $Y Y$ ) na extremidade da viga para duas condições: placa estacionária e com enrijecimento centrífugo correspondente a $10 \mathrm{~Hz}$

Figura 3.20 - Componentes de tensão em relação a um ângulo de referência $\omega t$ para o caso 2D (CHARRON; DONATO e FONTAINE, 1993) 105

Figura 4.1 - Ventilador centrífugo de dupla entrada empregado nas análises........108

Figura 4.2 - Modelo do impelidor para análise de tensões estáticas, com indicação de seus componentes, do carregamento inercial e das condições de contorno

Figura 4.3 - Deslocamentos no impelidor (mm).

Figura 4.4 - Tensões de von Mises nas palhetas $\left(\mathrm{N} / \mathrm{mm}^{2}\right)$ - superfície Z1 .111

Figura 4.5 - Tensões de von Mises nas palhetas $\left(\mathrm{N} / \mathrm{mm}^{2}\right)$ - superfície Z2.............112

Figura 4.6 - Tensões de von Mises no disco central $\left(\mathrm{N} / \mathrm{mm}^{2}\right)$ - superfície Z1 ........112

Figura 4.7 - Tensões de von Mises no disco central $\left(\mathrm{N} / \mathrm{mm}^{2}\right)$ - superfície Z2........113

Figura 4.8 - Tensões de von Mises nos discos laterais $\left(\mathrm{N} / \mathrm{mm}^{2}\right)$ - superfície Z1 ....113

Figura 4.9 - Tensões de von Mises nos discos laterais $\left(\mathrm{N} / \mathrm{mm}^{2}\right)$ - superfície Z2....114 
Figura 4.10 - Tensões de von Mises nos anéis dos discos laterais $\left(\mathrm{N} / \mathrm{mm}^{2}\right)$ superfície Z1

Figura 4.11 - Tensões de von Mises nos anéis dos discos laterais $\left(\mathrm{N} / \mathrm{mm}^{2}\right)$ superfície Z2.

Figura 4.12 - Tensões de von Mises nos cones de rigidez $\left(\mathrm{N} / \mathrm{mm}^{2}\right)$ superfície Z1 115

Figura 4.13 - Tensões de von Mises nos cones de rigidez $\left(\mathrm{N} / \mathrm{mm}^{2}\right)$ superfície Z2.

Figura 4.14 - Rotor analisado: dimensões e numeração dos nós do modelo de Elementos finitos.

Figura 4.15 - Curva de deflexão estática do rotor analisado. 120

Figura 4.16 - Diagrama de Campbell. 121

Figura 4.17 - Modo de vibração, $f_{n}=9.91 \mathrm{~Hz}$ 122

Figura 4.18 - Modo de vibração, $f_{n}=10.04 \mathrm{~Hz}$ 122

Figura 4.19 - Modo de vibração, $f_{n}=20.92 \mathrm{~Hz}$. 123

Figura 4.20 - Modo de vibração, $f_{n}=21.86 \mathrm{~Hz}$. 123

Figura 4.21 - Modo de vibração, $f_{n}=29.96 \mathrm{~Hz}$. 124

Figura 4.22 - Curva de resposta do rotor na posição correspondente ao mancal livre (nó 2)

Figura 4.23 - Detalhe das curvas correspondentes às translações no mancal livre (nó 2) nas proximidades da primeira rotação crítica do rotor. 125

Figura 4.24 - Curva de resposta do rotor na posição correspondente ao plano do cubo mais próximo do mancal livre (nó 8).

Figura 4.25 - Curva de resposta do rotor na posição correspondente ao impelidor (nó 9).

Figura 4.26 - Curva de resposta do rotor na posição correspondente ao plano do cubo mais próximo do mancal de escora (nó 10).

Figura 4.27 - Curva de resposta do rotor na posição correspondente ao mancal de escora (nó 16).

Figura 4.28 - Detalhe das curvas correspondentes às translações no mancal de escora (nó 16) nas proximidades da primeira rotação crítica do rotor

Figura 4.29 - Curva de resposta do rotor na posição correspondente ao acoplamento (nó 18). 
Figura 4.30 - Modelo do rotor para análise de vibrações livres.............................131

Figura 4.31 - Primeiro modo diametral (vertical, em fase com o eixo) ....................132

Figura 4.32 - Primeiro modo diametral (horizontal, em fase com o eixo) ................133

Figura 4.33 - Primeiro modo circular nodal.......................................................133

Figura 4.34 - Modo de duas linhas diametrais................................................134

Figura 4.35 - Modo diametral associado ao modo circular (vertical, fora de fase em relação ao eixo)....................................................................134

Figura 4.36 - Modo diametral associado ao modo circular (horizontal, fora de fase

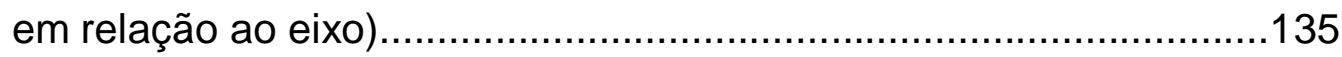

Figura 4.37 - Modo de três linhas diametrais....................................................135

Figura 4.38 - Segundo modo circular nodal.....................................................136

Figura 4.39 - Ondulação dos discos laterais..................................................136

Figura 4.40 - Modelo completo do impelidor centrífugo analisado.......................138

Figura 4.41 - Detalhe do cubo e do disco central do impelidor, com a indicação dos elementos rígidos utilizados..................................................139

Figura 4.42 - Módulo dos deslocamentos no impelidor $\left(10^{-3} \mathrm{~m}\right)$, evidenciando o comportamento de corpo rígido.....................................................141

Figura 4.43 - Módulo dos deslocamentos no impelidor $\left(10^{-3} \mathrm{~m}\right)$ em $21.86 \mathrm{~Hz} \ldots \ldots . .147$ 


\section{LISTA DE TABELAS}

Tabela 2.1 - Dados construtivos do ventilador estudado.

Tabela 2.2 - Tensões estáticas calculadas para o ventilador centrífugo estudado no Exemplo 2

Tabela 2.3 - Cálculo das tensões das palhetas do ventilador centrífugo por métodos analíticos

Tabela 2.4 - Cálculo das tensões nos discos do ventilador centrífugo por métodos analíticos.

Tabela 3.1 - Comparação das frequências naturais da placa parada e submetida à rotação

Tabela 4.1 - Dados construtivos e de operação do ventilador analisado. 109

Tabela 4.2 - Tensões estáticas calculadas pelo MEF. 116

Tabela 4.3 - Coordenadas dos nós do modelo de elementos finitos do rotor 118

Tabela 4.4 - Diâmetro dos elementos.

Tabela 4.5 - Coeficientes de rigidez e amortecimento dos mancais hidrodinâmicos.

Tabela 4.6 - Resultados da análise de vibrações livres.

Tabela 4.7 - Movimentos de translação impostos ao modelo de elementos finitos.

Os dados se referem à velocidade de operação do ventilador (14.67

$\mathrm{Hz}$ ou $880 \mathrm{rpm}$.

Tabela 4.8 - Deslocamentos calculados nas extremidades das palhetas

Tabela 4.9 - Comparação entre as máximas tensões de von Mises calculadas

pela equação (3.46) e os valores apresentados pelo MD Patran

para dois nós do disco central.

Tabela 4.10 - Exemplo de cálculo da máxima tensão de von Mises para um nó do disco central.

Tabela 4.11 - Tensões dinâmicas nos componentes do impelidor na rotação de operação do ventilador ( $880 \mathrm{rpm}$ ou $14.67 \mathrm{~Hz}$ ).

Tabela 4.12 - Tensões estáticas no impelidor na velocidade de $21.86 \mathrm{~Hz}$. .145

Tabela 4.13 - Comparação das frequências naturais do impelidor em duas condições de enrijecimento centrífugo: $14.67 \mathrm{~Hz}$ e $21.86 \mathrm{~Hz}$ .146

Tabela 4.14 - Movimentos de translação na passagem pela primeira rotação 
crítica $(21.86 \mathrm{~Hz})$ impostos ao modelo de elementos finitos................147

Tabela 4.15 - Deslocamentos calculados nas extremidades das palhetas na frequência de $21.86 \mathrm{~Hz}$..

Tabela 4.16 - Tensões dinâmicas nos componentes do impelidor na primeira

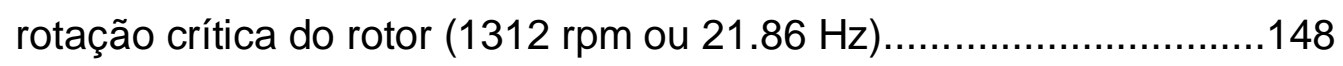




\section{LISTA DE SÍMBOLOS DE USO MAIS FREQUENTE}

$D$

BPF

$\omega_{r}$

$\omega_{n}$

velocidade angular;

densidade ou parte real de autovalor;

espessura de um disco rotativo ou largura da palheta;

tensão radial em um disco rotativo;

tensão tangencial em um disco rotativo;

deformação;

módulo de elasticidade;

coeficiente de Poisson;

raio;

tensão na periferia de um disco rotativo;

pressão no furo de um disco rotativo;

força centrífuga ou forças de excitação;

massa ou constante para o cálculo da vida em fadiga;

espessura da palheta ou número de círculos nodais;

ângulo de saída da palheta;

tensão na palheta;

módulo da seção transversal;

velocidade tangencial;

tensão de escoamento;

fator de serviço;

amplitude de tensão para o cálculo da vida em fadiga;

Constante para o cálculo da vida em fadiga ou constante associada a um modo de vibração;

número de ciclos ou número de palhetas ou número de diâmetros nodais;

superfícies externas dos elementos de casca;

diâmetro do disco;

frequência de passagem das palhetas;

frequência natural de um sistema rotativo;

frequência natural de um sistema estacionário; 
$\Omega$

U

$\sigma_{x x}, \sigma_{y y}, \sigma_{z z}$

$\tau_{x y}, \tau_{y z}, \tau_{z x}$

$\{q\}$

[M]

[G]

$[K]$

[C]

$\left[K_{g}\right]$

[N]

Y

B

Z

A

G

l

$J_{p}$

$J_{t}$

$k_{Y Y}, k_{Z Z}$, etc.

$c_{Y Y}, c_{Z Z}$, etc.

[D]

h

$\vec{U}_{e}$

$\vec{U}_{d}$

$\lambda$

$f_{n}$

$\mathrm{u}_{\mathrm{z}}$

$\mathrm{u}_{\mathrm{y}}$

$\theta_{z}$

$\theta_{\mathrm{y}}$

$\sigma_{V M}$

$\delta, \beta$ e $\varphi$ velocidade de rotação;

energia potencial;

componentes normais de tensão;

componentes de tensão de cisalhamento;

vetor de coordenadas generalizadas;

matriz de massa;

matriz de efeito giroscópico;

matriz de rigidez;

matriz de amortecimento;

matriz de rigidez devido ao carregamento centrífugo;

matriz de função de forma;

translações na direção do eixo Y;

rotações em torno do eixo $\mathrm{Y}$;

translações na direção do eixo Z;

rotações em torno do eixo Z;

módulo de cisalhamento;

comprimento;

momento polar;

momento transversal;

coeficientes de rigidez dos mancais;

coeficientes de amortecimento dos mancais;

matriz global de amortecimento;

vetor de carregamentos harmônicos;

desbalanceamento estático;

desbalanceamento dinâmico;

autovalores;

frequências naturais amortecidas do rotor;

translações na direção Z na região do impelidor;

translações na direção $Y$ na região do impelidor;

rotações em torno de $Z$ na região do impelidor;

rotações em torno de $Y$ na região do impelidor;

tensão de von Mises;

fases das componentes de tensão; 
ângulo de referência para cálculo das tensões de von Mises;

$\delta_{\mathrm{z}}$ deslocamentos na direção Z na extremidade das palhetas;

$\delta_{\mathrm{y}}$ deslocamentos na direção $\mathrm{Y}$ na extremidade das palhetas;

Subscritos:

adm

admissível;

máx

máxima;

CG

centro de gravidade; 


\section{SUMÁRIO}

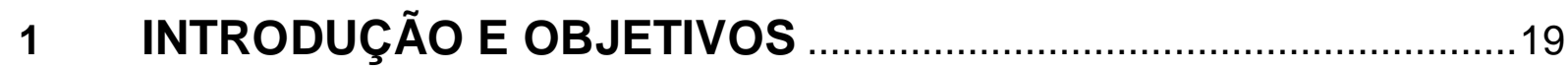

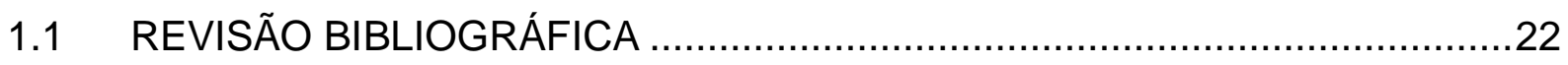

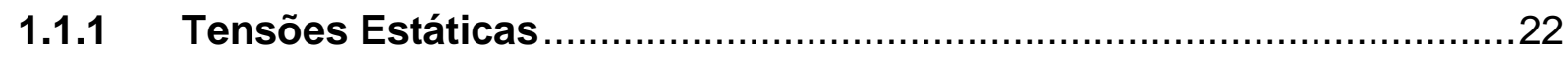

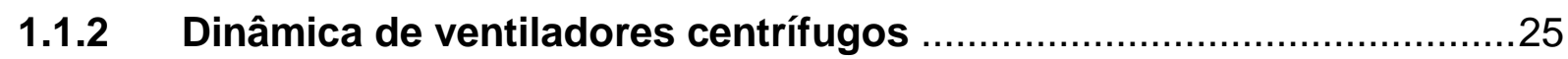

1.1.3 Resposta dinâmica à imposição de movimentos genéricos ..................30

1.1.4 Análise de fadiga de estruturas soldadas.........................................

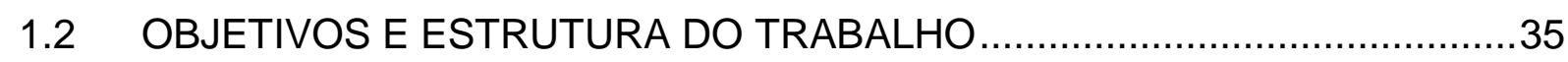

2 CÁLCULO DE TENSÕES EM VENTILADORES CENTRÍFUGOS .38

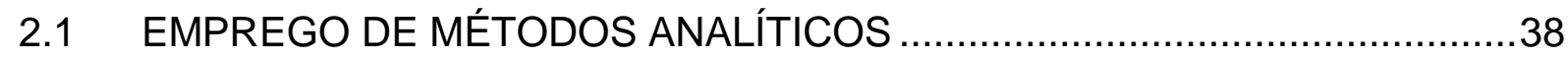

2.1.1 Discos Rotativos de espessura constante .........................................38

2.2 ANÁLISE ESTÁTICA ATRAVÉS DO MÉTODO DOS ELEMENTOS FINITOS

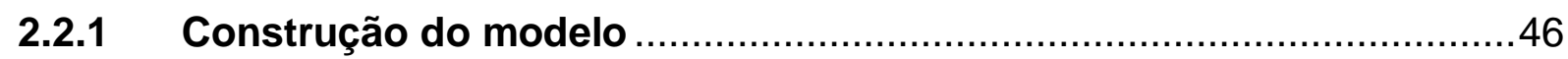

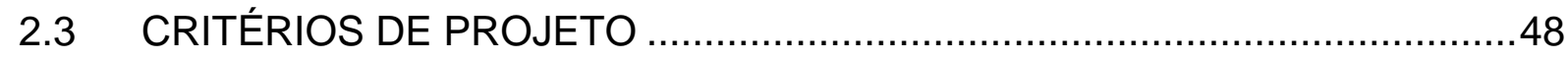

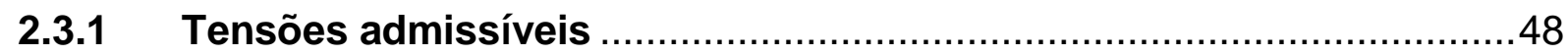

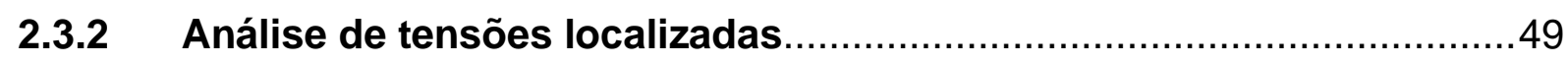

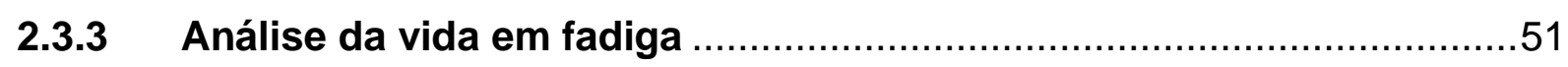

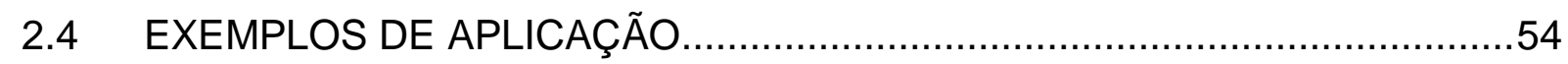

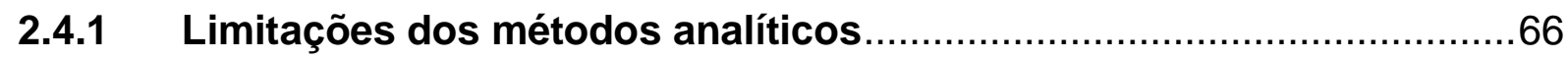

3 ANÁLISE DINÂMICA DE VENTILADORES CENTRÍFUGOS .......69

3.1 A ABORDAGEM TRADICIONAL: ANÁLISE DE VIBRAÇÕES LIVRES DE

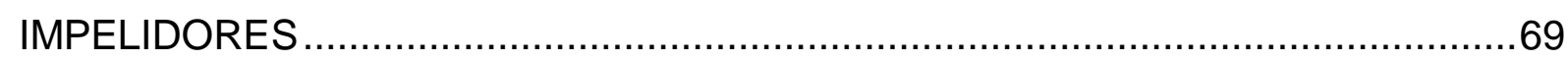

3.1.1 Modos de vibração no impelidor e fontes de excitação …………........70

3.1.2 O efeito de enrijecimento centrífugo ................................................

3.2 METODOLOGIA PROPOSTA PARA O CÁLCULO DE TENSÕES

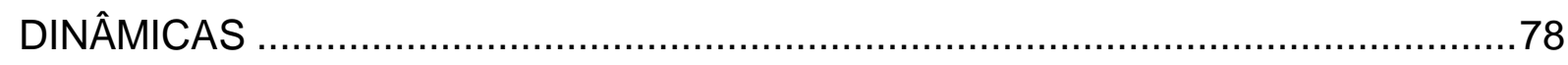

3.2.1 Análise de resposta em frequência do rotor pelo MEF .........................79

3.2.2 Análise de resposta em frequência do impelidor................................86

3.2.3 Modelo para análise dinâmica de impelidores ....................................89 
3.2.4 Superposição das tensões estáticas e dinâmicas ……………….......92

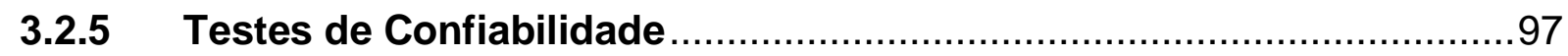

3.2.6 Determinação das tensões de von Mises no domínio da frequência.102 4 RESULTADOS DA SIMULAÇÃO DE UM VENTILADOR DE

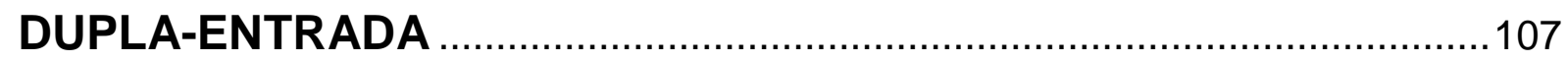

4.1 DESCRIÇÃO DO VENTILADOR CENTRÍFUGO ANALISADO …................107

4.2 ANÁLISE DE TENSÕES ESTÁTICAS ......................................................109

4.3 ANÁLISE DE RESPOSTA EM FREQUÊNCIA DO ROTOR ......................117

4.3.1 Modelo para análise dinâmica do rotor ..............................................117

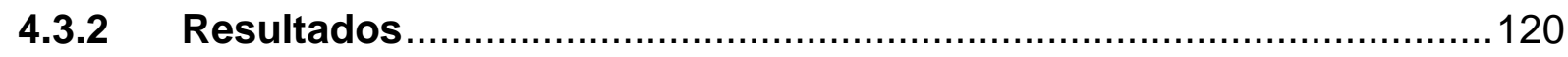

4.4 ANÁLISE DE VIBRAÇÕES LIVRES DO IMPELIDOR ...............................129

4.5 ANÁLISE DE RESPOSTA EM FREQUÊNCIA DO IMPELIDOR .................137

4.5.1 Modelo para análise dinâmica do impelidor centrífugo......................138

4.5.2 Determinação das tensões dinâmicas e considerações acerca da

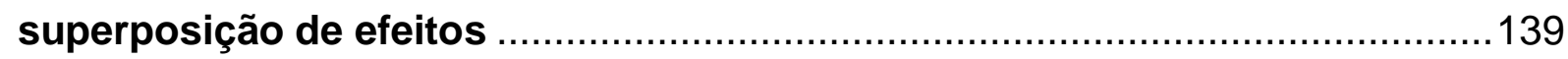

5 CONCLUSÕES E TRABALHOS FUTUROS ….............................152

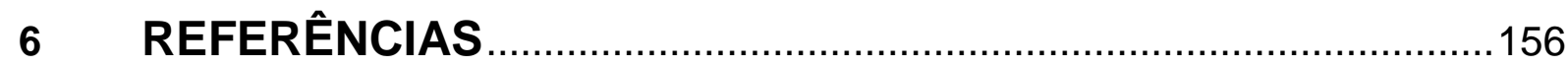




\section{INTRODUÇÃO E OBJETIVOS}

Ventiladores são máquinas rotativas que fornecem energia continuamente para um gás. Esse processo de transferência de energia é utilizado para vencer a resistência ao escoamento inerente à instalação, de modo a promover o escoamento e o aumento da pressão do gás. De acordo com a direção do escoamento através de um impelidor - elemento rotativo que transfere energia ao fluído, também denominado roda - os ventiladores podem ser classificados em duas categorias: axiais ou centrífugos; embora ainda existam tipos híbridos com características mistas. O presente trabalho tem como objetivo estudar exclusivamente os ventiladores centrífugos.

Como o próprio nome indica, ventiladores centrífugos utilizam o princípio da força centrífuga para movimentar um volume de ar ou gás: o fluído entra no impelidor na direção axial e sai na direção radial, a medida em que a pressão é desenvolvida. A carcaça do ventilador é utilizada para conduzir o fluído da periferia do impelidor - cujos diâmetros variam entre $200 \mathrm{~mm}$ a mais de $5 \mathrm{~m}$ - até a direção desejada. Como uma parcela considerável da pressão desenvolvida no rotor está na forma de energia cinética, a carcaça também converte parte desta pressão dinâmica em pressão estática. Um motor elétrico é comumente utilizado para acionar o rotor ${ }^{1}$. A Figura 1.1 apresenta os principais componentes de um ventilador centrífugo.

As palhetas (ou pás) constituem a principal superfície de trabalho da roda, arrastando $o$ ar em um movimento circular, enquanto as forças centrífugas aceleram radialmente o volume de ar. As palhetas são suportadas por um disco lateral e por um disco traseiro - no caso de ventiladores de simples-entrada - ou um disco central, para ventiladores de dupla-entrada. Existe uma grande variedade de impelidores de ventiladores centrífugos, cada qual com suas vantagens e desvantagens específicas em termos de eficiência e resistência, o que os torna adequados para diferentes aplicações.

\footnotetext{
${ }^{1}$ Embora os termos impelidor, roda e rotor sejam empregados com frequência como sinônimos, o presente estudo considerará o termo rotor como o conjunto formado pelo impelidor e o eixo do ventilador.
} 


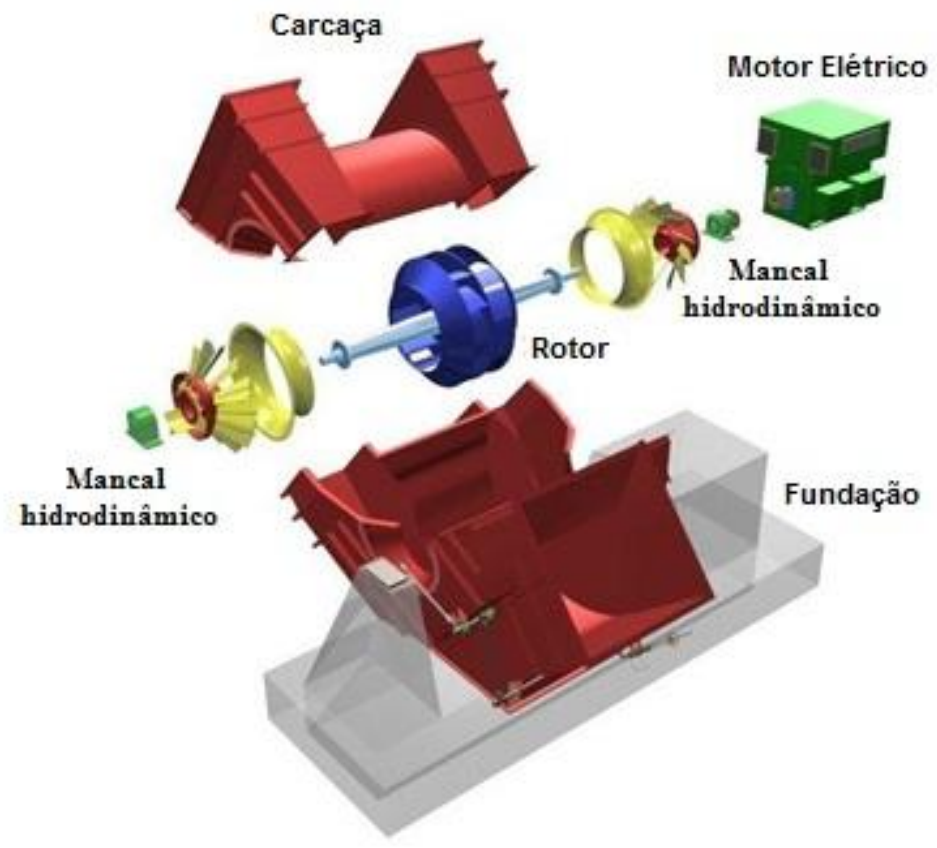

Figura 1.1 - Ventilador centrífugo com roda montada entre mancais (Disponível em: $<$ http://www.howden.com>)

Em geral, ventiladores centrífugos apresentam palhetas nas configurações radiais (pás retas), curvadas para frente, curvadas para trás ou aerofólio, sendo que as duas últimas configurações conduzem a eficiências mais elevadas. A Figura 1.2 mostra o rotor de um ventilador centrífugo, com a identificação de seus principais componentes.

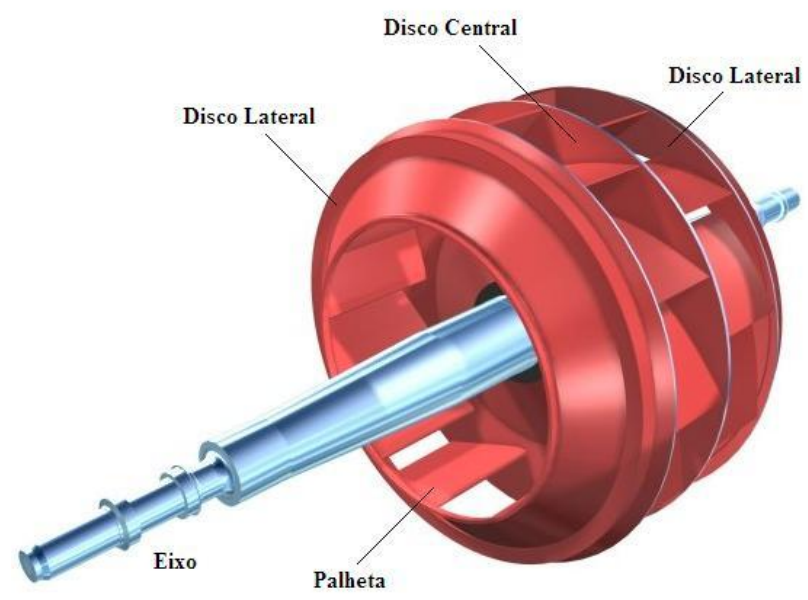

Figura 1.2 - Rotor de um ventilador centrífugo de dupla-entrada (Disponível em: $<$ http://www.howden.com>) 
Comumente, o impelidor é conectado ao eixo do ventilador através de um cubo, onde o disco traseiro ou central da roda é soldado. O rotor é apoiado em um mancal livre e em um mancal de escora (capaz de suportar cargas radiais e axiais), que podem ser hidrodinâmicos ou de rolamento. Dependendo da configuração, a roda pode ser posicionada entre mancais ou em balanço no eixo. $O$ acionamento por motor elétrico pode ser direto, através de polias e correias ou através de um acoplamento. Em geral, ventiladores menores apresentam uma estrutura de suporte metálica para o motor e os mancais, sendo esta parafusada à fundação. Em ventiladores mais robustos, com diâmetros maiores de 2 metros, são empregados pedestais metálicos na fundação.

Ventiladores centrífugos estão presentes em uma infinidade de indústrias primárias, tais como as de geração de energia, siderurgia, mineração, cimento, processos petroquímicos, dentre outras. Estima-se, por exemplo, que, no Reino Unido, os ventiladores utilizam cerca de $28500 \mathrm{GWh} / \mathrm{ano}$, representando um custo anual de £ 72 bilhões. O potencial para a economia de energia é de 20 a $25 \%$ equivalente a $£ 14.4$ a 18 bilhões/ano. Dois terços destas economias potenciais são provenientes de melhorias nos sistemas e um terço é proveniente dos ventiladores propriamente ditos (RADGEN, 2002). Verifica-se que em inúmeras plantas, os ventiladores de processo de aplicação pesada - denominados heavy duty centrifugal fans - assumem papéis essenciais na produção. A parada de um ventilador de processo em plantas de pelotização ou sinterização, por exemplo, implica em perdas incalculáveis associadas não somente aos prejuízos inerentes à parada da produção, mas também à danificação de componentes do sistema que dependem do funcionamento contínuo dos ventiladores. A importância econômica desta tecnologia também fica evidenciada pelos inúmeros sistemas de monitoramento e controle dos ventiladores, bem como pela aquisição de rotores e componentes sobressalentes, que garantem seu funcionamento contínuo ou que minimizam os tempos de parada.

Neste contexto, o projeto do ventilador deve considerar não somente os aspectos aerodinâmicos - no sentido de aumentar a eficiência dos ventiladores e dos sistemas visando à redução dos custos de energia - mas também os aspectos estruturais, de modo a garantir a integridade de seus componentes. A falha em algum componente do ventilador em operação, como a de uma palheta, pode provocar acidentes gravíssimos. $O$ seu dimensionamento deve passar 
obrigatoriamente pela avaliação das tensões e das características dinâmicas do ventilador quando em operação. A busca por maiores desempenhos implica na construção de ventiladores com rotação e diâmetros mais elevados, aumentando os esforços centrífugos (JORGENSEN, 1999). O compromisso entre estas duas frentes - aerodinâmica e estrutural - apesar de muitas vezes conflitantes, deve ser estabelecido no projeto de um ventilador.

\subsection{REVISÃO BIBLIOGRÁFICA}

Um impelidor em rotação armazena uma quantidade de energia cinética significativa que é liberada de forma explosiva no caso da falha de algum de seus componentes. O projeto mecânico de ventiladores centrífugos deve garantir níveis aceitáveis para as tensões provenientes da força centrífuga. Aspectos relacionados à dinâmica vibratória dos rotores e impelidores também devem ser avaliados detalhadamente a fim de garantir a sua integridade estrutural.

Neste contexto, a revisão bibliográfica que será apresentada a seguir busca discutir as diversas abordagens presentes na literatura no que diz respeito ao cálculo estrutural de máquinas rotativas e, a partir delas, identificar as necessidades específicas do projeto de ventiladores centrífugos.

\subsubsection{Tensões Estáticas}

Por tensões estáticas pode-se entender as tensões produzidas em decorrência de carregamentos constantes que atuam em um componente; ressaltando-se aqui que também os carregamentos externos podem contribuir para essas tensões. A pressão de um ventilador produz tensões estáticas no rotor e na carcaça. Um rotor de ventilador centrífugo que opera em velocidade constante está sujeito a tensões estáticas decorrentes da força centrífuga.

Segundo Jorgensen (1999), tensões estáticas podem ser obtidas por medições com auxílio de strain-gages e outras técnicas experimentais. Também 
para este fim podem ser utilizados métodos de cálculo analíticos ou técnicas de elementos finitos, apresentadas por Bathe (1996), Cook (1995), entre outros. Jorgensen (1999) pondera que a análise através do Método dos Elementos Finitos (MEF) propicia muitas informações, mas elas podem não ser suficientes para garantir a integridade estrutural de cada ventilador. Frequentemente, tanto o método experimental quanto o método dos elementos finitos revelam as áreas com problemas no projeto do ventilador. Caso um método de análise menos rigoroso seja utilizado, muitos destes problemas podem passar despercebidos. Apesar de 0 método experimental ser interessante, ele se torna impraticável, na medida em que a análise exige que o procedimento se realize para cada ventilador fabricado.

Inúmeros fabricantes desenvolveram regras de projeto para o cálculo estrutural de seus produtos e a verificação das tensões em cada um dos componentes dos ventiladores pode ser realizada a partir de formulações relativamente simples. Em muitos casos, o emprego de análises mais rigorosas não é conveniente, uma vez que os modelos desenvolvidos empregam cálculos analíticos que, aliados à experiência dos fabricantes, são suficientes para permitir a avaliação segura da integridade estrutural do ventilador. Entretanto, ventiladores de processo podem apresentar geometrias mais complexas ou estar submetidos a aplicações mais severas, como a operação contínua em altas temperaturas, ciclos de liga/desliga frequentes, movimentação de gases com particulados aderentes, dentre outras. Ademais, em alguns casos, é possível que o ventilador projetado esteja fora da experiência do fabricante. É interessante notar que o processo de produção de ventiladores de grande porte é caracterizado pela produção individual, evidenciando a importância do domínio da tecnologia do produto (PONGEFERREIRA, 1994). Nestas situações, os fabricantes frequentemente recorrem à análise por meio do MEF.

A distribuição de tensões em um ventilador centrífugo pode ser obtida aproximadamente através de cálculos analíticos simples. As palhetas, por exemplo, são modeladas como vigas engastadas em ambas as extremidades (disco lateral e disco central ou traseiro) e sujeitas a um carregamento uniforme. Neste caso, os momentos fletores e as correspondentes tensões são facilmente determinadas. Tal análise sugere que as tensões máximas ocorrem em ambas as extremidades, o que geralmente é verdade (JORGENSEN, 1999). 
Hearn (1997) e Young e Budynas (2002) apresentam o equacionamento da distribuição de tensões em discos, anéis e cilindros submetidos a um movimento rotativo. A análise de um disco rotativo com um furo central e de espessura constante conduz à distribuição das tensões radial e tangencial. Os valores máximos das tensões e sua localização também são facilmente determinados. Tal análise constitui um modelo válido para avaliar as tensões nos discos de um ventilador centrífugo. Entretanto, certamente existe interação entre as palhetas e os discos lateral e central ou traseiro, de modo que modelos mais complexos devem ser empregados na busca de resultados mais precisos.

Bohl $(1983,1988)$ apresenta o estudo mais valioso encontrado na literatura no que se refere ao cálculo analítico de tensões em ventiladores. O autor realiza a dedução das expressões para o cálculo das tensões radiais e tangenciais em discos rotativos - de espessura constante e variável - com um furo central, analisando seu comportamento através de gráficos. Calcula os deslocamentos radiais para um disco submetido a três condições: pressão interna no furo central, disco em rotação sem esforços externos e disco submetido a esforços externos na sua periferia. Também desenvolve o equacionamento para o cálculo dos momentos e tensões nas palhetas dos ventiladores segundo dois modelos distintos: palhetas engastadas em ambas as extremidades e palhetas apoiadas em suas extremidades através de articulações. $O$ equacionamento para os dois modelos é comparado e discutido.

Segundo Bell e Benham (1978), apesar das tensões no ventilador serem provocadas pela temperatura, pelas forças aerodinâmicas e pela rotação, o efeito dessa última é muito mais relevante que os demais fatores do ponto de vista da análise de tensões. Os autores utilizam o MEF para determinar a distribuição de tensões em um impelidor centrífugo a partir da modelagem de um quarto da estrutura completa, devido à sua propriedade de simetria. Para a elaboração de tal modelo, elementos de cascas triangulares com seis graus de liberdade em cada nó são empregados. Os resultados são comparados com medições experimentais através de strain-gages e brittle coating. Análises semelhantes são realizadas por Ramamurti e Balasubramnian (1987) e por Nabi e Ganeshan (1993), cuja avaliação das tensões assume que a estrutura geometricamente periódica pode ser dividida em setores posicionados simetricamente com relação ao eixo de rotação, de modo que as forças, deslocamentos e tensões são considerados idênticos para cada setor. 
Abordagens semelhantes são realizadas por Glessner (1967), Deutsch (1962) e Haerle (1918).

Bhope e Padole (2004) apresentam uma análise teórica e experimental das tensões em um ventilador centrífugo de pás inclinadas para trás, mostrando que o impelidor é um componente do ventilador altamente solicitado e sujeito a um campo de tensões complexo. Através do MEF, os autores investigam a influência de anéis de reforço nas palhetas da roda, mostrando que a sua presença pode auxiliar na redução das tensões no impelidor. A análise da roda foi realizada somente para as tensões devidas à força centrífuga, uma vez que as forças aerodinâmicas são de menor magnitude. Para tanto, apenas uma seção do ventilador foi discretizada correspondente a uma palheta - devido à simetria da roda. Segundo os autores, os melhores resultados foram obtidos em softwares comerciais e com a discretização dos componentes a partir de elementos de placa triangulares (TRIA3) e quadriláteros (QUAD4). Tais elementos são baseados na Teoria de Placas de Mindlin que leva em consideração o efeito da deformação transversal em cisalhamento, em contraste com o emprego de elementos de cascas triangulares com 6 graus de liberdade por nó. Estes últimos se baseiam na Teoria de Placas Clássica de Kirchhoff, em que a convergência e os resultados são comparativamente menos satisfatórios.

\subsubsection{Dinâmica de ventiladores centrífugos}

Vibrações de ventiladores e dos sistemas estruturais que os suportam constituem um problema comum na indústria, uma vez que a segurança e a vida em serviço destes equipamentos estão diretamente relacionadas ao seu comportamento dinâmico. Por essa razão, as máquinas rotativas requerem uma modelagem detalhada para o seu projeto mecânico e para as manutenções preventivas. Consequentemente, o estudo da disciplina dinâmica de rotores assume relevância, na medida em que avalia as respostas livres e forçadas de sistemas estruturais turbinas a gás e a vapor, bombas, compressores, ventiladores centrífugos e axiais que compõem as máquinas rotativas. Análises de vibração lateral e torcional são realizadas para avaliar o comportamento dinâmico de máquinas rotativas. $O$ 
presente trabalho tem como foco de estudo apenas as vibrações laterais. $O$ movimento lateral é definido como perpendicular ao eixo de rotação e tipicamente inclui componentes de pequenas amplitudes de translação e de rotação em relação a duas direções perpendiculares (NELSON; TALBERT, 2003).

Todo sistema rotor-mancais possui um número de frequências naturais de vibração lateral que podem ser excitadas por diversas fontes, sendo 0 desbalanceamento a principal delas. Quando uma das frequências naturais é excitada pelo desbalanceamento, a velocidade angular do eixo que coincide com a frequência natural é denominada velocidade crítica (VANCE, 1988). Uma vez que é impossível balancear perfeitamente um ventilador, sempre haverá uma força de excitação com uma frequência correspondente à velocidade de operação. Portanto, se uma das frequências naturais do sistema coincidir com a frequência de rotação, o resultado será a ressonância.

Em ventiladores centrífugos, a primeira frequência natural normalmente está acima da máxima velocidade de operação. Para controlar a resposta ao desbalanceamento, normalmente é especificada uma margem entre o modo lateral de menor frequência e a velocidade de operação. As normas AMCA 801-01 e API 619 apresentam recomendações para o projeto dinâmico de ventiladores.

As velocidades críticas não são apenas propriedades do rotor. Os mancais, suportes e pedestais, a fundação e o solo também contribuem para as propriedades elásticas do sistema (JORGENSEN, 1999). Modelos para a avaliação da resposta em frequência ao desbalanceamento estático são apresentados por Rao (1983) e Vance (1988). Entretanto, cabe lembrar a diversidade de ventiladores existentes. É o caso de alguns ventiladores de simples entrada, que possuem arranjos que não são simétricos. Nesse caso particular, a análise de rotores com impelidores em balanço deve considerar o efeito giroscópico no aumento da primeira frequência natural do eixo (IRONS, 1996). Outros ventiladores são apoiados em mancais hidrodinâmicos e as propriedades de rigidez e amortecimento constituem elementos essenciais na avaliação da resposta ao desbalanceamento. Essa variedade de ventiladores centrífugos justifica o emprego também diversificado de modelos nas suas análises dinâmicas. Citem-se os modelos mais simples, como o de Jeffcott-Laval, até os mais elaborados - que incluem na sua formulação os efeitos giroscópicos e as propriedades de rigidez e amortecimento dos mancais como função da velocidade 
angular do rotor. Estudos da vibração lateral de rotores também são explorados por Traexler (1977), Lalanne e Ferraris (1990), Genta (1993), entre outros.

Combescure e Lazarus (2008) discutem técnicas de modelagem para a análise de vibrações em máquinas rotativas de grande porte através do método dos elementos finitos. $\mathrm{O}$ autor apresenta simulações de rotores para diversos níveis de modelagem, desde o modelo clássico de elementos de viga para o eixo e discos considerados rígidos, até modelos com elementos tridimensionais para avaliar possíveis interações entre os modos do disco flexível e do eixo.

É importante observar que o impelidor de um ventilador é composto por placas e vigas, e cada uma dessas possui uma frequência natural. Bohl (1988) e Jorgensen (1999) apresentam expressões analíticas para estimar as menores frequências naturais de certos componentes de um ventilador, tais como palhetas e anéis, assumindo que sejam uniformes. Cálculos mais complexos devem ser realizados para outras formas.

Sayer (1999) apresenta uma discussão acerca das frequências naturais e modos de vibrar característicos de rotores de ventiladores centrífugos e seus sistemas estruturais (pedestais, estruturas metálicas e fundações). Descreve as características dos modos de vibrar de impelidores de ventiladores centrífugos e discute as possíveis fontes de excitação para cada um dos modos. O autor mostra que sistemas mecânicos contendo ventiladores centrífugos podem estar sujeitos a inúmeras forças dinâmicas que constituem fontes de excitação, sejam elas de origem mecânica ou aerodinâmica. Algumas destas forças dinâmicas são inerentes ao projeto do ventilador, tais como o desbalanceamento, a pressão de pulsação devido à passagem das palhetas, as forças provenientes do acionamento por polias e correias; enquanto que outras podem estar presentes devido a um projeto mecânico ou aerodinâmico inadequado, como por exemplo, a operação na condição de stall.

Ponge-Ferreira (1994) aborda a dinâmica vibratória de ventiladores centrífugos excitados por ação aerodinâmica. De acordo com o autor, o estudo da dinâmica estrutural torna-se importante para ventiladores de grande porte, pois a propensão para a ocorrência de falhas aumenta com o raio do impelidor e a velocidade periférica, embora também tenham sido verificadas falhas em impelidores pequenos. $O$ autor utiliza O MEF para avaliar as características dinâmicas de um impelidor e avalia sua confiabilidade estrutural à vibração, também 
determinando experimentalmente as frequências naturais e modos de vibrar de um disco. Finalmente, conclui que a modelagem por elementos finitos apresenta boa concordância com os resultados experimentais.

É importante notar que as frequências naturais de um rotor de ventilador aumentam devido ao efeito denominado enrijecimento centrífugo. Em outras palavras, as frequências naturais do rotor em operação são diferentes daquelas obtidas a partir de um teste de impacto com o ventilador parado (SAYER, 1999). Ventiladores centrífugos são constantemente submetidos a variações de velocidade de operação para atender aos requisitos aerodinâmicos de uma instalação. Devido ao efeito de enrijecimento centrífugo, as frequências naturais do impelidor serão distintas para cada rotação de operação. Trata-se de uma consideração importante na avaliação do comportamento dinâmico destes equipamentos.

Uma vasta quantidade de estudos relacionados ao enrijecimento centrífugo é apresentada na literatura para o estudo dos modos e frequências naturais de palhetas de turbinas. É o caso de Den Hartog (1956) e Irretier (1988), que utilizam o Teorema de Southwell aplicado a uma viga rotativa. Den Hartog (1956) afirma que uma boa aproximação da frequência natural de uma palheta rotativa pode ser determinada a partir da frequência natural da palheta não rotativa (condição estática) e de um fator de força centrífuga que considera o efeito de enrijecimento devido à rotação, cujo valor é diferente para cada modo de vibrar da viga. Gans e Anderson (1991) utilizam este conceito para propor otimizações em palhetas de turbina e apresentam a possibilidade de redução de seu peso caso o enrijecimento centrífugo seja considerado no projeto mecânico. Simulações foram realizadas no software MD Nastran a partir de um modelo de elementos finitos constituído de elementos de casca de quatro nós. Os autores apresentam a formulação utilizada pelo software, a qual consiste na inclusão de uma matriz de rigidez diferencial devido ao carregamento estático - força centrífuga - que é incorporada à matriz de rigidez dos elementos do impelidor. Os resultados indicam que o efeito de enrijecimento centrífugo é mais pronunciado para os primeiros modos de vibrar da palheta, o que pode ser observado a partir da Figura 1.3.

Irretier (1988) destaca a importância de se considerar o enrijecimento centrífugo na análise de vibrações forçadas em palhetas de turbinas. Esta consideração também é realizada por Xiong et al. (2010) a partir da comparação da resposta no domínio do tempo de uma palheta de turbina eólica, com e sem o efeito 
do enrijecimento centrífugo, conforme ilustrado na Figura 1.4. Abordagens semelhantes são apresentadas por Hitchings (1992), Ramamurti; Subramani e Sridhara (1995) e Rao; Yu e Shiau (1999). Análises voltadas à resposta em frequência de impelidores centrífugos não foram encontradas na literatura.

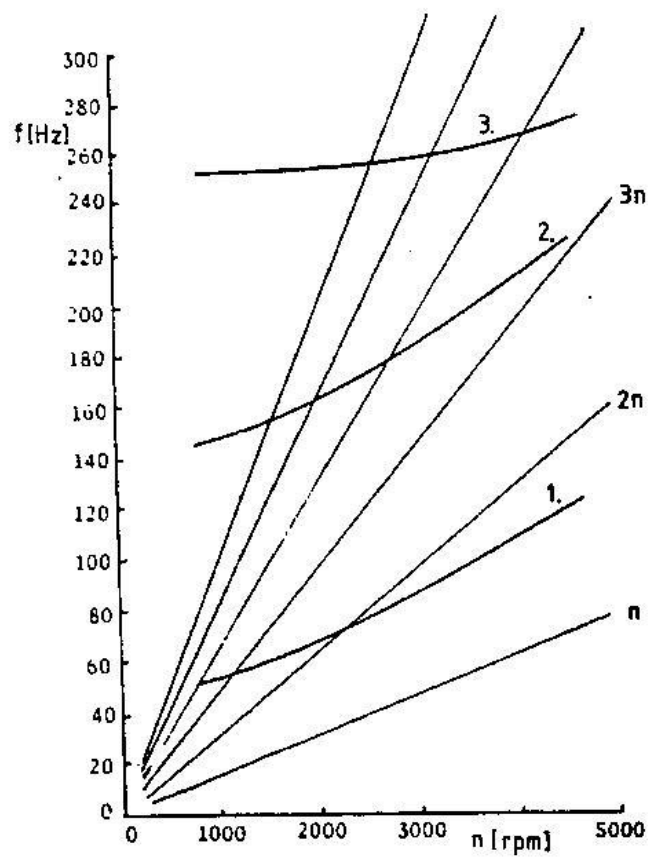

Figura 1.3 - Diagrama de Campbell para uma palheta de turbina. As linhas retas indicam as frequências de excitação, e as hipérboles as frequências naturais da palheta (IRRETIER, 1988)

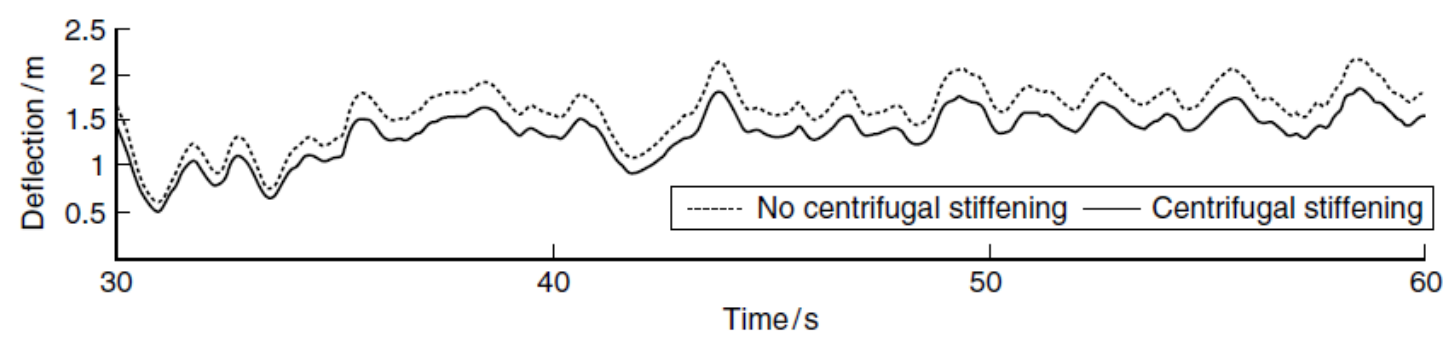

Figura 1.4 - Efeito do enrijecimento centrífugo nos deslocamentos das extremidades das palhetas de uma turbina eólica (XIONG et al., 2010)

A aplicação do Teorema de Southwell para considerar o efeito do enrijecimento centrífugo também é discutida por Irons (1996) com o objetivo de incluir a flexibilidade do impelidor nos modelos de dinâmica de rotores - resposta ao desbalanceamento do rotor apoiado em mancais e suportes. Vance (1988) afirma que testes experimentais mostraram ser benéfica a inclusão da flexibilidade da conexão entre os discos e o eixo para a determinação das frequências naturais. 
Trata-se de um refinamento para melhorar a exatidão das frequências naturais calculadas. $\mathrm{O}$ autor pondera que a abordagem usualmente utilizada é a de que a conexão entre os discos e o eixo é rígida, de modo que os discos permanecem em posições normais ao eixo em todos os modos. Entretanto, sobretudo nos primeiros modos, existe a possibilidade de haver interações entre o disco e o eixo.

Vale dizer que o presente trabalho se isenta de desenvolver um modelo de dinâmica de rotores que inclua o efeito da flexibilidade dos discos. Deste modo, os modelos de dinâmica de rotores utilizados consideram uma conexão rígida entre o impelidor e o eixo. O efeito do enrijecimento centrífugo é considerado apenas na análise de resposta em frequência do impelidor. Tal abordagem não traz prejuízos à metodologia proposta para o cálculo estrutural de ventiladores centrífugos, como será evidenciado nas próximas seções.

\subsubsection{Resposta dinâmica à imposição de movimentos genéricos}

À fabricação de qualquer máquina rotativa é inerente um grau de desbalanceamento. Ventiladores centrífugos em geral são fabricados com um grau de balanceamento G 2.5 ou G 6.3 segundo a norma ISO 1940-1. Em inúmeras aplicações, os ventiladores movimentam gases que contém materiais aderentes ou particulados abrasivos, os quais aumentam o desbalanceamento destes equipamentos ao longo da sua vida útil. Em plantas de cimento, por exemplo, um ventilador centrífugo certamente está sujeito a particulados que aderem à superfície da palheta uniformemente. $O$ desprendimento de uma quantidade de material de uma dessas palhetas implica na elevação do desbalanceamento da máquina e, consequentemente, no aumento dos níveis de vibração; o que, em muitos casos, exige a parada imediata do equipamento. As recomendações para os níveis de vibração admissíveis para ventiladores são previstas nas normas AMCA 204-01 e ISO 14694.

Níveis de vibração elevados estão associados a grandes deslocamentos na região dos mancais e do impelidor, o que é traduzido pelo aumento dos esforços, isto é, dos níveis de tensão dinâmica nos componentes do impelidor. Portanto, os deslocamentos de translação e rotação na região da conexão entre o impelidor e o 
eixo podem ser considerados como excitações de natureza dinâmica no impelidor. Um exemplo análogo é o dos movimentos de translação ou rotação das fundações de um edifício durante um terremoto.

O estudo do cálculo da resposta dinâmica de estruturas sujeitas a movimentos genéricos através do MEF é realizado por Zachariadis (1986), que verifica a resposta dinâmica de uma linha de eixos; o que permite estudar os níveis de tensão a partir da imposição de movimentos de translação dos mancais.

As formulações necessárias para as análises de vibrações lineares de rotores simples biapoiados através do MEF são apresentadas por Müller e Schiehlen (1985), Meirovitch (1986), Genta (1993), entre outros. É importante ressaltar que, no caso de um ventilador centrífugo, o modelo para uma análise da resposta em frequência ao desbalanceamento deve incluir os efeitos giroscópicos e considerar as propriedades de rigidez e amortecimento dos mancais hidrodinâmicos. A metodologia e as ferramentas para a resposta dinâmica de rotores empregadas pelo presente trabalho são descritas por Zachariadis $(2000,2006)$.

Neste ponto, é importante ressaltar que o projeto mecânico de um ventilador centrífugo tradicionalmente é dividido em duas frentes: a análise estática do impelidor, na qual as tensões estáticas devido ao carregamento centrífugo são calculadas; e a análise dinâmica do rotor e do impelidor, com a determinação das velocidades críticas do eixo e com a avaliação dos modos de vibrar e frequências naturais do impelidor. Em alguns casos, as tensões dinâmicas são obtidas em campo a partir de strain-gages; em especial na investigação de alguma falha do ventilador, como, por exemplo, a presença de trincas no impelidor. Entretanto, não foram encontrados registros na literatura de métodos para o cálculo das tensões dinâmicas dos componentes de um ventilador centrífugo.

Neste contexto, mostra-se interessante 0 desenvolvimento de uma metodologia de cálculo das tensões dinâmicas através do MEF. Adicionalmente, a determinação das tensões estáticas e dinâmicas em uma dada velocidade do ventilador sugere o desenvolvimento de uma metodologia que permita realizar a composição das mesmas, de tal modo que se possa avaliar o nível total de tensões no impelidor. Timoshenko (1955), Meirovitch (1986), entre outros, descrevem a formulação matemática do chamado Princípio da Superposição e as condições segundo as quais ele é válido. Segundo este princípio, as respostas para um dado número de excitações distintas realizadas em sistemas lineares podem ser obtidas 
separadamente, e então combinadas para obter a resposta considerando-se os efeitos agregados. O emprego deste princípio se mostra como uma interessante ferramenta para a composição das tensões estáticas e dinâmicas do impelidor e na avaliação da sua integridade estrutural - o que será discutido em detalhe nas próximas seções.

\subsubsection{Análise de fadiga de estruturas soldadas}

Muitas das falhas apresentadas por impelidores centrífugos estão relacionadas a danos por fadiga, o que se traduz pela redução da vida útil dos ventiladores. Os processos industriais exigem que estes equipamentos sejam submetidos a variações de velocidade, sendo este o método preferencial para o controle da vazão dos gases. Também se verifica que os ventiladores centrífugos são ligados e desligados com relativa frequência, em especial em períodos de manutenção. É essencial que tais condições de operação sejam consideradas através de análises quanto à vida em fadiga dos impelidores, ainda na fase de projeto mecânico.

Neste ponto, busca-se identificar na literatura recomendações e procedimentos para análises de fadiga que possam ser aplicadas no estudo dos ventiladores centrífugos, de modo a ressaltar a relevância desta análise como uma das etapas no projeto mecânico destes equipamentos. Não é o objetivo da presente dissertação discutir em detalhes os conceitos e os critérios de projeto envolvidos nas análises de fadiga, mas sim fornecer elementos para que estudos mais detalhados sejam realizados a partir da metodologia apresentada neste trabalho para a análise estática e dinâmica de ventiladores centrífugos. Os conceitos e teorias utilizadas para modelar as falhas por fadiga são apresentados por Juvinall (1967), Norton (1998), entre outros.

Ventiladores estão sujeitos a carregamentos centrífugos que introduzem elevados níveis de tensão estáticas em seus componentes. Estes níveis de tensão frequentemente são maiores que o limite de fadiga das soldas do impelidor, de modo que as variações na velocidade do ventilador, ou ciclos de liga e desliga, conduzem à redução da vida em fadiga do ventilador. Portanto, raramente os impelidores 
centrífugos apresentam vida em fadiga infinita e atenção especial é dada à análise das soldas no impelidor. A análise de fadiga em estruturas soldadas volta-se para o estudo da propagação das trincas inerentes às soldas a cada ciclo de tensões a que estas estruturas são submetidas.

Os critérios de projeto voltados para análises de fadiga em estruturas soldadas são discutidos por Maddox (2000). O autor ressalta que a fadiga é a principal causa de falha em estruturas soldadas, o que justifica o emprego de procedimentos que permitam avaliar a fadiga destes componentes ainda na fase de projeto. Acrescente-se que a maioria das normas e critérios de projeto apresenta séries de curvas S-N para detalhes particulares de junções soldadas, onde $\mathrm{S}$ é a amplitude da tensão nominal adjacente à solda e $\mathrm{N}$ é o número de ciclos. Maddox (2000) ainda destaca o emprego da norma BS 7608, que apresenta curvas S-N obtidas experimentalmente e define classes (ou categorias) de solda associadas à geometria da junção e à direção do carregamento, como ilustra a Figura 1.5, apresentada por Macdonald e Maddox (2003).

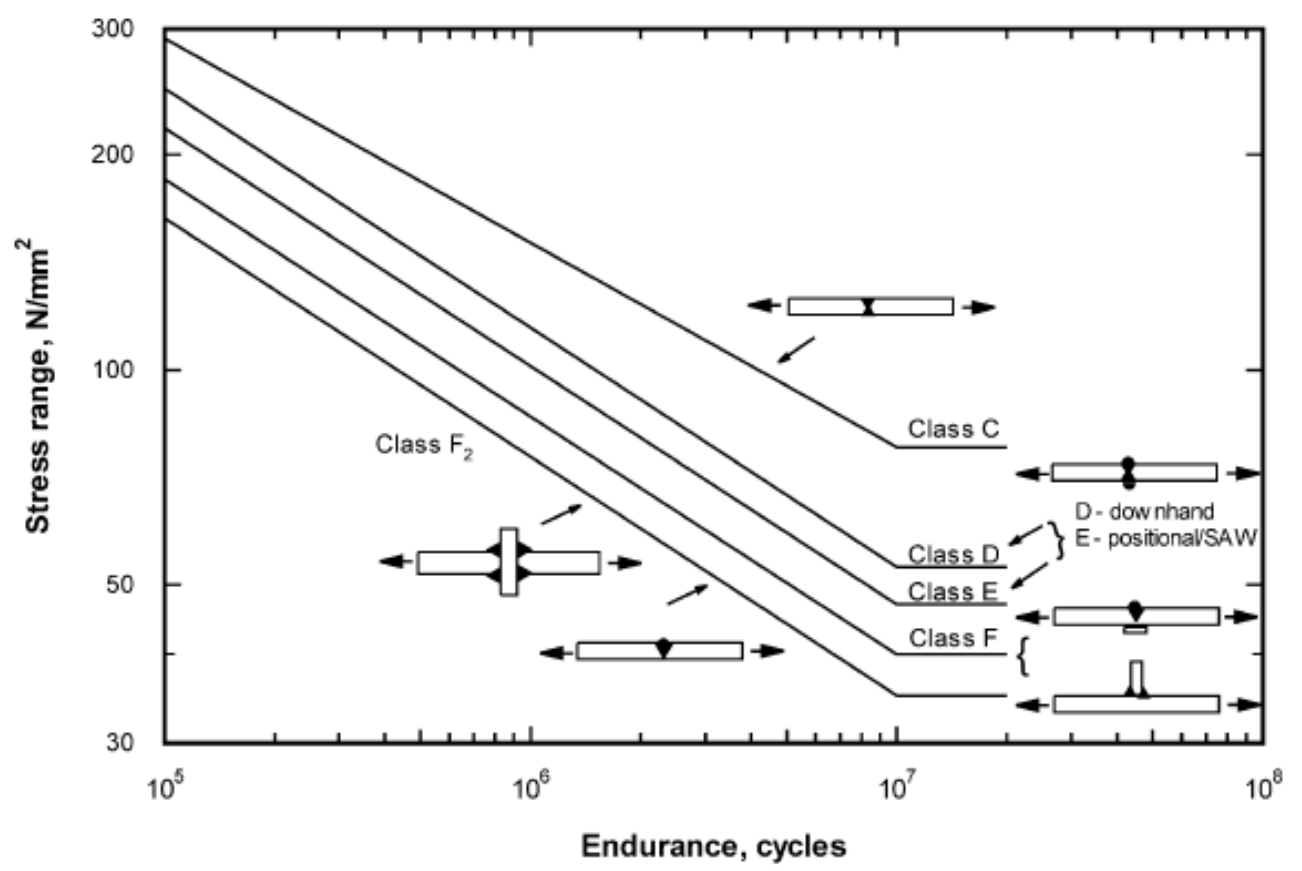

Figura 1.5 - Curvas S-N segundo a classificação da norma BS 7608 para algumas configurações de junções soldadas (MACDONALD e MADDOX, 2003)

É interessante notar que a resistência à fadiga de uma junção soldada não é modificada com o emprego de materiais de resistência mecânica mais elevada, 
conforme discussão realizada por Maddox (2000), que ressalta que a taxa de propagação das trincas em junções soldadas é insensível à elevação da resistência mecânica do material considerado nos elementos da estrutura. A influência das tensões residuais e da espessura dos componentes na análise de fadiga também é discutida pelo autor. É importante ressaltar que a resistência em fadiga de uma junção soldada diminui com o aumento da espessura das chapas, o que justifica o emprego de fatores de redução da vida em fadiga por algumas normas, como a Eurocode 3 e BS 7608, cujo uso é recorrente na indústria de ventiladores centrífugos.

O estudo da fadiga é frequentemente dividido entre os regimes de fadiga de baixo ciclo e fadiga de alto ciclo, cuja distinção se baseia no número de ciclos de tensão que uma estrutura é submetida durante a sua vida útil. Juvinall (1967) sugere $10^{3}$ ciclos como o limiar entre os dois regimes. Nicholas (2006) define a fadiga de alto ciclo como a condição de fadiga em que o número de ciclos entre possíveis inspeções é muito grande, dificultando a tomada de providências. $O$ autor discute que o diagrama mais empregado nas análises de fadiga de baixo ciclo são as curvas $\mathrm{S}-\mathrm{N}$, o qual relaciona a máxima tensão como uma função do número de ciclos para a falha. Já para a fadiga de alto ciclo, ênfase é dada ao valor da tensão no limite de fadiga e as análises são realizadas em um diagrama comumente denominado diagrama de Goodman ou diagrama de Haigh. De modo geral, a fadiga de baixo ciclo envolve altas amplitudes de tensão e baixas frequências, de modo que uma fração considerável da vida em fadiga ocorre durante a propagação da trinca. Por outro lado, a fadiga de alto ciclo envolve baixas amplitudes e altas frequências, e a maior parcela desta vida em fadiga diz respeito à iniciação das trincas (NICHOLAS, 1999).

Tradicionalmente, o projeto mecânico de ventiladores centrífugos volta-se ao estudo da fadiga proveniente dos ciclos de partida e parada do equipamento, e das grandes variações de velocidade. Estas análises não levam em consideração a possibilidade do desenvolvimento das trincas ser influenciada pelas tensões dinâmicas de alto ciclo e baixa amplitude. A Figura 1.6 ilustra as diferenças entre os regimes de baixo ciclo (alta amplitude de tensões estáticas) e de alto ciclo (baixa amplitude de tensões dinâmicas) na operação de um ventilador centrífugo. 


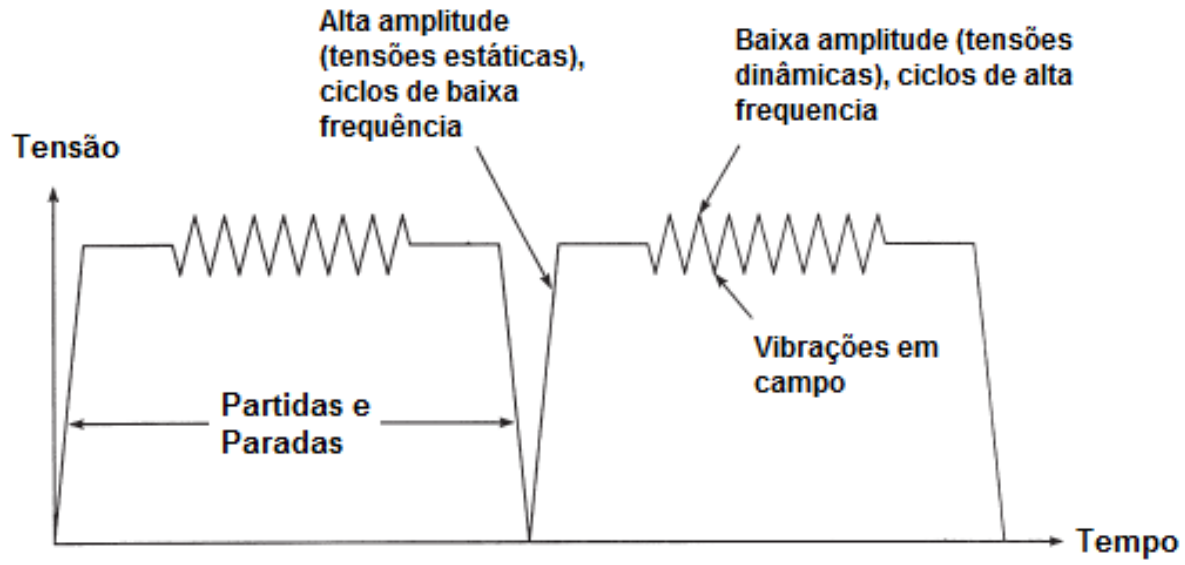

Figura 1.6 - Regimes de fadiga de baixo ciclo e alto ciclo durante a operação do ventilador

No que se refere ao projeto mecânico de impelidores centrífugos, nota-se que a análise de fadiga de baixo ciclo é bem estabelecida. Por outro lado, o estudo da fadiga de alto ciclo é ausente na fase de projeto, devido à dificuldade em se prever as tensões dinâmicas durante a operação do ventilador. Ressalte-se que a magnitude das tensões dinâmicas está relacionada aos efeitos aerodinâmicos e às frequências naturais do rotor e do impelidor, entre outros fatores. A ausência de análises detalhadas dos níveis de tensões dinâmicas é contornada, na prática, evitando-se a operação destes equipamentos na proximidade das suas frequências naturais. Este trabalho tem como um de seus objetivos propor uma metodologia para o cálculo das tensões dinâmicas de impelidores centrífugos, contribuindo para que estudos futuros relacionados à análise de fadiga de alto ciclo em impelidores centrífugos sejam realizados.

\subsection{OBJETIVOS E ESTRUTURA DO TRABALHO}

Tendo em vista os resultados da pesquisa bibliográfica, verifica-se a ausência de estudos que explorem de forma sistemática os diversos aspectos envolvidos na avaliação da integridade estrutural de ventiladores centrífugos. Evidentemente, os métodos analíticos para a avaliação das tensões estáticas em um impelidor têm sido gradualmente preteridos pelo MEF. Entretanto, embora seja consenso o valor e a eficácia da utilização do MEF enquanto ferramenta para a avaliação da integridade 
estrutural dos ventiladores centrífugos, não há como negar que, ainda assim, inúmeros equipamentos que operam com sucesso foram submetidos apenas aos métodos de cálculo analíticos. Isso pode revelar a necessidade de uma discussão acerca das particularidades de ambos os métodos, suas vantagens e suas desvantagens. Esta pesquisa reúne a um só tempo a apresentação da metodologia para o cálculo das tensões estáticas de ventiladores centrífugos pelo método analítico, uma discussão das suas limitações em relação ao MEF e, finalmente, propõe no caso deste último, uma metodologia para a modelagem de impelidores e para a avaliação dos resultados obtidos.

A demanda crescente por ventiladores de maiores diâmetros e rotações torna o projeto estrutural destes equipamentos um desafio não somente com relação aos níveis de tensões estáticas, mas também no que se refere ao comportamento dinâmico em campo. Neste contexto, uma análise detalhada da dinâmica vibratória do rotor e do impelidor passa a ser, cada vez mais, um item obrigatório durante o dimensionamento de ventiladores centrífugos. O emprego de análises de resposta dinâmica é explorado especialmente no projeto mecânico de turbinas, mas ainda pouco difundido quando se trata da análise de ventiladores. Não foram encontradas referências com procedimentos ou orientações para a avaliação das tensões dinâmicas em ventiladores, mostrando-se esta uma atividade ainda essencialmente experimental. Destaque-se, assim, a crescente necessidade de avaliações mais rigorosas, que permitam, ainda na fase de projeto, prever o comportamento dinâmico dos ventiladores, especialmente em condições extremas - como, por exemplo, a operação próxima a uma das velocidades críticas ou na condição de falha de algum componente.

Neste contexto, propõe-se a realização um estudo teórico que preencha, em diversos aspectos, as lacunas apontadas acima. Os objetivos específicos do presente trabalho são:

- Apresentar os métodos analíticos disponíveis para o cálculo das tensões estáticas em impelidores de ventiladores centrífugos e desenvolver uma metodologia para a sua determinação através do método dos elementos finitos, discutindo as limitações do primeiro método face ao segundo.

- Identificar os conhecimentos relativos à análise dinâmica de rotores e impelidores, discutindo os critérios tradicionalmente utilizados no projeto mecânico de ventiladores. 
- Desenvolver uma metodologia para a avaliação das tensões dinâmicas em impelidores de ventiladores centrífugos através do estudo da resposta em frequência de rotores e impelidores.

Durante a realização da pesquisa, o autor participou ativamente do cálculo estrutural de ventiladores centrífugos de grande porte e inúmeras particularidades referentes ao projeto destes equipamentos foram identificadas. Algumas referências relativas a esta experiência são mencionadas ao longo do texto, e contribuem para evidenciar a relevância do assunto estudado.

O desenvolvimento do tema nos capítulos seguintes da dissertação é iniciado com a apresentação dos métodos analíticos disponíveis na literatura para o cálculo das tensões estáticas nos discos e palhetas de ventiladores centrífugos. Exemplos numéricos permitem observar a validade destes métodos e discutir os casos em que - MEF representa a escolha mais adequada. Critérios para a avaliação dos resultados e para a aceitação dos mesmos são discutidos. O Capítulo 3 apresenta um estudo teórico dos conhecimentos relativos à análise dinâmica de máquinas rotativas e propõe uma metodologia para a determinação de tensões dinâmicas em impelidores centrífugos, discutindo através de exemplos a possibilidade de superposição das tensões estáticas e dinâmicas obtidas pelo MEF. A análise estática e dinâmica de um ventilador centrífugo de dupla-entrada é detalhada no Capítulo 4, e seus resultados mostram a importância de se considerar análises mais rigorosas na avaliação do comportamento dinâmico destes equipamentos. Um resumo dos principais resultados, seguido de conclusões e recomendações de trabalhos futuros, encerra o trabalho no Capítulo 5. 


\section{CÁLCULO DE TENSÕES EM VENTILADORES CENTRÍFUGOS}

Inicialmente, serão apresentados os métodos analíticos para o cálculo das tensões estáticas em discos e palhetas de impelidores centrífugos. Na sequência, apresenta-se o procedimento para o cálculo de tensões através do MEF, abordando a construção do modelo e a interpretação dos resultados. A partir de exemplos numéricos aplicados a um ventilador de simples-entrada são discutidas as vantagens e desvantagens de ambos os métodos. Por fim, são expostas formulações que permitem avaliar a vida em fadiga destes equipamentos a partir das tensões estáticas no impelidor.

\subsection{EMPREGO DE MÉTODOS ANALÍTICOS}

\subsubsection{Discos Rotativos de espessura constante}

O equacionamento para o cálculo de tensões em discos rotativos de espessura constante pode ser encontrado em inúmeras referências, porém são deduzidas detalhadamente por Bohl (1988). Considera-se um disco de espessura $b$ e velocidade angular $\omega$ - indicado na Figura 2.1. Parte-se do pressuposto que não existem tensões na direção axial, de modo que as tensões estudadas estão presentes no plano do disco. 


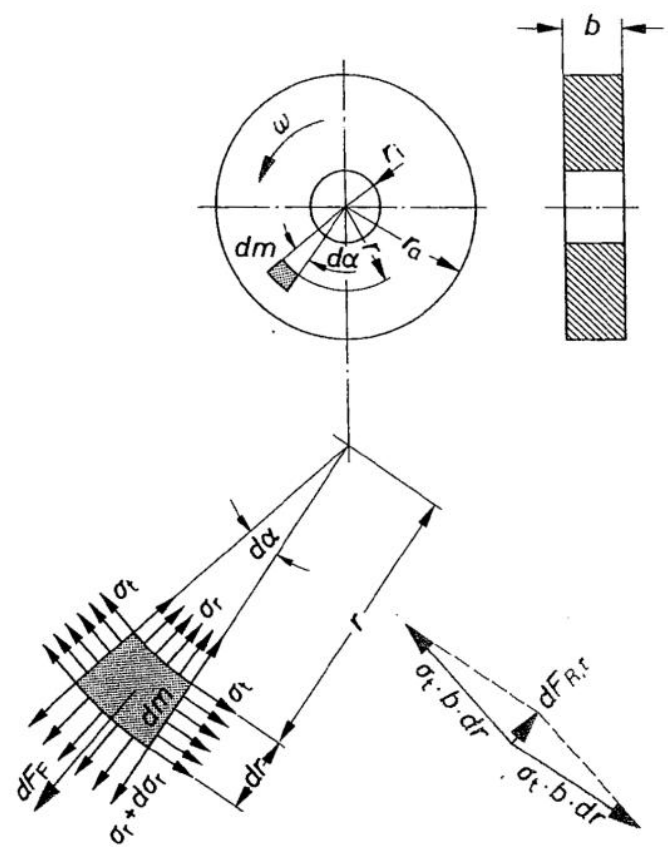

Figura 2.1- Disco sob o efeito da força centrífuga (BOHL, 1988)

A determinação da distribuição das tensões radiais e tangenciais no disco assume duas condições: equilíbrio de forças em um elemento de disco de massa $d m$ - como indicado na Figura 2.1 e as deformações elásticas do elemento devido às tensões. A força centrífuga no elemento considerado pode ser escrita na forma:

$$
d F_{F}=d m \cdot r \cdot \omega^{2}=\rho \cdot r^{2} \cdot \omega^{2} \cdot b \cdot d \alpha \cdot d r
$$

\section{Onde:}

$d F_{F}$ é a força centrífuga no elemento de disco; $d m$ é a massa do elemento de disco; $r$ é o raio interno do elemento de disco; $d r$ é o raio diferencial do elemento de disco; $\omega$ é a velocidade angular; $\rho$ é a densidade; $b$ é espessura do disco; $d \alpha$ é o ângulo diferencial do elemento de disco;

As forças radiais e tangenciais presentes no disco podem ser escritas em termos das tensões radiais e tangenciais atuantes, respectivamente:

$$
\begin{gathered}
d F_{R, r}=\left(\sigma_{r}+d \sigma_{r}\right)\left(r+d_{r}\right) d \alpha \cdot b-\sigma_{r} \cdot r \cdot d \alpha \cdot b \\
d F_{R, t}=-\sigma_{t} \cdot d r \cdot b \cdot d \alpha
\end{gathered}
$$


Assumindo o equilíbrio das forças centrífugas, radiais e tangenciais:

$$
d F_{F}+d F_{R, r}+d F_{R, t}=0
$$

Substituindo as equações (2.1), (2.2) e (2.3) na equação (2.4), obtém-se:

$$
\sigma_{r}+r \frac{d \sigma_{r}}{d r}-\sigma_{t}+\rho \cdot \omega^{2} \cdot r^{2}=0
$$

Uma equação adicional que relaciona as tensões radiais e tangenciais pode ser obtida através da análise das deformações no elemento de disco esquematizado na Figura 2.2. A deformação radial é dada por:

$$
\varepsilon_{r}=\frac{(u+d u)-u}{d r}=\frac{d u}{d r}
$$

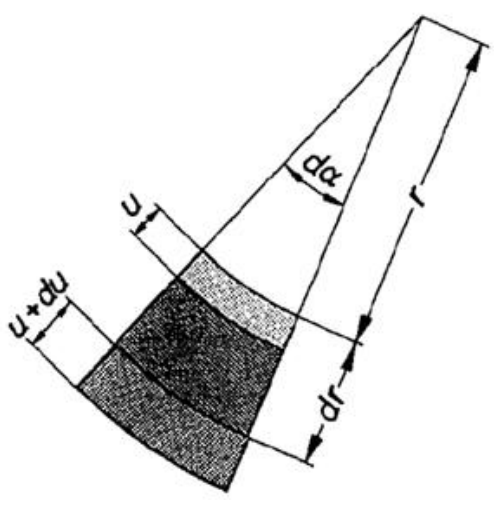

Figura 2.2 - Deformação do elemento do disco em estudo (BOHL, 1988)

A deformação tangencial pode ser escrita na forma:

$$
\varepsilon_{t}=\frac{(r+u) d \alpha-r \cdot d \alpha}{r \cdot d \alpha}=\frac{u}{r}
$$

Manipulando algebricamente a equação (2.7) e de posse da equação (2.6), obtém-se:

$$
\varepsilon_{t}-\varepsilon_{r}+r \cdot \frac{d \varepsilon_{t}}{d r}=0
$$


Da Lei de Hook é possível obter as relações entre as deformações radiais e tangenciais com as respectivas tensões:

$$
\begin{aligned}
& \varepsilon_{r}=\frac{1}{E} \cdot\left(\sigma_{r}-v \cdot \sigma_{t}\right) \\
& \varepsilon_{t}=\frac{1}{E} \cdot\left(\sigma_{t}-v \cdot \sigma_{r}\right)
\end{aligned}
$$

Substituindo as equações (2.9) e (2.10) na equação (2.8), tem-se:

$$
(1+v)\left(\sigma_{t}-\sigma_{r}\right)+r\left(\frac{d \sigma_{t}}{d r}-v \cdot \frac{d \sigma_{r}}{d r}\right)=0
$$

A solução da equação diferencial (2.11) conduz à determinação das expressões para o cálculo das tensões radiais e tangenciais para o disco apresentado na Figura 2.3.

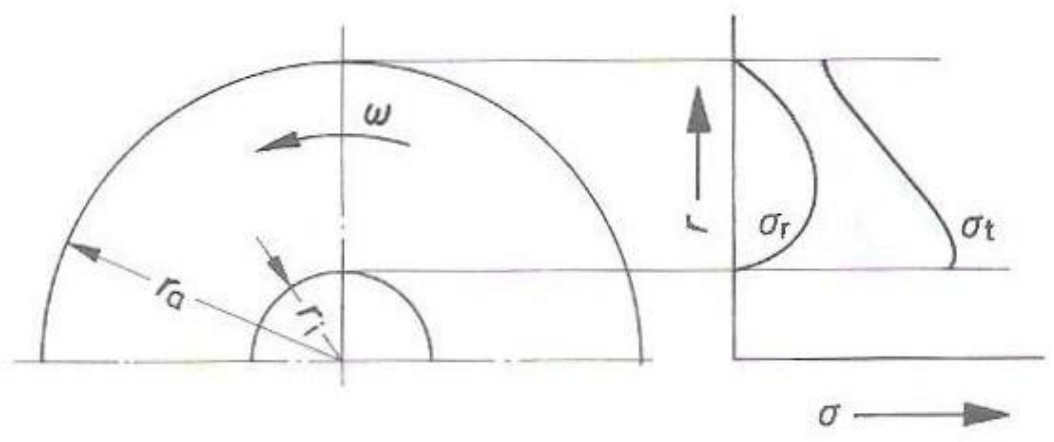

Figura 2.3 - Representação do disco rotativo e esquematização da distribuição das tensões radiais e tangenciais devido à força centrífuga (BOHL, 1988)

A distribuição das tensões radiais é dada por:

$$
\sigma_{r}=\frac{\rho \cdot \omega^{2}(3+v)}{8}\left(r_{i}^{2}+r_{a}^{2}-\frac{r_{i}^{2} \cdot r_{a}^{2}}{r^{2}}-r^{2}\right)
$$

Portanto, a expressão final para as tensões tangenciais fica:

$$
\sigma_{t}=\frac{\rho \cdot \omega^{2}(3+v)}{8}\left(r_{i}^{2}+r_{a}^{2}+\frac{r_{i}^{2} \cdot r_{a}^{2}}{r^{2}}-\frac{1+3 v}{3+v} r^{2}\right)
$$


A partir da Figura 2.3 é possível observar a distribuição das tensões radiais e tangenciais ao longo do raio do disco. Existem casos em que o disco de espessura constante é submetido a esforços no furo central ou na sua periferia, como indica a Figura 2.4. Nestas situações, é possível modificar as expressões (2.12) e (2.13) de modo que o efeito destes esforços seja considerado.

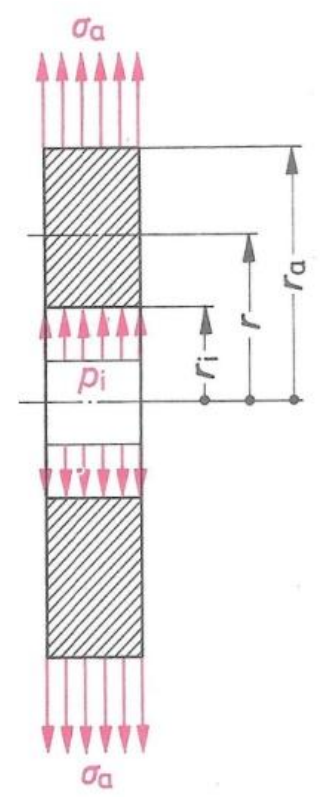

Figura 2.4 - Disco rotativo submetido a esforços no furo central e na sua periferia (BOHL, 1988)

Nestas condições, é possível demonstrar que a expressão para o cálculo das tensões radiais é da forma:

$$
\sigma_{r}=K_{1}+\frac{K_{2}}{r^{2}}-\frac{\rho \cdot r^{2} \cdot \omega^{2} \cdot(3+v)}{8}
$$

Os valores de $\mathrm{K}_{1}$ e $\mathrm{K}_{2}$ são dados por:

$$
\begin{aligned}
& K_{1}=\frac{\sigma_{a} \cdot r_{a}^{2}-p_{i} \cdot r_{i}^{2}}{r_{a}^{2}-r_{i}^{2}}+\frac{3+v}{8} \cdot \rho \cdot \omega^{2} \cdot\left(r_{a}^{2}+r_{i}^{2}\right) \\
& K_{2}=-\left(\sigma_{a}-p_{i}\right) \frac{r_{a}^{2} \cdot r_{i}^{2}}{r_{a}^{2}-r_{i}^{2}}-\frac{3+v}{8} \cdot \rho \cdot \omega^{2} \cdot r_{a}{ }^{2} \cdot r_{i}{ }^{2}
\end{aligned}
$$


Finalmente, a expressão obtida para a tensão tangencial é:

$$
\sigma_{t}=K_{1}-\frac{K_{2}}{r^{2}}-\frac{1+3 v}{8} \cdot \rho \cdot \omega^{2} \cdot r^{2}
$$

É importante notar que anulando os termos referentes aos esforços na periferia e no centro do disco, as equações (2.14) e (2.17) ficam idênticas às equações (2.12) e (2.13).

\subsubsection{Palhetas}

Ventiladores centrífugos apresentam geometrias complexas compostas por discos, anéis e palhetas. $O$ cálculo das tensões em cada componente envolve formulações complexas, sendo de difícil obtenção até mesmo quando métodos numéricos - como o MEF - são utilizados (BOHL, 1983). Passa-se então ao estudo das tensões nas palhetas de ventiladores centrífugos.

A formulação das tensões parte da análise de um elemento de palheta conforme indicado na Figura 2.5. A força centrífuga presente neste elemento de massa $d m$ pode ser expressa na forma:

$$
d F=d m \cdot r \cdot \omega^{2}=\rho \cdot b \cdot s \cdot d l \cdot r \cdot \omega^{2}
$$

Onde:

$d F$ é a força centrífuga no elemento de palheta; $d m$ é a massa associada ao elemento de palheta; $r$ é o raio do elemento de palheta; $\omega$ é a velocidade angular; $\rho$ é a densidade; $b$ é a largura da palheta; $s$ é a espessura da palheta; $d l$ é 0 comprimento diferencial do elemento de palheta; ré o raio do elemento de palheta. 


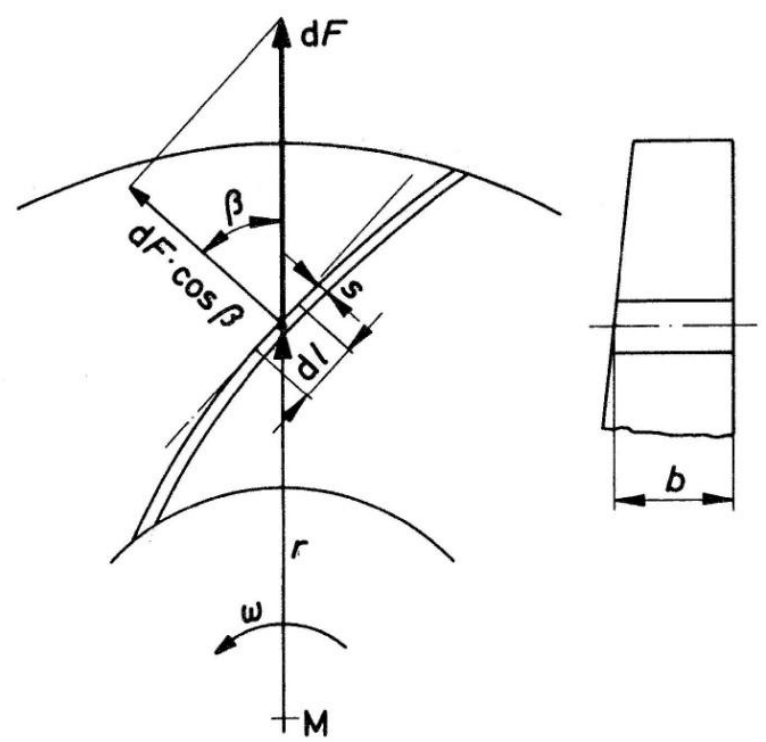

Figura 2.5 - Análise das forças em um elemento de palheta de ventilador centrífugo (BOHL, 1983)

É possível modelar as palhetas dos ventiladores de dois modos distintos no que diz respeito a sua união com os discos dos ventiladores. O primeiro modelo considera a palheta como uma viga engastada em suas extremidades, de modo que o momento de flexão máximo ocorre na união da palheta com os discos. O segundo modelo admite que a palheta seja presa aos discos através de articulações fixas e que o maior momento de flexão é encontrado no meio do vão. A comparação entre estes dois modelos é apresentada na Figura 2.6.
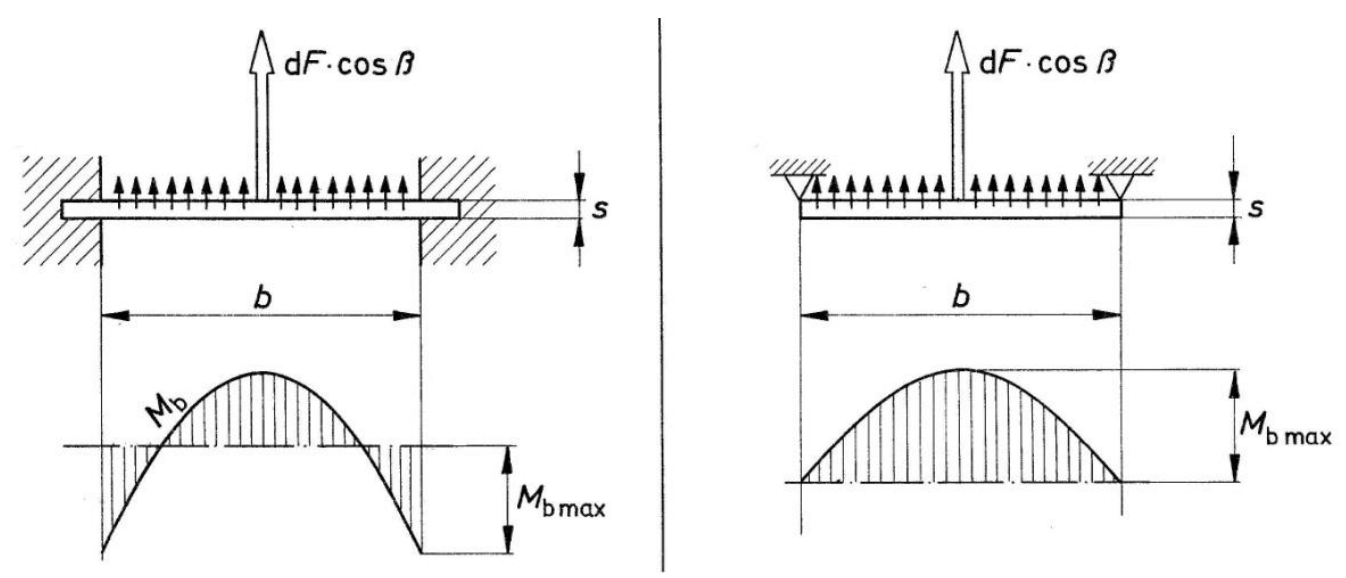

Figura 2.6 - Dois possíveis modelos para o cálculo de tensões em palhetas de ventiladores centrífugos (BOHL, 1983) 
Inicialmente, considera-se o modelo no qual as palhetas estão engastadas aos discos. O máximo momento de flexão é dado por:

$$
M_{\text {bmáx }}=\frac{d F \cdot \cos \beta \cdot b}{12}
$$

Onde:

$\beta$ é o ângulo formado pelo vetor normal ao elemento de palheta e o vetor correspondente à força centrífuga neste elemento.

O módulo da seção transversal da palheta é $W_{b}=\frac{s^{2} \cdot d l}{6}$ e a velocidade tangencial do elemento é $v=\omega \cdot r$. A máxima tensão na palheta é dada por $\sigma_{b m a ́ x}=\frac{M_{b m a ́ x}}{W_{b}}$ que, através de manipulações algébricas e considerando o diâmetro $D_{2}$ na saída da palheta, pode ser expressa na forma:

$$
\sigma_{\text {bmáx }}=\frac{\rho}{2} \cdot v_{2}^{2} \cdot \frac{b_{2}^{2}}{r_{2} \cdot s} \cdot \cos \beta_{2}
$$

Considerando-se que a máxima velocidade periférica admissível corresponda à situação em que a tensão é máxima, é possível escrever:

$$
v_{2 a d m}=\sqrt{2 \cdot \frac{\sigma_{b m a ́ x}}{\rho} \cdot \frac{r_{2} \cdot s}{b_{2}{ }^{2} \cdot \cos \beta_{2}}}
$$

Procedendo de forma análoga ao outro modelo apresentado na Figura 2.6 palhetas conectadas aos discos através de articulações fixas - é possível deduzir a expressão para a máxima tensão:

$$
\sigma_{b m a ́ x}=\frac{3}{4} \cdot \rho \cdot v_{2}{ }^{2} \cdot \frac{b_{2}{ }^{2}}{r_{2} \cdot s} \cdot \cos \beta_{2}
$$

A máxima velocidade periférica admissível para este caso é dada por:

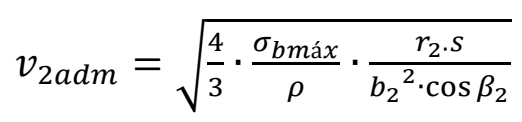


É importante notar que, na realidade, a conexão das palhetas com os discos não é nem completamente rígida como sugere o modelo com engastamentos, nem livre de momentos nas extremidades, como assumido para o segundo modelo estudado. Desta forma, é esperado que as velocidades periféricas admissíveis estejam entre os valores encontrados a partir das equações (2.21) e (2.23).

\subsection{ANÁLISE ESTÁTICA ATRAVÉS DO MÉTODO DOS ELEMENTOS FINITOS}

\subsubsection{Construção do modelo}

Uma prática comum em análises estáticas lineares de ventiladores centrífugos é fazer uso de suas propriedades de simetria, isto é, considerar apenas o setor correspondente a uma palheta na modelagem do impelidor. Portanto, a título de exemplo, caso o impelidor analisado possua 12 palhetas, o modelo pode ser construído a partir de um setor correspondente a $30^{\circ}$ do impelidor completo. Este procedimento resulta em tempos de processamento mais reduzidos e também é preferido devido à maior facilidade na verificação erros de modelagem e dos resultados obtidos.

Com relação ao tipo de elemento utilizado para a construção das malhas, em geral são preferidos elementos de casca de quatro nós. A geometria de uma casca é definida pela sua espessura e pela sua superfície média. $O$ presente trabalho utilizará elementos de casca no modelo do impelidor, também apresentado por Bhope e Padole (2004) na análise teórica e experimental de um ventilador centrífugo de pás curvadas.

Deste modo, as chapas que constituem o impelidor - os discos laterais ou central, os anéis, as palhetas e os cones de proteção - são modelados a partir da sua superfície média, como mostrado na Figura 2.7. A preferência pelo emprego de elementos de casca a elementos tridimensionais muitas vezes está associada à facilidade do primeiro em permitir estudar o efeito da modificação das espessuras dos componentes de um ventilador nos resultados de tensões estáticas. Isto é realizado nos softwares comerciais através da simples alteração das propriedades 
informadas para cada componente, ao passo que alterações de espessura em modelos tridimensionais exigem um tempo maior para a construção de uma nova geometria. É importante ressaltar que não é o intuito do presente trabalho discutir os detalhes relacionados à formulação dos elementos empregados, bem como outros aspectos relacionados às técnicas de modelagem e à convergência dos resultados.

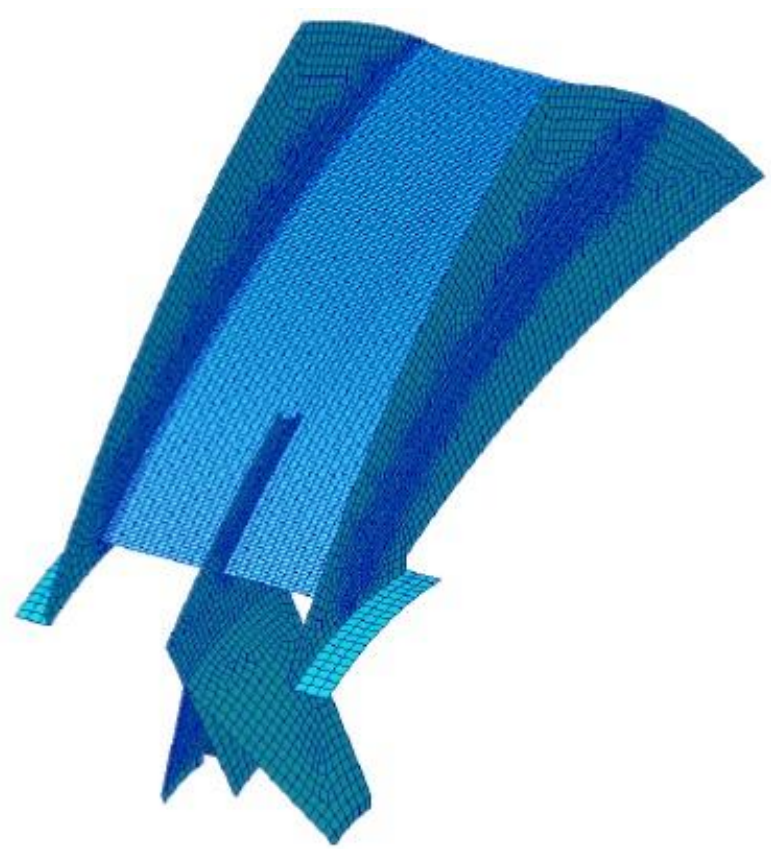

Figura 2.7 - Modelo do impelidor de um ventilador centrífugo de dupla-entrada para a análise de tensões estáticas através do MEF

Impelidores de ventiladores centrífugos em geral possuem um disco central ou um disco traseiro soldado a um cubo no eixo. Como condição de contorno, os seis graus de liberdade dos elementos presentes no furo do disco central - ou traseiro - são restringidos. Em geral, o cubo não é incluído na análise porque não influencia significativamente nos resultados de tensão estática. Os modelos também devem incorporar a simetria rotacional do impelidor, informação facilmente especificada nos softwares comerciais. O presente trabalho faz uso do software MD Nastran e a simetria rotacional é obtida através de elementos denominados multipoint constrain equations (MPC's), que realizam a correspondência entre os seis graus de liberdade dos elementos pertencentes às arestas equivalentes. Os elementos de casca de quatro nós são denominados QUAD4.

Conforme apresentado por Cook (1995), nenhum elemento de casca está livre de tensões provenientes de momentos fletores. Estas tensões, em geral, são 
verificadas em reforços, mudanças de curvatura, suportes e transições presentes nas mais diversas estruturas. O impelidor de um ventilador centrífugo, em particular, é composto por inúmeras palhetas soldadas aos discos laterais e central, de modo que a região das soldas representa uma descontinuidade geométrica e consequentemente apresenta tensões de momento fletor mais elevadas, muitas vezes consideradas não realistas. As normas PD 5500 e ASME VIII fornecem orientações para a avaliação dos resultados, como será discutido nas próximas seções. Devido à presença de tensões de momentos fletores próximas às singularidades geométricas - como a união de uma palheta com os seus discos, Cook (1995) sugere o emprego de ao menos dois elementos de casca nestas regiões para garantir a convergência dos resultados. Fora destas regiões, os deslocamentos e tensões possuem gradientes menores, de modo que elementos de casca maiores podem ser empregados.

$\mathrm{Na}$ determinação das tensões estáticas em um ventilador centrífugo, o único carregamento considerado é a força centrífuga. Esta é especificada através de um carregamento inercial no MD Nastran, a partir da especificação da velocidade do ventilador e do seu eixo de rotação. É importante ressaltar a necessidade de se considerar no modelo de elementos finitos as propriedades adequadas relativas ao material utilizado para a fabricação do impelidor, em especial o módulo de elasticidade. Sabendo-se que ventiladores centrífugos podem operar em temperaturas elevadas e considerando-se que o módulo de elasticidade de um aço decresce com a temperatura, o uso incorreto desta propriedade implica em resultados pouco realistas das deformações no impelidor.

\subsection{CRITÉRIOS DE PROJETO}

\subsubsection{Tensões admissíveis}

Os termos fator de segurança ou fator de serviço são frequentemente utilizados como sinônimos para indicar a relação entre a resistência do material estimada e a tensão calculada. Quanto mais precisa for a estimativa da resistência 
do material e da tensão, tanto menores podem ser os fatores de segurança empregados (JUVINALL, 1967). Em alguns casos, as tensões - frequentemente denominadas "tensões nominais" (NORTON, 1998), são calculadas a partir de expressões analíticas aplicadas a uma geometria uniforme, sem levar em consideração possíveis variações de carregamento ou concentradores de tensão.

A partir deste conceito, a prática comum no projeto mecânico de ventiladores consiste na comparação das tensões estáticas calculadas - seja através de métodos analíticos, seja através do método dos elementos finitos - com uma tensão admissível definida pela razão entre o limite de escoamento do material (na temperatura de projeto) e um fator de serviço, como apresentado na equação (2.24).

$$
\sigma_{a d m}=\frac{\sigma_{e}}{F S}
$$

Os valores para fatores de serviço usualmente utilizados no projeto mecânico de ventiladores centrífugos, em geral, encontram-se entre 1.3 e 2 . A definição dos valores admissíveis é definida pelos fabricantes em função dos materiais empregados na fabricação - considerando as incertezas nos valores de limites de escoamento - e também em função do componente analisado frente às incertezas

provenientes dos métodos analíticos. É importante ressaltar que, em inúmeras situações, as tensões obtidas através do cálculo pelo método dos elementos finitos são maiores que as tensões admissíveis consolidadas para os métodos de cálculo analíticos. Nestes casos, a abordagem utilizada é a da análise de tensões localizadas, assunto que será discutido na próxima seção.

\subsubsection{Análise de tensões localizadas}

O emprego do MEF na análise estática de impelidores centrífugos frequentemente revela a presença de áreas cujos níveis de tensão são maiores que os valores admissíveis estabelecidos pelos fabricantes. Uma análise mais conservadora conduziria a mudanças no projeto mecânico impelidor, como, por exemplo, a modificação das espessuras de seus componentes ou a utilização de 
materiais mais resistentes. Entretanto, algumas normas tradicionalmente utilizadas no dimensionamento de vasos de pressão constituem uma ferramenta complementar aos critérios de projeto usualmente utilizados. Assim, as normas ASME VIII e PD 5500 fornecem elementos para uma avaliação mais rigorosa dos pontos de alta tensão no impelidor, o que, em alguns casos, conduz à aceitação do projeto mecânico cuja análise, segundo os critérios convencionais, indica a necessidade de redimensionamento dos componentes do impelidor.

O procedimento proposto por estas normas consiste na decomposição do campo de tensões estáticas e na sua categorização em 'famílias' definidas com base na localização das tensões na estrutura e nos mecanismos de falha envolvidos. As tensões são classificadas em tensões de membrana geral ou local, bem como tensões primárias ou secundárias de flexão. A cada uma destas categorias de tensão são associados valores admissíveis específicos, utilizados para avaliar a integridade estrutural do componente analisado. Não é o objetivo do presente trabalho apresentar os detalhes envolvidos na categorização de tensões. Ressaltase, contudo, que o emprego destes critérios é de grande interesse para os fabricantes, uma vez que o redimensionamento destes equipamentos pode, em muitos casos, ser evitado através de análises detalhadas dos pontos de alta tensão do impelidor.

Áreas próximas a concentradores de tensão, por exemplo, podem apresentar tensões muito elevadas, em alguns casos superiores à tensão de escoamento do material. O emprego desta abordagem permite, em muitos casos, concluir que as tensões na região em estudo não representam risco à integridade estrutural do componente, de modo que valores de tensão admissíveis mais elevados podem ser considerados para estas áreas. Assim, o projeto mecânico de um impelidor centrífugo pode ser aprovado, mesmo quando são verificadas tensões acima do limite admissível - previsto pelo critério de projeto convencional - dependendo da classificação utilizada para a área em estudo. Nesta ótica, mesmo que ocorra alguma deformação plástica nestas regiões, admite-se que a estrutura permanecerá íntegra, uma vez que a pequena região de deformação plástica é restringida por uma região em regime elástico de tensões. A Figura 2.8 ilustra o campo de tensões estáticas em um impelidor, com a indicação de uma área que comumente apresenta tensões elevadas. 


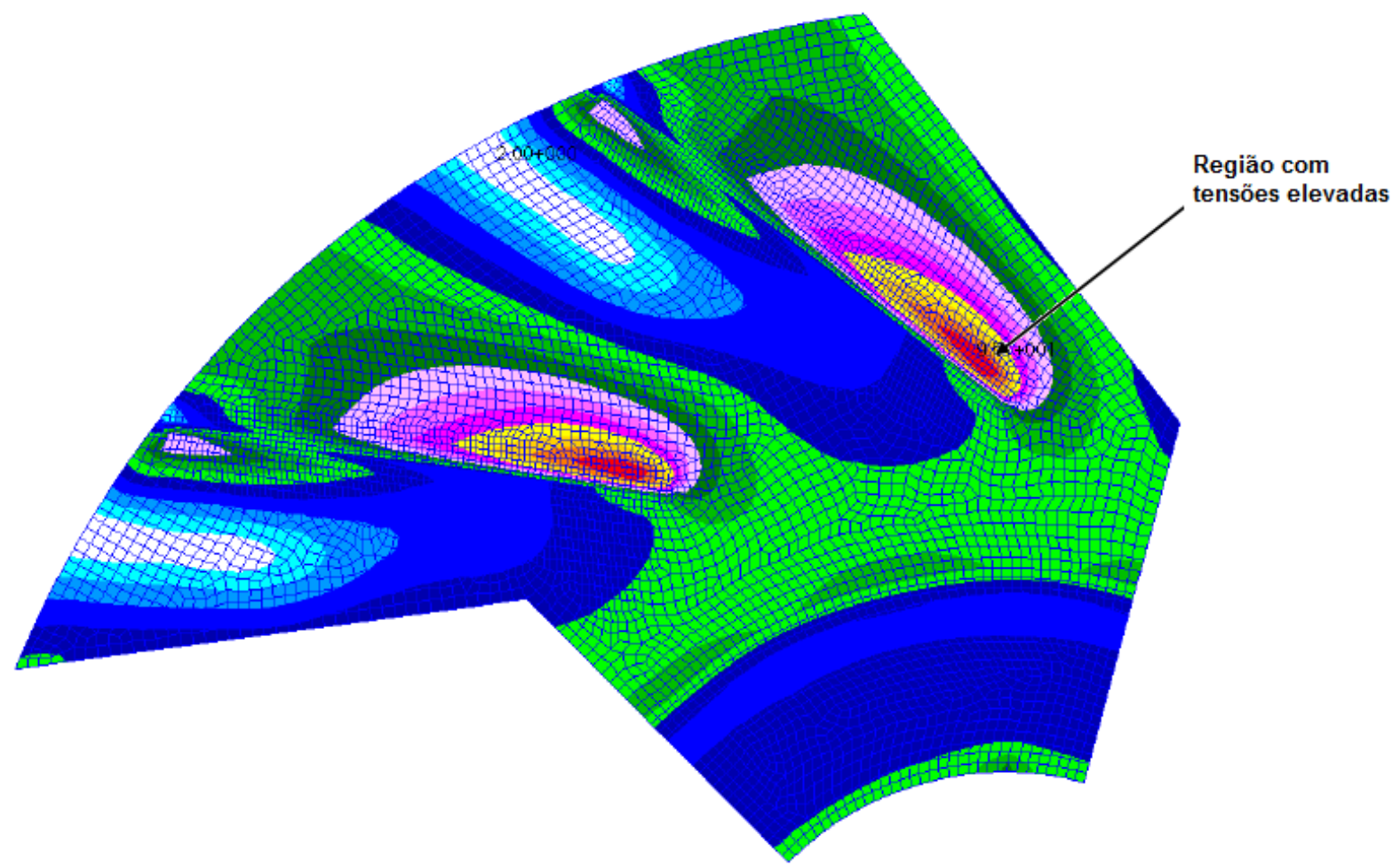

Figura 2.8 - Indicação das regiões de alta tensão no disco lateral de um impelidor centrífugo, nas imediações das palhetas tipo aerofólio

A categorização dos componentes do impelidor frequentemente revela que estas tensões podem ser consideradas aceitáveis, sem que isto represente um risco à operação do equipamento. Deve-se ressaltar, entretanto, que este critério deve ser utilizado com cautela, uma vez que a categorização das tensões é de certo modo subjetiva e pode conduzir à aceitação de projetos mecânicos inadequados. A experiência dos fabricantes, já discutida em outras seções deste trabalho, volta a ser um fator de suma importância na avaliação dos projetos mecânicos, mesmo quando o MEF é utilizado.

\subsubsection{Análise da vida em fadiga}

Ressalta-se neste ponto a necessidade de se considerar, ainda na fase de projeto, o potencial de falha por fadiga das uniões soldadas de ventiladores centrífugos. As palhetas são soldadas aos discos em suas extremidades, onde frequentemente são verificados os maiores níveis de tensão estática nos 
impelidores. As partidas e paradas destes equipamentos, bem como as variações de velocidade, implicam em grandes amplitudes de tensão nestas regiões e contribuem para a diminuição da vida em fadiga dos impelidores. Conforme discutido por Maddox (2000), atenção especial deve ser dada ao projeto mecânico de estruturas soldadas, devido ao seu comportamento em fadiga. A Figura 2.9 compara a resistência em fadiga das uniões soldadas com outras configurações sem a presença de soldas.

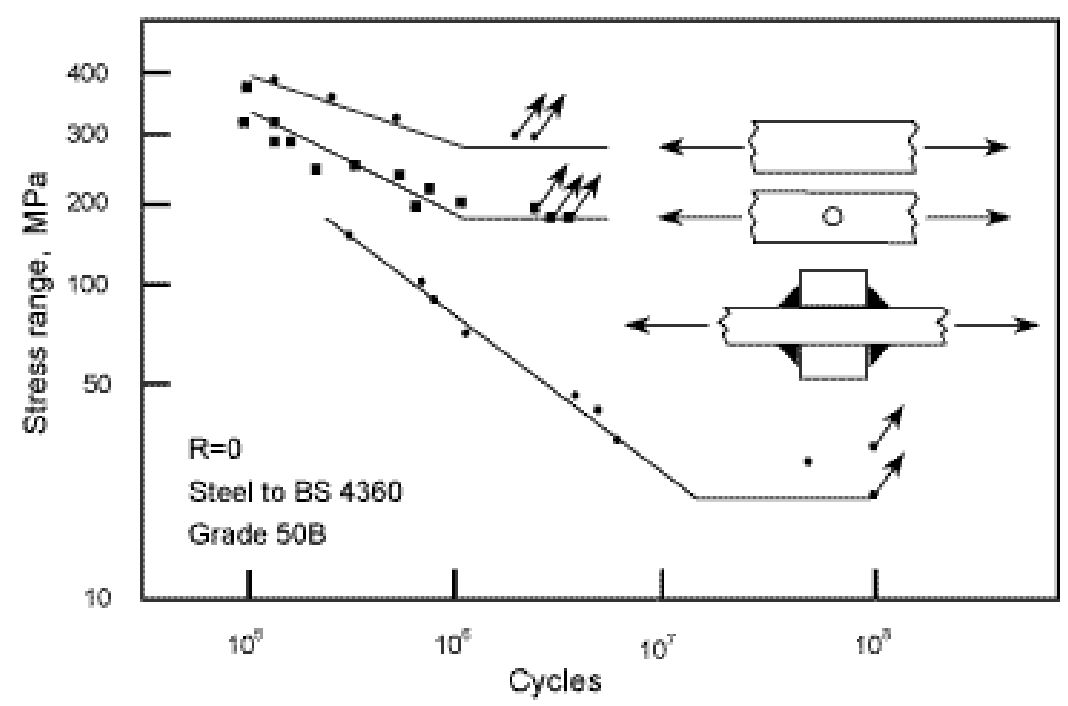

Figura 2.9 - Efeito das soldas na resistência à fadiga (MADDOX, 2000).

A base da análise de fadiga consiste em obter a melhor estimativa das tensões na região das soldas, considerando-se as incertezas envolvidas, e utilizar curvas S-N derivadas a partir de dados experimentais e apresentadas por normas como a Eurocode 3 e BS 7608. Estas normas categorizam as diferentes configurações de união soldada a partir da geometria da união, da direção do carregamento e da localização das trincas. Cada classe de união possui uma curva S-N correspondente, de modo que a relação entre a amplitude de tensão aplicada $\mathrm{S}_{\mathrm{r}}$, e o número de ciclos $\mathrm{N}$ para falha, é dada pela equação (2.25) abaixo:

$$
S_{r}{ }^{m} \cdot N=C_{d}
$$

Onde: 
$\mathrm{m}$ e $\mathrm{C}_{\mathrm{d}}$ são constantes correspondentes às classes de união soldada e suas respectivas curvas $\mathrm{S}-\mathrm{N}^{2}$, que são construídas com auxílio de métodos estatísticos; e $\mathrm{N}$ é o número de ciclos.

Considerando que os ventiladores centrífugos são submetidos a muitos ciclos de variações de velocidade ou de partida e parada ao longo de sua vida útil, a avaliação da vida em fadiga é frequentemente realizada através da regra do dano acumulado ou regra de Miner. Juvinall (1967) descreve que esta regra assume que a vida total de uma estrutura (neste caso as uniões soldadas) pode ser estimada adicionando-se uma porcentagem da vida consumida para cada ciclo de tensão. A regra de Miner é apresentada na equação (2.26), onde $n_{1}, n_{2}, \ldots, n_{k}$ representam o número de ciclos que a estrutura é submetida a uma amplitude de tensão $S_{1}, S_{2} \ldots$, $S_{k}$, e $N_{1}, N_{2}, \ldots, N_{k}$ representam a vida (em ciclos) correspondentes a estes níveis de tensão, obtidas a partir das curvas S-N.

$$
\frac{n_{1}}{N_{1}}+\frac{n_{2}}{N_{2}}+\cdots+\frac{n_{k}}{N_{k}}=\sum_{j=1}^{j=k} \frac{n_{j}}{N_{j}}=1
$$

Embora a regra de Miner seja tradicionalmente utilizada na avaliação da vida em fadiga de estruturas soldadas, Zhang e Maddox (2009) mostram que testes experimentais indicam que o valor de $\sum(n / N)$ é fortemente dependente da sequência com que os carregamentos são aplicados. Entretanto, como não é objetivo do presente trabalho apresentar detalhes sobre o cálculo de fadiga ou discutir a validade dos métodos tradicionalmente utilizados em estruturas soldadas, recomenda-se ao leitor a consulta de estudos de caso mais detalhados na literatura apresentada.

\footnotetext{
2 No caso da BS 7608, as curvas S-N representam a condição em que a probabilidade de falha, baseada em uma distribuição normal e dois desvios-padrões, é de $2.3 \%$.
} 


\subsection{EXEMPLOS DE APLICAÇÃO}

Nessa seção são apresentados alguns exemplos com a comparação dos valores de tensão estática calculadas pelos métodos analíticos - descritos na seção 2.1 - e pelo MEF, com o objetivo de ilustrar a aplicação de ambos os métodos e discutir as limitações envolvidas na utilização dos métodos analíticos no cálculo estrutural de ventiladores centrífugos.

Os exemplos consideram o caso de um ventilador centrífugo de simples entrada. As principais dimensões do ventilador e as condições de operação são apresentadas na Tabela 2.1. Para as simulações em elementos finitos, os softwares MD Patran 2010 (pré e pós-processador) e MD Nastran (solver) foram utilizados.

Tabela 2.1 - Dados construtivos do ventilador estudado

\begin{tabular}{lcccc}
\hline \hline Dimensões do ventilador & $\begin{array}{c}\text { Raio interno } \\
(\mathrm{mm})\end{array}$ & $\begin{array}{c}\text { Raio externo } \\
(\mathrm{mm})\end{array}$ & $\begin{array}{c}\text { Espessuras } \\
(\mathrm{mm})\end{array}$ & $\begin{array}{c}\text { Ângulo de saída } \\
\text { (graus) }\end{array}$ \\
\hline Palhetas & 477.0 & 880.5 & 6.35 & $54^{\circ}$ \\
Disco lateral & 457.5 & 887.5 & 12.7 & - \\
Disco traseiro & 92.5 & 887.5 & 12.7 & - \\
Largura das palhetas & \multicolumn{3}{c}{$144 \mathrm{~mm}$} \\
Número de palhetas & \multicolumn{3}{c}{12 (curvadas para trás) } \\
\hline \hline
\end{tabular}

Condições de operação

\begin{tabular}{|c|c|}
\hline Rotação (rpm) & 1780 \\
\hline $\begin{array}{l}\text { Temperatura de projeto } \\
\text { mecânico }\left({ }^{\circ} \mathrm{C}\right)\end{array}$ & 25 \\
\hline \multicolumn{2}{|c|}{ Propriedades do material } \\
\hline Denominação & ASTM A242 \\
\hline $\begin{array}{l}\text { Limite de escoamento } \\
\left(\mathrm{N} / \mathrm{mm}^{2}\right)\end{array}$ & 350 \\
\hline $\begin{array}{l}\text { Limite de resistência à } \\
\text { tração }\left(\mathrm{N} / \mathrm{mm}^{2}\right)\end{array}$ & 500 \\
\hline $\begin{array}{l}\text { Módulo de elasticidade } \\
\left(\mathrm{N} / \mathrm{mm}^{2}\right)\end{array}$ & 210000 \\
\hline Coeficiente de Poisson & 0.33 \\
\hline
\end{tabular}




\section{Exemplo 1}

Neste exemplo, as tensões radiais e tangenciais de um disco rotativo, calculadas pelos métodos analíticos, são comparadas com os respectivos valores obtidos na simulação por elementos finitos. O estudo considerou a geometria do disco lateral e a rotação de operação do ventilador apresentado na Tabela 2.1.

Para o cálculo analítico das tensões radiais e tangenciais foram consideradas as equações (2.12) e (2.13). Na simulação em elementos finitos, apenas 1/4 do disco foi modelado. O modelo utiliza elementos de casca de quatro nós. As Figuras 2.10 e 2.11 mostram os valores obtidos para os casos estudados. A distribuição de tensões obtidas no cálculo por elementos finitos é apresentada nas Figuras 2.12 e 2.13 .

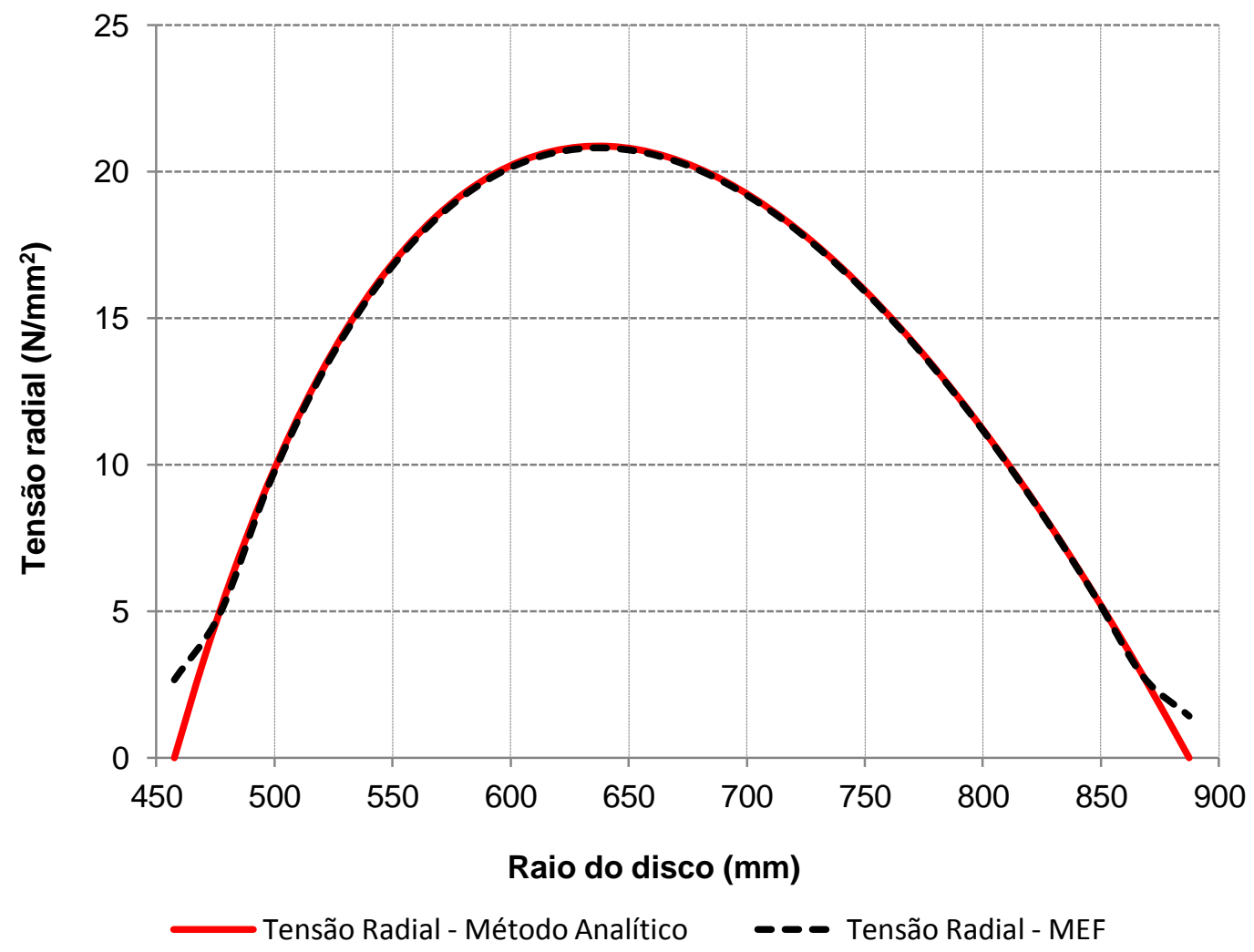

Figura 2.10 - Comparação entre as tensões radiais obtidas através de cálculos analíticos e do MEF para um disco rotativo 


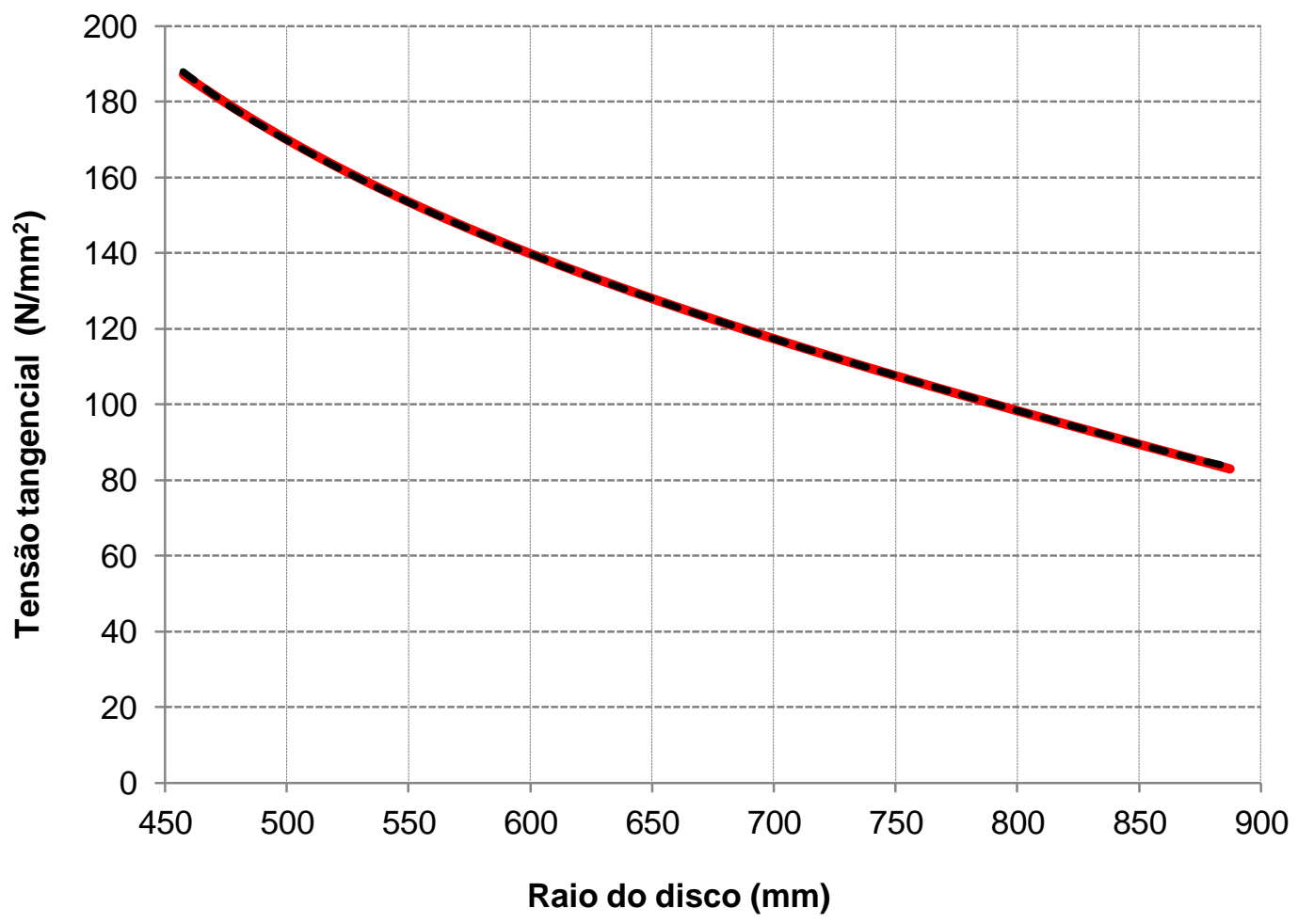

Tensão Tangencial - Método Analítico ㄴ - ensão Tangencial - MEF

Figura 2.11 - Comparação entre as tensões tangenciais obtidas através de cálculos analíticos e do MEF para um disco rotativo

Fringe: Default, A1:Static Subcase. Stress Tensor, , Y Component, At Z1
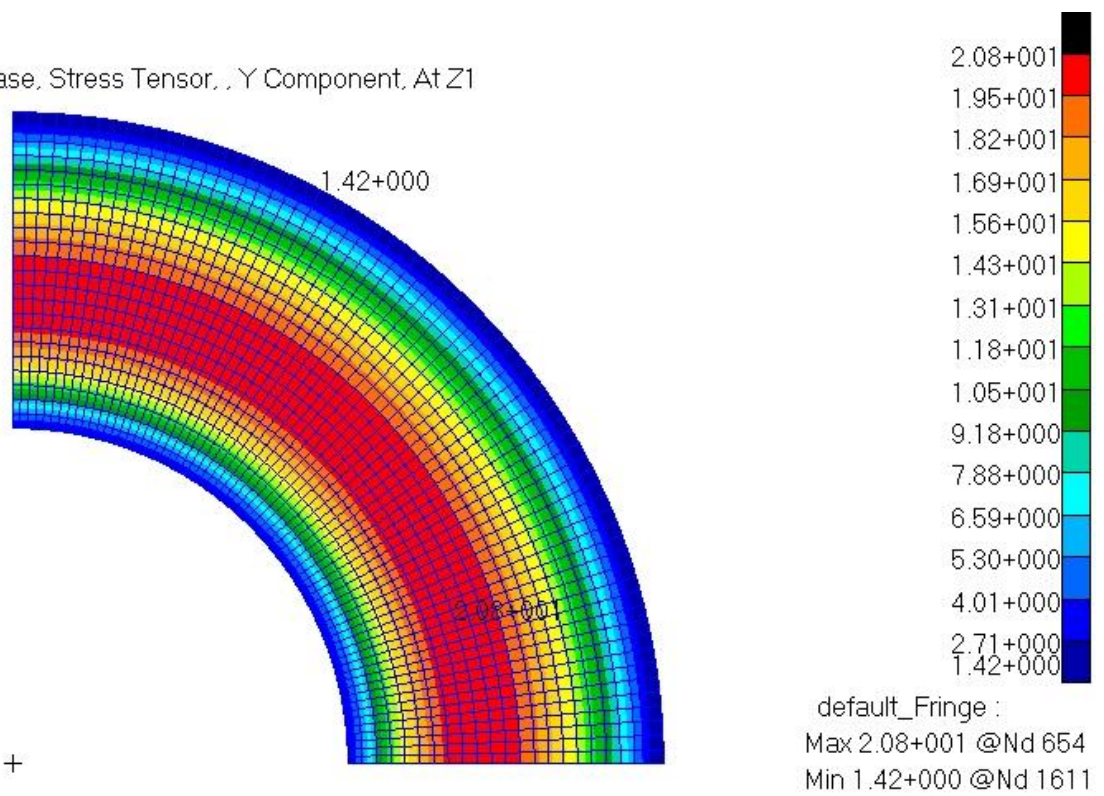

Figura 2.12 - Tensões radiais obtidas através do cálculo pelo MEF 
Fringe: Default, A2:Static Subcase, Stress Tensor, , X Component, At Z1

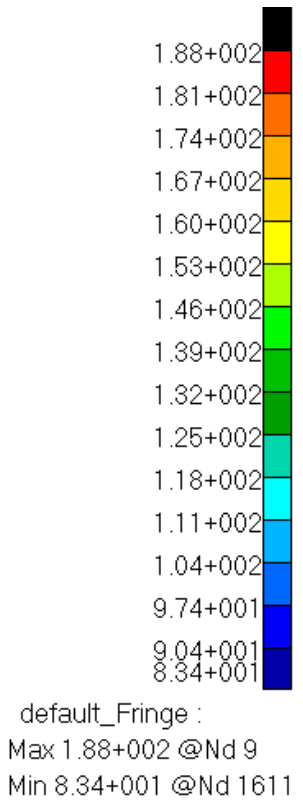

Figura 2.13 - Tensões tangenciais obtidas através do cálculo pelo MEF

Verifica-se que as máximas tensões radiais e tangenciais para o disco rotativo são $20.86 \mathrm{~N} / \mathrm{mm}^{2}$ e $187.21 \mathrm{~N} / \mathrm{mm}^{2}$, respectivamente. Da simulação em elementos finitos, os valores encontrados são $20.8 \mathrm{~N} / \mathrm{mm}^{2}$ e $188 \mathrm{~N} / \mathrm{mm}^{2}$. Conclui-se que os resultados decorrentes do método analítico correspondem exatamente aos obtidos na simulação por elementos finitos, o que já era esperado, visto que a solução para este tipo de problema é exata, não incluindo nenhum esforço proveniente das palhetas.

\section{Exemplo 2}

Neste exemplo é ilustrada a determinação das tensões nos componentes do impelidor através do método dos elementos finitos. Apenas 1/12 do impelidor foi considerado, isto é, o modelo foi realizado a partir de um setor de $30^{\circ}$, como mostrado na Figura 2.14: 


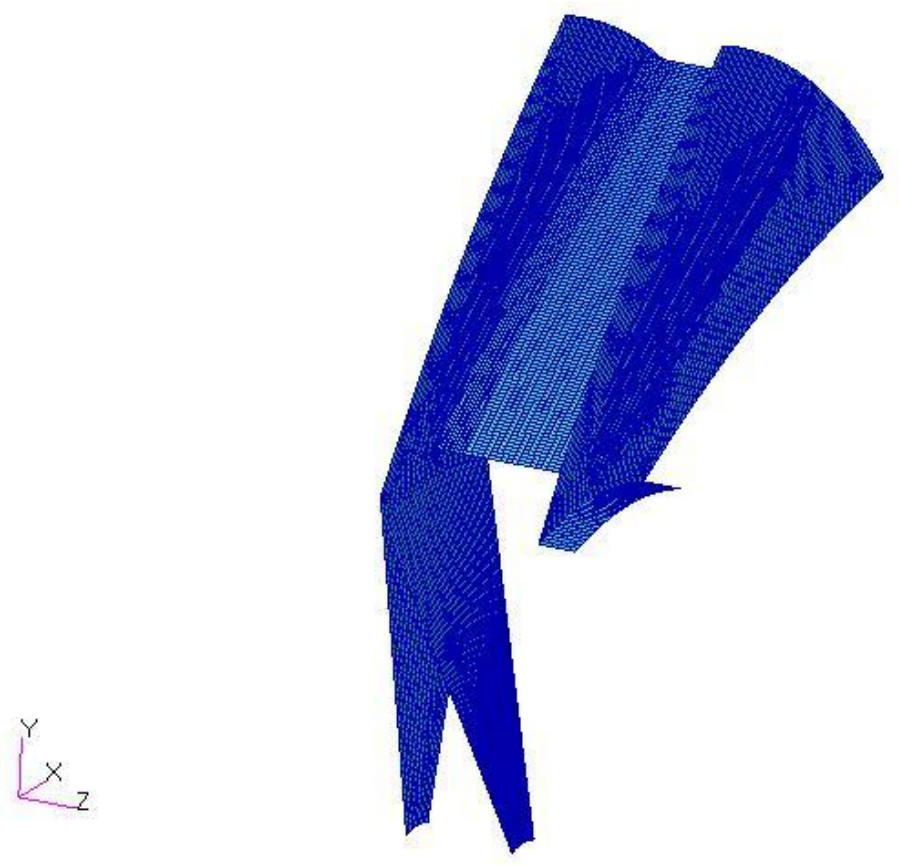

Figura 2.14 - Ventilador de simples entrada modelado para o Exemplo 2

O ventilador é modelado a partir das superfícies médias das chapas que constituem cada um de seus componentes. São considerados elementos de casca de 4 nós para a elaboração da malha. O software MD Nastran identifica como Z1 e Z2 as superfícies externas dos componentes modelados com elementos de casca, de acordo com a Figura 2.15. Portanto, a distância entre as superfícies Z1 e Z2 e a superfície média é igual à metade da espessura do componente. Deste modo, para cada componente do ventilador analisado, são determinados os níveis de tensão estática nos planos Z1 e Z2.

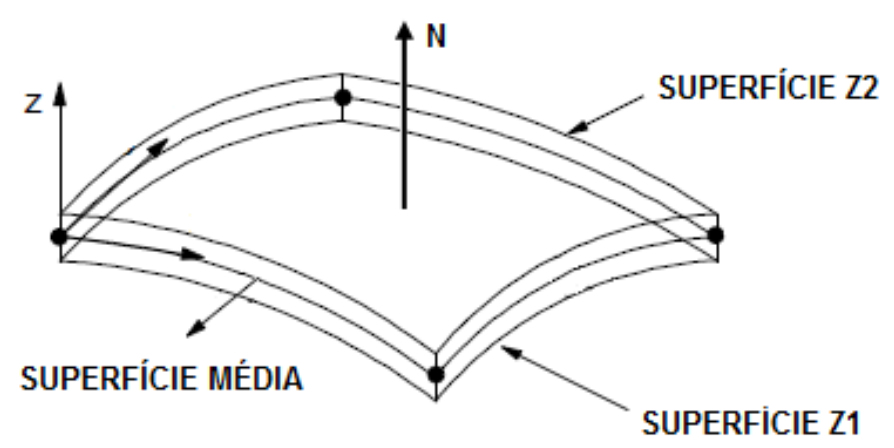

Figura 2.15 - Superfícies Z1 e Z2 consideradas pelo MD Nastran 
As Figuras 2.16 a 2.26 mostram as tensões de von Mises em cada um dos componentes do ventilador. A maior tensão é verificada na palheta (superfície Z1), na borda de saída da mesma. A Tabela 2.2 apresenta o resumo dos resultados.

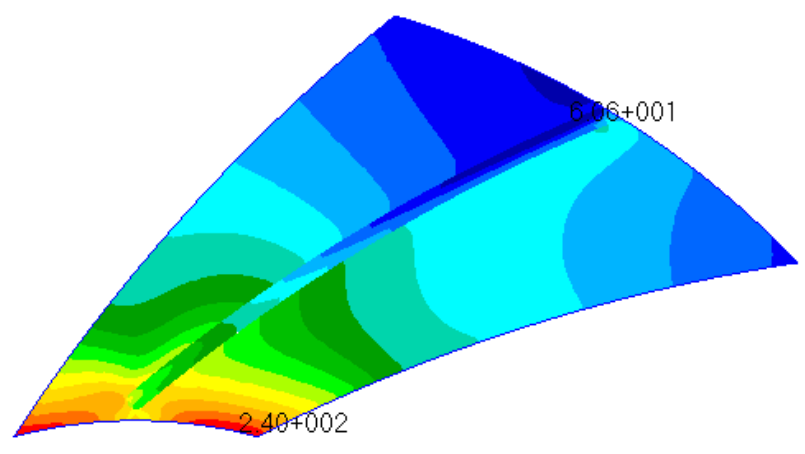

default_Fringe :

Max 2.40+002@EIm 7697.1

Min 6.06+001@EIm 7306.3

Figura 2.16 - Tensões de von Mises no disco lateral $\left(\mathrm{N} / \mathrm{mm}^{2}\right)$ - superfície Z1

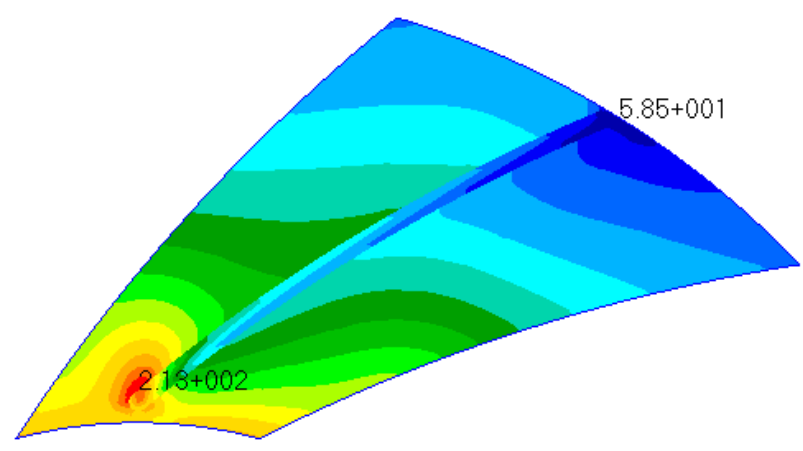

Figura 2.17 - Tensões de von Mises no disco lateral $\left(\mathrm{N} / \mathrm{mm}^{2}\right)$ - superfície Z2 
Fringe: Default, A2:Static Subcase, Stress Tensor, , von Mises, At Z1
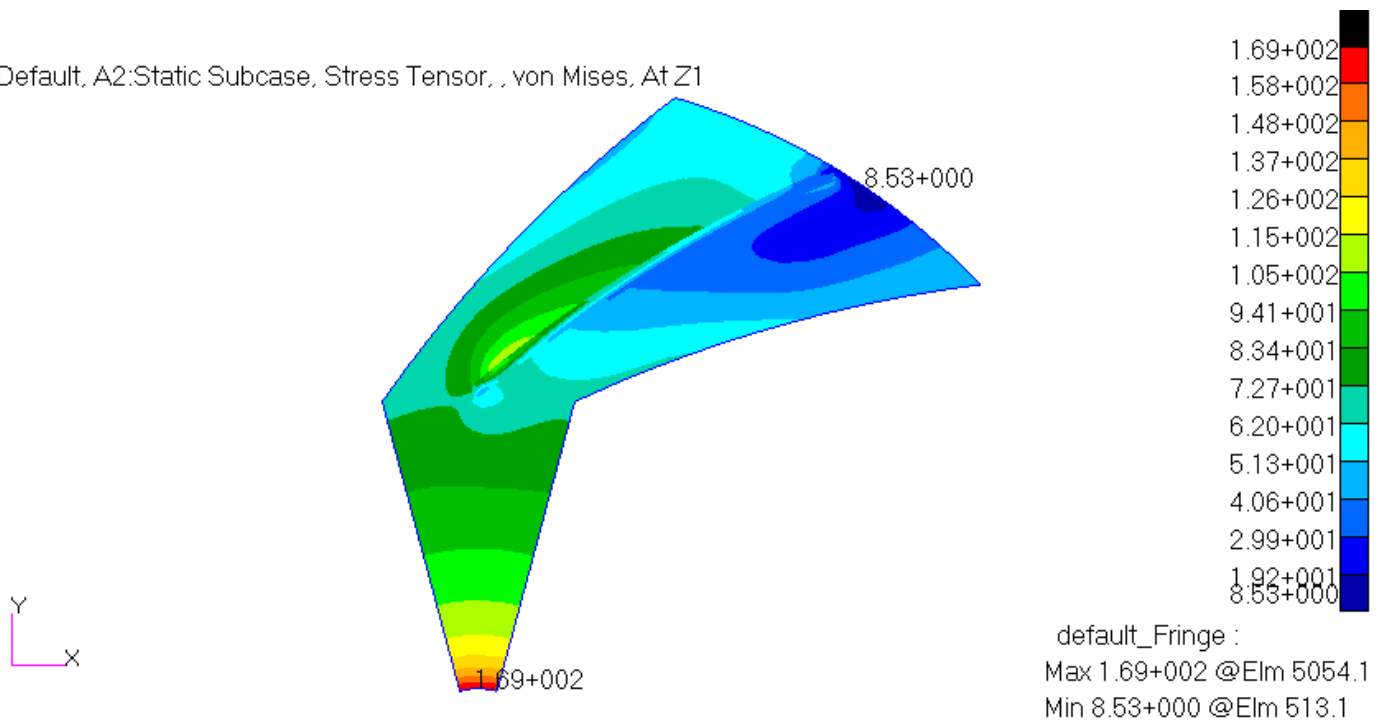

Figura 2.18 - Tensões de von Mises no disco traseiro $\left(\mathrm{N} / \mathrm{mm}^{2}\right)$ - superfície Z1

Fringe: Default, A2:Static Subcase, Stress Tensor, , von Mises, At Z2

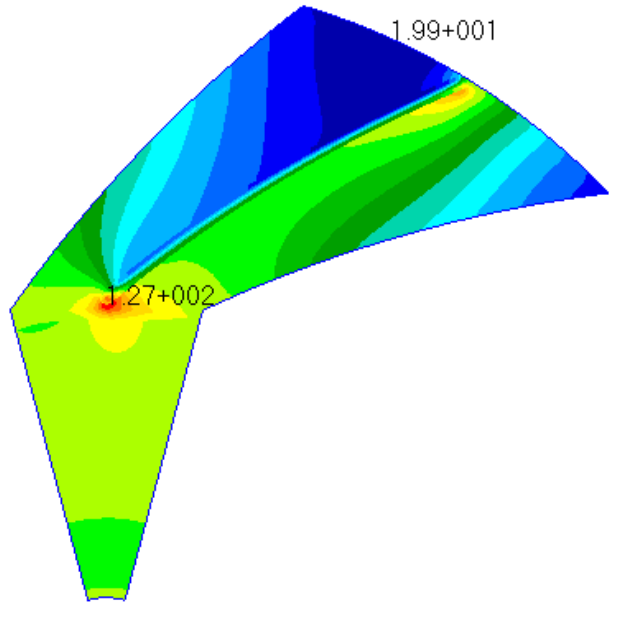

default_Fringe Max1.27+002@EIm 643.1 Min 1.99+001@EIm 782.1

Figura 2.19 - Tensões de von Mises no disco traseiro $\left(\mathrm{N} / \mathrm{mm}^{2}\right)$ - superfície Z2 


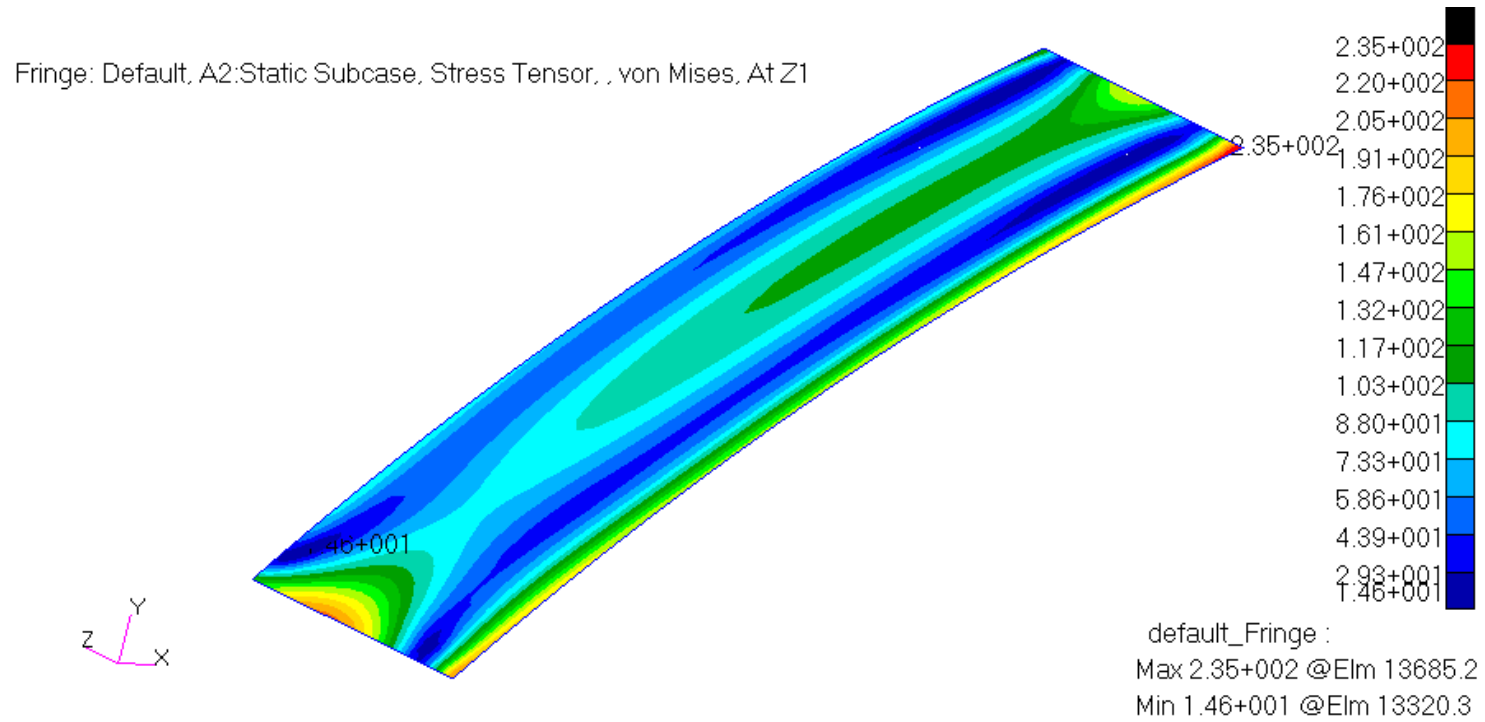

Figura 2.20 - Tensões de von Mises na palheta $\left(\mathrm{N} / \mathrm{mm}^{2}\right)$ - superfície Z1

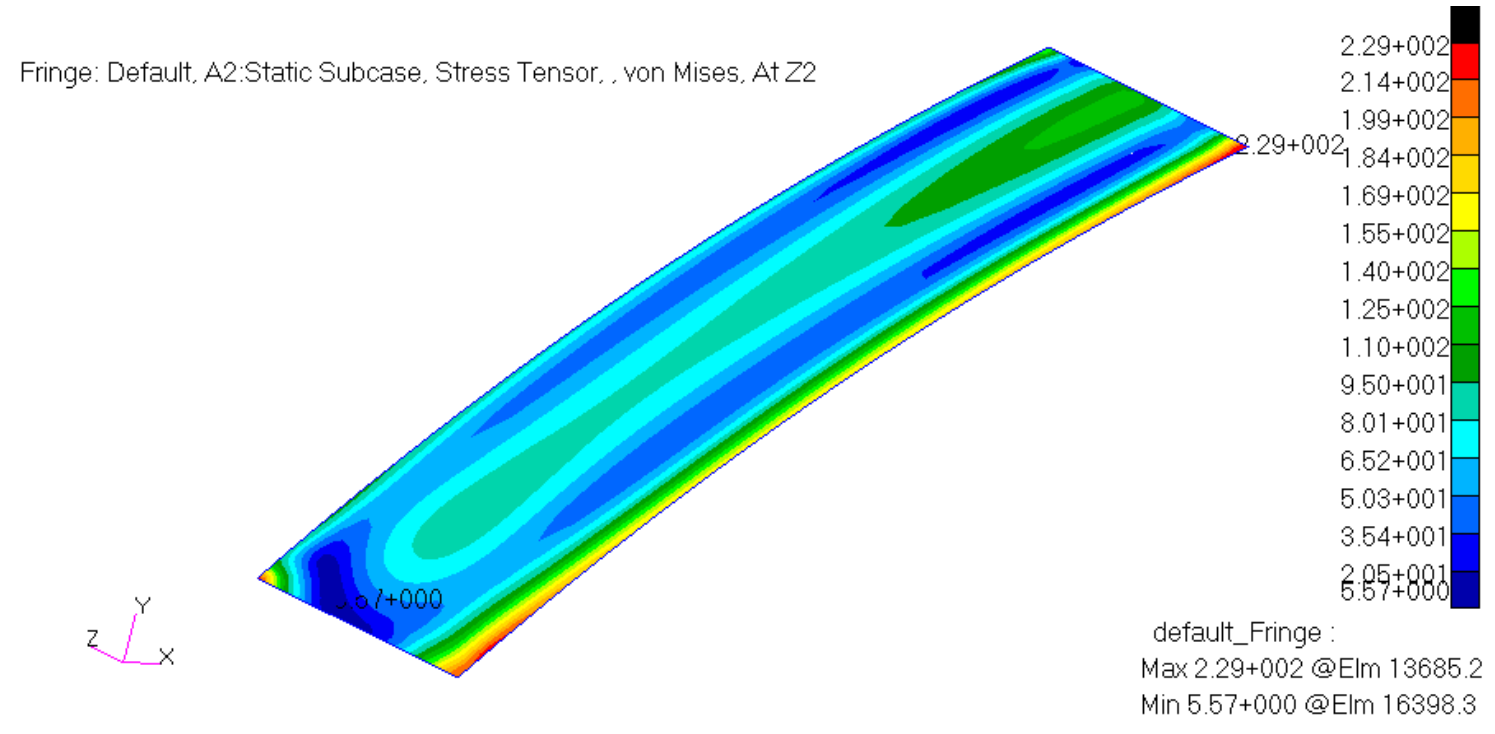

Figura 2.21 - Tensões de von Mises na palheta $\left(\mathrm{N} / \mathrm{mm}^{2}\right)$ - superfície Z2 


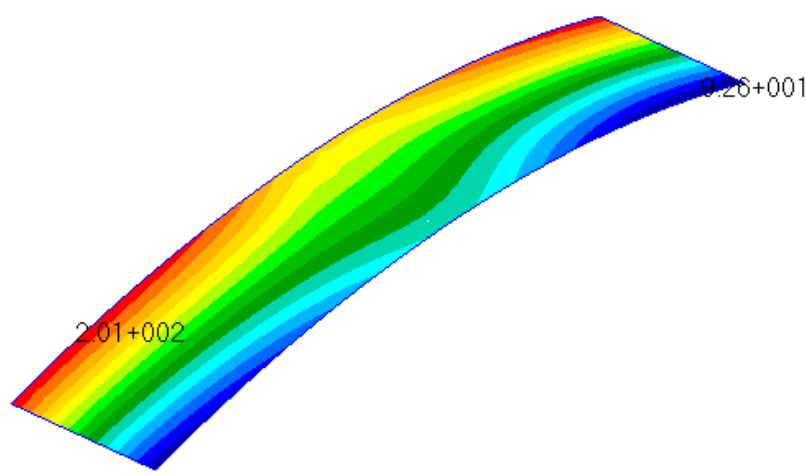

Figura 2.22 - Tensões de von Mises no anel de entrada $\left(\mathrm{N} / \mathrm{mm}^{2}\right)$ - superfície Z1

Fringe: Default, A2:Static Subcase, Stress Tensor, , von Mises, At Z2

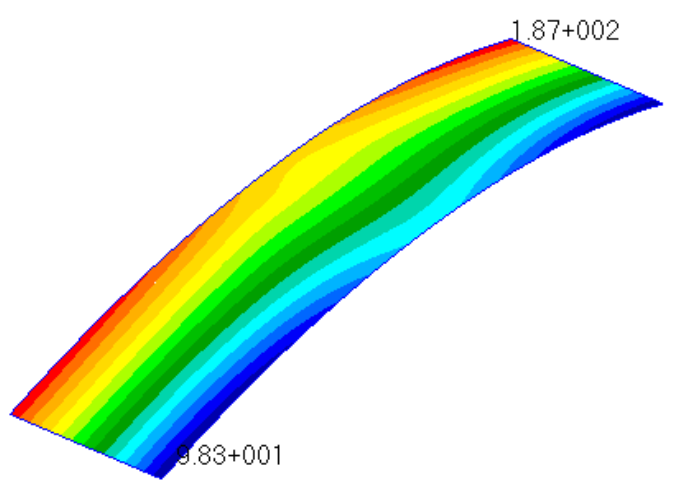

Figura 2.23 - Tensões de von Mises no anel de entrada $\left(\mathrm{N} / \mathrm{mm}^{2}\right)$ - superfície Z2 
Figura 2.24 - Tensões de von Mises no cone de rigidez $\left(\mathrm{N} / \mathrm{mm}^{2}\right)$ - superfície Z1

Fringe: Default, A2:Static Subcase, Stress Tensor, , von Mises, At Z2

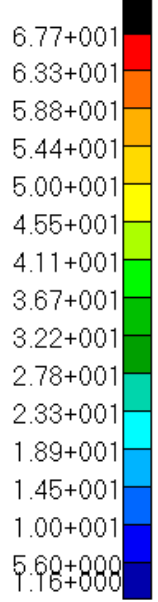

default_Fringe

Max6.77+001@EIm 17848.3 Min 1.16+000@EIm 17729.4

Figura 2.25 - Tensões de von Mises no cone de rigidez $\left(\mathrm{N} / \mathrm{mm}^{2}\right)$ - superfície Z2 
Tabela 2.2 - Tensões estáticas calculadas para o ventilador centrífugo estudado no Exemplo 2

\begin{tabular}{lcc}
\hline \hline \multicolumn{1}{c}{ Componente } & $\begin{array}{c}\text { Tensão de von Mises } \\
\text { Superfície Z1 }\left(\mathrm{N} / \mathrm{mm}^{2}\right)\end{array}$ & $\begin{array}{c}\text { Tensão de von Mises } \\
\text { Superfície Z2 }\left(\mathrm{N} / \mathrm{mm}^{2}\right)\end{array}$ \\
\hline Palhetas & 235 & 229 \\
Disco lateral & 240 & 213 \\
Disco traseiro & 169 & 127 \\
Anel de entrada & 201 & 187 \\
Cone de rigidez & 78 & 68 \\
\hline \hline
\end{tabular}

Com base na discussão realizada na Seção 2.3.1, o emprego de um fator de serviço no valor de 1.3 conduz a uma tensão admissível de $269 \mathrm{~N} / \mathrm{mm}^{2}$. Os valores de tensão estática apresentados na Tabela 2.2 são inferiores ao máximo valor admissível, de modo que a integridade estrutural do impelidor é verificada, no que diz respeito às tensões estáticas.

\section{Exemplo 3}

Neste ponto é interessante realizar a comparação entre as tensões calculadas pelos métodos analíticos considerando a presença das palhetas e as tensões obtidas pelo método dos elementos finitos.

- Tensões nas palhetas

Como discutido na seção 2.1.2, dois modelos analíticos podem ser empregados para estimar as tensões nas palhetas de um ventilador centrífugo. $O$ primeiro admite que as mesmas estão engastadas aos discos, enquanto que o segundo admite que a conexão se dá por meio de articulações fixas. As equações (2.20) e (2.22) fornecem estimativas inferiores e superiores, respectivamente, para a máxima tensão na palheta. Estas estimativas são apresentadas na Tabela 2.3.

Tabela 2.3 - Cálculo das tensões das palhetas do ventilador centrífugo por métodos analíticos

\begin{tabular}{|c|c|c|}
\hline Componente & $\begin{array}{l}\text { Máxima tensão } \\
\text { Modelo com engastamento } \\
\left(\mathrm{N} / \mathrm{mm}^{2}\right)\end{array}$ & $\begin{array}{l}\text { Máxima tensão } \\
\text { Modelo com articulações fixas } \\
\left(\mathrm{N} / \mathrm{mm}^{2}\right)\end{array}$ \\
\hline Palhetas & 229 & 343 \\
\hline
\end{tabular}


- Tensões nos discos

O método analítico utilizado no Exemplo 1 para o caso do disco lateral considerou como carregamento a força centrífuga devido ao próprio disco. Entretanto, as tensões estáticas nos discos certamente são dependentes da interação dos mesmos com as palhetas. Ao desconsiderar esta interação - que certamente é complexa de ser modelada - o cálculo estará subestimando as tensões nos discos. Uma alternativa para contornar esta dificuldade é assumir que uma parcela do esforço centrífugo exercido pelas palhetas será transferida às periferias dos discos, resultando no modelo apresentado na Figura 2.4. Deste modo, podem ser consideradas as equações (2.14) e (2.17).

Este exemplo utilizará a hipótese de que a metade do esforço centrífugo das palhetas é transferida para cada um dos discos (lateral e central). A tensão na periferia dos discos pode, então, ser calculada pela relação entre a força centrífuga devido às palhetas, dividida pela área resistente dos discos, como mostra a equação (2.27).

$$
\sigma_{a}=\frac{\frac{m_{\text {palheta }}}{2} \cdot \omega^{2} \cdot r_{C G \text { palhetas }}}{\pi \cdot D_{\text {disco }} \cdot b_{\text {disco }}}
$$

Para o ventilador estudado, as palhetas representam uma massa de aproximadamente $46 \mathrm{~kg}$. O raio do centro de gravidade das palhetas é $664.5 \mathrm{~mm}$. As máximas tensões radiais e tangenciais, calculadas pelas equações (2.14) e (2.17), são mostradas na Tabela 2.4. Os cálculos consideram o esforço no diâmetro interno dos discos como sendo nulos.

Tabela 2.4 - Cálculo das tensões nos discos do ventilador centrífugo por métodos analíticos

\begin{tabular}{lcc}
\hline \hline Componente & $\begin{array}{c}\text { Máxima Tensão } \\
\text { Radial }\left(\mathrm{N} / \mathrm{mm}^{2}\right)\end{array}$ & $\begin{array}{c}\text { Máxima Tensão } \\
\text { Tangencial }\left(\mathrm{N} / \mathrm{mm}^{2}\right)\end{array}$ \\
\hline Disco lateral & 26 & 208 \\
Disco traseiro & 78 & 193 \\
\hline \hline
\end{tabular}

É importante notar que, caso seja considerado algum valor para os esforços no diâmetro interno dos furos dos discos, as tensões radiais serão maiores que as apresentadas na Tabela 2.4, enquanto que as tangenciais serão menores. 
Assim, dos resultados obtidos é possível destacar:

- Na análise da palheta, o modelo que considera a conexão com os discos por meio de articulações fixas conduziu a valores superiores à máxima tensão admissível. Já o modelo que considera a conexão através de um engastamento forneceu valores inferiores ao critério estabelecido. É interessante notar que a máxima tensão obtida na simulação por elementos finitos encontra-se entre os dois valores calculados. Vale destacar que a proximidade dos resultados com um modelo ou outro está associada a fatores como a rigidez da conexão das palhetas com os discos, que por sua vez é dependente das soldas e da espessura dos discos. É importante ressaltar que tais fatores só podem ser modelados corretamente através do MEF.

- Tanto as tensões calculadas pelos métodos analíticos, quanto as calculadas pelo MEF encontram-se abaixo da máxima tensão admissível $\left(269 \mathrm{~N} / \mathrm{mm}^{2}\right)$.

\subsubsection{Limitações dos métodos analíticos}

As geometrias dos impelidores de ventiladores centrífugos podem assumir as mais variadas formas, o que, em inúmeros casos, torna uma tarefa difícil a previsão das tensões estáticas em seus componentes. Ventiladores com palhetas do tipo aerofólio, por exemplo, são compostos por chapas de geometrias diferentes, incluindo reforços internos. Neste caso, a análise por elementos finitos revela um campo de tensões complexo, evidenciando a impossibilidade de cálculo através de métodos analíticos. Algumas regras são desenvolvidas pelos fabricantes, com expressões para a estimativa das tensões estáticas, mas estas são baseadas em extrapolações provenientes de testes experimentais e análises através do MEF.

As dificuldades inerentes ao uso dos métodos analíticos podem ser estendidas para inúmeras geometrias. Frequentemente, os impelidores são projetados com recortes nos discos lateral, central ou traseiro, o que lhes reduz o peso, introduz melhorias no projeto dinâmico do rotor e minimiza a área de desgaste em determinadas aplicações. A utilização dos métodos analíticos torna-se difícil, na medida em que não existem expressões que permitam calcular as tensões nestas 
geometrias. Tais recortes introduzem pontos de concentração de tensão nos discos, exigindo uma análise de fadiga detalhada e tornando o cálculo por elementos finitos essencial para o sucesso do projeto mecânico do equipamento.

Assim como foi verificado no exemplo apresentado na seção 2.4.1, as tensões calculadas pelos métodos analíticos podem ser superestimadas em alguns casos. Quando a tensão é maior que o limite admissível, recorre-se ao aumento das espessuras das chapas. O emprego do método dos elementos finitos pode ser uma valiosa ferramenta no sentido de otimizar o projeto. A análise por tensões localizadas - discutida na Seção 2.3.2 - frequentemente revela a possibilidade de manter as espessuras "não aprovadas" por um método analítico.

Outro aspecto a ser considerado é a demanda crescente por ventiladores que operam com variadores de velocidade. Isto introduz ao projeto uma atenção especial no que diz respeito ao cálculo de fadiga das soldas. A segurança na determinação da vida em fadiga de um ventilador centrífugo está essencialmente ligada à confiabilidade do cálculo das tensões estáticas na região das soldas. Considerações baseadas em experiências prévias ou em métodos de cálculo pouco precisos passam a dar lugar a simulações por elementos finitos, cada vez mais justificadas pela crescente evolução dos computadores e das ferramentas de cálculo.

Neste ponto, é interessante ressaltar que, embora o MEF constitua uma ferramenta eficaz para o cálculo estrutural de ventiladores centrífugos, não dispensa completamente o emprego dos métodos analíticos. Em muitos casos, o emprego de análises mais rigorosas não é praticável, além do que o uso dos métodos analíticos, associado à experiência dos fabricantes, mostra-se satisfatório para a operação segura de uma infinidade de equipamentos. $O$ aspecto da experiência é um fator que não deve ser descartado, mesmo nas simulações por elementos finitos: na indústria, são frequentes as discussões que envolvem o desenvolvimento de modelos que representam de forma eficiente a presença das soldas, as vantagens e as desvantagens do emprego de elementos de casca ou tridimensionais, os critérios de projeto tradicionalmente aceitos frente à categorização de tensões localizadas, entre muitas outras questões. Estas discussões constituem uma busca constante por modelos que melhor representem os casos reais. 


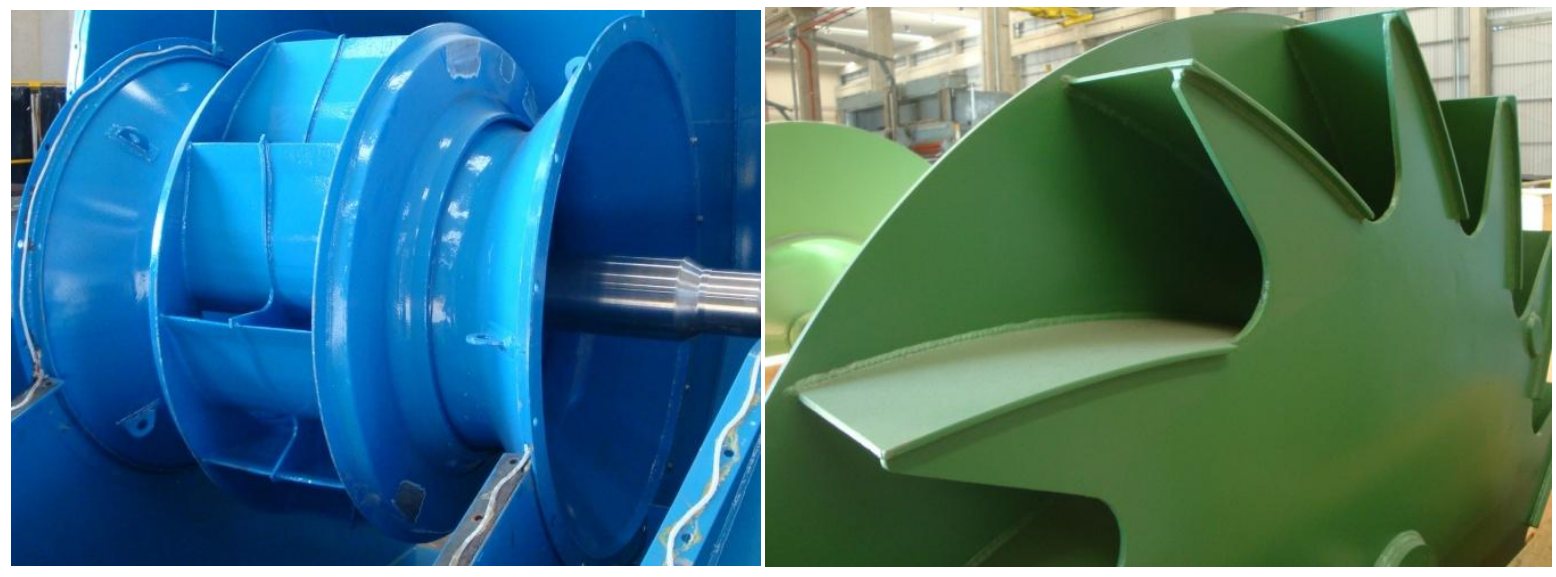

(a)

(b)

Figura 2.26 - Exemplos de geometrias complexas em ventiladores centrífugos: (a) impelidor com palhetas do tipo aerofólio; (b) impelidor com disco recortado 


\section{ANÁLISE DINÂMICA DE VENTILADORES CENTRÍFUGOS}

Este capítulo se inicia com uma breve apresentação dos procedimentos usualmente utilizados na avaliação do comportamento dinâmico de ventiladores centrífugos. Em seguida, é proposta uma metodologia para o cálculo de resposta do rotor e do impelidor, o que conduz à determinação das tensões dinâmicas. Por fim, discute-se a superposição das tensões estáticas e dinâmicas na avaliação da integridade estrutural de impelidores centrífugos.

\subsection{A ABORDAGEM TRADICIONAL: ANÁLISE DE VIBRAÇÕES LIVRES DE IMPELIDORES}

A dinâmica vibratória de ventiladores centrífugos frequentemente envolve dois tipos de abordagem. A primeira busca avaliar o comportamento dinâmico do rotor como um todo, isto é, são determinadas as velocidades críticas do conjunto formado pelo impelidor, eixo e suportes (mancais, pedestais e fundação). Esta análise admite que os impelidores são rígidos e os eixos flexíveis. Portanto, o dimensionamento de um ventilador passa, obrigatoriamente, por uma análise dinâmica do rotor para avaliar a margem existente entre a primeira rotação crítica e a velocidade de operação. Como se sabe, ventiladores centrífugos, em sua maioria, apresentam suas velocidades críticas acima da máxima velocidade de operação. Em alguns casos, os cálculos de resposta ao desbalanceamento são realizados na fase de projeto para prever os níveis de vibração na região dos mancais. Uma discussão sobre a análise da resposta de rotores será realizada na Seção 3.2.

A segunda abordagem remete à análise dinâmica dos impelidores centrífugos, que consiste na determinação dos modos e das frequências naturais da roda e na identificação das fontes que possam excitar estes modos. Assim, uma vez identificados os modos de vibração do impelidor, são investigadas as condições onde a energia é fornecida para os movimentos vibratórios que representem um 
risco à integridade estrutural da máquina. Tradicionalmente, não são realizadas análises que avaliem a resposta dos impelidores centrífugos às excitações.

\subsubsection{Modos de vibração no impelidor e fontes de excitação}

A análise de vibrações livres de impelidores centrífugos consiste na determinação das suas frequências naturais e dos respectivos modos de vibração. Esta análise revela que os impelidores possuem características dinâmicas bastante complexas. Assim, a fim de interpretar corretamente os modos de vibração do impelidor, é usual classificá-los em famílias cujo comportamento dinâmico seja semelhante. Esta identificação é facilitada a partir do conhecimento das características dinâmicas apresentadas por placas circulares.

Os modos de vibração de placas circulares são caracterizados pela presença de um determinado número de círculos nodais ou diâmetros nodais - ou ambos associados - nos quais as amplitudes modais são nulas. Alguns dos modos de vibração de uma placa circular são apontados na Figura 3.1, com a indicação dos círculos e dos diâmetros nodais através de linhas pontilhadas.
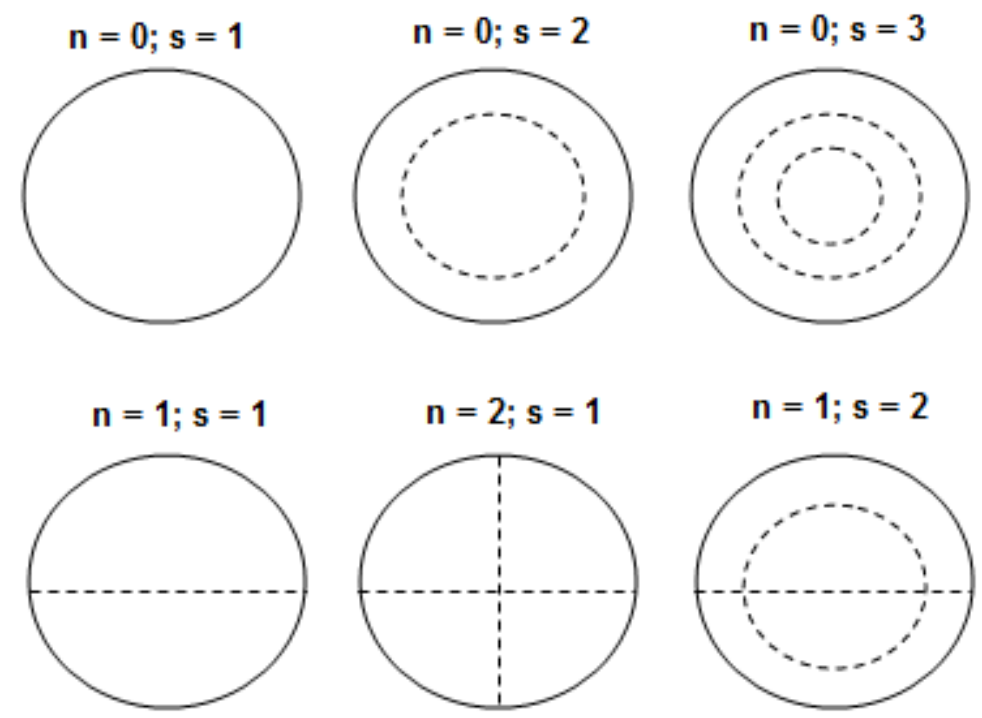

Figura 3.1 - Modos de vibração de uma placa circular com a periferia engastada: $n$ é o número de diâmetros nodais e s é o número de círculos nodais (WEAVER; TIMOSHENKO; YOUNG, 1990) 
A análise das formas dos modos de vibração permite avaliar a confiabilidade estrutural de sistemas vibratórios, bem como analisar a sensibilidade do comportamento da estrutura às modificações estruturais. Também pode se fazer necessário analisar se uma determinada distribuição de esforços ou um determinado movimento imposto é capaz de excitar alguma ressonância (PONGE-FERREIRA, 1994).

Em geral, as menores frequências naturais do impelidor são apresentadas pelo modo de uma linha diametral e pelo modo de um círculo nodal. O primeiro modo diametral, indicado na Figura 3.2, é caracterizado pela flexão do disco traseiro ou central, de modo que os deslocamentos axiais da parte superior e inferior do impelidor se encontram em oposição de fase. Este modo pode ser muito sensível às forças dinâmicas provenientes do desbalanceamento.

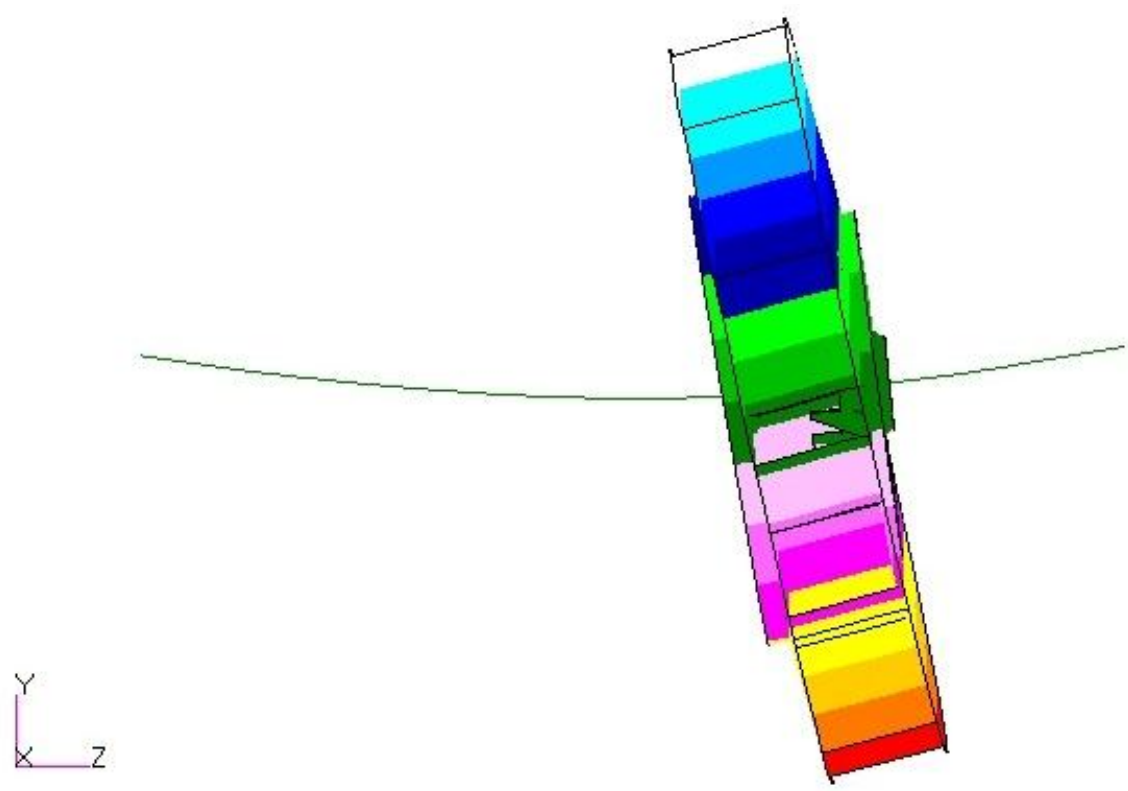

Figura 3.2 - Primeiro modo diametral nodal

O primeiro modo circular nodal, também caracterizado pelo nome 'guardachuva' (Figura 3.3), é normalmente excitado por componentes de aceleração axial no impelidor provenientes da associação do desbalanceamento do rotor com a diferença de rigidez da estrutura de suporte. Efeitos aerodinâmicos também podem excitar este modo (IRONS, 1996). Em geral, a magnitude da frequência natural associada ao primeiro modo circular é maior que a verificada para o primeiro modo diametral. Com exceção dos ventiladores de dupla entrada, em que o impelidor é 
posicionado de forma simétrica entre os mancais, nota-se que existe uma interação significativa destes modos com o eixo e com as estruturas de suporte.

A análise dinâmica de impelidores também revela o modo de duas linhas diametrais, indicado na Figura 3.4, caracterizado por quatro pontos de flexão. Este modo é sensível a efeitos aerodinâmicos como o stall. Também são verificados modos de mais alta frequência cuja característica é semelhante ao modo de duas linhas diametrais, porém apresentando três ou mais diâmetros nodais.

É interessante notar que os modos diametrais possuem frequências naturais coincidentes com multiplicidade igual a dois. Uma vez que nenhum impelidor é perfeitamente axissimétrico, as duas frequências naturais são ligeiramente diferentes na prática. Adicionalmente, verifica-se modos diametrais combinados com modos circulares, como o apresentado na Figura 3.5.

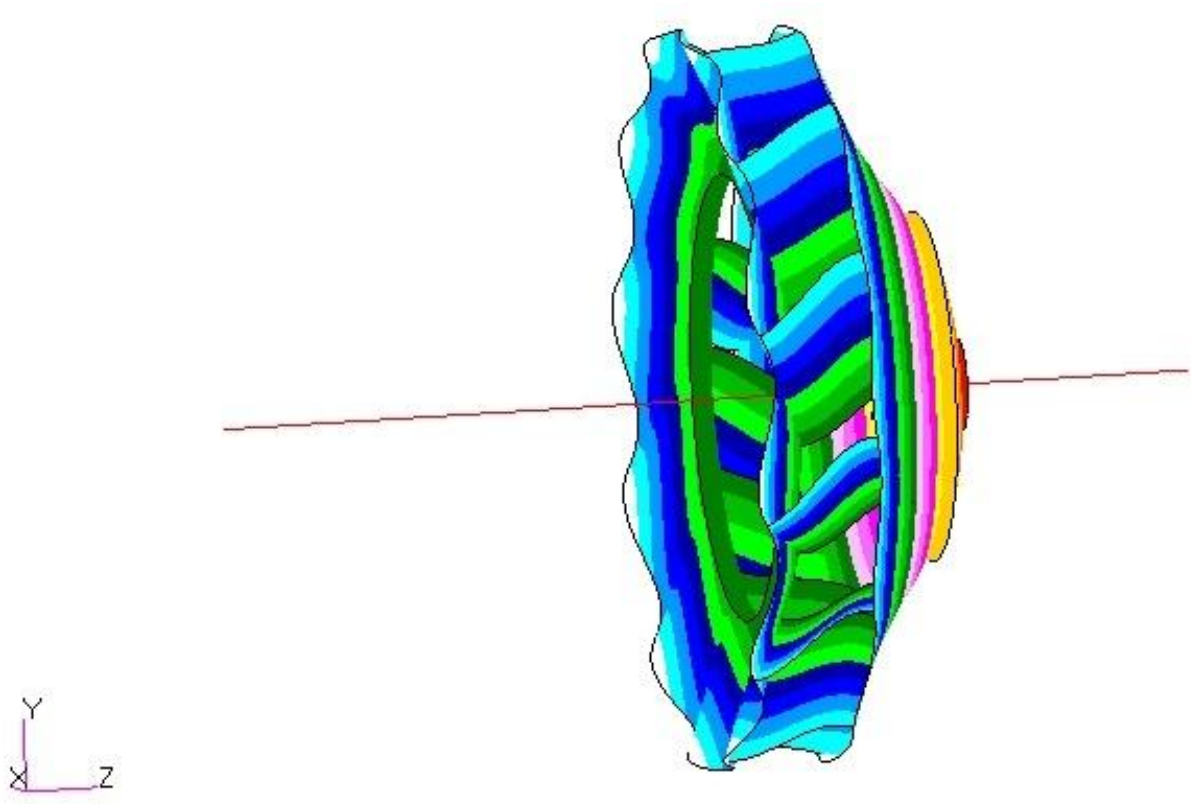

Figura 3.3 - Primeiro modo circular nodal 

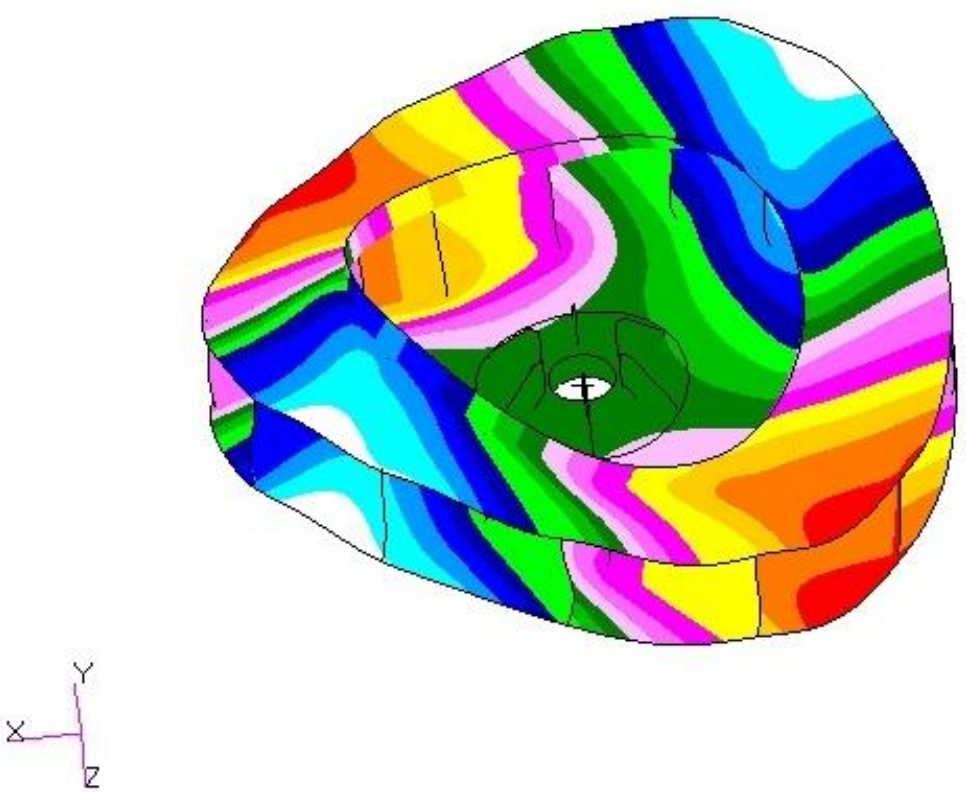

Figura 3.4 - Modo de duas linhas diametrais

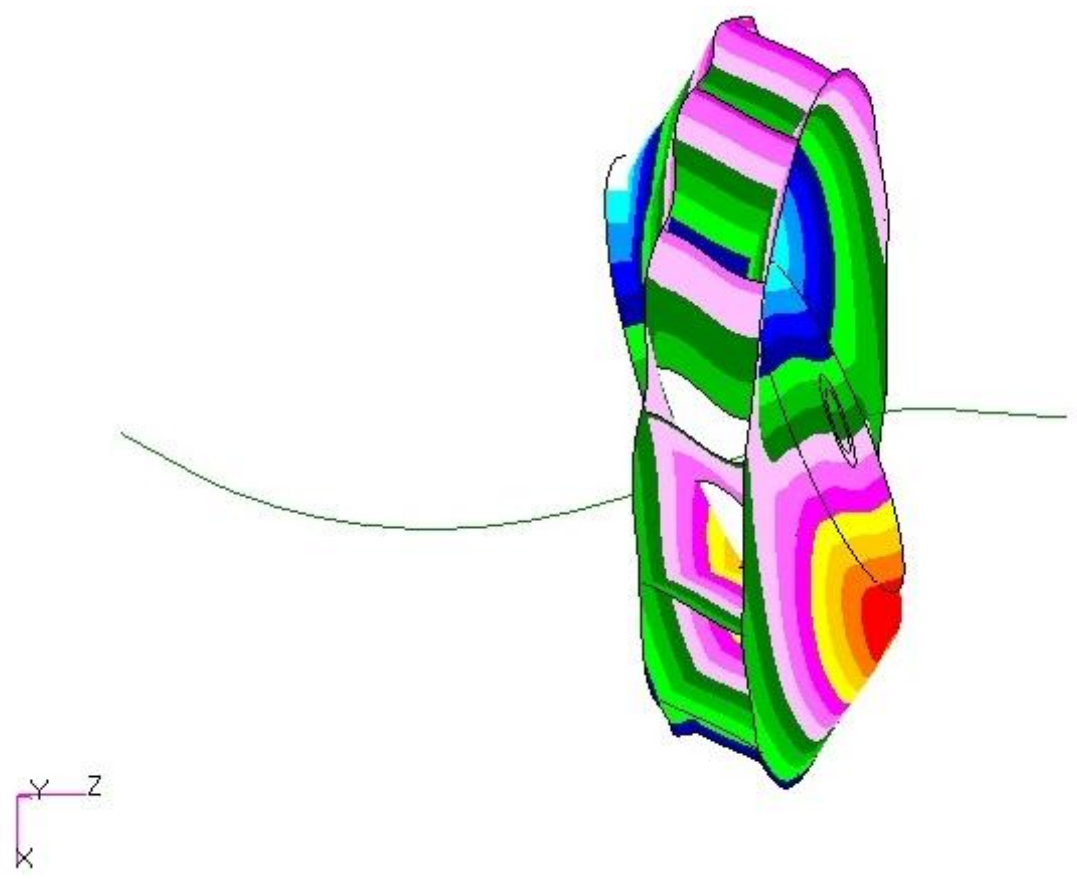

Figura 3.5 - Modo diametral associado ao modo circular

Embora as frequências naturais e os modos de vibração sejam, a rigor, propriedades de toda a estrutura, verifica-se que as energias cinética e potencial são acumuladas de formas diferentes em cada frequência natural. Tais modos são frequentemente classificados como modos locais dos discos ou das palhetas, 
normalmente estão associados a frequências naturais mais elevadas e podem ser sensíveis às excitações de origem aerodinâmica, isto é, à interação do fluído com a dinâmica do impelidor. Consequentemente, a descontinuidade estrutural presente nas carcaças de todo ventilador centrífugo, denominada cut-off, contribui para a não uniformidade no campo de pressão na voluta da carcaça. Assim, pode-se verificar uma distribuição de pressão oscilante no tempo e estacionária no espaço, proveniente da passagem das palhetas pelo cut-off. Deste modo, a avaliação do comportamento dinâmico dos impelidores centrífugos também compreende a verificação de possíveis coincidências entre as suas frequências naturais e a frequência de passagem das palhetas, dada pelo produto do número de palhetas (n) e a velocidade de rotação do ventilador; como mostra a equação (3.1):

$$
B P F=\Omega \cdot n
$$

A título de ilustração, a Figura 3.6 apresenta um dos modos de ondulação do disco lateral de um impelidor de simples entrada, correspondente ao modo de seis linhas diametrais do disco. É importante ressaltar que a coincidência da frequência de passagem das palhetas com alguma das frequências naturais do impelidor não é a única condição necessária para excitar o correspondente modo de vibração. As fases dos pulsos de pressão e do movimento de ondulação dos discos e palhetas devem ser cuidadosamente analisadas de modo a avaliar se há condição favorável para que estes pulsos forneçam energia para dar início ao movimento vibratório. Entretanto, o presente trabalho considera exclusivamente as excitações provenientes do desbalanceamento do rotor na análise dinâmica do impelidor, de modo que as excitações aerodinâmicas não serão abordadas em detalhes. 


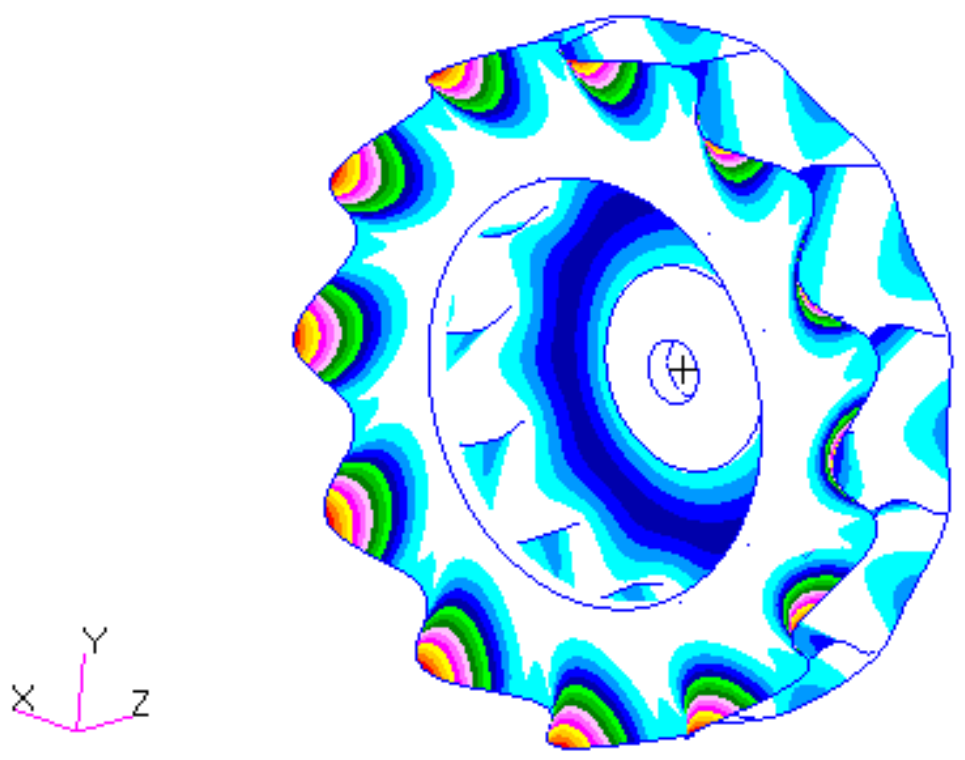

Figura 3.6 - Modo de ondulação do disco lateral

\subsubsection{O efeito de enrijecimento centrífugo}

Os efeitos da força centrífuga nas frequências naturais de um sistema rotativo podem ser melhor compreendidos através da aplicação do Teorema de Southwell, discutido por Den Hartog (1956). Segundo este teorema, se em um sistema mecânico, a energia potencial total for dada pela soma de duas energias potenciais parciais, então a frequência natural $\omega$ deste sistema poderá ser calculada aproximadamente a partir da expressão:

$$
\omega^{2}=\omega_{1}{ }^{2}+\omega_{2}{ }^{2}
$$

Onde:

$\omega_{1}$ e $\omega_{2}$ são as frequências naturais exatas do sistema modificado, no qual um dos efeitos elásticos está ausente.

Um caso muito simples e que ilustra este teorema é o de uma massa $m$ conectada a um suporte com duas molas em paralelo de rigidez $k_{1}$ e $k_{2}$. A frequência 
natural deste sistema é $\omega^{2}=\left(k_{1}+k_{2}\right) / m$, o que é exatamente igual à $\omega_{1}^{2}+\omega_{2}^{2}=$ $\frac{k_{1}}{m}+\frac{k_{2}}{m}$. A resposta é exata neste caso, pois a configuração da vibração não é alterada ao omitir uma das molas do sistema.

Den Hartog (1956) e Irretier (1988) aplicam o Teorema de Southwell para constatar que uma boa aproximação das frequências naturais de palhetas de turbinas pode ser obtida a partir da frequência natural exata do sistema estacionário, segundo a equação (3.3).

$$
\omega_{r}^{2}=\omega_{\mathrm{n}}^{2}+\mathrm{C} \cdot \Omega^{2}
$$

Onde:

$\omega_{r}$ é a frequência natural do sistema rotativo; $\omega_{n}$ é a frequência natural do sistema estacionário; $\Omega$ é a velocidade angular de rotação; C é a constante associada ao modo de vibração.

Portanto, verifica-se um aumento parabólico das frequências naturais em função da velocidade angular. Esta constatação pode então ser estendida ao estudo de impelidores centrífugos. Ponge-Ferreira (1994) deriva a seguinte expressão para um disco rotativo:

$$
\omega_{r}=\omega_{\mathrm{n}}+\mathrm{n} \cdot \Omega^{2}
$$

Onde:

$\mathrm{n}=$ número de diâmetros nodais.

Este efeito de deslocamento em frequência decorrente do movimento de rotação do impelidor é frequentemente denominado enrijecimento centrífugo. É de interesse, portanto, que este efeito seja incorporado às formulações de elementos finitos para a análise dinâmica de impelidores. Esta formulação pode ser ilustrada a partir do estudo realizado por Rao; Yu e Shiau (1999) da resposta transiente de uma placa rotativa, indicada na Figura 3.7, considerando o efeito de enrijecimento centrífugo. 


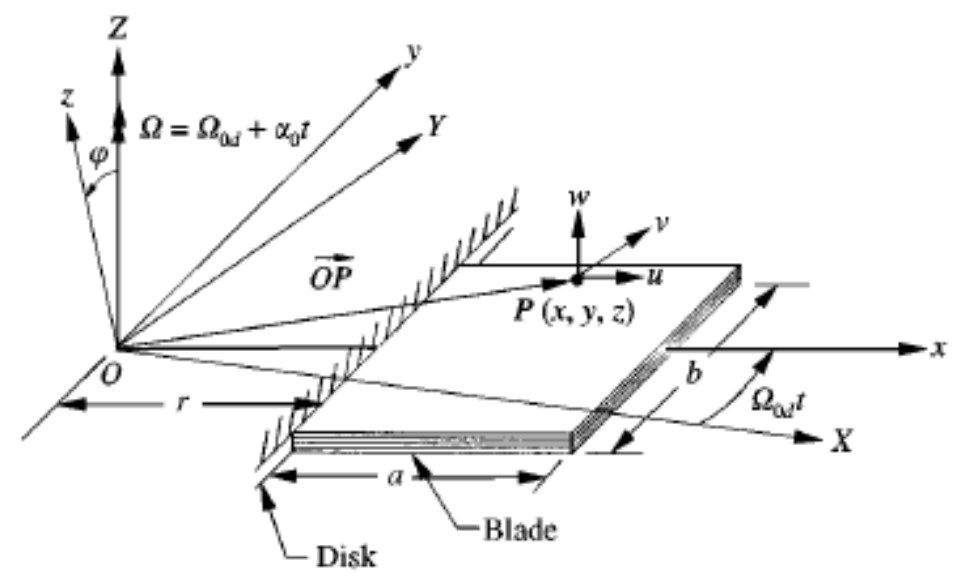

Figura 3.7 - Configuração da palheta estudada por Rao; Yu e Shiau (1999), representada através de uma placa rotativa

A energia potencial total da placa pode ser escrita em termos das contribuições das tensões elásticas no material $\left(U_{b}\right)$ e do efeito de enrijecimento devido à rotação $\left(U_{p}\right)$, indicadas pelas equações (3.5) e (3.6), respectivamente.

$$
\begin{aligned}
& \left.\mathrm{U}_{\mathrm{b}}=\frac{1}{2} \iiint_{\mathrm{V}}\left\{\begin{array}{lllll}
\sigma_{\mathrm{x}} & \sigma_{\mathrm{y}} & \sigma_{\mathrm{xy}} & \sigma_{\mathrm{yz}} & \sigma_{\mathrm{zx}}
\end{array}\right\} \begin{array}{c}
\varepsilon_{\mathrm{x}} \\
\varepsilon_{\mathrm{y}} \\
\varepsilon_{\mathrm{xy}} \\
\varepsilon_{\mathrm{yz}} \\
\varepsilon_{\mathrm{zx}}
\end{array}\right\} \mathrm{dV}=\frac{1}{2} \iiint_{\mathrm{V}}\{\sigma\}^{T}\{\varepsilon\} \mathrm{dV} \\
& \mathrm{U}_{\mathrm{p}}=\frac{1}{2} \iiint_{\mathrm{V}}\left\{\begin{array}{lll}
\sigma_{\mathrm{x}}{ }^{0} & \sigma_{\mathrm{y}}{ }^{0} & \sigma_{\mathrm{xy}}{ }^{0}
\end{array}\right\}\left\{\begin{array}{c}
1 / 2^{w^{2}, x} \\
1 / 2^{2} w^{2}, y \\
w_{, x} w_{, y}
\end{array}\right\} \mathrm{dV} \\
& =\frac{1}{2} \iiint_{\mathrm{V}}\left\{\begin{array}{ll}
w_{, x} & w_{, y}
\end{array}\right\}\left[\begin{array}{cc}
\sigma_{\mathrm{x}}{ }^{0} & \sigma_{\mathrm{xy}}{ }^{0} \\
\sigma_{\mathrm{xy}}{ }^{0} & \sigma_{\mathrm{y}}{ }^{0}
\end{array}\right]\left\{\begin{array}{l}
w_{, x} \\
w_{, y}
\end{array}\right\} d V \\
& =\frac{1}{2} \iiint_{\mathrm{V}}\left\{\varepsilon_{g}\right\}^{T}\left[\sigma^{0}\right]\left\{\varepsilon_{g}\right\} \mathrm{dV}
\end{aligned}
$$

Onde:

$\sigma_{\mathrm{x}}, . ., \sigma_{\mathrm{zx}}$ são as componentes de tensão; $\varepsilon_{\mathrm{x}}, . ., \varepsilon_{\mathrm{zx}}$ as componentes de deformação; $\left[\sigma^{0}\right]$ é a matriz de tensões iniciais devido ao efeito da força centrífuga na placa rotativa; $w$ são os deslocamentos e $\left\{\varepsilon_{g}\right\}$ o vetor gradiente. 
Para o problema de vibração livre da placa, a equação de movimento do elemento, considerando os deslocamentos armazenados no vetor de coordenadas generalizadas, é da forma:

$$
[\widehat{M}]\{\ddot{q}\}+[\widehat{G}]\{\dot{q}\}+\left([\widehat{K}]+\left[\widehat{K}_{g}\right]\right)\{q\}=0
$$

Onde:

$\left[\mathrm{K}_{\mathrm{g}}\right]$ é a matriz de rigidez geométrica do elemento devido ao carregamento centrífugo, obtida por:

$$
\left[\widehat{K}_{g}\right]=\iiint[N]^{T}\left\{\sigma^{0}\right\}[N] d V
$$

Esta mesma formulação é empregada por Genta, Feng e Tonoli (2010) no estudo do comportamento dinâmico de discos rotativos. O autor ressalta que a força restauradora devido às tensões centrífugas é de extrema relevância, especialmente quando o disco se comporta como uma membrana, isto é, possui uma baixa rigidez à flexão. Esta característica é inerente aos impelidores de ventiladores centrífugos, justificando a necessidade de considerar o enrijecimento centrífugo na análise dinâmica destes equipamentos. Gans e Anderson (1991) utilizam o MD Nastran cuja formulação também compreende a equação (3.8) - para incorporar o efeito de enrijecimento centrífugo na análise de palhetas de turbinas e discutem as consequências deste na otimização dos projetos.

\subsection{METOdologia PROPOSta PARA O CÁlCULO DE TENSÕES DINÂMICAS}

A análise dinâmica de impelidores centrífugos está normalmente associada à comparação das frequências naturais do impelidor e as frequências das fontes de excitação existentes, como por exemplo, o desbalanceamento. Neste caso, o projeto mecânico do impelidor é realizado de modo que coincidências entre a velocidade de operação do ventilador $e$ as frequências naturais do impelidor conduzam à modificação do projeto estrutural do equipamento. Saliente-se aqui que não são 
realizadas análises para prever a resposta dinâmica dos impelidores nas condições de ressonância.

A partir do exposto, propõe-se uma metodologia para o cálculo da resposta dinâmica de impelidores centrífugos, traduzida na determinação das tensões dinâmicas nos componentes do impelidor. Em um primeiro momento, o método consiste em avaliar a resposta em frequência do rotor completo, considerando o eixo flexível e o impelidor rígido. Os coeficientes de rigidez e amortecimento dos mancais, bem como o efeito giroscópico são considerados neste ponto. A análise de resposta do rotor permite determinar as translações e rotações do eixo na região dos mancais e do impelidor.

Em um segundo momento, o método proposto consiste em impor os movimentos de translação e rotação obtidos no cálculo de resposta do rotor como movimentos de base para o cálculo de resposta do impelidor, cujos componentes são modelados em um software de elementos finitos. Portanto, esta última análise considera que a flexibilidade dos impelidores e as tensões dinâmicas provenientes destes movimentos de base podem ser utilizadas para a avaliação da integridade estrutural do ventilador. O efeito do enrijecimento centrífugo, discutido na seção anterior, também é incorporado ao modelo nesta etapa. Adicionalmente, as tensões estáticas e dinâmicas podem ser sobrepostas para determinar o nível total de tensões no impelidor. As formulações utilizadas nesta metodologia são discutidas em detalhe nas próximas seções.

\subsubsection{Análise de resposta em frequência do rotor pelo MEF}

Neste ponto, os rotores são modelados por eixos flexíveis nos quais estão montados rigidamente impelidores indeformáveis. A metodologia e as ferramentas de cálculo de resposta em frequência através do MEF utilizadas neste trabalho são apresentadas por Zachariadis $(2000,2006)$. O modelo de elementos finitos é constituído por elementos de viga de Timoshenko, compostos por uma barra prismática homogênea de seção circular e cuja formulação considera a deformação por cisalhamento e o momento de inércia transversal. Em cada um dos nós do 
elemento de viga são considerados quatro graus de liberdade, isto é, duas translações e duas rotações com relação aos eixos $\mathrm{Y}$ e $\mathrm{Z}$ indicados na Figura 3.8.

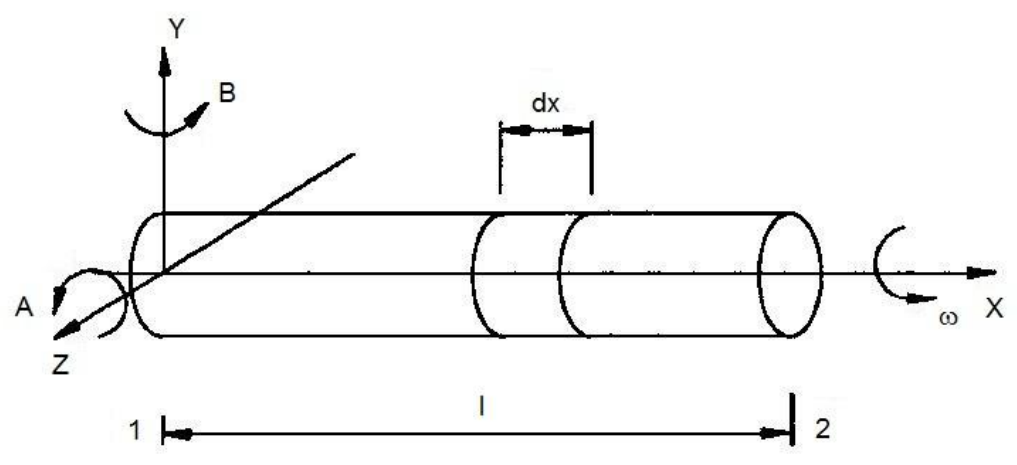

Figura 3.8 - Elemento de viga de Timoshenko e coordenadas de referência

O vetor de deslocamentos nodais, isto é, das coordenadas generalizadas do elemento, é mostrado na equação (3.9):

$$
\{q\}_{e}=\left\{\begin{array}{llllllll}
Y_{1} & B_{1} & Z_{1} & A_{1} & Y_{2} & B_{2} & Z_{2} & A_{2}
\end{array}\right\}^{t}
$$

A obtenção das matrizes de rigidez, $[\mathrm{K}]_{\mathrm{e}}$, e de inércia, $[\mathrm{M}]_{\mathrm{e}}$, deste elemento de viga, indicadas respectivamente nas equações (3.10) e (3.11), é descrita por Genta (1993). O eixo do ventilador é discretizado a partir da definição dos nós nas variações de seção transversal e nas posições dos mancais e do impelidor. Os nós também são definidos para subdividir os trechos de diâmetro constante. Adicionalmente, são consideradas as matrizes de inércia e de efeito giroscópico do impelidor, [M]। e [G]।, apresentadas nas equações (3.12) e (3.13), respectivamente.

$$
[K]_{e}=\frac{E I}{l^{3}(1+f)}\left[\begin{array}{cccc}
12 & 6 l & -12 & 6 l \\
& (4+f) l^{2} & -6 l & (2-f) l^{2} \\
& & 12 & -6 l \\
& & & (4+f) l^{2}
\end{array}\right]
$$

Onde:

$f=\frac{12 E I k}{G A l^{2}}, k=\frac{6(1+v)\left(1+m^{2}\right)}{(7+6 v)\left(1+m^{2}\right)^{2}+(20+12 v) m^{2}}, m=b / a$, sendo $E$ o módulo de elasticidade, I o momento de inércia de área, $k$ o fator de cisalhamento, $G$ o módulo de 
cisalhamento, $A$ a área da seção transversal, $l$ o comprimento do elemento, $v 0$ módulo de Poisson, b o raio externo do eixo e a o raio interno do eixo.

$$
[M]_{e}=\frac{\rho A l}{420(1+f)^{2}}\left[\begin{array}{cccc}
m_{1} & l m_{2} & m_{3} & -l m_{4} \\
& l^{2} m_{5} & l m_{4} & -l^{2} m_{6} \\
& & m_{1} & -l m_{2} \\
& & & l^{2} m_{5}
\end{array}\right]+\frac{\rho I}{30 l(1+f)^{2}}\left[\begin{array}{cccc}
m_{7} & l m_{8} & -m_{7} & l m_{8} \\
& l^{2} m_{9} & -l m_{8} & -l^{2} m_{10} \\
& & m_{7} & -l m_{8} \\
& & & l^{2} m_{9}
\end{array}\right]
$$

Onde:

$\rho$ é a densidade e $m_{1}=156+294 f+140 f^{2} ; m_{2}=22+38.5 f+17.5 f^{2} ; m_{3}=54+$ $126 f+70 f^{2} ; m_{4}=13+31.5 f+17.5 f^{2} ; m_{5}=4+7 f+3.5 f^{2} ; m_{6}=3+7 f+3.5 f^{2}$ $; m_{7}=36 ; m_{8}=3-15 f ; m_{9}=4+5 f+10 f^{2} ; m_{10}=1+5 f-5 f^{2}$

$$
\begin{gathered}
{[M]_{I}=\left[\begin{array}{cccc}
m_{I} & 0 & 0 & 0 \\
& J_{I t} & 0 & 0 \\
& & m_{I} & 0 \\
& & & J_{I t}
\end{array}\right]} \\
{[G]_{I}=\left[\begin{array}{cccc}
0 & 0 & 0 & 0 \\
0 & 0 & 0 & \omega J_{I p} \\
0 & 0 & 0 & 0 \\
0 & -\omega J_{I p} & 0 & 0
\end{array}\right]}
\end{gathered}
$$

Onde:

$m_{l}$ é a massa do impelidor e $J_{l p}$ e $J_{l t}$ são os momentos polar e transversal do impelidor, respectivamente.

A formulação utilizada considera que o ventilador está apoiado em mancais hidrodinâmicos, de modo que os seus coeficientes de rigidez e amortecimento devem ser considerados. Formulações e procedimentos para o cálculo dos esforços hidrodinâmicos são apresentados por Zachariadis (2000), conduzindo à determinação dos 32 coeficientes dinâmicos do modelo completo de mancais. Entretanto, cabe ressaltar que o presente trabalho não tem como objetivo o cálculo destes coeficientes, devendo os mesmos ser tratados como dados de entrada para o cálculo de resposta em frequência. As matrizes de rigidez $[K]_{b}$ e de amortecimento $[\mathrm{C}]_{\mathrm{b}}$ dos mancais são dadas por: 


$$
\begin{gathered}
{[K]_{b}=\left[\begin{array}{llll}
k_{Y Y} & k_{Y B} & k_{Y Z} & k_{Y A} \\
k_{B Y} & k_{B B} & k_{B Z} & k_{B A} \\
k_{Z Y} & k_{Z B} & k_{Z Z} & k_{Z A} \\
k_{A Y} & k_{A B} & k_{A Z} & k_{A A}
\end{array}\right]} \\
{[C]_{b}=\left[\begin{array}{llll}
c_{Y Y} & c_{Y B} & c_{Y Z} & c_{Y A} \\
c_{B Y} & c_{B B} & c_{B Z} & c_{B A} \\
c_{Z Y} & c_{Z B} & c_{Z Z} & c_{Z A} \\
c_{A Y} & c_{A B} & c_{A Z} & c_{A A}
\end{array}\right]}
\end{gathered}
$$

Tradicionalmente, os fabricantes de mancais de deslizamento determinam apenas 8 dos 32 coeficientes, de acordo com as translações em $Y$ e $Z$ apenas; isto é, $k_{y y}, k_{y z}, k_{z y}, k_{z z}, c_{y y}, c_{y z}, c_{z y}$ e $c_{z z}$. Neste caso, os demais coeficientes são admitidos nulos. Além do amortecimento dos mancais, também é possível levar em consideração outras formas de amortecimento viscoso, tais como a dissipação de energia por histerese ou o amortecimento introduzido pelo meio circundante. Estes esforços de amortecimento podem ser incluídos no equacionamento através da matriz de amortecimento [D] para os elementos de viga considerados.

A partir da modelagem do rotor e da definição de suas propriedades, as equações resultantes são escritas em função das matrizes de rigidez globais $[\mathrm{K}]_{\mathrm{G}}$, $[M]_{G}$ e $[D]_{G}$ para a rigidez, inércia e amortecimento do eixo, respectivamente. Adicionalmente, são incluídas as matrizes de inércia e efeito giroscópico do impelidor e as matrizes de rigidez e amortecimento dos mancais. É interessante observar que no caso em que os coeficientes dinâmicos dos mancais não estão disponíveis, a etapa prévia à análise de vibrações lineares consiste no cálculo das posições relativas de equilíbrio estático dos moentes, das quais dependem estes coeficientes, conforme apresentado por Zachariadis (2000).

Deve-se ressaltar que o modelo empregado não considera a flexibilidade dos pedestais e das fundações do rotor, o que exigiria o desenvolvimento de modelos de rigidez, inércia e amortecimentos equivalentes que seriam então incluídos na análise de vibração do ventilador. Também a flexibilidade da conexão entre o impelidor e o eixo não são considerados no modelo. Estudos realizados por Vance (1988) e Irons (1996) mostram que a modelagem desta flexibilidade pode conduzir a resultados mais precisos das rotações críticas do eixo, uma vez que pode haver interação entre 
alguns modos do eixo e do impelidor. Embora estes procedimentos sejam aplicáveis, em hipótese, ao estudo aqui proposto, sua implementação teria finalidade apenas ilustrativa, sem alterar a validade dos demais resultados e conclusões.

A análise de vibrações lineares apresentadas neste trabalho compreende o cálculo da resposta em regime permanente a excitações harmônicas. A equação do movimento é dada por:

$$
[M]\{\ddot{q}\}+[D+G]\{\dot{q}\}+[K]\{q\}=h
$$

Onde:

[M] é a matriz de massa do eixo acrescida da matriz de inércia do impelidor, [D] é a matriz global de amortecimento - e que incorpora o amortecimento dos mancais; G é a matriz global de efeito giroscópico, $[\mathrm{K}]$ é a matriz de rigidez que incorpora a matriz de rigidez global do eixo $[\mathrm{K}]_{G}$ e dos mancais $[\mathrm{K}]_{b}$. O desbalanceamento do impelidor é representado pelo vetor $h=h(t)$ de carregamentos harmônicos.

Deste modo, a resposta em regime permanente é realizada a partir da solução da equação (3.17), descrita por Müller e Schiehlen (1985).

$$
\left[-\omega^{2}+i \omega(D+G)+K\right] Q=H
$$

Onde:

$$
\begin{gathered}
\left\{\begin{array}{l}
Q=\frac{1}{2}\left(Q_{1}-i Q_{2}\right) \\
H=\frac{1}{2}\left(H_{1}-i H_{2}\right)
\end{array}\right. \\
\left\{\begin{array}{l}
q=Q_{1} \cos \omega t+Q_{2} \sin \omega t \\
h=H_{1} \cos \omega t+H_{2} \sin \omega t
\end{array}\right.
\end{gathered}
$$

No caso de um ventilador centrífugo, a excitação síncrona de maior relevância é proveniente dos desbalanceamentos estático e dinâmico do impelidor, representado pelos vetores $\vec{U}_{e}$ e $\vec{U}_{d}$, respectivamente, na Figura 3.9. Os 
desbalanceamentos estático e dinâmico são representados através das expressões (3.20) e $(3.21)^{3}$.

$$
\begin{aligned}
& \vec{U}_{e}=-M u \omega^{2}\left(\cos \varphi_{u} \vec{K}-\sin \varphi_{u} \vec{J}\right) \\
& \vec{U}_{d}=-m_{d} r_{d} l_{d} \omega^{2}\left(\cos \varphi_{d} \vec{J}-\sin \varphi_{d} \vec{K}\right)
\end{aligned}
$$

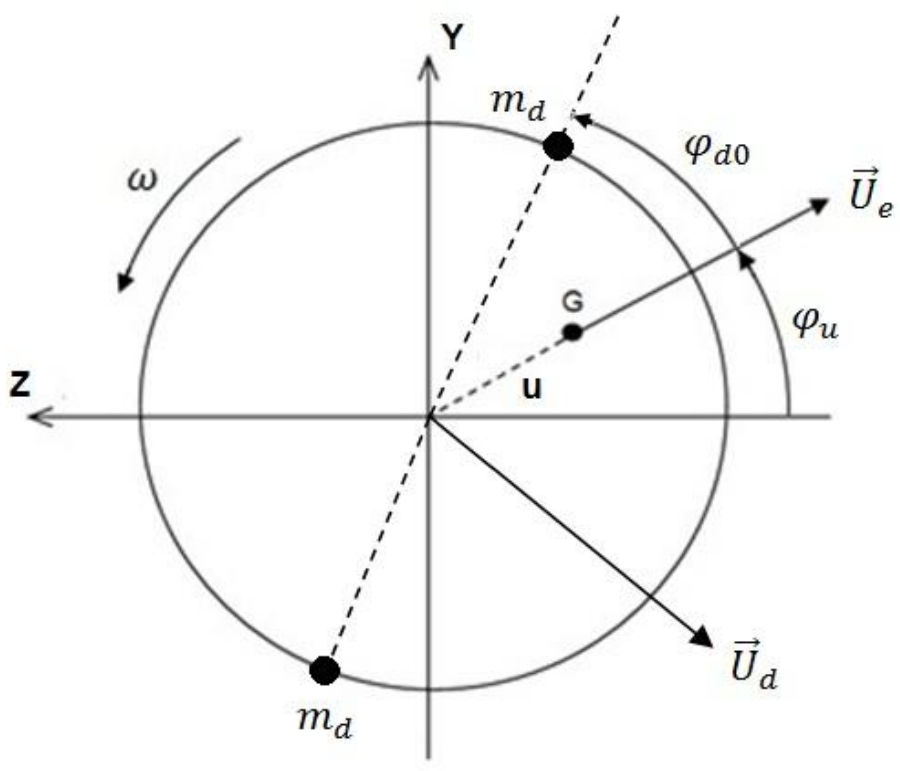

Figura 3.9 - Desbalanceamento estático $\vec{U}_{\mathrm{e}}$ e dinâmico $\overrightarrow{\mathrm{U}}_{\mathrm{d}}$ no impelidor centrífugo

\section{Onde:}

$u=|(G-O)|$ é a excentricidade do centro de massa do impelidor (G) com relação ao seu centro geométrico (O), $\varphi_{u}=\varphi_{u 0}+\omega t$ e $\varphi_{d}=\varphi_{u 0}+\varphi_{d 0}+\omega t$.

Os vetores $\mathrm{H}_{1}$ e $\mathrm{H}_{2}$ são escritos na forma:

$$
H_{1}=-\omega^{2}\left\{\begin{array}{c}
-M u \sin \varphi_{u 0} \\
m_{d} r_{d} l_{d} \cos \left(\varphi_{u 0}+\varphi_{d 0}\right) \\
M u \cos \varphi_{u 0} \\
m_{d} r_{d} l_{d} \sin \left(\varphi_{u 0}+\varphi_{d 0}\right)
\end{array}\right\} ; H_{2}=-\omega^{2}\left\{\begin{array}{c}
-M u \cos \varphi_{u 0} \\
m_{d} r_{d} l_{d} \sin \left(\varphi_{u 0}+\varphi_{d 0}\right) \\
-M u \sin \varphi_{u 0} \\
-m_{d} r_{d} l_{d} \cos \left(\varphi_{u 0}+\varphi_{d 0}\right)
\end{array}\right\}
$$

\footnotetext{
${ }^{3} \mathrm{O}$ desbalanceamento dinâmico do impelidor não será considerado nas análises.
} 
O estudo da estabilidade das vibrações livres do rotor nas vizinhanças das posições de equilíbrio estático, que variam em função de sua velocidade angular $\omega$, é realizado a partir da solução homogênea da equação (3.17):

$$
\underbrace{\left[\begin{array}{cc}
0 & I \\
-M^{-1} K & -M^{-1}(D+G)
\end{array}\right]}_{Z}\left\{\begin{array}{l}
q \\
\dot{q}
\end{array}\right\}=\left[\begin{array}{ll}
I & 0 \\
0 & I
\end{array}\right]\left\{\begin{array}{l}
\dot{q} \\
\ddot{q}
\end{array}\right\}
$$

Onde:

0 é a matriz nula e I é a matriz identidade. Fazendo $\tilde{q}=\left\{\begin{array}{ll}q & \dot{q}\end{array}\right\}^{t}$ e $\tilde{q}=\tilde{Q} e^{\lambda t}$, chegase ao problema de autovalor:

$$
(Z-\lambda I) \tilde{Q}=0
$$

cujos autovalores são apresentados na equação (3.25).

$$
\lambda(\omega)=\rho(\omega)+i f_{n}(\omega)
$$

Os autovalores são agrupados em ordem crescente dos valores das frequências naturais amortecidas $f_{n}(\omega)$ do rotor.

Por todo o exposto, verifica-se que, a partir do cálculo da resposta ao desbalanceamento estático do rotor, são determinados os movimentos de translação e de rotação na região do impelidor, o que é ilustrado na Figura 3.10. Estes movimentos são utilizados como dados de entrada para a análise de resposta em frequência do impelidor, assunto que será discutido na próxima seção. 


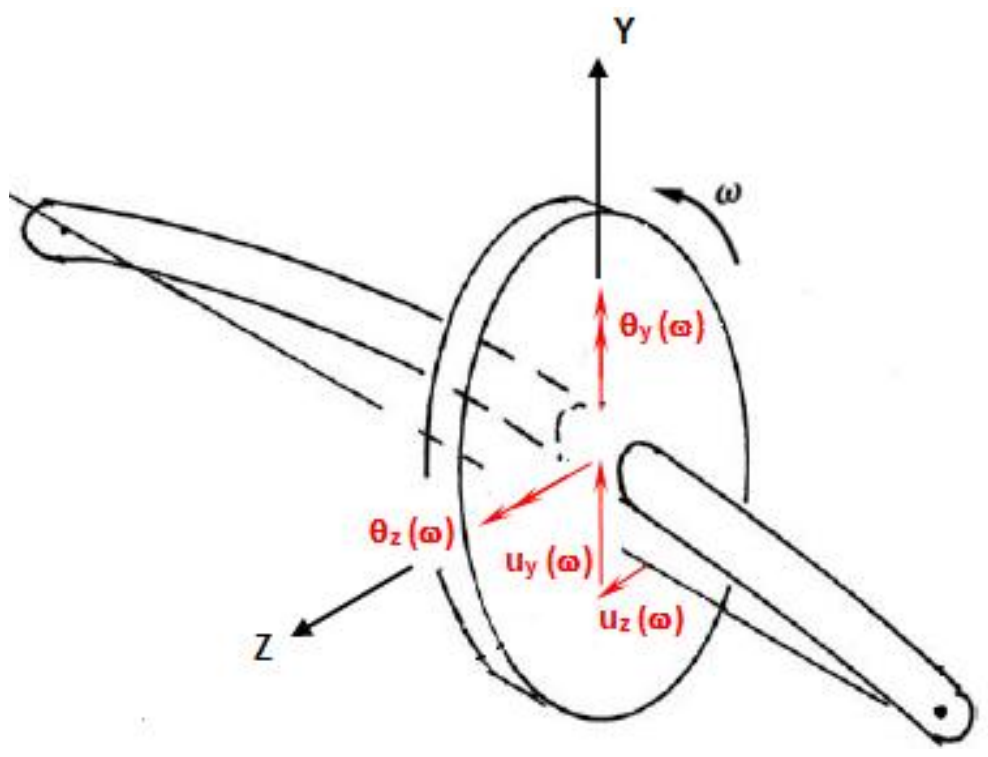

Figura 3.10 - Translações e rotações na região do impelidor obtidas a partir do cálculo de resposta ao desbalanceamento estático no rotor completo

\subsubsection{Análise de resposta em frequência do impelidor}

A análise de resposta ao desbalanceamento estático do rotor, descrita na seção anterior, conduz à determinação dos movimentos de translação e rotação em cada uma das seções do eixo do ventilador centrífugo. Nesta análise, os impelidores foram considerados rígidos e indeformáveis.

Passa-se, então, ao cálculo da resposta em frequência dos impelidores, agora admitidos como flexíveis. Os movimentos de translação e rotação do impelidor, provenientes do cálculo de resposta ao desbalanceamento do rotor - e ilustrados na Figura 3.10 - podem ser impostos ao cubo do impelidor centrífugo, modelado em um software de elementos finitos. A Figura 3.11 apresenta a metodologia proposta. 

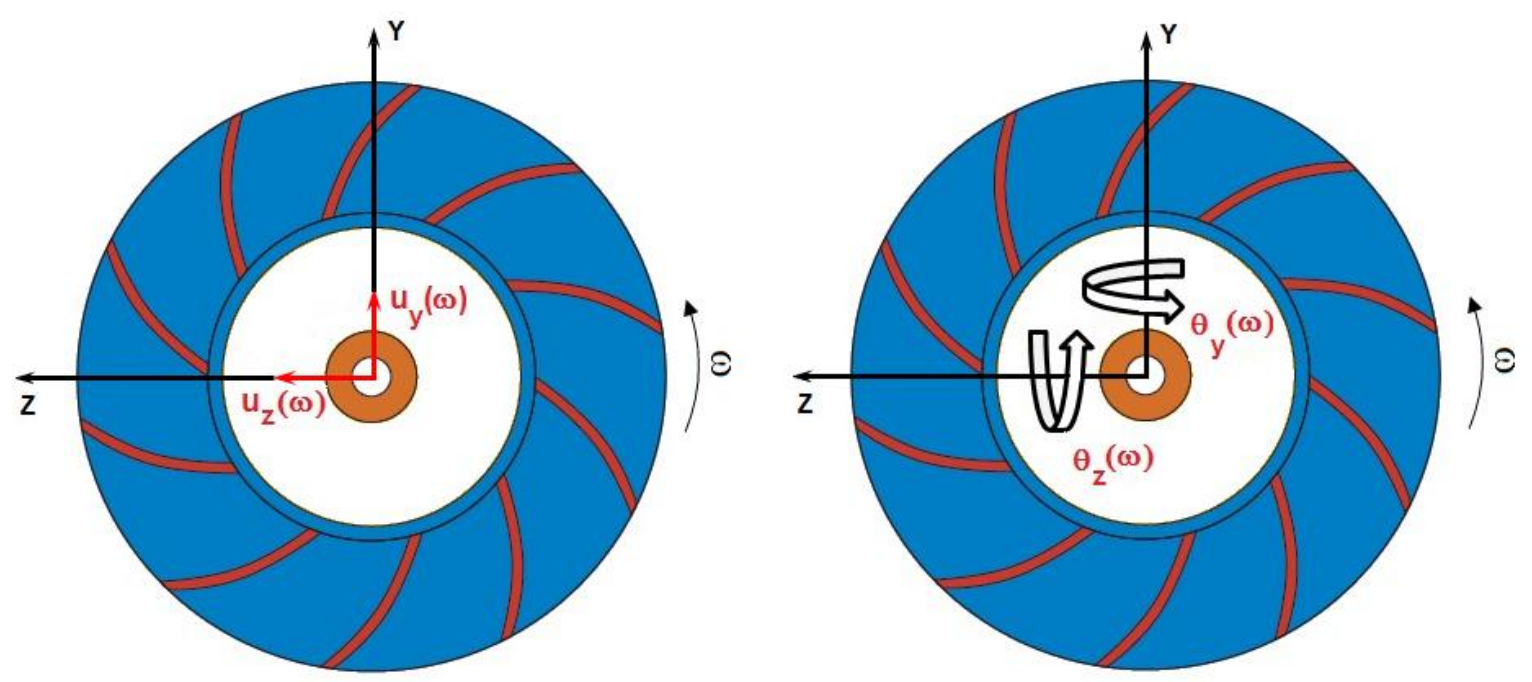

Figura 3.11 - Imposição dos movimentos de base no cubo do impelidor

O problema do cálculo da resposta dinâmica de estruturas à excitação provocada pela imposição de movimentos independentes é abordada por Pestel e Leckie (1964) e por Clough e Penzien (1975) com o emprego de métodos matriciais. Um método alternativo para o cálculo da resposta dinâmica de estruturas à imposição de movimentos genéricos é apresentado por Zachariadis (1986), em que os deslocamentos são aplicados em molas de rigidez suficientemente elevadas, definindo os carregamentos aplicados nos graus de liberdade associados às molas. Uma abordagem outrora preferida por alguns softwares comerciais consistia no uso de grandes massas e forças para obter o deslocamento desejado nos graus de liberdade selecionados. Flanigan (1994) discute que esta aproximação pode conduzir a resultados pouco precisos, caso os valores de massa adotados sejam muito grandes ou muito pequenos. Entretanto, os softwares de elementos finitos atuais permitem considerar nas análises de resposta a imposição direta dos movimentos de base ao modelo. Neste trabalho, são apresentadas apenas as soluções que utilizam métodos matriciais, uma vez que esta é a formulação empregada pelas versões mais recentes do MD Nastran, software utilizado para as simulações.

A equação do movimento para 0 caso geral da resposta à imposição de movimentos em quaisquer pontos de uma estrutura é indicada na equação (3.26):

$$
\left[M_{n n}\right]\left\{\ddot{u}_{n}\right\}+\left[C_{n n}\right]\left\{\dot{u}_{n}\right\}+\left[K_{n n}\right]\left\{u_{n}\right\}=\left\{P_{n}\right\}
$$


Os $n$ conjuntos de graus de liberdade indicados na equação (3.26) são subdivididos entre os graus de liberdade internos da estrutura (indicados pelo índice $i$ em (3.27)) e os graus de liberdade nos quais os deslocamentos são impostos (indicados pelo índice $d$ ). Os deslocamentos nos graus de liberdade internos da estrutura são as incógnitas do problema.

$$
\left\{u_{n}\right\}=\left\{\frac{u_{i}}{u_{d}}\right\}
$$

A equação (3.26) pode ser reescrita na forma:

$$
\left[\begin{array}{ll}
M_{i i} & M_{i d} \\
M_{d i} & M_{d d}
\end{array}\right]\left\{\begin{array}{l}
\ddot{u}_{i} \\
\ddot{u}_{d}
\end{array}\right\}+\left[\begin{array}{cc}
C_{i i} & C_{i d} \\
C_{d i} & C_{d d}
\end{array}\right]\left\{\frac{\dot{u}_{i}}{\dot{u}_{d}}\right\}+\left[\begin{array}{cc}
K_{i i} & K_{i d} \\
K_{d i} & K_{d d}
\end{array}\right]\left\{\frac{u_{i}}{u_{d}}\right\}=\left\{\frac{P_{i}}{P_{d}}\right\}
$$

Os termos $\mathrm{M}_{\mathrm{ii}}, \mathrm{C}_{\mathrm{ii}}$ e $\mathrm{K}_{\mathrm{ii}}$ contêm os elementos relacionados unicamente aos graus de liberdade internos da estrutura. Já os termos $M_{i d}, C_{i d}$ e $K_{i d}$ contêm os elementos que acoplam os graus de liberdade internos com os graus de liberdade submetidos a um movimento de base. Desenvolvendo a equação (3.28), chega-se a:

$$
\begin{aligned}
& {\left[M_{i i}\right]\left\{\ddot{u}_{i}\right\}+\left[C_{i i}\right]\left\{\dot{u}_{i}\right\}+\left[K_{i i}\right]\left\{u_{i}\right\}=\left\{P_{i}\right\}-\left(\left[M_{i d}\right]\left\{\ddot{u}_{d}\right\}+\left[C_{i d}\right]\left\{\dot{u}_{d}\right\}+\left[K_{i d}\right]\left\{u_{d}\right\}\right)} \\
& \left\{P_{d}\right\}=\left[M_{d i}\right]\left\{\ddot{u}_{i}\right\}+\left[M_{d d}\right]\left\{\ddot{u}_{d}\right\}+\left[C_{d i}\right]\left\{\dot{u}_{i}\right\}+\left[C_{d d}\right]\left\{\dot{u}_{d}\right\}+\left[K_{d i}\right]\left\{u_{i}\right\}+\left[K_{d d}\right]\left\{u_{d}\right\}
\end{aligned}
$$

A partir da equação (3.29), a resposta do sistema é obtida a através do método da superposição modal ou do método da integração direta. Uma vez calculada a resposta, a equação (3.30) pode ser utilizada para determinar as cargas atuantes nos graus de liberdade onde os deslocamentos foram impostos.

É importante ressaltar que o enrijecimento centrífugo é um relevante fator no estudo da resposta em frequência de impelidores centrífugos. Este efeito é incluído nas análises de resposta em frequência através da modificação da matriz de rigidez da estrutura, segundo as equações (3.7) e (3.8), discutidas na seção 3.1.2. A matriz de rigidez assume a forma:

$$
[K]_{n n}=[K]^{*}+[K(\omega)]_{g}
$$


Onde:

$[\mathrm{K}]^{*}$ é a matriz de rigidez global do impelidor parado e $[\mathrm{K}(\omega)]_{\mathrm{g}}$ é a matriz que introduz o efeito de enrijecimento, devido às tensões estáticas no impelidor na velocidade angular considerada.

O desenvolvimento das expressões para o cálculo de resposta ocorre de forma análoga à apresentada, devendo-se considerar a matriz de rigidez indicada na equação (3.31). No MD Nastran, o efeito do enrijecimento centrífugo é computado através do comando STATSUB com referência ao carregamento inercial correspondente à velocidade de operação do impelidor.

\subsubsection{Modelo para análise dinâmica de impelidores}

Devido à simetria rotacional dos impelidores centrífugos, os modelos para o cálculo das tensões estáticas através do MEF consideram apenas um setor para representar o comportamento da estrutura completa, conforme discussão realizada na seção 2.2.1. O modelo construído pode, então, ser aproveitado para a análise dinâmica, seja para o estudo das vibrações livres - abordagem metodológica tradicional - seja para o cálculo de resposta em frequência à imposição de movimentos (abordagem metodológica proposta). A visualização e a interpretação dos modos envolvidos são facilitadas a partir da expansão do modelo para um setor de $360^{\circ}$, correspondente ao impelidor completo. Frequentemente opta-se pela diminuição da densidade da malha para a análise de vibrações livres, o que introduz ganhos no tempo de processamento, uma vez que os modos e as correspondentes frequências naturais do impelidor não são alterados significativamente pela diminuição do número de elementos; ao contrário do que se verifica para a análise de tensões estáticas, em que a convergência dos resultados é substancialmente mais sensível à densidade da malha.

Ressalte-se que o cálculo de resposta aos movimentos de base impostos ao impelidor tem como objetivo final a determinação dos níveis de tensão dinâmica em seus componentes. Nesse sentido, a diminuição da densidade da malha, apesar de diminuir os tempos de processamento, conduz a resultados de tensão pouco 
precisos, em especial na região das soldas - região que, em geral, apresenta os maiores níveis de tensão e cuja convergência é satisfatória quando ao menos dois elementos são utilizados (COOK, 1995). Por este motivo, o presente trabalho utiliza metade da espessura de cada componente do ventilador para definir o tamanho dos elementos e ao menos dois elementos são considerados na região das soldas, tanto para a análise de tensões estáticas, quanto para o cálculo de tensões dinâmicas, através da análise de resposta em frequência do impelidor.

O modelo para a análise de resposta deve ainda incluir o cubo do impelidor, onde são impostos os movimentos de base provenientes da análise de resposta em frequência do rotor completo. Neste trabalho, consideram-se os elementos hexaédricos de 8 nós na modelagem do cubo. Os movimentos de translação e rotação - conforme as coordenadas $Y$ e Z indicadas na Figura 3.11 - são transferidos aos nós internos do cubo, correspondentes à região que está em contato direto com o eixo. Para facilitar a modelagem e garantir que todos os nós internos do cubo serão submetidos ao mesmo movimento de translação e rotação, estes são conectados a um nó central através de elementos rígidos denominados RBE2 (Rigid Body Element). Este elemento é especificado no MD Nastran a partir da definição de um nó com graus de liberdade independentes (neste caso o nó central) e um conjunto de nós com graus de liberdade dependentes (nós internos do cubo). Assim, é possível especificar que todo carregamento - deslocamento, força, aceleração imposto ao nó independente seja transferido integralmente aos graus de liberdade dos nós dependentes. A Figura 3.12 ilustra uma das etapas da construção do modelo, em que o cubo do impelidor é considerado. 


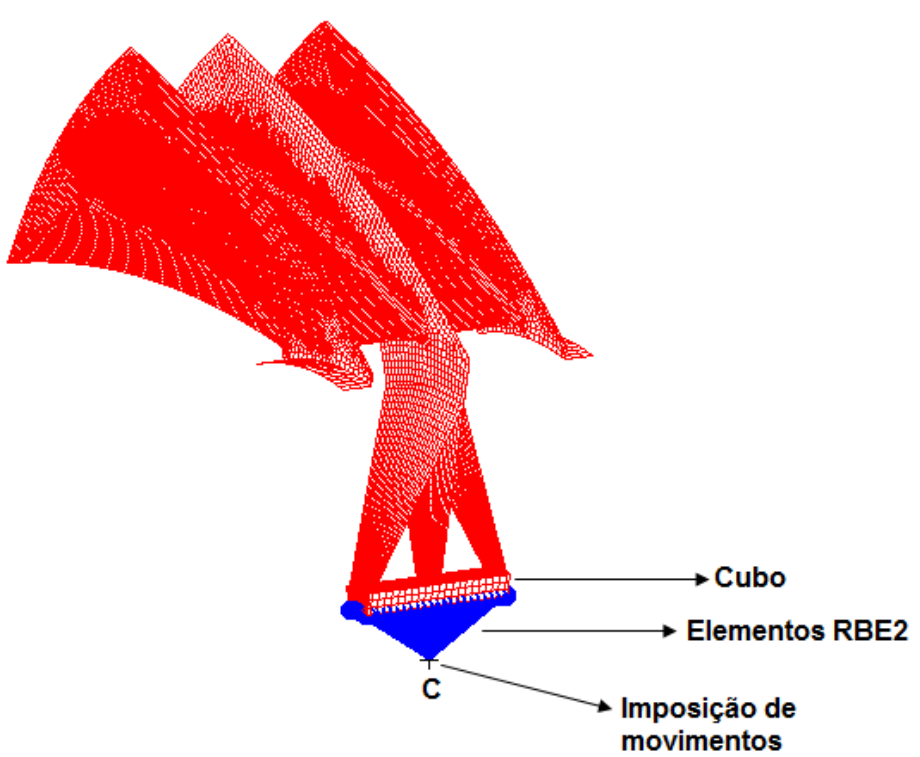

Figura 3.12 - Construção do modelo para a análise de resposta do impelidor, onde $C$ é o nó central

A etapa seguinte consiste na expansão do modelo para o impelidor completo. Por motivos didáticos, os elementos RBE2 são apresentados no modelo setorial do impelidor na Figura 3.12. Entretanto, recomenda-se a inclusão dos elementos após a expansão para o modelo de $360^{\circ}$, de modo a evitar a presença de elementos RBE2 duplicados. A Figura 3.13 ilustra o modelo final do cubo do impelidor com a indicação do nó que será submetido aos movimentos de translação e rotação. Uma vez que os movimentos são impostos a quatro graus de liberdade do nó do centro do cubo (translações em $\mathrm{Y}$ e $Z$, rotações em $\mathrm{Y}$ e Z), os demais graus de liberdade devem ter seus movimentos restringidos. Estas restrições podem ser realizadas no ponto $\mathrm{C}$ indicado na Figura 3.12.

Concluído o modelo completo do impelidor, especifica-se a velocidade de rotação do ventilador no software de elementos finitos. O modelo deve ser, então, submetido a uma análise estática linear. Esta etapa é necessária para que o MD Nastran calcule a matriz de enrijecimento centrífugo, que é incorporada à matriz de rigidez global do impelidor para as análises subsequentes. 


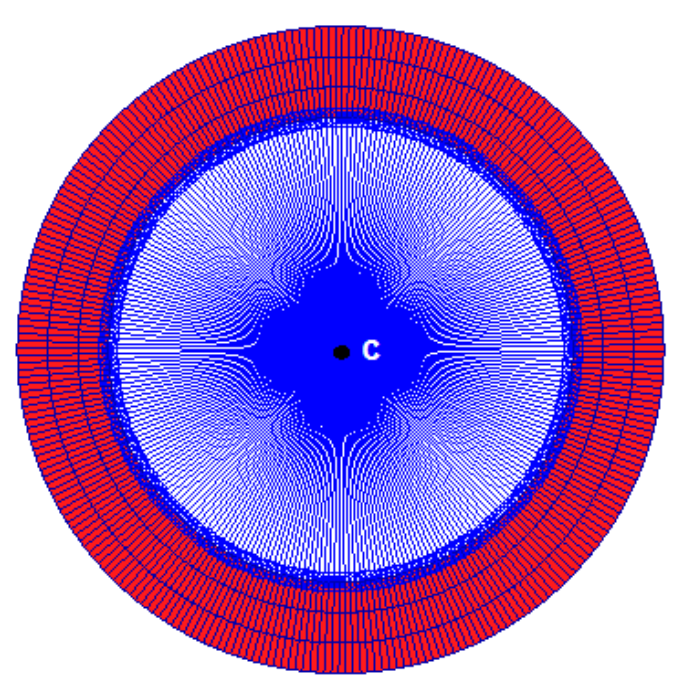

Figura 3.13 - Detalhe do modelo do cubo após a expansão do modelo para o impelidor completo. Os movimentos de base são impostos em C

Os movimentos de base calculados para a velocidade do ventilador são especificados no nó central. O modelo é submetido a uma análise de resposta no domínio da frequência, realizada para a frequência correspondente à rotação do ventilador. Caso exista o interesse de avaliar a resposta dinâmica do impelidor para diferentes valores de rotação, ressalta-se que a matriz correspondente ao efeito de enrijecimento centrífugo deve ser calculada para cada condição. Portanto, para cada rotação considerada deve ser realizada uma nova análise de resposta em frequência. Esta análise conduz aos deslocamentos e às tensões dinâmicas no impelidor.

\subsubsection{Superposição das tensões estáticas e dinâmicas}

A metodologia apresentada nas seções anteriores prevê que a avaliação do nível de tensões nos componentes do impelidor de um ventilador centrífugo compreende não somente o cálculo das tensões estáticas, provenientes da força centrífuga, mas também a determinação das tensões dinâmicas provocadas pela resposta ao desbalanceamento do ventilador. Estas tensões dinâmicas estão presentes no impelidor durante toda a sua operação e sua magnitude está associada ao grau de desbalanceamento do ventilador em campo e à proximidade 
da rotação do ventilador com as frequências naturais do rotor e do impelidor. Não é o objetivo do presente trabalho estudar as tensões dinâmicas causadas por excitações de origem aerodinâmica, tampouco aquelas decorrentes das forças dinâmicas inerentes ao carregamento gravitacional.

O cálculo das tensões dinâmicas para uma dada condição de operação do ventilador sugere que as mesmas possam ser combinadas com as tensões estáticas de modo a obter o nível total de tensões no impelidor. Trata-se de uma abordagem interessante para o cálculo da vida em fadiga do impelidor ou para a avaliação de sua integridade estrutural em uma dada condição de operação. A combinação dos efeitos de força centrífuga e de resposta ao desbalanceamento pode ser realizada a partir do chamado Princípio (ou Método) da Superposição, discutido por Meirovitch (1986) ao derivar a resposta de sistemas lineares a excitações periódicas e não periódicas. Esta discussão é apresentada a seguir, a fim de justificar o emprego deste princípio na análise dinâmica de ventiladores centrífugos.

A ilustração do Princípio da Superposição pode ser realizada a partir do estudo de um sistema linear de segunda ordem. A equação diferencial do sistema a uma força de excitação arbitrária é dada pela equação (3.32)

$$
m \ddot{x}+c \dot{x}+k x=F(t)
$$

Onde:

$m, c$ e $k$ representam a massa, o coeficiente de atrito viscoso e a rigidez do sistema, respectivamente.

Neste ponto, é conveniente a definição de um operador linear diferencial:

$$
D=m \frac{d^{2}}{d t^{2}}+c \frac{d}{d t}+k
$$

A equação (3.32) pode ser reescrita na forma:

$$
D[x(t)]=F(t)
$$

Um operador é linear se a expressão diferencial $D[x(t)]$ contiver a função $x(t) e$ se sua derivada no tempo contiver apenas termos de potência unitária ou nula. 
Produtos cruzados e termos envolvendo outras potências de $x(t)$ devem estar ausentes. O operador D contém todas as características do sistema e especifica a ordem das derivadas que multiplicam cada um dos parâmetros $m, c$ e $k$. Este operador pode ser utilizado para definir o conceito de linearidade de um sistema. Duas excitações são consideradas neste ponto: $F_{1}(t)$ e $F_{2}(t)$, cujas respostas são dadas por $\mathrm{x}_{1}(\mathrm{t})$ e $\mathrm{x}_{2}(\mathrm{t})$, respectivamente.

$$
F_{1}(t)=D\left[x_{1}(t)\right] \quad F_{2}(t)=D\left[x_{2}(t)\right]
$$

Uma terceira excitação $F_{3}(t)$ é considerada como uma combinação linear de $F_{1}(t)$ e $F_{2}(t)$ :

$$
F_{3}(t)=a F_{1}(t)+b F_{2}(t)
$$

Onde:

$a$ e $b$ são constantes conhecidas.

Caso a resposta $x_{3}(t)$ à excitação $F_{3}(t)$ satisfaça a relação:

$$
x_{3}(t)=a x_{1}(t)+b x_{2}(t)
$$

o sistema é considerado linear; caso contrário, admite-se que o sistema é não linear. Esta definição pode ser escrita a partir das equações (3.35) e (3.36) em termos do operador D.

$$
D\left[x_{3}(t)\right]=D\left[a x_{1}(t)+b x_{2}(t)\right]=a D\left[x_{1}(t)\right]+b D\left[x_{2}(t)\right]=F_{3}(t)
$$

A equação (3.38) representa a definição matemática do Princípio da Superposição. É importante ressaltar que a validade deste princípio é verificada apenas quando todos os sistemas envolvidos são lineares. Conforme discutido por Meirovitch (1986), as respostas de sistemas lineares para um dado número de excitações distintas podem ser obtidas separadamente e então combinadas para se obter uma resposta agregada. 
A aplicação do Princípio da Superposição no estudo da deflexão de vigas também é discutida por Timoshenko $(1955,1956)$. Mostra-se que o momento fletor produzido em qualquer seção de uma viga pela presença de cargas transversais é igual à soma dos momentos fletores produzidos na mesma seção transversal por carregamentos individuais agindo separadamente. Deste modo, a deflexão produzida em qualquer ponto da viga pode ser obtida através da soma das deflexões produzidas no ponto em questão pelos carregamentos individuais. Este método pode ser empregado desde que a flexão da viga não introduza nenhuma mudança na ação das forças externas. Por exemplo, pequenas deflexões de vigas por carregamentos laterais não alteram o diagrama de momento fletor para estes carregamentos, e o Princípio da Superposição pode ser utilizado. O autor alerta para as limitações do método no estudo de vigas em que a flexão está associada com carregamentos axiais de tração ou compressão, de modo que a deflexão produzida pelos carregamentos laterais altera a ação das forças axiais, de tal forma que esta última produz não somente tensões axiais, mas também alguma flexão adicional.

Neste ponto, é interessante ressaltar que todas as discussões realizadas neste trabalho para o cálculo estrutural de impelidores centrífugos assumem o regime elástico de tensões, de modo que as tensões no impelidor são sempre inferiores ao limite de escoamento da material. As tensões, devido à força centrífuga correspondente à rotação do ventilador, são provenientes de análises estáticas lineares com auxílio do MEF, cuja metodologia foi apresentada no Capítulo 2.

Atenção especial deve ser dada ao cálculo das tensões dinâmicas a partir da análise de resposta do rotor e do impelidor segundo a metodologia apresentada. Os coeficientes de rigidez e amortecimento dos mancais hidrodinâmicos estão associados à posição de equilíbrio dos moentes e, portanto, assumem diferentes valores de acordo com a velocidade do ventilador, conforme discussão apresentada na seção 3.2.1 na análise de resposta ao desbalanceamento de rotores com eixo flexível e impelidor rígido. Constata-se que a matriz de rigidez global do rotor, indicada na equação (3.16), é função da rotação do ventilador, uma vez que a matriz de rigidez correspondente aos mancais hidrodinâmicos assume diferentes valores para cada rotação considerada. O mesmo ocorre para a matriz global de amortecimento do rotor, em que a dependência com a rotação é introduzida pela matriz de amortecimento dos mancais hidrodinâmicos. Também a matriz de efeito giroscópico introduz uma dependência com a velocidade angular do ventilador. As 
análises apresentadas assumem que a matriz de efeito giroscópico, bem como os coeficientes de rigidez e amortecimento dos mancais, são atualizados para cada rotação cujo comportamento dinâmico do impelidor for estudado. Portanto, os movimentos de translação e rotação obtidos na análise de resposta do rotor - dados de entrada para a análise de resposta do impelidor - incorporam a influência da rotação do ventilador.

A incorporação do enrijecimento centrífugo no cálculo de resposta do impelidor também deve ser cuidadosamente analisada. A matriz de rigidez que representa o efeito de enrijecimento provocado pelas tensões estáticas - incorporada pelos softwares de elementos finitos à matriz de rigidez da estrutura - apresenta uma dependência quadrática com a velocidade angular do ventilador. Portanto, a análise de resposta em frequência do impelidor deve ser realizada apenas para a frequência correspondente à rotação do ventilador. Caso seja de interesse avaliar as tensões dinâmicas em velocidades angulares diferentes, o efeito de enrijecimento deve ser incorporado especialmente para a condição analisada.

A partir destas considerações, verifica-se que as tensões estáticas podem ser superpostas às tensões dinâmicas desde que duas condições específicas sejam respeitadas:

- As matrizes de rigidez, amortecimento e de efeito giroscópico utilizadas no cálculo de resposta em frequência ao desbalanceamento do rotor devem ser obtidas especialmente para a rotação de projeto do ventilador.

- A análise de resposta em frequência do impelidor deve considerar o efeito de enrijecimento centrífugo correspondente à rotação de projeto do ventilador. Esta rotação deve ser a mesma utilizada para a determinação das tensões estáticas do impelidor.

Portanto, esta abordagem considera que as tensões estáticas em uma dada rotação do ventilador são superpostas às tensões dinâmicas nesta mesma rotação, sendo estas últimas calculadas com todos os parâmetros atualizados para a velocidade angular considerada. As condições impostas para a análise dinâmica do impelidor respeitam o Princípio da Superposição, uma vez que a condição de linearidade dos sistemas combinados é garantida para cada rotação. 


\subsubsection{Testes de Confiabilidade}

As ferramentas de modelagem e simulação dos softwares MD Patran e MD Nastran, respectivamente, foram avaliadas a partir da realização de testes de confiabilidade quanto à análise de resposta em frequência às excitações por movimentos de base e à incorporação do efeito de enrijecimento centrífugo, consolidando, assim, a metodologia proposta para a análise dinâmica de impelidores centrífugos. Para tanto, escolheu-se o problema de uma placa submetida a um movimento rotativo e os resultados obtidos foram avaliados com base nas discussões encontradas na literatura.

A Figura 3.14 ilustra a placa considerada nas simulações, com a indicação das suas dimensões e propriedades. Admite-se que uma das extremidades da placa encontra-se engastada em um suporte rotativo. A rotação da placa ocorre em torno do eixo $\mathrm{Y}$ indicado na figura. Buscou-se, neste ponto, aplicar exatamente o mesmo procedimento de modelagem e simulação considerado para os impelidores de ventiladores centrífugos, de modo a verificar através de um exemplo simples a confiabilidade dos resultados e identificar eventuais dificuldades inerentes à utilização dos softwares.

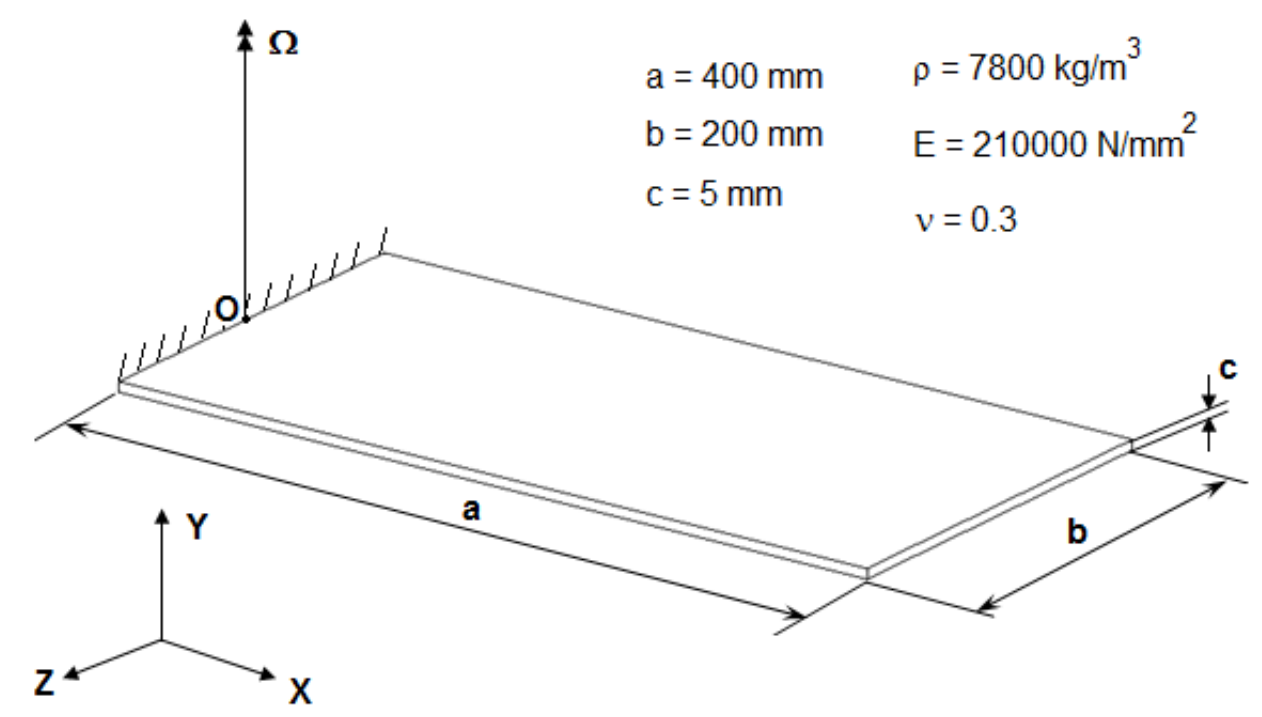

Figura 3.14 - Placa rotativa estudada nos testes, com a indicação de suas dimensões e propriedades 
O modelo de elementos finitos da placa é constituído por elementos de casca de quatro nós. Os nós correspondentes à extremidade engastada são conectados a um nó central através de elementos rígidos, de modo que todas as condições de contorno e carregamentos aplicadas neste nó são transferidas aos nós pertencentes à extremidade da placa.

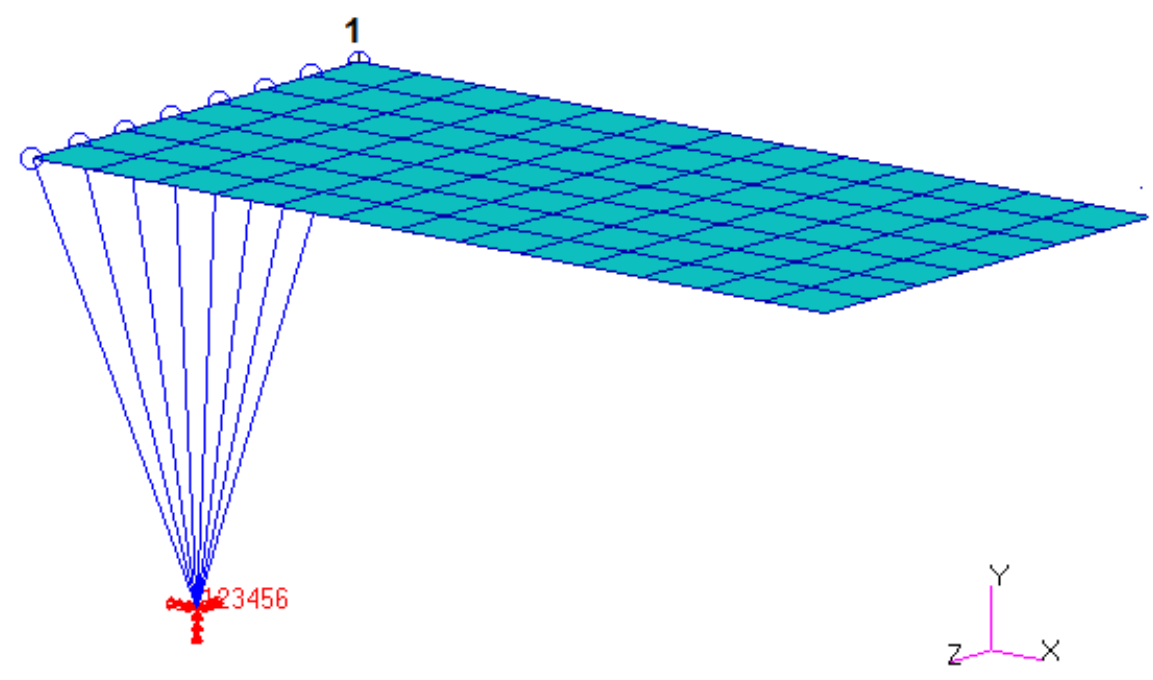

Figura 3.15 - Modelo de elementos finitos da placa rotativa

Inicialmente, foram realizadas análises de vibrações livres da placa rotativa, com o estudo de duas situações distintas. A primeira análise admite que a placa encontra-se parada; em seguida, uma rotação de $10 \mathrm{~Hz}$ (600 rpm) em torno de Y é considerada no modelo; e o estudo de vibrações livres é realizado novamente. A Tabela 3.1 indica as frequências naturais correspondentes aos quatro primeiros modos nas duas condições estudadas. O efeito do enrijecimento centrífugo foi incorporado no modelo para a segunda simulação através da especificação da velocidade angular da placa, seguindo a formulação discutida na seção 3.1.2. 
Tabela 3.1 - Comparação das frequências naturais da placa parada e submetida à rotação

\begin{tabular}{cccc}
\hline \hline Descrição & $\begin{array}{c}\text { Frequências } \\
\text { Naturais }(\mathrm{Hz}) \\
\text { Placa parada }\end{array}$ & $\begin{array}{c}\text { Frequências Naturais }(\mathrm{Hz}) \\
\text { Placa com rotação } \\
\text { de 10 Hz }\end{array}$ & $\begin{array}{c}\text { Alteração das } \\
\text { Frequências Naturais (\%) }\end{array}$ \\
\hline Modo 1 (Flexão) & 26.78 & 28.92 & 7.99 \\
Modo 2 (Torção) & 112.17 & 113.07 & 0.80 \\
Modo 3 (Flexão) & 165.74 & 167.63 & 1.14 \\
Modo 4 (Torção) & 362.59 & 363.62 & 0.28 \\
\hline \hline
\end{tabular}

Verifica-se que a incorporação do enrijecimento centrífugo no modelo provoca um aumento das frequências naturais da placa, em especial para o primeiro modo de flexão. $O$ efeito do enrijecimento centrífugo nas frequências naturais correspondentes aos quatro primeiros modos da placa pode ser observado através do Diagrama de Campbell mostrado na Figura 3.16. Estes resultados estão de acordo com a discussão realizada por Gans e Anderson (1991), que propõem que o projeto estrutural de palhetas de compressores centrífugos seja otimizado a partir da consideração do efeito da rotação na análise dinâmica destes componentes.

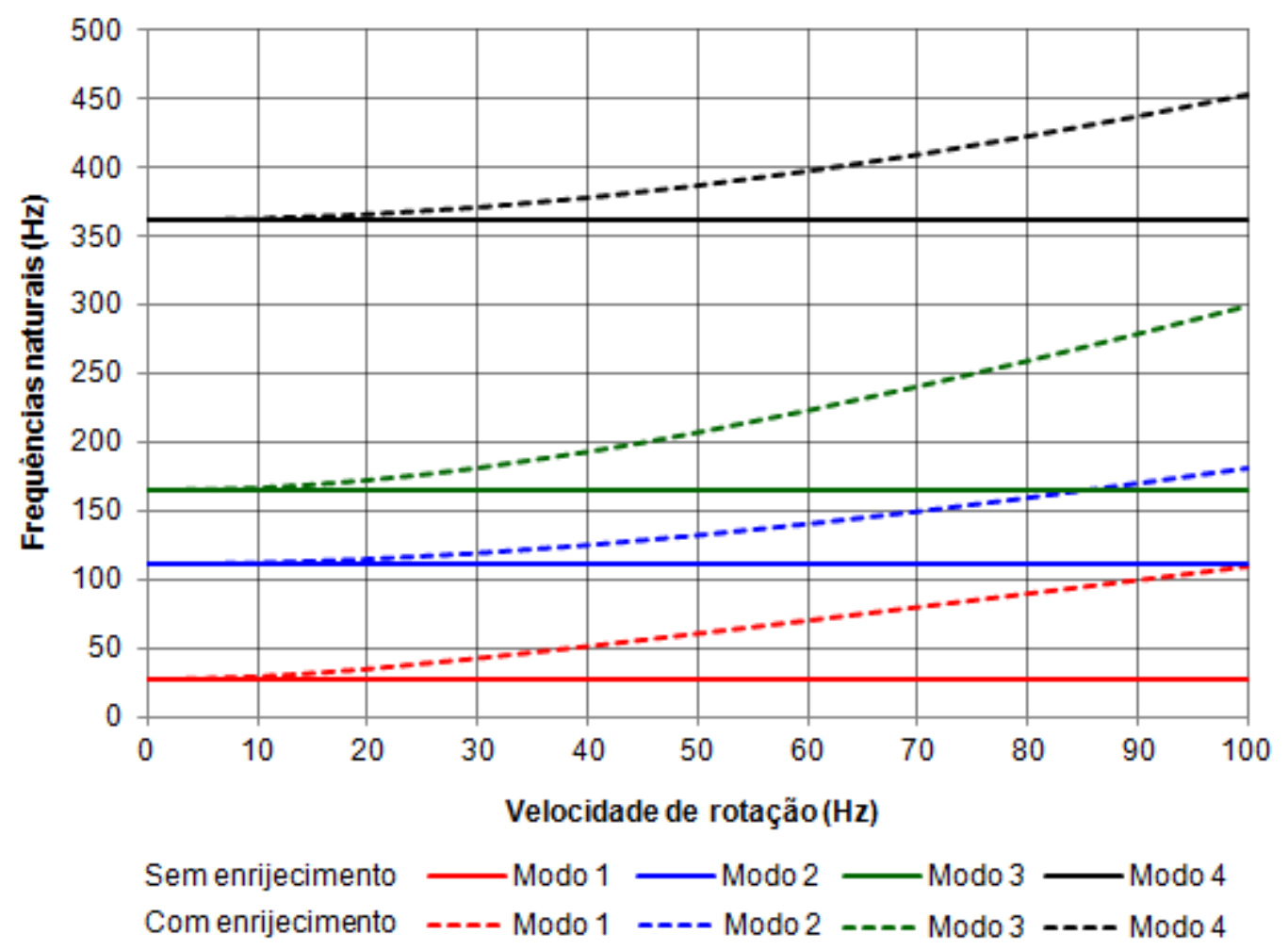

Figura 3.16 - Diagrama de Campbell para a placa rotativa 
Um segundo teste é realizado a partir do exemplo da placa rotativa, desta vez com o estudo da resposta em frequência aos movimentos de translação impostos em uma de suas extremidades, o que conduz à determinação das tensões dinâmicas máximas na estrutura. Um movimento de translação na direção $Y$ é imposto ao nó central do modelo da Figura 3.15. A excitação empregada nas simulações é apresentada na Figura 3.17.

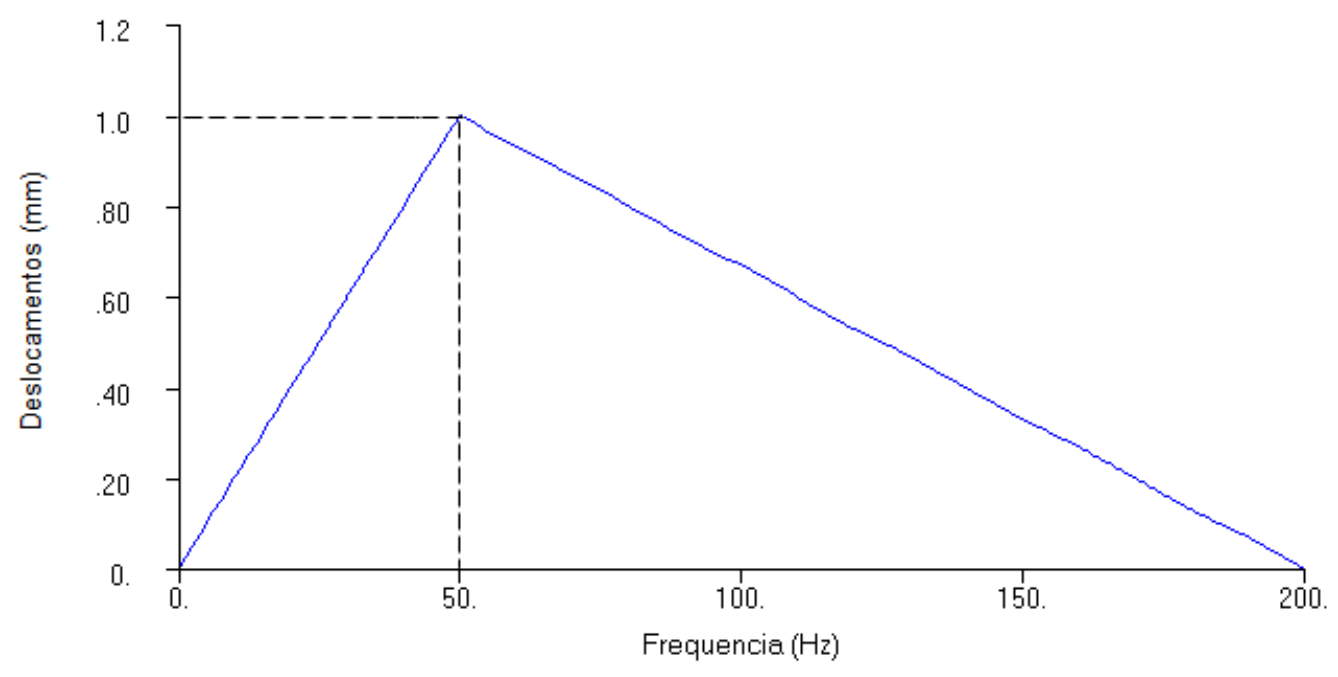

Figura 3.17 - Movimento de translação imposto à extremidade da placa

Os resultados do cálculo da resposta em frequência, realizado com um passo de frequência de $5 \mathrm{~Hz}$, são mostrados nas Figuras 3.18 e 3.19. Um amortecimento estrutural de $2 \%$ foi considerado nas simulações. Verificou-se que os deslocamentos do nó 1, indicado na Figura 3.15, assim como de todos os outros nós da extremidade engastada da placa, reproduziram exatamente os movimentos impostos no nó central, como mostra a Figura 3.18. 


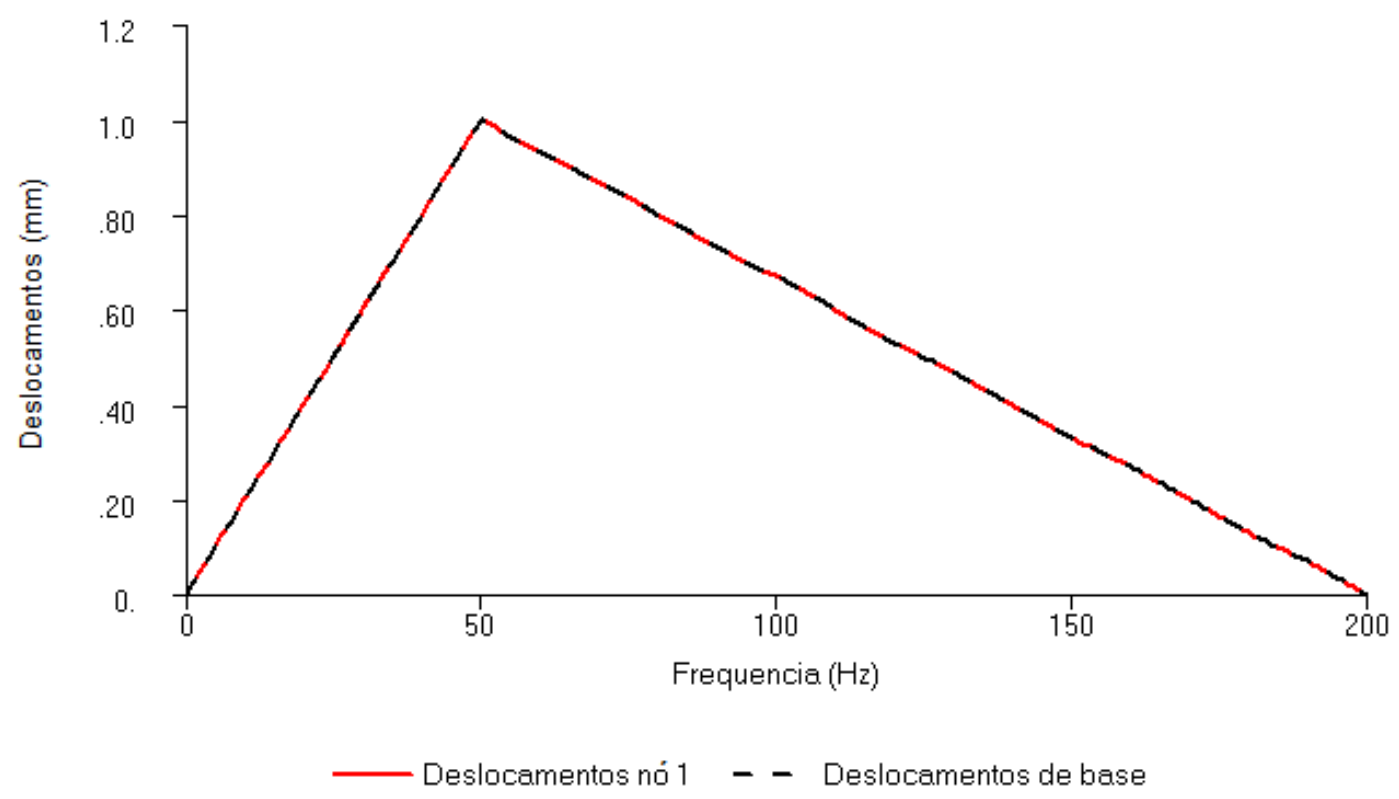

Figura 3.18 - Correspondência entre os deslocamentos de base e os deslocamentos obtidos na simulação para os nós da extremidade da placa

$\mathrm{Na}$ faixa de frequências analisada, as máximas tensões dinâmicas ocorrem na extremidade engastada da placa. A Figura 3.19 apresenta as tensões dinâmicas referentes ao nó 1 (Figura 3.15). De forma análoga ao estudo de vibrações livres, a resposta em frequência aos movimentos impostos foi realizada primeiramente para a placa estacionária e, em seguida, considerou-se uma rotação correspondente a 10 $\mathrm{Hz}$ em torno do eixo $\mathrm{Y}$. 


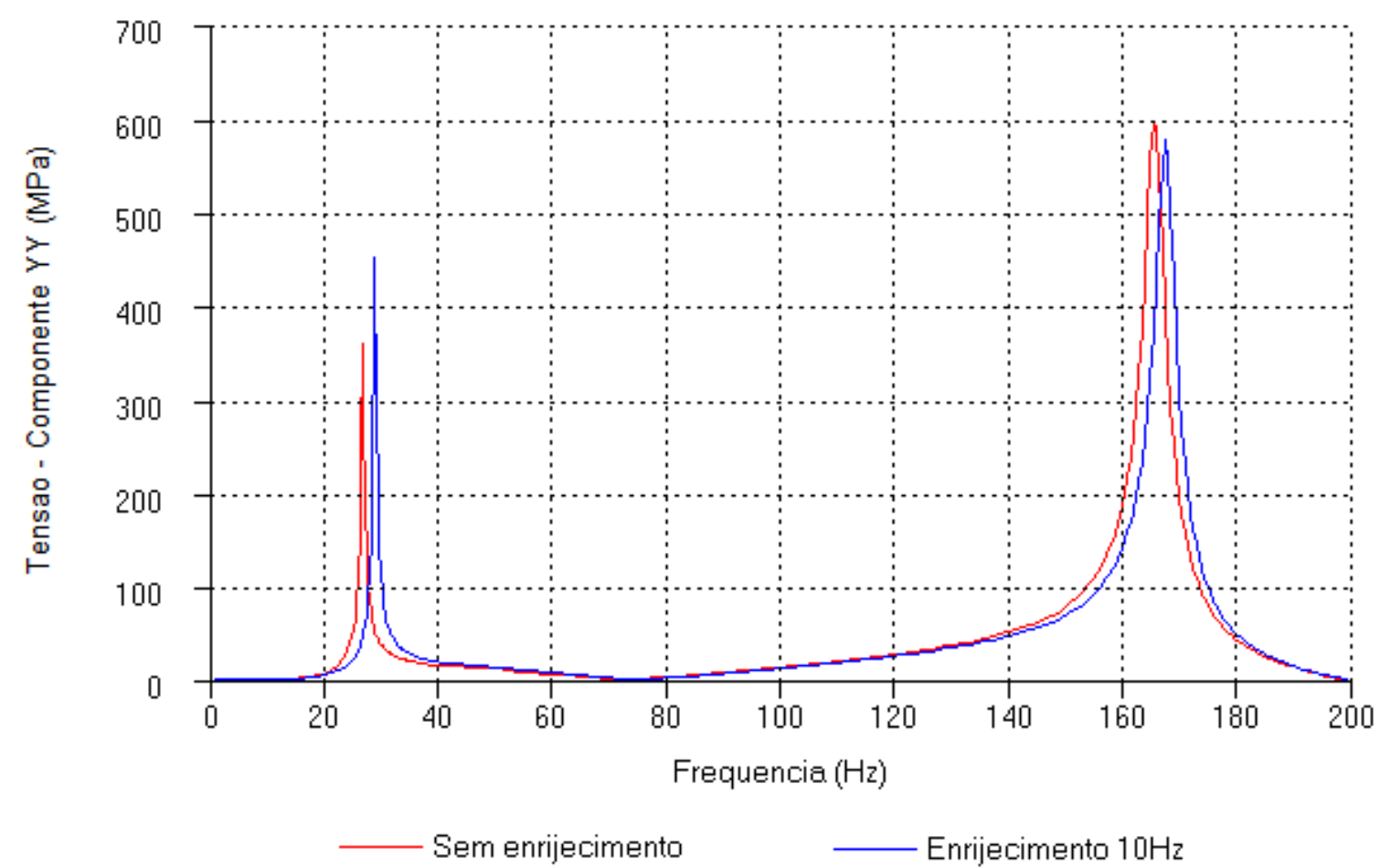

Figura 3.19 - Tensões dinâmicas (componente YY) na extremidade da viga para duas condições: placa estacionária e com enrijecimento centrífugo correspondente a $10 \mathrm{~Hz}$

As máximas amplitudes de tensão dinâmica ocorrem na proximidade das frequências naturais de flexão da placa. Nota-se que a incorporação do efeito de enrijecimento centrífugo provocou um deslocamento em frequência na resposta. É importante ressaltar que as diferenças nas amplitudes de tensão entre as duas simulações estão associadas ao comportamento dos movimentos de base impostos na extremidade engastada. Deslocamentos na frequência natural devido à rotação fornecem respostas amplificadas com relação à condição estacionária até a frequência de $50 \mathrm{~Hz}$. Desta frequência em diante, as respostas são reduzidas, como pode se observar a partir das Figuras 3.17 e 3.19 .

\subsubsection{Determinação das tensões de von Mises no domínio da frequência}

$\mathrm{Na}$ análise de tensões estáticas, discutida na Seção 2, as tensões de von Mises são determinadas a partir das componentes de tensão calculadas para cada elemento, isto é, $\sigma_{x x}, \sigma_{y y}, \sigma_{z z}, \tau_{x y}, \tau_{x z}$ e $\tau_{y z}$, no caso tridimensional. $O$ pós- 
processamento dos níveis de tensão estática em cada elemento é então realizado através da equação (3.39):

$$
\sigma_{V M}=\sqrt{\frac{\left(\sigma_{x}-\sigma_{y}\right)^{2}+\left(\sigma_{y}-\sigma_{z}\right)^{2}+\left(\sigma_{z}-\sigma_{x}\right)^{2}}{2}+3 \cdot\left(\tau_{x y}^{2}+\tau_{y z}^{2}+\tau_{z x}^{2}\right)}
$$

No caso dos elementos de casca, empregados na modelagem dos discos e palhetas dos ventiladores centrífugos, as componentes $\sigma_{z z}, \tau_{x z}$ e $\tau_{y z}$ são nulas. A expressão geral das tensões de von Mises para estes elementos assume a forma:

$$
\sigma_{V M}=\sqrt{\sigma_{x}^{2}-\sigma_{x} \sigma_{y}+\sigma_{y}^{2}+3 \cdot \tau_{x y}^{2}}
$$

Em análises de resposta em frequência, todas as componentes de deslocamento e de tensão são números complexos, isto é, cada uma das componentes possui módulo e fase. Observa-se, entretanto, que o cálculo da tensão de von Mises não é realizado corretamente pelo MD Patran, uma vez que as fases das diferentes componentes de tensão $\left(\sigma_{x x}, \sigma_{y y}\right.$ e $\tau_{x y}$ para um elemento de casca) não são consideradas ${ }^{4}$. Contudo, o cálculo destas tensões pode ser realizado manualmente, ou através do desenvolvimento de softwares auxiliares. Formulações para o cálculo da máxima tensão de von Mises a partir das componentes complexas de tensão são apresentadas por Charron; Donato e Fontaine (1993). As tensões, provenientes de uma excitação harmônica, em um elemento de casca, são expressas na forma:

$$
\begin{aligned}
& \sigma_{x x}(t)=\left|\sigma_{x x}\right| \cdot \cos (\omega t+\delta) \\
& \sigma_{y y}(t)=\left|\sigma_{y y}\right| \cdot \cos (\omega t+\beta) \\
& \tau_{x y}(t)=\left|\tau_{x y}\right| \cdot \cos (\omega t+\varphi)
\end{aligned}
$$

Onde:

\footnotetext{
${ }^{4}$ De acordo com MSC Software Corporation (2010, p.12), deve-se atentar para a seguinte recomendação no uso do software: "It is not recommended to calculate invariants (e.g., von Mises) from complex results because the phase is not accounted for."
} 
$\sigma_{\mathrm{xx}}$ (t) e $\sigma_{\mathrm{yy}}$ ( $\mathrm{t}$ ) são componentes de tensão normal nas direções $\mathrm{x}$ e $\mathrm{y}$, respectivamente; $\tau_{x y}(\mathrm{t})$ é a tensão de cisalhamento no plano xy; $\left|\sigma_{x x}\right|$ e $\left|\sigma_{y y}\right|$ são os módulos das tensões normais $\sigma_{x x}$ e $\sigma_{y y}$, respectivamente; $\left|\tau_{x y}\right|$ é o módulo da tensão de cisalhamento $\tau_{x y} ; \delta, \beta$ e $\varphi$ são as fases das tensões $\sigma_{x x}, \sigma_{y y}$ e $\tau_{x y}$, respectivamente; $\omega t$ é o ângulo de fase de referência.

Fazendo $\omega t$ igual a $\theta$ nas equações (3.41) a (3.43) e introduzindo estas relações na expressão geral para o cálculo da tensão de von Mises para o caso 2D vide equação (3.40) - é possível demonstrar que a tensão equivalente no domínio da frequência é obtida pela expressão:

$$
\begin{aligned}
\sigma_{\mathrm{VM}}{ }^{2}= & \left|\sigma_{\mathrm{xx}}\right|^{2} \cdot \cos ^{2}(\theta+\delta)+\left|\sigma_{\mathrm{yy}}\right|^{2} \cdot \cos ^{2}(\theta+\beta)+3 \cdot\left|\tau_{\mathrm{xy}}\right|^{2} \cdot \cos ^{2}(\theta+\varphi)- \\
& \left|\sigma_{\mathrm{xx}}\right|\left|\sigma_{\mathrm{yy}}\right| \cos (\theta+\delta) \cdot \cos (\theta+\beta)
\end{aligned}
$$

Charron; Donato e Fontaine (1993) demonstram que os ângulos de referência que resultam nos valores máximos e mínimos das tensões de von Mises satisfazem a seguinte relação:

$$
\begin{gathered}
-\tan (2 \theta)=\frac{\left|\sigma_{\mathrm{xx}}\right|^{2} \cdot \operatorname{sen}(2 \delta)+\left|\sigma_{\mathrm{yy}}\right|^{2} \cdot \operatorname{sen}(2 \beta)+3 \cdot\left|\tau_{\mathrm{xy}}\right|^{2} \cdot \operatorname{sen}(2 \varphi)-}{\left|\sigma_{\mathrm{xx}}\right|^{2} \cdot \cos (2 \delta)+\left|\sigma_{\mathrm{yy}}\right|^{2} \cdot \cos (2 \beta)+3 \cdot\left|\tau_{\mathrm{xy}}\right|^{2} \cdot \cos (2 \varphi)-} \\
\frac{\left|\sigma_{\mathrm{xx}}\right|\left|\sigma_{\mathrm{yy}}\right| \cdot \operatorname{sen}(\delta+\beta)}{\left|\sigma_{\mathrm{xx}}\right|\left|\sigma_{\mathrm{yy}}\right| \cdot \cos (\delta+\beta)}
\end{gathered}
$$

Portanto, a partir do emprego da equação (3.45), é possível determinar ângulo de referência $\theta$ correspondente à máxima tensão de von Mises, cuja solução exata é obtida através da equação (3.44).

Abordagem semelhante é realizada por Bonte; Boer e Liebregts (2007), que destacam que a determinação das tensões de von Mises nas análises de fadiga no domínio da frequência não são triviais. Através do estudo de estruturas submetidas a múltiplas excitações randômicas, os autores ressaltam a importância de se considerar as diferenças de fase das componentes de tensão, a fim de avaliar 
corretamente as tensões de von Mises resultantes. A expressão apresentada para a determinação da máxima tensão de von Mises em um estado de tensões biaxial é:

$$
\begin{gathered}
\max \left(\sigma_{\mathrm{VM}}{ }^{2}\right)=0.5 \cdot\left(\left|\sigma_{\mathrm{xx}}\right|^{2}+\left|\sigma_{\mathrm{yy}}\right|^{2}-\left|\sigma_{\mathrm{xx}}\right|\left|\sigma_{\mathrm{yy}}\right| \cos \left(\varphi_{\mathrm{xx}}-\varphi_{\mathrm{yy}}\right)+3\left|\tau_{\mathrm{xy}}\right|^{2}\right)+ \\
\left.0.5 \cdot|| \sigma_{\mathrm{xx}}\right|^{2}+\left|\sigma_{\mathrm{yy}}\right|^{2} \mathrm{e}^{2 \mathrm{j}\left(\varphi_{\mathrm{yy}}-\varphi_{\mathrm{xx}}\right)}-\left|\sigma_{\mathrm{xx}}\right|\left|\sigma_{\mathrm{yy}}\right| \mathrm{e}^{\mathrm{j}\left(\varphi_{\mathrm{yy}}-\varphi_{\mathrm{xx}}\right)}+3 \cdot\left|\tau_{\mathrm{xy}}\right|^{2} \mathrm{e}^{2 \mathrm{j}\left(\varphi_{\mathrm{xy}}-\varphi_{\mathrm{yy}}\right)} \mid
\end{gathered}
$$

Onde:

$\varphi_{\mathrm{xx}}, \varphi_{\mathrm{yy}}$ e $\varphi_{\mathrm{xy}}$ são as fases das tensões $\sigma_{\mathrm{xx}}, \sigma_{\mathrm{yy}} \mathrm{e} \tau_{\mathrm{xy}}$, respectivamente.

É possível verificar que os resultados obtidos pela equação (3.44) são equivalentes aos resultados calculados através da equação (3.46), desde que considerado o ângulo de referência $\theta$ correspondente à máxima tensão de von Mises, segundo a equação (3.45). A relevância da análise das fases das diferentes componentes de tensão no cálculo das tensões de von Mises pode ser ilustrada através do exemplo discutido por Charron; Donato e Fontaine (1993). São consideradas três componentes de tensão com ângulos de fase completamente distintos, como ilustra a Figura 3.20.

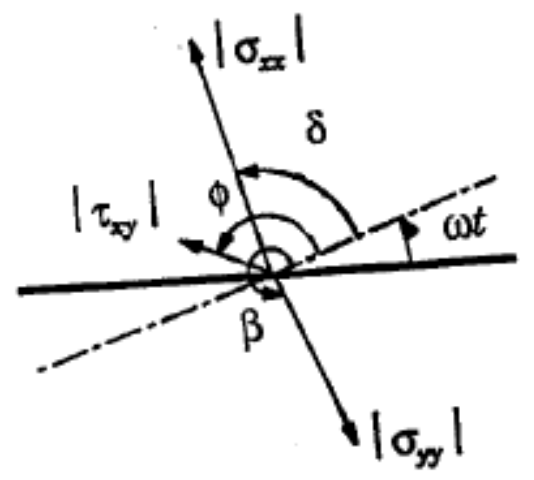

$$
\begin{aligned}
& \mid \begin{array}{l}
\sigma_{x x} \mid=20000 \text { PSI } \\
\sigma_{y y} \mid=15000 \text { PSI } \\
\tau_{x y} \mid=8000 \text { PSI }
\end{array} \\
& \delta \quad=85^{\circ} \\
& \beta \quad=275^{\circ} \\
& \phi \quad=130^{\circ}
\end{aligned}
$$

Figura 3.20 - Componentes de tensão em relação a um ângulo de referência $\omega$ t para o caso 2D (CHARRON; DONATO e FONTAINE, 1993)

A expressão (3.45) conduz aos ângulos de referência correspondentes à mínima e à máxima tensão de von Mises: $\theta_{1}=-4.75^{\circ}$ e $\theta_{2}=85.25^{\circ}$, respectivamente. Os valores mínimos e máximos, calculados através da equação (3.44), 
correspondem a 8672 psi e 32206 psi, respectivamente. O cálculo da máxima tensão de von Mises a partir da equação (3.46) conduz ao mesmo resultado. 


\section{RESULTADOS DA SIMULAÇÃO DE UM VENTILADOR DE DUPLA-ENTRADA}

Este capítulo apresenta a aplicação da metodologia proposta para a análise estrutural do impelidor de um ventilador centrífugo real. A integridade estrutural do impelidor quanto às tensões estáticas em seus componentes é avaliada a partir do MEF. Neste ponto, opta-se pela não utilização dos métodos analíticos, tendo em vista os aspectos relacionados às suas limitações, discutidas no Capítulo 2. Ressalte-se, contudo, que o emprego dos métodos analíticos constitui uma ferramenta valiosa para os estudos preliminares e seu uso não deve ser descartado.

Uma vez determinados os níveis de tensão estática na estrutura, passa-se à análise dinâmica do impelidor a partir da metodologia proposta no Capítulo 3. A análise de resposta ao desbalanceamento é realizada no rotor do ventilador centrífugo, conduzindo à determinação dos movimentos na região do cubo do impelidor. Estes movimentos são utilizados como dados de entrada para o modelo completo do impelidor no software de elementos finitos, onde se calcula a resposta do impelidor à imposição destas excitações de base. Objetiva-se, assim, o cálculo das tensões dinâmicas nos componentes do impelidor, o que constitui uma nova abordagem para o cálculo estrutural destes equipamentos, uma vez que, tradicionalmente, as análises dinâmicas são voltadas para os estudos de vibrações livres. Além de sugerir uma metodologia que possa ser seguida em estudos semelhantes, pretende-se efetuar uma análise quantitativa das tensões dinâmicas calculadas, discutindo as vantagens desta abordagem. Por fim, discute-se a combinação das tensões estáticas e das tensões dinâmicas para o exemplo estudado, a partir do Princípio da Superposição, apresentado no Capítulo 3.

\subsection{DESCRIÇÃO DO VENTILADOR CENTRÍFUGO ANALISADO}

As análises consideram um ventilador centrífugo de dupla-entrada, cujo impelidor é posicionado simetricamente no eixo em relação aos mancais 
hidrodinâmicos. $\mathrm{O}$ acionamento é realizado a partir de um motor elétrico e de um acoplamento. A título de ilustração, a Figura 4.1 apresenta o arranjo em escala do ventilador centrífugo completo, com a indicação de seus principais componentes. $\mathrm{O}$ ventilador movimenta gases de alta temperatura - até $400^{\circ} \mathrm{C}$ - contendo particulados aderentes. Trata-se de uma configuração muito utilizada em indústrias de cimento, nas quais a presença de particulados aderentes nos gases movimentados exige uma atenção especial quanto ao nível de desbalanceamento em campo durante a operação do ventilador.

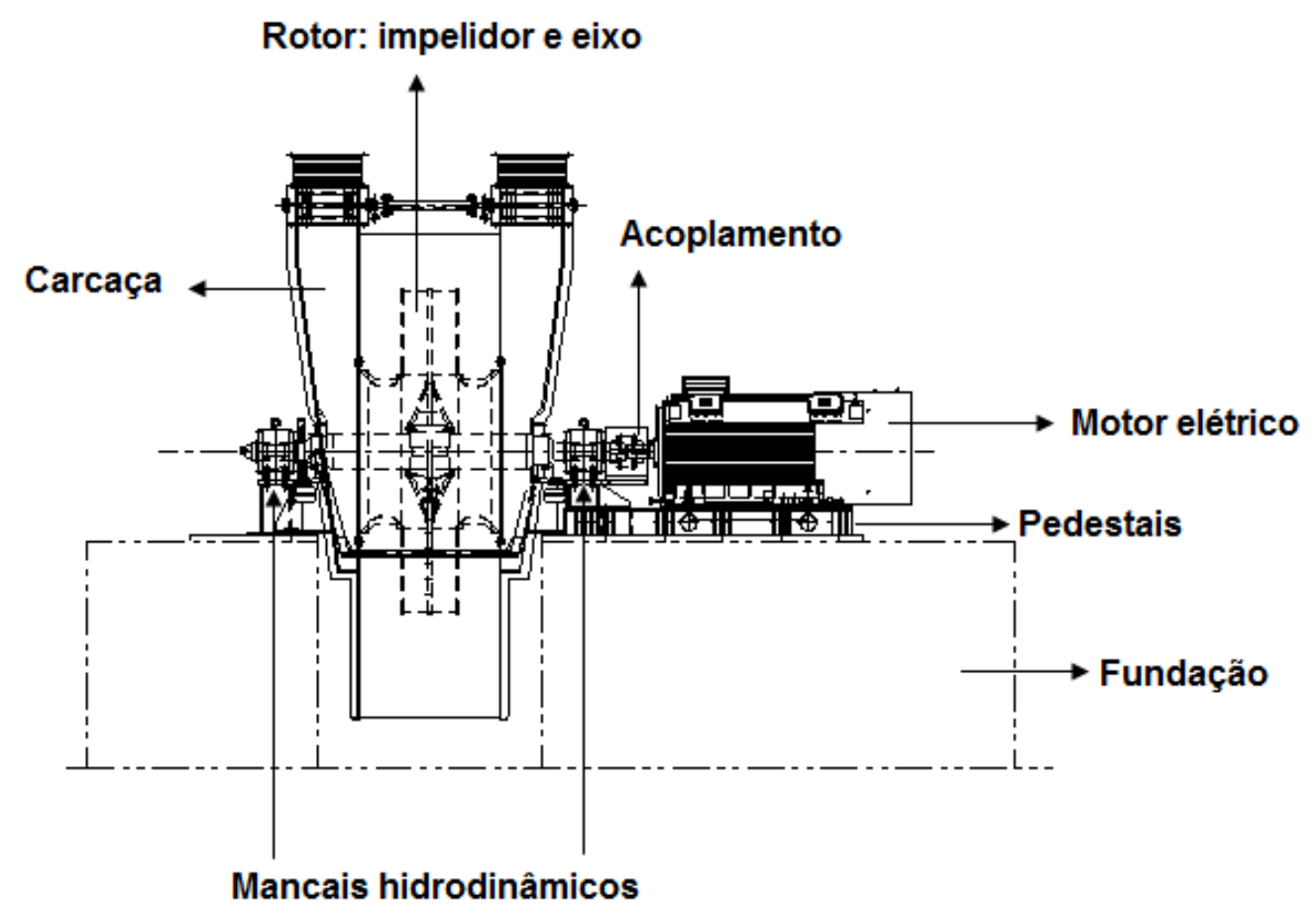

Figura 4.1 - Ventilador centrífugo de dupla entrada empregado nas análises

O impelidor de um ventilador centrífugo de dupla entrada é constituído de dois discos laterais, um disco central, palhetas, anéis dos discos laterais, cones de rigidez e um cubo, no qual a conexão com o eixo é realizada por uma chaveta. As condições de operação do ventilador e as principais dimensões do impelidor, utilizadas para as simulações em elementos finitos, são apresentadas na Tabela 4.1. 
Tabela 4.1 - Dados construtivos e de operação do ventilador analisado

\begin{tabular}{lcccc}
\hline Dimensões do impelidor & $\begin{array}{c}\text { Raio interno } \\
(\mathrm{mm})\end{array}$ & $\begin{array}{c}\text { Raio externo } \\
(\mathrm{mm})\end{array}$ & $\begin{array}{c}\text { Espessuras } \\
(\mathrm{mm})\end{array}$ & $\begin{array}{c}\text { Ângulo de saída } \\
(\text { graus })\end{array}$ \\
\hline Palhetas & 740.5 & 1523.0 & 13.0 & 52.0 \\
Discos laterais & 709.5 & 1532.4 & 16.0 & - \\
Anéis dos discos laterais & 694.0 & 725.0 & 31.0 & - \\
Disco central & 188.0 & 1532.4 & 32.0 & - \\
Cones de rigidez & 188.0 & 629.0 & 8.0 & - \\
Cubo & 135.0 & 188.0 & - & - \\
Largura das palhetas & & \multicolumn{2}{c}{232} & \\
Número de palhetas & \multicolumn{2}{c}{24 (curvadas) $^{5}$} \\
\hline \hline
\end{tabular}

Condições de operação

\begin{tabular}{|c|c|}
\hline Rotação (rpm) & 880 \\
\hline $\begin{array}{l}\text { Temperatura de projeto } \\
\text { mecânico }\left({ }^{\circ} \mathrm{C}\right)\end{array}$ & 400 \\
\hline \multicolumn{2}{|c|}{ Propriedades do material } \\
\hline Denominação & ASTM 514B \\
\hline $\begin{array}{l}\text { Limite de escoamento a } \\
400^{\circ} \mathrm{C}\left(\mathrm{N} / \mathrm{mm}^{2}\right)\end{array}$ & 635 \\
\hline $\begin{array}{l}\text { Limite de resistência à } \\
\text { tração }\left(\mathrm{N} / \mathrm{mm}^{2}\right)\end{array}$ & 800 \\
\hline $\begin{array}{l}\text { Módulo de elasticidade } \\
\text { a } 400^{\circ} \mathrm{C}\left(\mathrm{N} / \mathrm{mm}^{2}\right)\end{array}$ & 161000 \\
\hline Coeficiente de Poisson & 0.33 \\
\hline Densidade $\left(\mathrm{kg} / \mathrm{m}^{3}\right)$ & 7800 \\
\hline
\end{tabular}

\subsection{ANÁLISE DE TENSÕES ESTÁTICAS}

A construção do modelo para análise de tensões estáticas através do MEF segue a metodologia apresentada na seção 2.2.1. Um setor correspondente a 1/12 do impelidor completo foi considerado. Para a análise de tensões estáticas, apenas elementos de casca de 4 nós são empregados. Admite-se que o disco central e os

\footnotetext{
${ }^{5} 12$ palhetas em linha para cada lado do disco central.
} 
cones de rigidez estão engastados ao cubo do ventilador, de modo que todos os seis graus de liberdade dos nós localizados na região de conexão destes elementos são restringidos. Um carregamento inercial de $14.667 \mathrm{~Hz}$ (880 rpm), correspondente à rotação do ventilador, foi imposto ao modelo, representado na Figura 4.2.

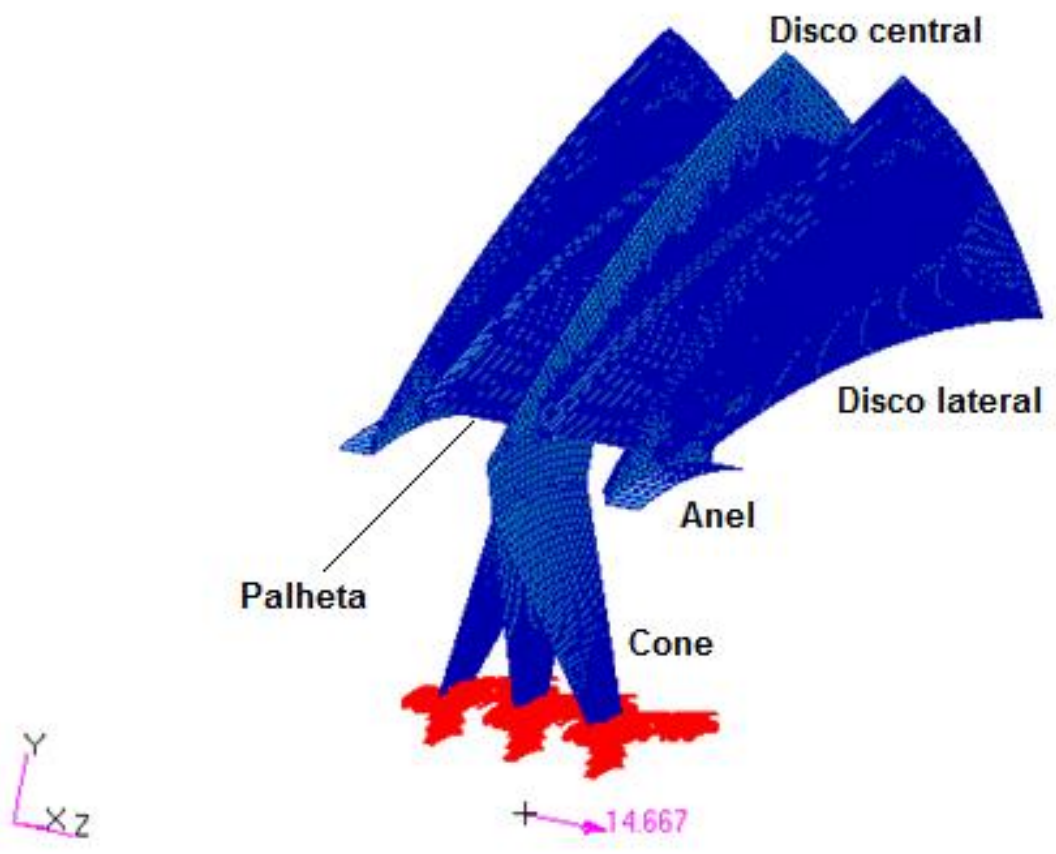

Figura 4.2 - Modelo do impelidor para análise de tensões estáticas, com indicação de seus componentes, do carregamento inercial e das condições de contorno

O máximo deslocamento calculado foi de $0.89 \mathrm{~mm}$, localizado na saída das palhetas. A Figura 4.3 apresenta o impelidor em sua condição deformada. 

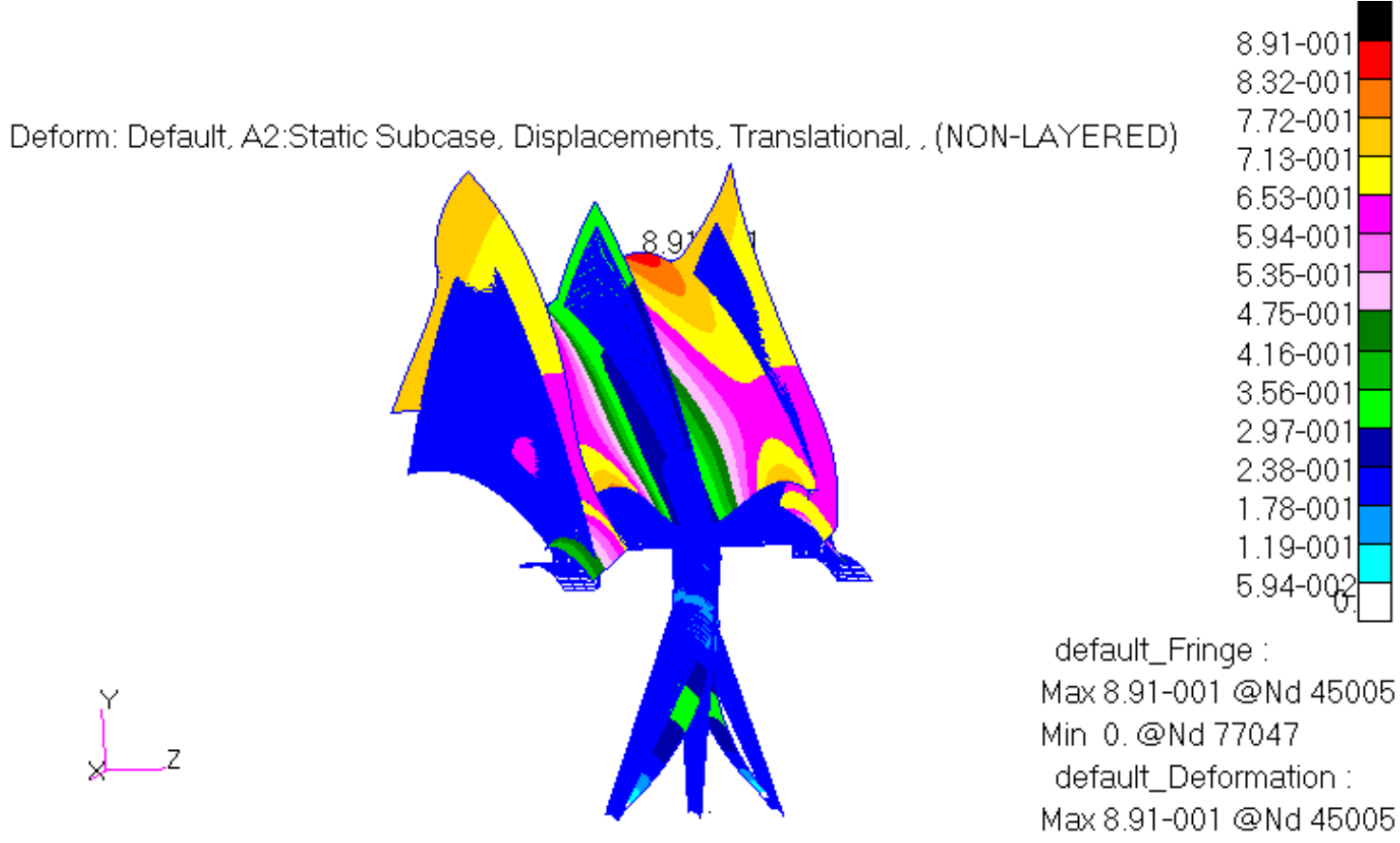

default_Fringe

Max8.91-001@Nd 45005

Min 0.@Nd 77047

default_Deformation :

Max8.91-001@Nd 45005

Figura 4.3 - Deslocamentos no impelidor (mm)

As Figuras 4.4 a 4.13 mostram as tensões de von Mises calculadas para cada um dos componentes do impelidor nas superfícies Z1 e Z2.

Figura 4.4 - Tensões de von Mises nas palhetas $\left(\mathrm{N} / \mathrm{mm}^{2}\right)$ - superfície Z1 


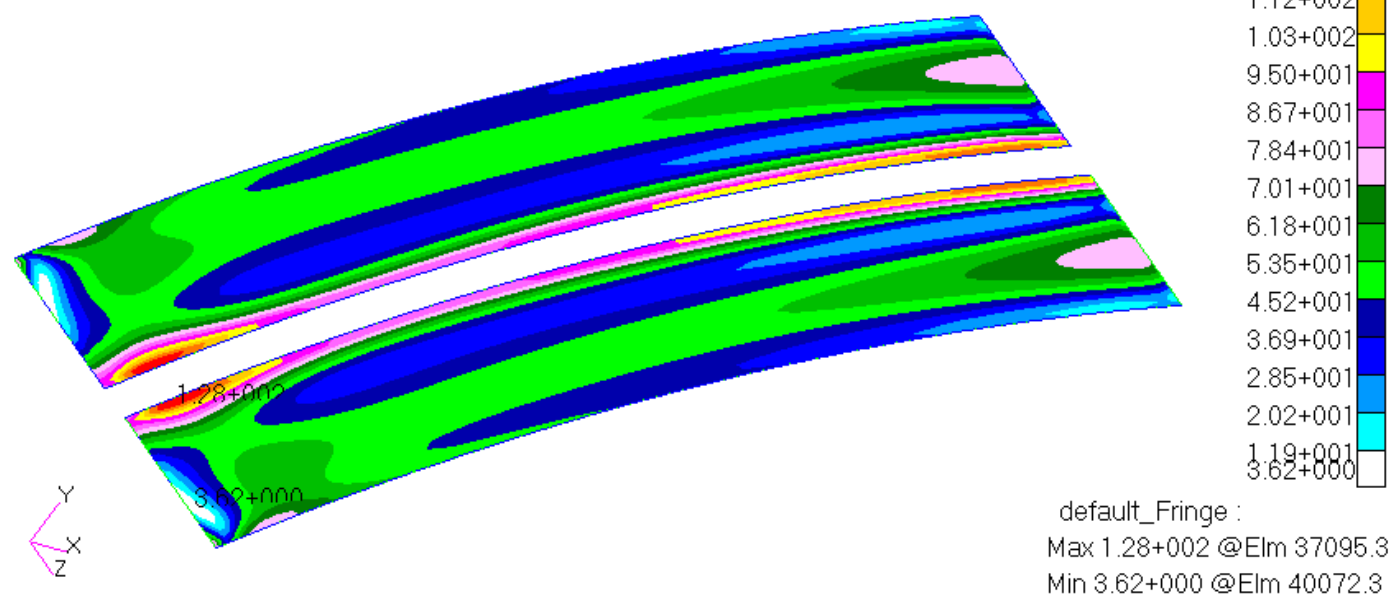

Figura 4.5 - Tensões de von Mises nas palhetas $\left(\mathrm{N} / \mathrm{mm}^{2}\right)$ - superfície Z2

Fringe: Default, A2:Static Subcase, Stress Tensor, , von Mises, At Z1

Figura 4.6 - Tensões de von Mises no disco central $\left(\mathrm{N} / \mathrm{mm}^{2}\right)$ - superfície Z1 
Fringe: Default, A2:Static Subcase, Stress Tensor, , von Mises, At Z2

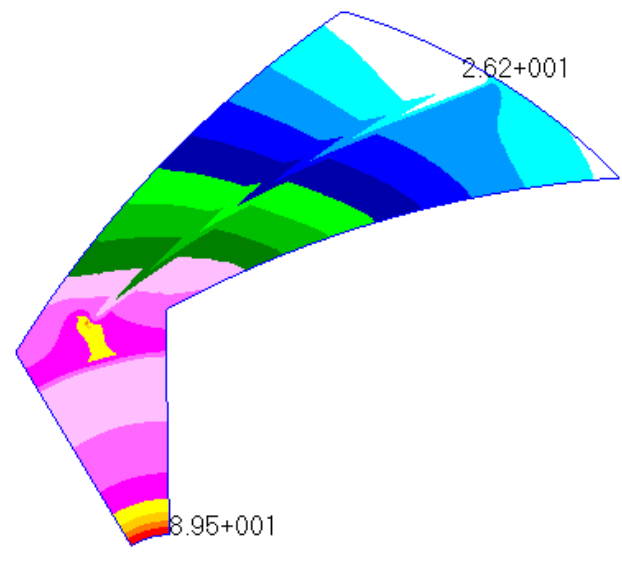

default_Fringe

Max8.95+001@EIm 70683.4 Min 2.62+001@EIm 44073.2

Figura 4.7 - Tensões de von Mises no disco central $\left(\mathrm{N} / \mathrm{mm}^{2}\right)$ - superfície Z2

Fringe: Default, A2:Static Subcase, Stress Tensor, , von Mises, At Z1

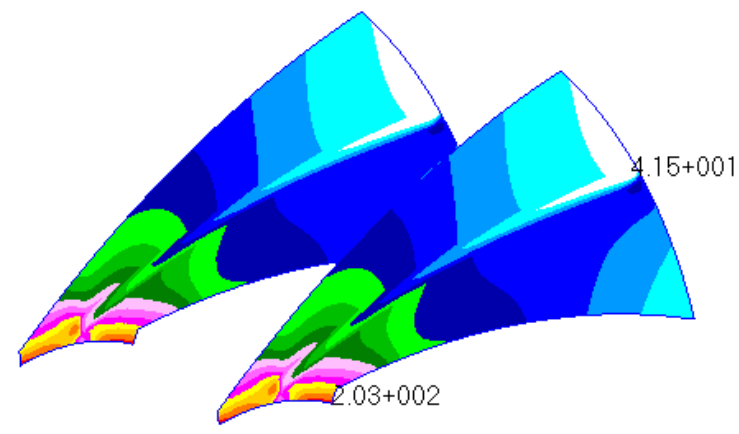

default_Fringe

Max 2.03+002@Elm 47862.4 Min 4.15+001@Elm 28929.3

Figura 4.8 - Tensões de von Mises nos discos laterais $\left(\mathrm{N} / \mathrm{mm}^{2}\right)$ - superfície Z1 
Fringe: Default, A2:Static Subcase, Stress Tensor, , von Mises, At Z2

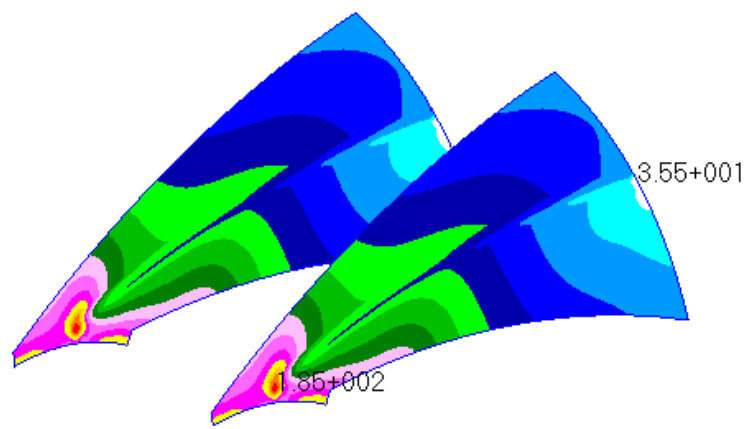

$1.55+002$

$1.45+002$

$1.35+002$

$1.25+002$

$1.15+002$

$1.05+002$

$9.51+00$

$8.52+00$

$7.52+001$

$6.53+001$

$5.54+00$

3.:55+881

$Y_{X Z}^{Y}$

default_Fringe:

Max 1.85+002@Elm 29427.3

Min 3.55+001@EIm 47858.1

Figura 4.9 - Tensões de von Mises nos discos laterais $\left(\mathrm{N} / \mathrm{mm}^{2}\right)$ - superfície Z2

Fringe: Default, A2:Static Subcase, Stress Tensor, , von Mises, At Z1

default_Fringe

Max 1.51+002@Elm 15823.2

Min 2.76+001@EIm 15808.4

Figura 4.10 - Tensões de von Mises nos anéis dos discos laterais $\left(\mathrm{N} / \mathrm{mm}^{2}\right)$ - superfície Z1 
Fringe: Default, A2:Static Subcase, Stress Tensor, , von Mises, At Z2

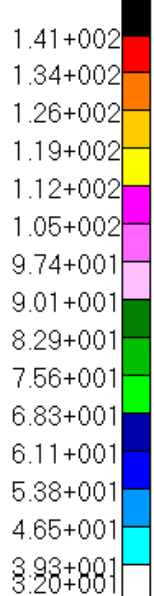

default_Fringe

Max 1.41+002@Elm 15824.2 Min3.20+001@EIm 15844.3

Figura 4.11 - Tensões de von Mises nos anéis dos discos laterais $\left(\mathrm{N} / \mathrm{mm}^{2}\right)$ - superfície Z2

Fringe: Default, A2:Static Subcase, Stress Tensor, , von Mises, At Z1

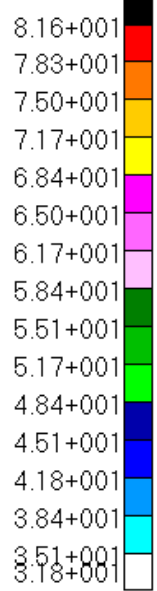

default_Fringe Max 8.16+001@EIm 71258.4 Min 3.18+001@EIm 71395.3

Figura 4.12 - Tensões de von Mises nos cones de rigidez $\left(\mathrm{N} / \mathrm{mm}^{2}\right)$ - superfície Z1 


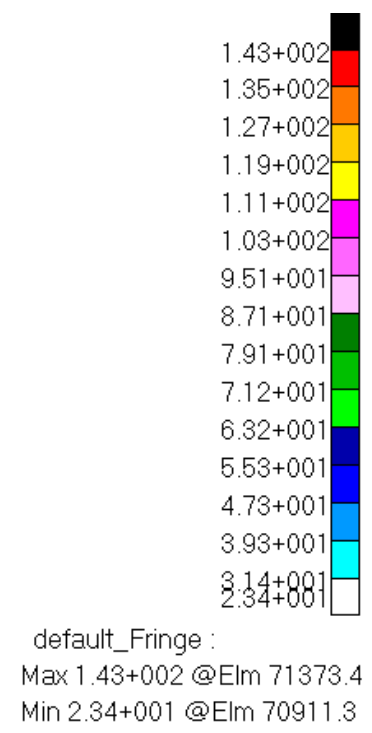

Figura 4.13 - Tensões de von Mises nos cones de rigidez $\left(\mathrm{N} / \mathrm{mm}^{2}\right)$ - superfície Z2

Os valores máximos de tensão de von Mises são reunidos na Tabela 4.2. A máxima tensão calculada no impelidor foi de $203 \mathrm{~N} / \mathrm{mm}^{2}$, presente nos discos laterais na proximidade da sua união com os respectivos anéis de entrada.

Tabela 4.2 - Tensões estáticas calculadas pelo MEF

\begin{tabular}{lcc}
\hline \hline Componente & $\begin{array}{c}\text { Tensão de von Mises } \\
\text { Plano Z1 }\left(\mathrm{N} / \mathrm{mm}^{2}\right)\end{array}$ & $\begin{array}{c}\text { Tensão de von Mises } \\
\text { Plano Z2 }\left(\mathrm{N} / \mathrm{mm}^{2}\right)\end{array}$ \\
\hline Palhetas & 177 & 128 \\
Disco central & 89.5 & 89.5 \\
Discos laterais & 203 & 185 \\
Anéis dos discos laterais & 151 & 141 \\
Cones de rigidez & 81.6 & 143 \\
\hline \hline
\end{tabular}

Para a avaliação dos resultados é empregado um fator de serviço de 1.3, embora fatores maiores possam ser utilizados. A máxima tensão admissível calculada a partir do limite de escoamento do material na temperatura de projeto é de $488 \mathrm{~N} / \mathrm{mm}^{2}$, conforme indica a Tabela 4.1. Todas as tensões obtidas são consideravelmente inferiores a este valor, garantindo a integridade estrutural do impelidor no que diz respeito às tensões estáticas.

Estes resultados revelam a possibilidade de otimizar o projeto do impelidor a partir da diminuição da espessura de seus componentes, proporcionando benefícios 
não somente de ordem econômica, mas também aqueles relacionados ao comportamento dinâmico do rotor. Em alguns casos, a diminuição da massa do impelidor pode ser um método interessante para elevar a primeira rotação crítica do rotor e para se garantir uma margem adequada entre a menor frequência natural e a rotação de operação. Entretanto, vale ressaltar que as eventuais modificações realizadas no impelidor na análise de tensões estáticas devem ser verificadas quanto ao comportamento dinâmico do impelidor, assunto que será explorado nas próximas seções. Também é interessante notar que as regiões das soldas das palhetas com o disco central e os laterais também constituem pontos de alta tensão, como é possível observar nas Figuras 4.4 e 4.5, para as soldas nas palhetas, e na Figura 4.9, para as soldas no disco lateral. Atenção especial deve ser dada a estes pontos, cujos níveis de tensão devem ser considerados na análise da vida em fadiga do ventilador centrífugo, frequentemente submetido a ciclos de liga e desliga.

\subsection{ANÁLISE DE RESPOSTA EM FREQUÊNCIA DO ROTOR}

O cálculo da resposta ao desbalanceamento estático do ventilador centrífugo em análise é realizado conforme a metodologia discutida na seção 3.2.1. Para tanto, utilizam-se as ferramentas de cálculo desenvolvidas por Zachariadis (2000).

\subsubsection{Modelo para análise dinâmica do rotor}

O modelo para o cálculo da resposta ao desbalanceamento do rotor assume que este é constituído por um eixo flexível e por um impelidor rígido e indeformável. A Figura 4.14 apresenta as principais dimensões do eixo do ventilador centrífugo analisado, com a indicação dos nós do modelo de elementos finitos considerados nas posições correspondentes aos mancais hidrodinâmicos e ao impelidor. Uma vez que metade do acoplamento utilizado no acionamento do ventilador encontra-se fixo ao eixo, este também é incluído nas análises. 


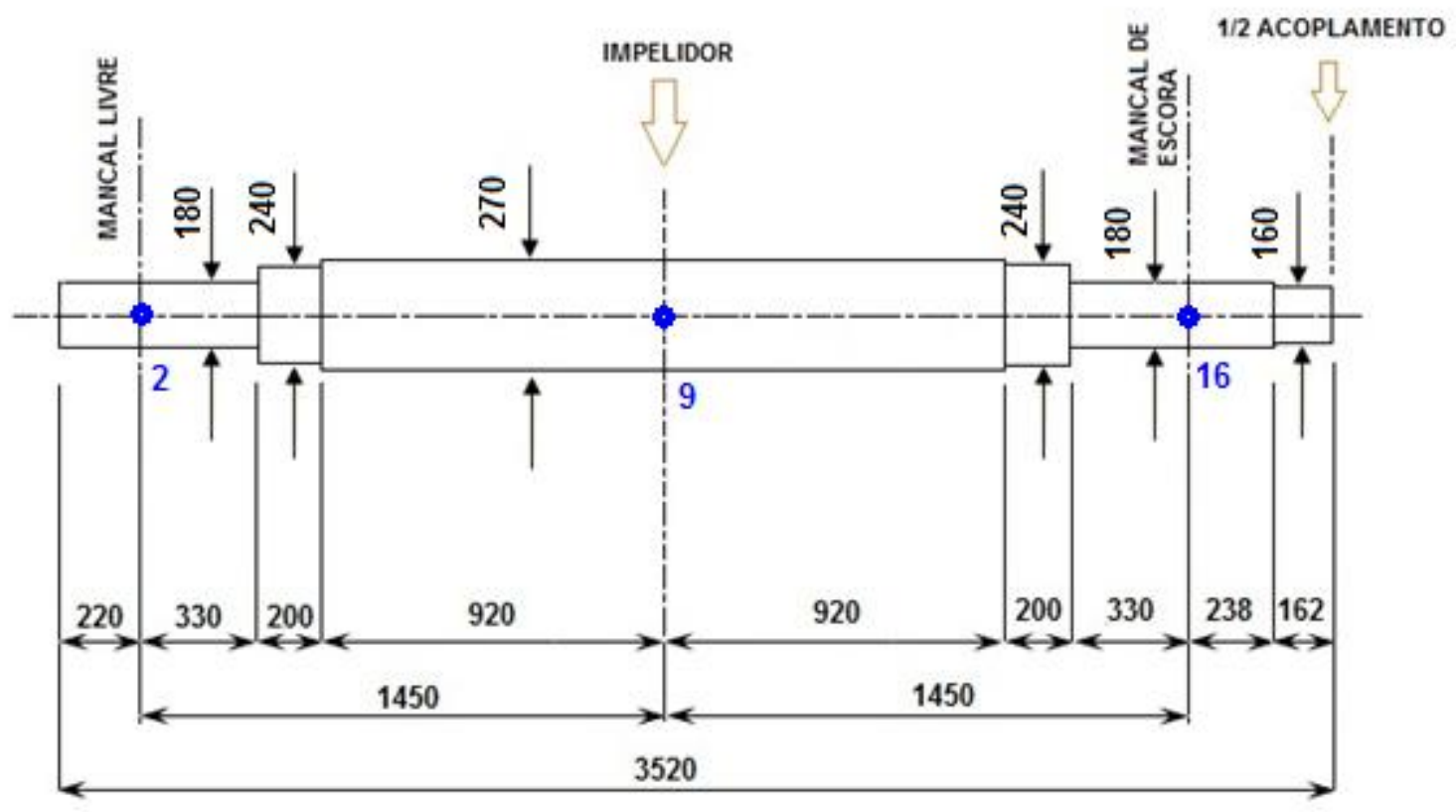

Figura 4.14 - Rotor analisado: dimensões e numeração dos nós do modelo de elementos finitos

As coordenadas dos nós, começando pelo nó 1 (o primeiro da esquerda), são dadas na Tabela 4.3.

Tabela 4.3 - Coordenadas dos nós do modelo de elementos finitos do rotor

\begin{tabular}{ccccccc}
\hline \multicolumn{7}{c}{ Coordenadas nodais } \\
\hline Nó & 1 & 2 & 3 & 4 & 5 & 6 \\
$\mathrm{X}(\mathrm{m})$ & 0.000 & 0.220 & 0.385 & 0.550 & 0.750 & 0.980 \\
\hline Nó & 7 & 8 & 9 & 10 & 11 & 12 \\
$\mathrm{X}(\mathrm{m})$ & 1.210 & 1.440 & 1.670 & 1.900 & 2.130 & 2.360 \\
\hline $\mathrm{Nó}$ & 13 & 14 & 15 & 16 & 17 & 18 \\
$\mathrm{X}(\mathrm{m})$ & 2.590 & 2.790 & 2.955 & 3.120 & 3.358 & 3.520 \\
\hline \hline
\end{tabular}

O material do eixo é um aço carbono com densidade $\rho=7800 \mathrm{~kg} / \mathrm{m}^{3}$. Para o valor do módulo de elasticidade adota-se $E=1.61 \times 10^{11} \mathrm{~N} / \mathrm{m}^{2}$ para os nós correspondentes à região quente do eixo (situada dentro da carcaça), e $\mathrm{E}=$ $2.10 \times 10^{11} \mathrm{~N} / \mathrm{m}^{2}$, para os nós correspondentes à região fria do eixo (situada fora da carcaça). Os diâmetros dos elementos são apresentados na Tabela 4.4. 
Tabela 4.4 - Diâmetro dos elementos

\begin{tabular}{cc}
\hline Diâmetro $(\mathrm{m})$ & Elementos \\
\hline 0.160 & 17 \\
0.180 & $1,2,3,14,15,16$ \\
0.240 & 4 e 13 \\
0.270 & 5 a 12 \\
\hline \hline
\end{tabular}

Foi admitida a presença de massas e inércias concentradas nas posições dos nós 9 e 18, que correspondem, respectivamente, ao impelidor e ao acoplamento. A massa total do impelidor, $M_{l}=4576 \mathrm{~kg}$, foi obtida do modelo de elementos finitos construído para a análise de tensões estáticas e pela adição da massa do cubo, calculada a partir das dimensões e propriedades indicadas na Tabela 4.1. De forma análoga, determinou-se o momento polar de inércia do impelidor, $J_{\mathrm{PI}}=5442 \mathrm{~kg} \cdot \mathrm{m}^{2}$, bem como seu momento diametral de inércia, $J_{D I}=2850 \mathrm{~kg} \cdot \mathrm{m}^{2}$. Para o acoplamento, foi admitida uma massa de $60 \mathrm{~kg}$ e sua inércia polar não foi considerada por representar um valor muito pequeno frente à inércia total do rotor. A massa total do rotor, calculada a partir da modelo de elementos finitos, é $M_{R}=5846 \mathrm{~kg}$.

As dimensões dos mancais hidrodinâmicos seguem a norma DIN 31690. Os coeficientes de rigidez e amortecimento de cada mancal, livre e de escora, são apresentados na Tabela 4.5. Trata-se dos coeficientes reais do ventilador estudado, calculados a partir da rotação do ventilador e das cargas estáticas radiais suportadas por cada mancal. Não foram encontrados coeficientes para outras rotações, de modo que a análise de resposta em frequência ao desbalanceamento do rotor admite que estes são constantes. Análises mais detalhadas podem ser realizadas, incluindo no modelo de elementos finitos a variação destes coeficientes com a rotação do ventilador centrífugo.

O cálculo de resposta considerou uma classe de balanceamento G 2.5 frequentemente empregada na fabricação da maioria dos ventiladores centrífugos de grande porte - segundo a norma ISO 1940-1. Assim, foram especificados desbalanceamentos de 79460 g.mm em cada um dos planos correspondentes às duas faces do cubo do ventilador, isto é, nas posições dos nós 8 e 10 do modelo de elementos finitos. 
Tabela 4.5 - Coeficientes de rigidez e amortecimento dos mancais hidrodinâmicos

\begin{tabular}{cccc}
\hline \hline Propriedades & Coeficientes & Mancal Livre & $\begin{array}{c}\text { Mancal de } \\
\text { Escora }\end{array}$ \\
\hline Rigidez & $\mathrm{K}_{\mathrm{zz}}$ & 3.963 & 4.121 \\
$\left(\times 10^{8} \mathrm{~N} / \mathrm{m}\right)$ & $\mathrm{K}_{\mathrm{zy}}$ & -0.6158 & -0.5935 \\
& $\mathrm{~K}_{\mathrm{yz}}$ & 9.152 & 9.567 \\
& $\mathrm{~K}_{\mathrm{yy}}$ & 9.865 & 10.501 \\
\hline & $\mathrm{C}_{\mathrm{zz}}$ & 4.364 & 4.491 \\
Amortecimento & $\mathrm{C}_{\mathrm{zy}}$ & 5.414 & 5.673 \\
$\left(\mathrm{x} 10^{6} \mathrm{~N} . \mathrm{s} / \mathrm{m}\right)$ & $\mathrm{C}_{\mathrm{yz}}$ & 5.455 & 5.720 \\
& $\mathrm{C}_{\mathrm{yy}}$ & 19.847 & 20.796 \\
\hline \hline
\end{tabular}

\subsubsection{Resultados}

A curva de deflexão estática do rotor é apresentada na Figura 4.15. A máxima deflexão é de 0.52 mm e ocorre na posição do impelidor (nó 9).

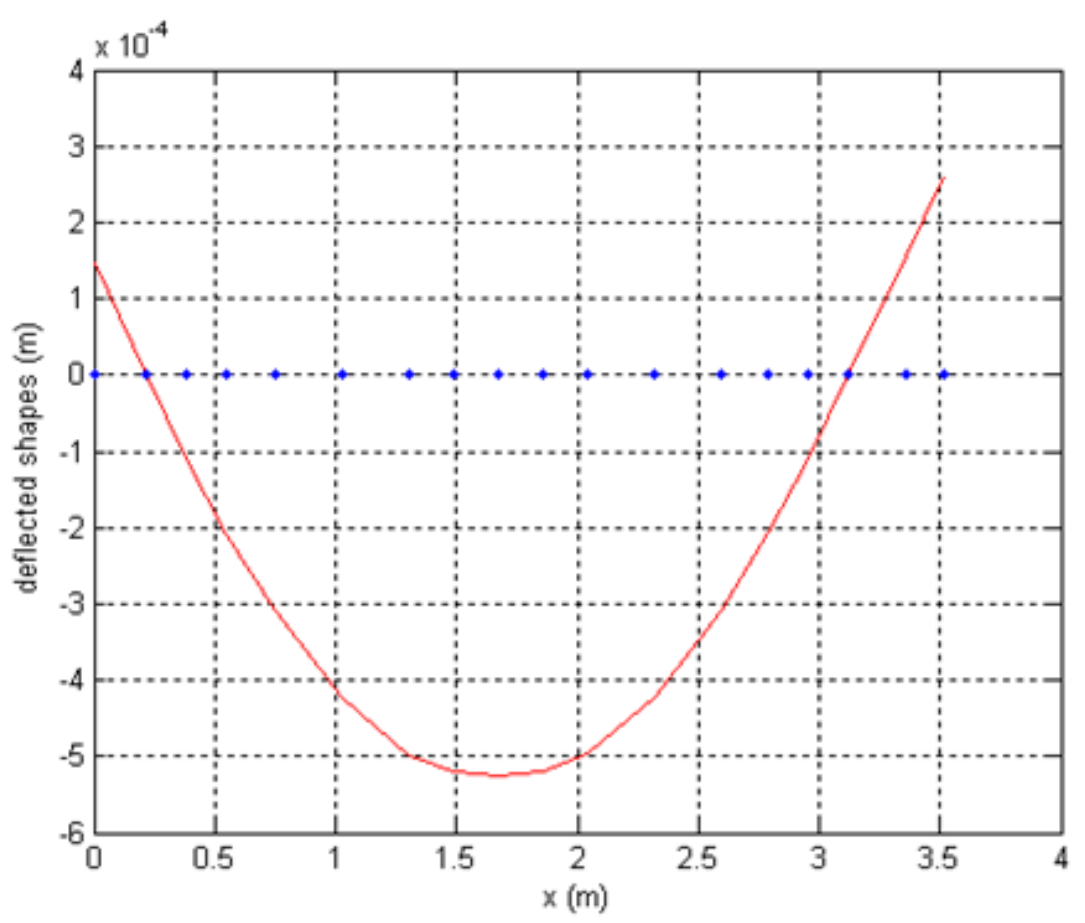

Figura 4.15 - Curva de deflexão estática do rotor analisado 
Inicialmente, uma análise de vibrações livres do rotor foi realizada com o objetivo de calcular os autovalores $\lambda_{n}$ e os correspondentes autovetores $\phi_{n}$, onde $\lambda_{n}=\rho_{n}+j f_{n}$; sendo $\rho_{n}$ e $f_{n}$ os $n$-nésimos expoentes de amortecimento e frequências naturais amortecidas, respectivamente. As cinco primeiras frequências naturais do rotor podem ser verificadas no Diagrama de Campbell apresentado na Figura 4.16. As Figuras 4.17 a 4.21 mostram os modos de vibrar do rotor associados a estas frequências.

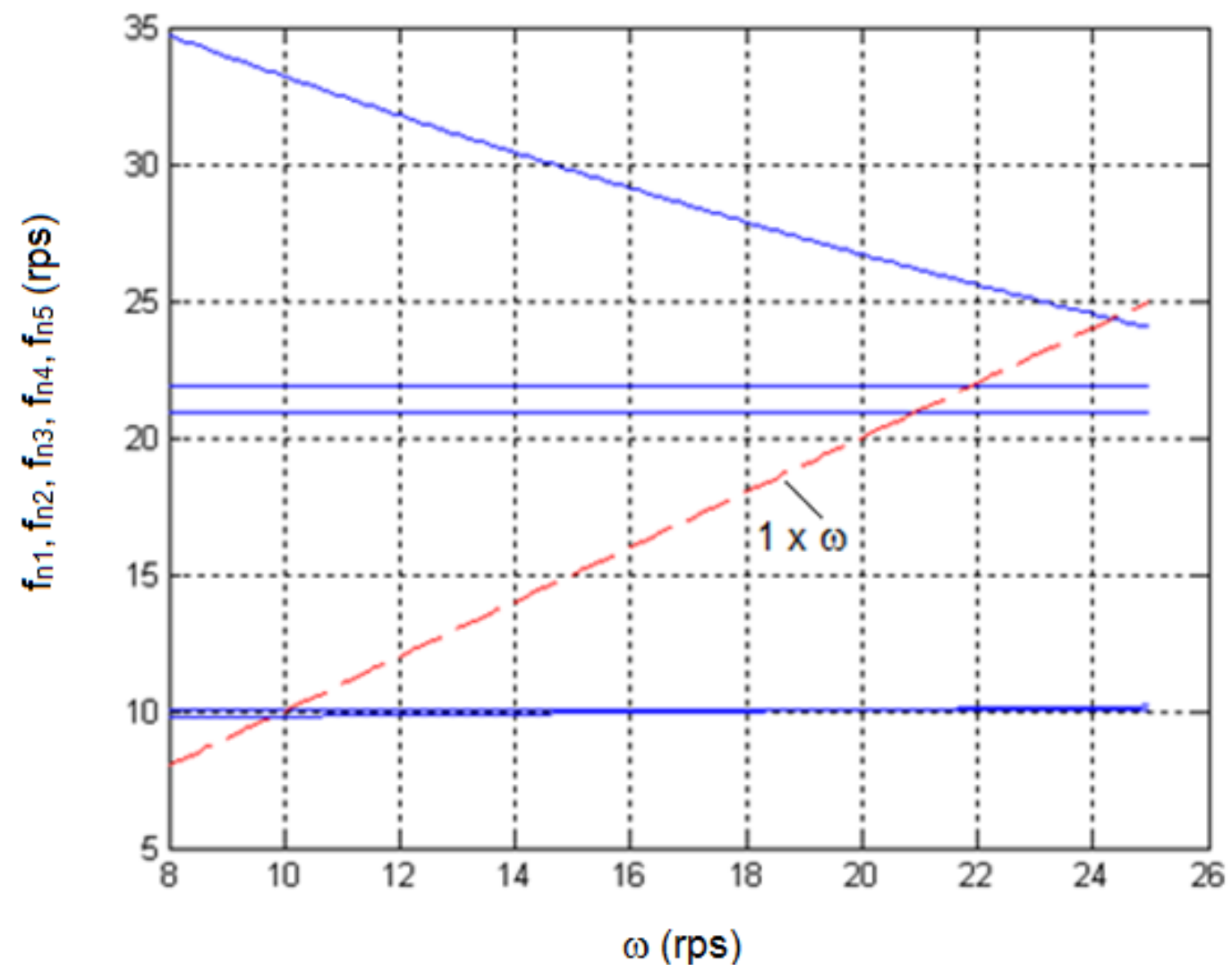

Figura 4.16 - Diagrama de Campbell

As Figuras 4.17 e 4.18 indicam que os primeiros modos de precessão direta são de corpo rígido - cônico na frequência de $9.91 \mathrm{~Hz}$ e cilíndrico na frequência de $10.04 \mathrm{~Hz}$. As Figuras 4.19 e 4.20 mostram os modos vertical e horizontal correspondentes às primeiras rotações críticas do rotor nas frequências de $20.92 \mathrm{~Hz}$ e $21.86 \mathrm{~Hz}$, respectivamente, potencialmente excitados pelo desbalanceamento estático. O modo de vibração em $29.96 \mathrm{~Hz}$, indicado na Figura 4.21, pode ser excitado pelo desbalanceamento dinâmico. 


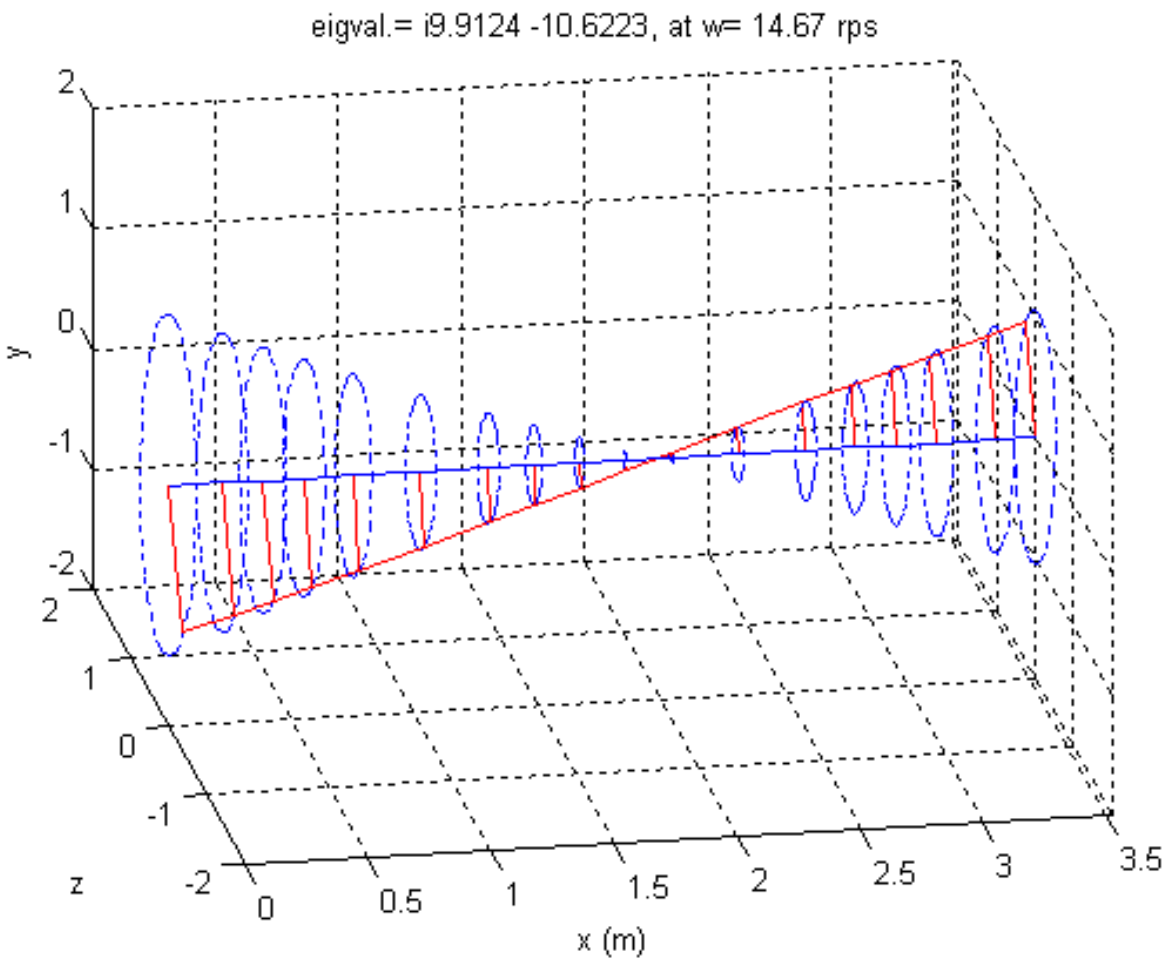

Figura 4.17 - Modo de vibração, $\mathrm{f}_{\mathrm{n}}=9.91 \mathrm{~Hz}$

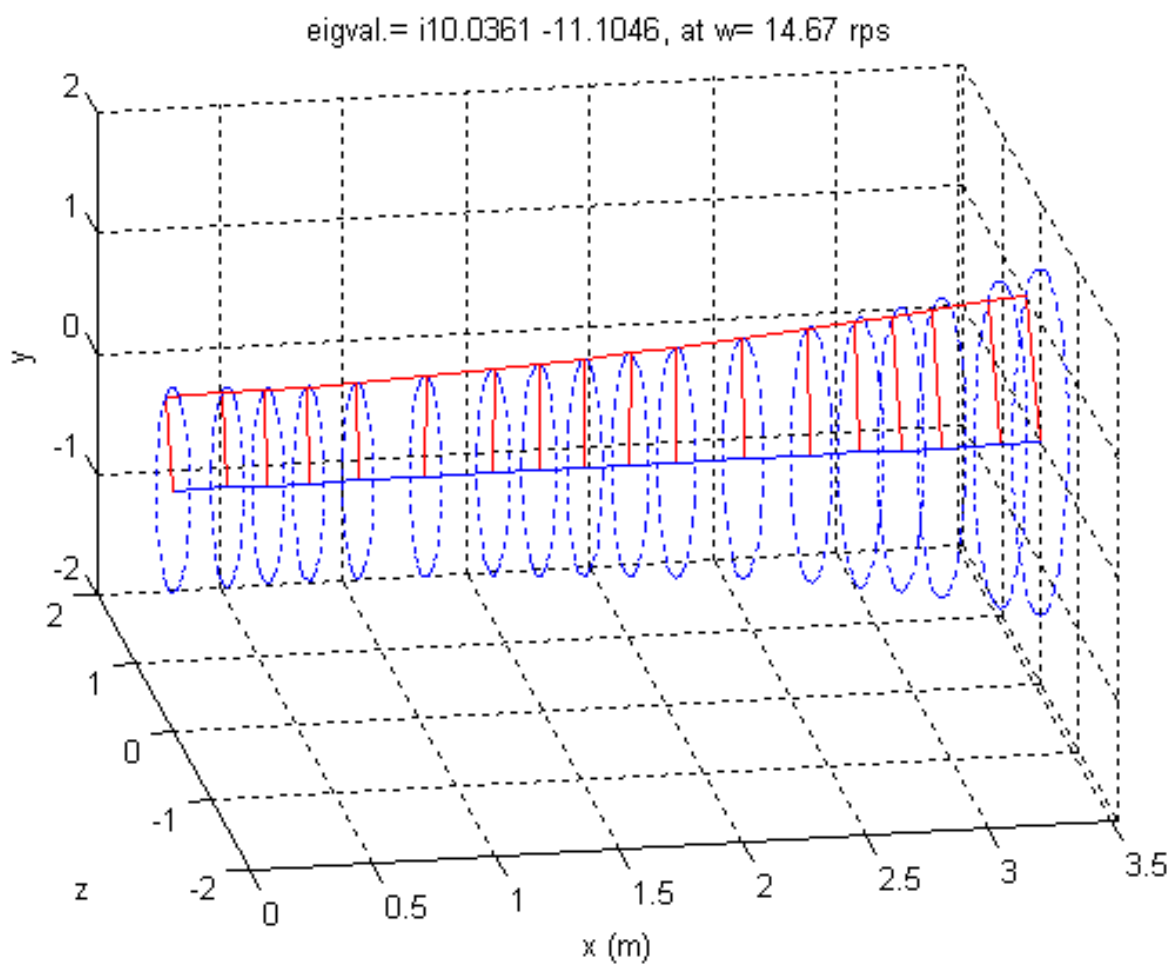

Figura 4.18 - Modo de vibração, $f_{n}=10.04 \mathrm{~Hz}$ 


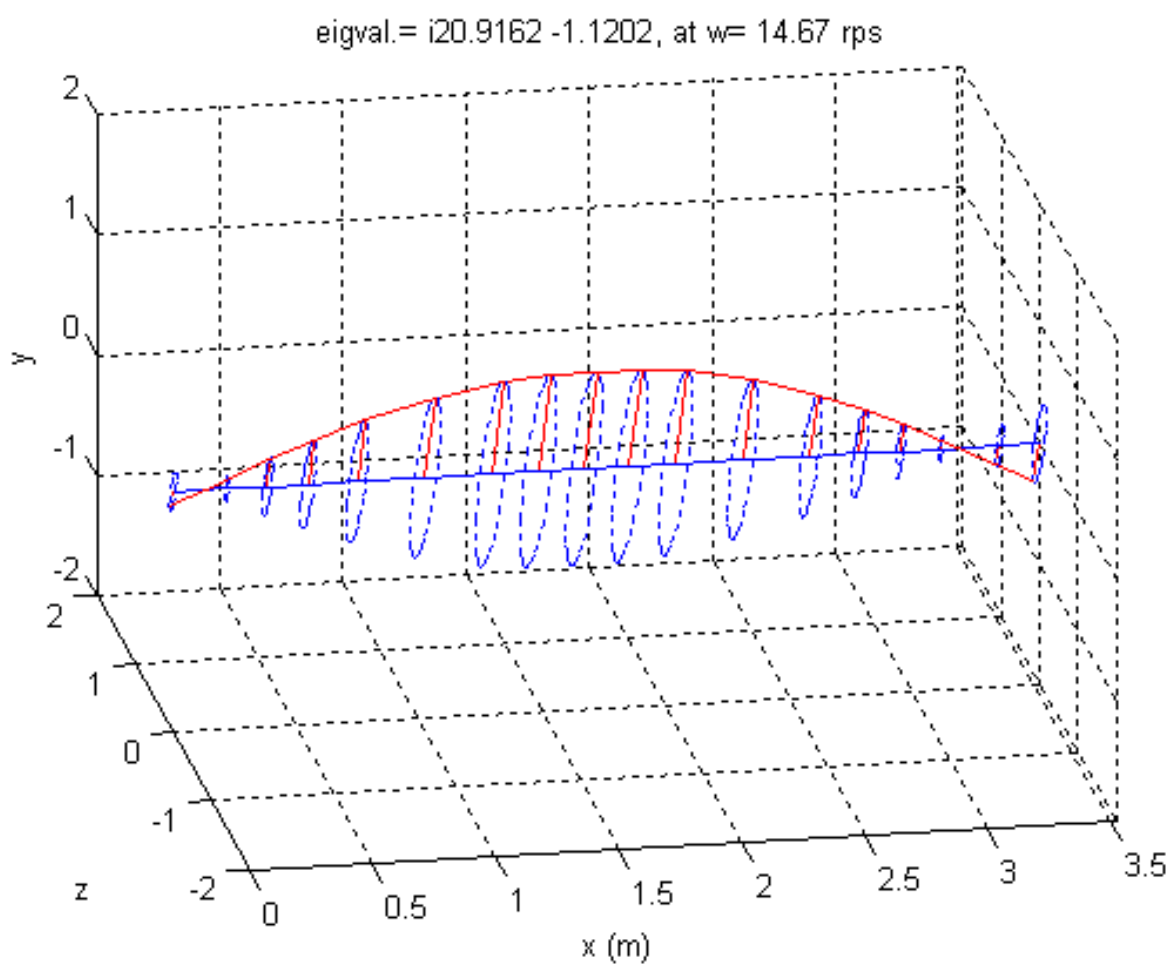

Figura 4.19 - Modo de vibração, $f_{n}=20.92 \mathrm{~Hz}$

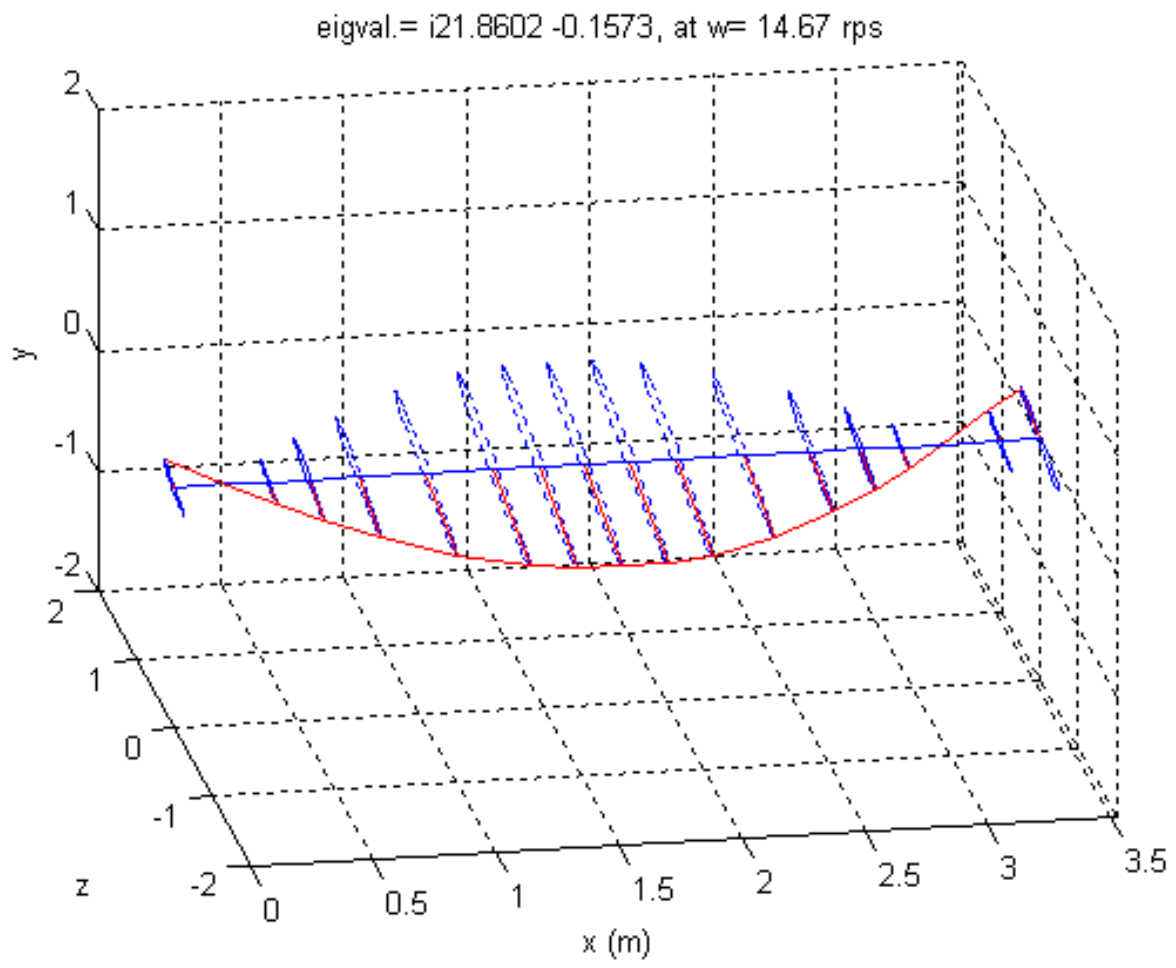

Figura 4.20 - Modo de vibração, $f_{n}=21.86 \mathrm{~Hz}$ 


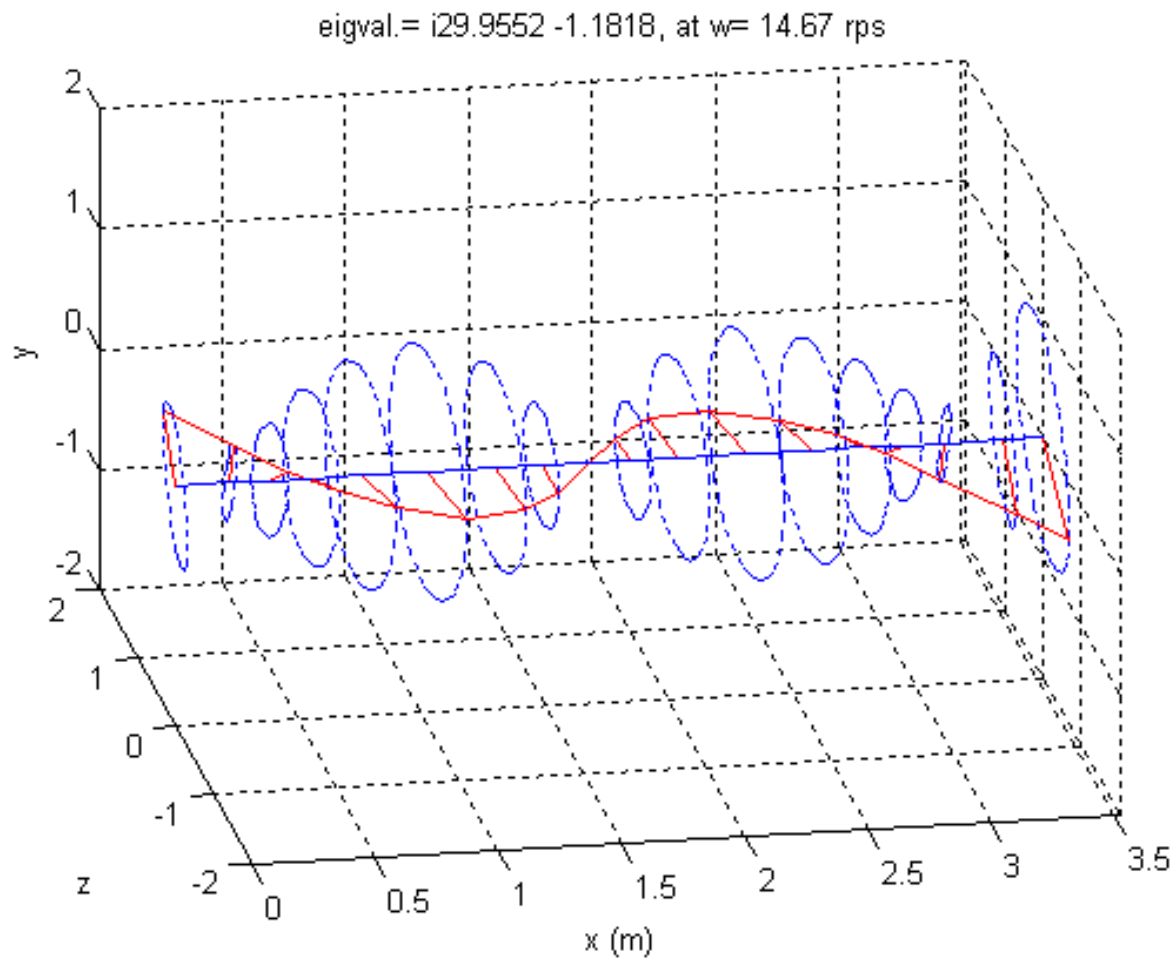

Figura 4.21 - Modo de vibração, $f_{n}=29.96 \mathrm{~Hz}$

Uma vez determinadas os principais modos de vibração e as correspondentes frequências naturais, procede-se com a análise de resposta ao desbalanceamento estático do rotor estudado. As curvas de resposta na posição correspondente ao mancal livre (nó 2) são apresentadas na Figura 4.22. Uma ampliação deste gráfico nas proximidades da frequência de $21.8 \mathrm{~Hz}$, em que as translações e rotações atingem valores máximos no mancal livre, é mostrada na Figura 4.23. As amplitudes de translação e de rotação nos nós 8,9 e 10, correspondentes à face do cubo do lado do mancal livre, ao impelidor, e à face do cubo do lado do mancal de escora, respectivamente, são apresentadas nas Figuras 4.24 a 4.26. De forma análoga, a Figura 4.27 mostra a resposta no mancal de escora (nó 16), enquanto que o detalhe ampliado das translações segundo os eixos $Z$ e $Y$ é mostrado na Figura 4.28. A curva de resposta para o nó 18 , correspondente à posição do acoplamento, é apresentada na Figura 4.29. 


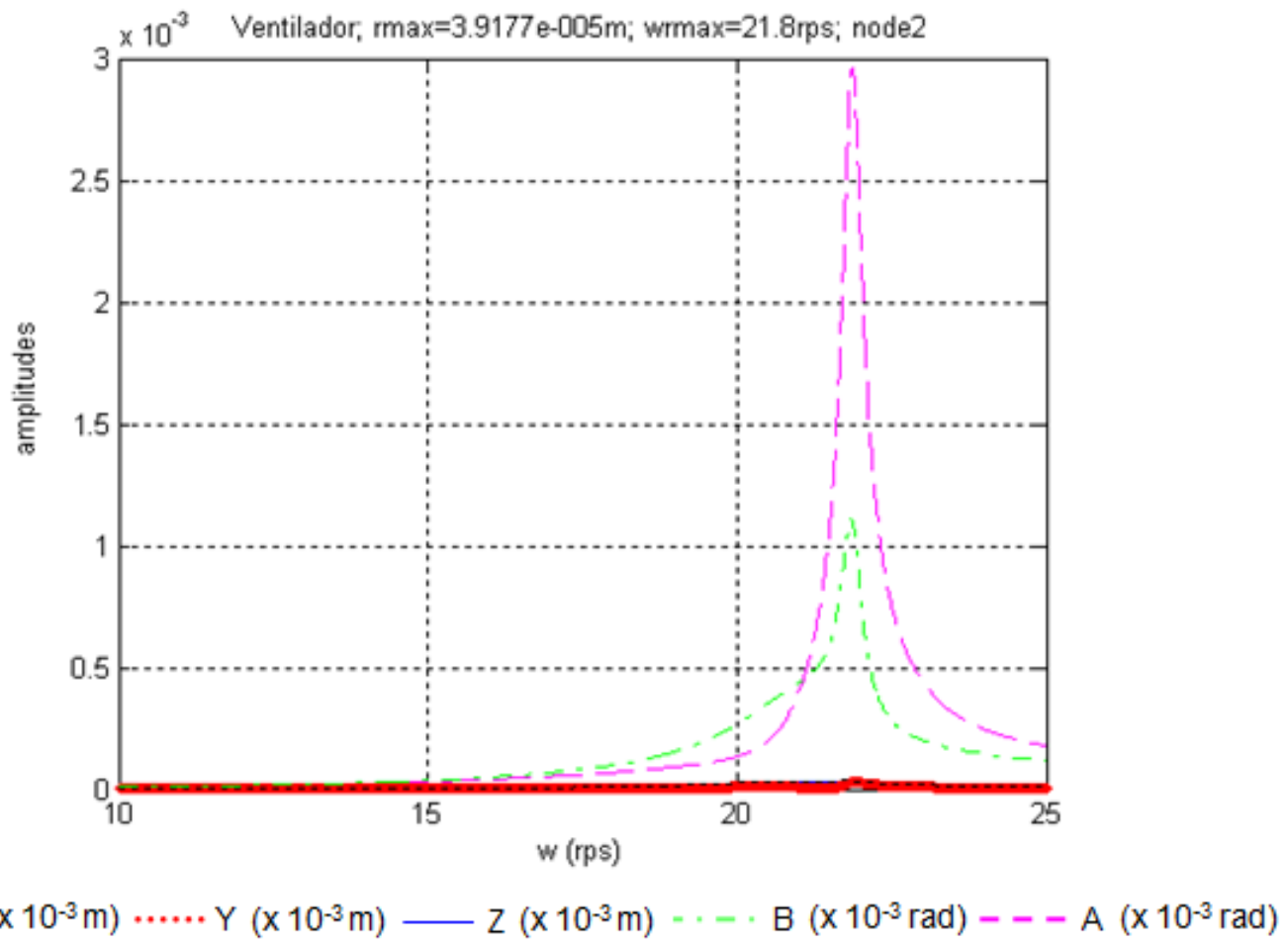

Figura 4.22 - Curva de resposta do rotor na posição correspondente ao mancal livre (nó 2)

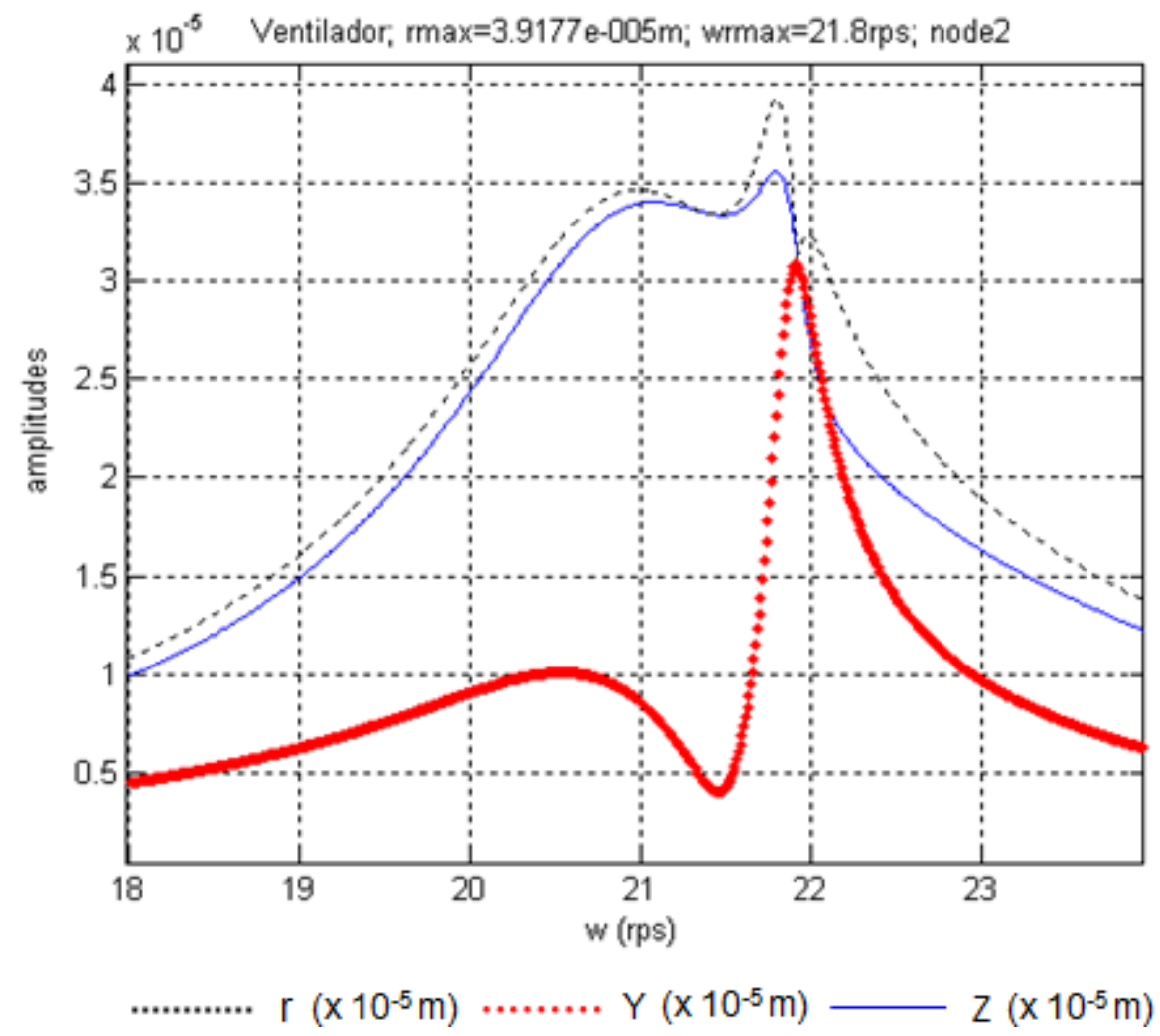

Figura 4.23 - Detalhe das curvas correspondentes às translações no mancal livre (nó 2) nas proximidades da primeira rotação crítica do rotor 


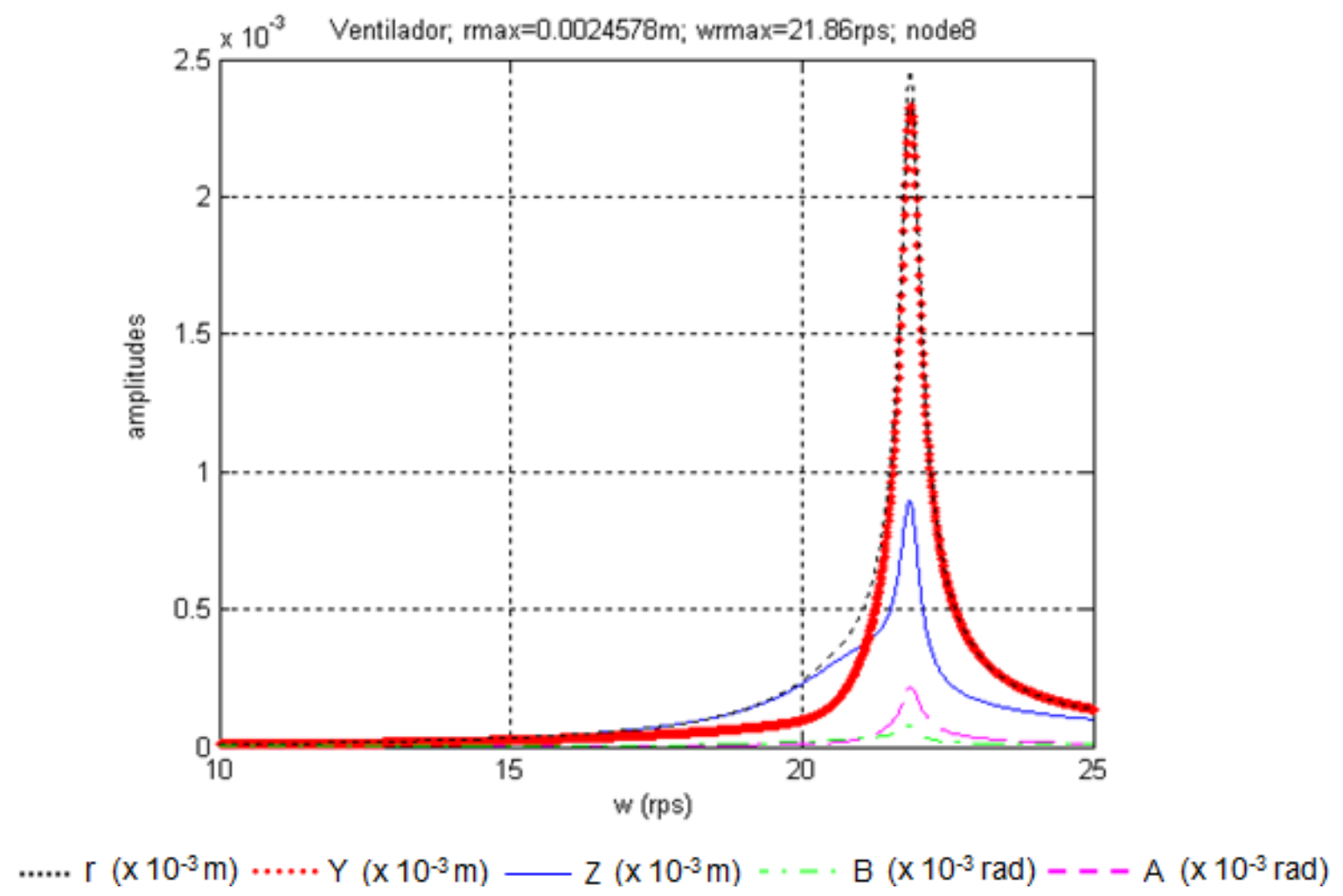

Figura 4.24 - Curva de resposta do rotor na posição correspondente ao plano do cubo mais próximo do mancal livre (nó 8)

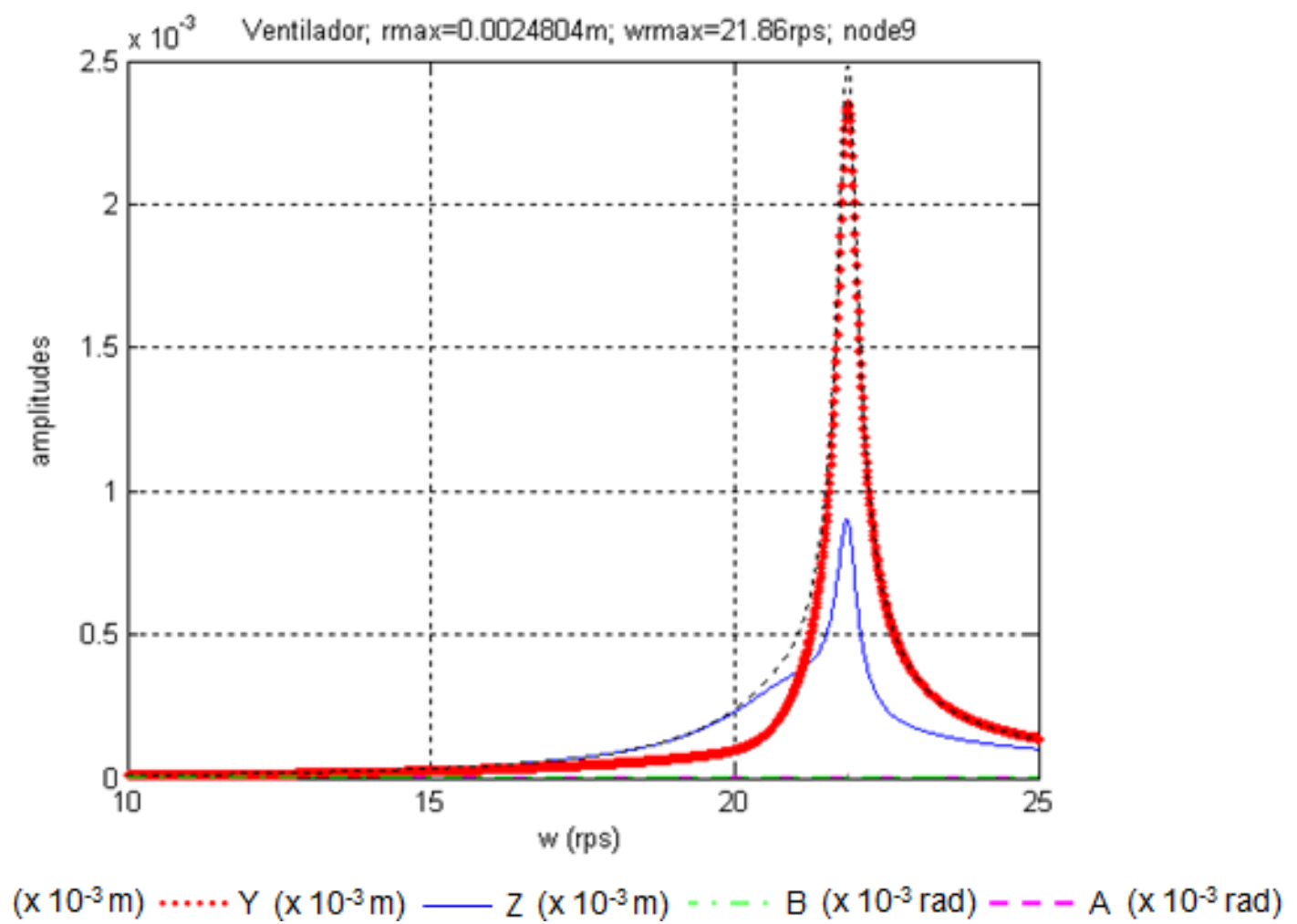

Figura 4.25 - Curva de resposta do rotor na posição correspondente ao impelidor (nó 9) 


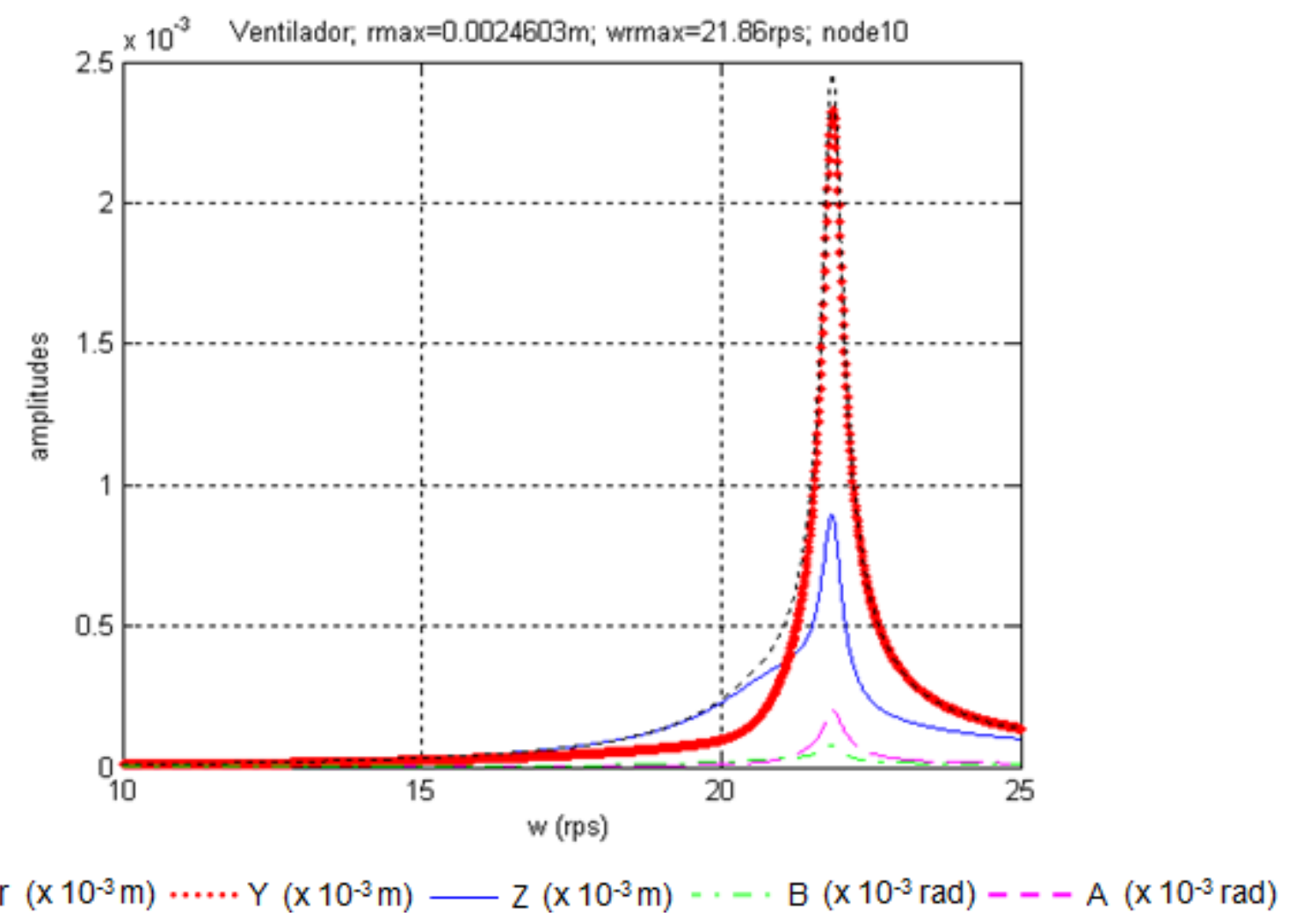

Figura 4.26 - Curva de resposta do rotor na posição correspondente ao plano do cubo mais próximo do mancal de escora (nó 10)

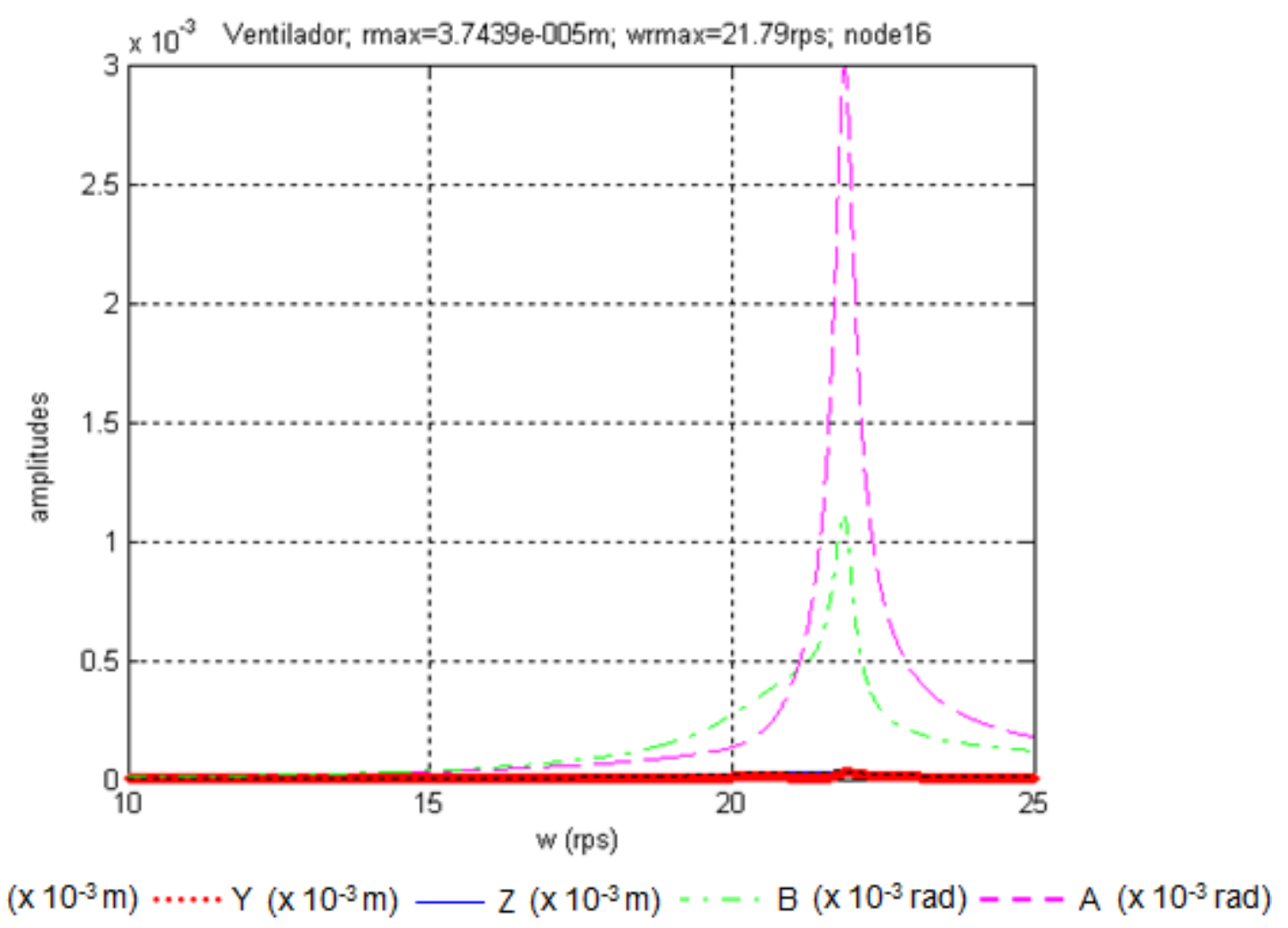

Figura 4.27 - Curva de resposta do rotor na posição correspondente ao mancal de escora (nó 16) 


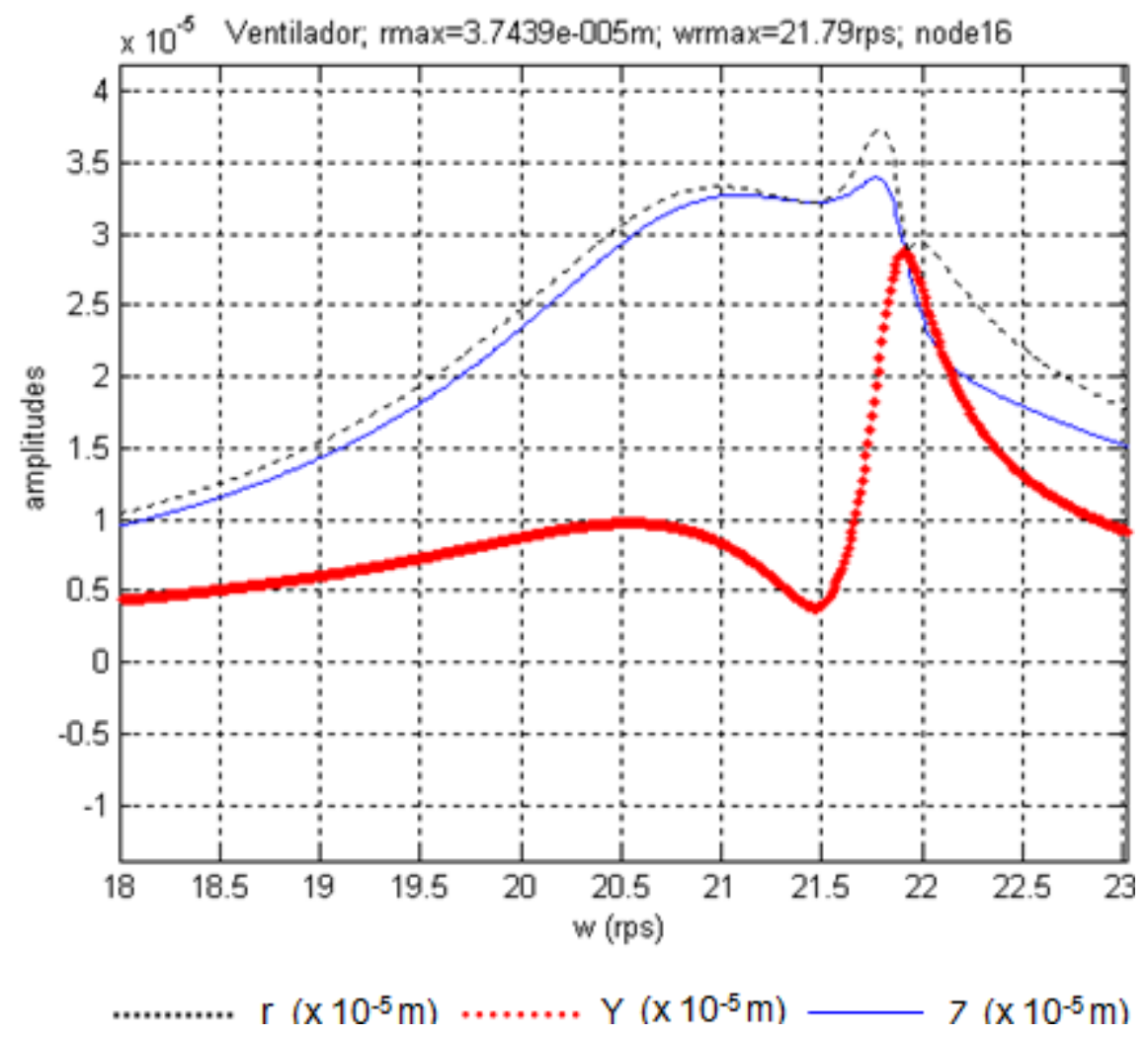

Figura 4.28 - Detalhe das curvas correspondentes às translações no mancal de escora (nó 16) nas proximidades da primeira rotação crítica do rotor.

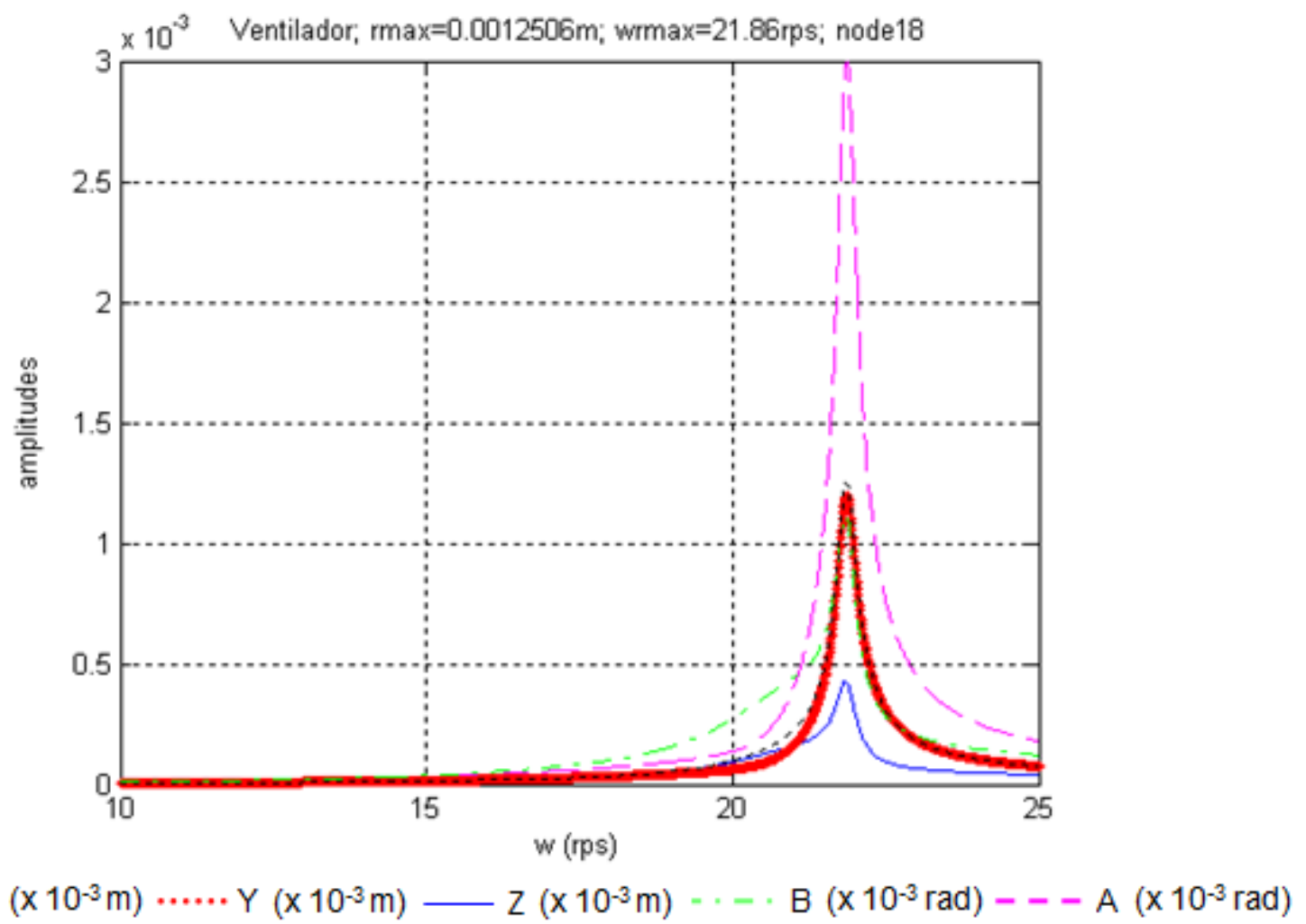

Figura 4.29 - Curva de resposta do rotor na posição correspondente ao acoplamento (nó 18) 
As curvas de resposta evidenciam que a primeira rotação crítica do rotor corresponde à frequência de $21.86 \mathrm{~Hz}$. A partir da comparação das Figuras 4.22 e 4.25, é possível observar que os deslocamentos angulares são máximos na região dos mancais e praticamente desprezíveis na posição do impelidor. Esta análise mostra, ainda, que as translações são máximas na posição do impelidor e que seus valores mínimos ocorrem na posição dos mancais. É interessante notar que as amplitudes de translação no impelidor na velocidade de operação do ventilador 14.67 Hz ou 880 rpm - são consideravelmente menores do que as observadas na passagem pela rotação crítica: aproximadamente $0.02854 \mathrm{~mm}$ na direção $\mathrm{Y}$ em $14.67 \mathrm{~Hz}$ frente a $2.3611 \mathrm{~mm}$ em $21.86 \mathrm{~Hz}$ nesta mesma direção, isto é, aproximadamente 83 vezes menor. Esta grande amplificação reforça uma característica típica do projeto de ventiladores centrífugos, em que se observa uma busca frequente por uma grande margem entre a primeira rotação critica e a rotação de operação do equipamento: para o caso estudado, a razão entre a primeira rotação crítica e a velocidade de operação é igual a 1.49. Evidencia-se, assim, que os efeitos da passagem pelas rotações críticas do rotor são pouco estudados ou praticamente esquecidos no projeto mecânico dos rotores de ventiladores centrífugos, bem como dos mancais hidrodinâmicos que os suportam.

Deste modo, os resultados da resposta ao desbalanceamento na região do impelidor, representados na Figura 4.25, são utilizados como dados de entrada para a análise de resposta do impelidor, o que será discutido em detalhe na próxima seção.

\subsection{ANÁLISE DE VIBRAÇÕES LIVRES DO IMPELIDOR}

A análise dinâmica do ventilador centrífugo em estudo tem como objetivo final a determinação das tensões dinâmicas em seus componentes. Segundo a metodologia proposta neste trabalho, as tensões dinâmicas são calculadas a partir da resposta em frequência aos movimentos de base provenientes do desbalanceamento do rotor na rotação de operação. Ressalte-se, neste ponto, a importância da investigação prévia de uma possível condição de ressonância do impelidor na rotação de operação do ventilador. Esta investigação possibilita uma 
interpretação mais precisa dos resultados de tensão dinâmica do impelidor, uma vez que os níveis de tensão dinâmica são elevados tanto nas condições de ressonância do rotor, quanto nas condições de ressonância do impelidor, isoladamente. Procedese, assim, com a análise de vibrações livres impelidor centrífugo.

Para tanto, o modelo do impelidor utilizado para a análise de tensões estáticas é copiado doze vezes em torno do eixo de rotação, de modo a obter o modelo completo do impelidor para a análise de vibrações livres. O eixo do ventilador, cujas dimensões foram apresentadas na Figura 4.14, também é incluído no modelo através do emprego de elementos de viga com seis graus de liberdade em cada nó (também utilizados para a modelagem do cubo do ventilador). A conexão do disco central e dos cones de rigidez com o cubo do ventilador é realizada por meio de elementos rígidos (RBE2).

Nas posições dos mancais livre e de escora são considerados elementos de mola nas direções $\mathrm{Y}$ e $\mathrm{Z}$ com os respectivos valores de rigidez dos mancais hidrodinâmicos. A inclusão do eixo e da rigidez dos mancais no modelo possibilita que as possíveis interações entre os modos do impelidor e do eixo sejam consideradas, assim como a influência da diferença de rigidez dos suportes em alguns dos modos do impelidor. Por fim, os graus de liberdade correspondentes à rotação do ventilador em torno do eixo e às translações na direção axial são restringidos, a fim de se evitar a presença de modos de corpo rígido. A Figura 4.30 ilustra o modelo do rotor para a análise de vibrações livres. 


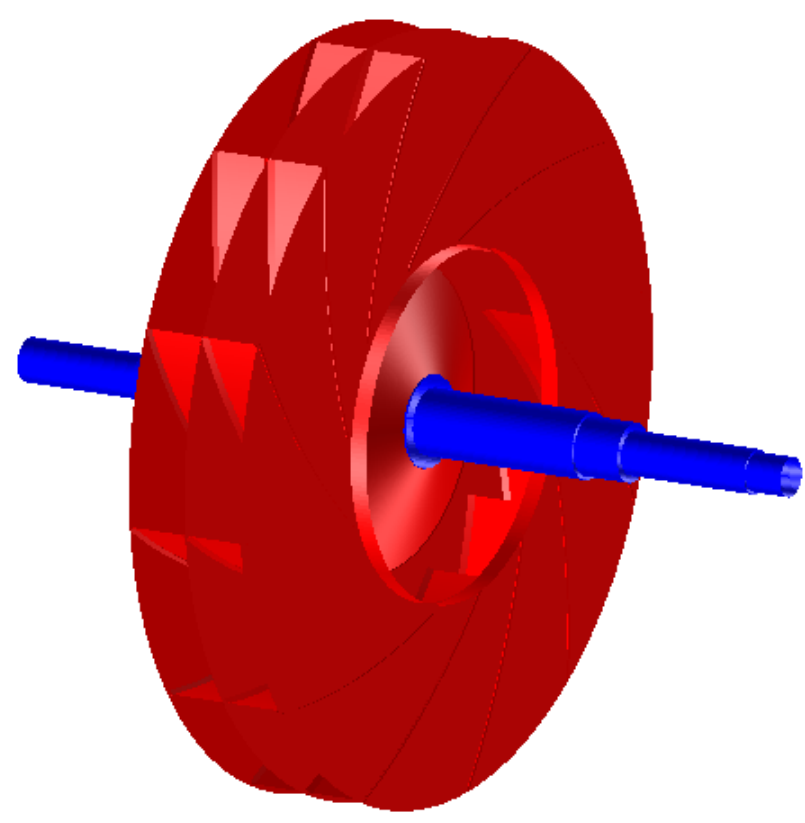

Figura 4.30 - Modelo do rotor para análise de vibrações livres

Foram investigados os modos de vibração do impelidor na faixa de $0 \mathrm{~Hz}$ à máxima frequência de passagem das palhetas, isto é, $176 \mathrm{~Hz}$. É importante ressaltar que o efeito do enrijecimento centrífugo, correspondente à velocidade de operação do ventilador $(14.667 \mathrm{~Hz})$, foi incorporado ao modelo nesta etapa.

Adicionalmente aos modos de vibração e às frequências naturais do impelidor, as simulações também fornecem informações a respeito das velocidades críticas laterais e torcionais do rotor. Estes modos de vibração não estão presentes na análise que será apresentada a seguir, uma vez que o estudo da vibração lateral do rotor já foi discutido em detalhe na seção anterior. Ressalte-se que os fenômenos de vibração torcional não são objeto de estudo do presente trabalho. A Tabela 4.6 mostra os principais modos de vibração do impelidor e as correspondentes frequências naturais obtidas. Os modos de vibração indicados na tabela podem ser visualizados nas Figuras 4.31 a 4.39 . 
Tabela 4.6 - Resultados da análise de vibrações livres

\begin{tabular}{cl}
\hline \hline Frequência $(\mathrm{Hz})$ & \multicolumn{1}{c}{ Descrição dos modos do impelidor } \\
\hline 26.41 & $1^{\circ}$ modo diametral, em fase com o eixo (vertical) \\
26.43 & $1^{\circ}$ modo diametral, em fase com o eixo (horizontal) \\
40.03 & $1^{\circ}$ modo circular nodal \\
82.04 & $\begin{array}{l}\text { Modo de duas linhas diametrais } \\
\text { Modo diametral + circular nodal, fora de fase com o eixo } \\
\text { (vertical) } \\
125.29\end{array}$ \\
125.55 & $\begin{array}{l}\text { Modo diametral + circular nodal, fora de fase com o eixo } \\
\text { (horizontal) } \\
135.29\end{array}$ \\
136.96 & $\begin{array}{l}\text { Modo de três linhas diametrais } \\
164.23\end{array}$ \\
\hline \hline
\end{tabular}

Fringe: static_centrifugal, A7: Mode $4:$ Freq. $=26.413$. Eigenvectors, Translational, Magnitude.

$$
\begin{gathered}
1.03+000 \\
9.59-001 \\
8.90-001 \\
8.22-001 \\
7.53-001 \\
6.85-001 \\
6.16-001 \\
5.48-001 \\
4.79-001 \\
4.11-001 \\
3.42-001 \\
2.74-001 \\
2.06-001 \\
1.37-001 \\
6.87-002 \\
1.96-004
\end{gathered}
$$

Figura 4.31 - Primeiro modo diametral (vertical, em fase com o eixo) 
Fringe: static_centrifugal, A7:Mode 5 : Freq. $=26.432$, Eigenvectors, Translational, $Z$ Component,
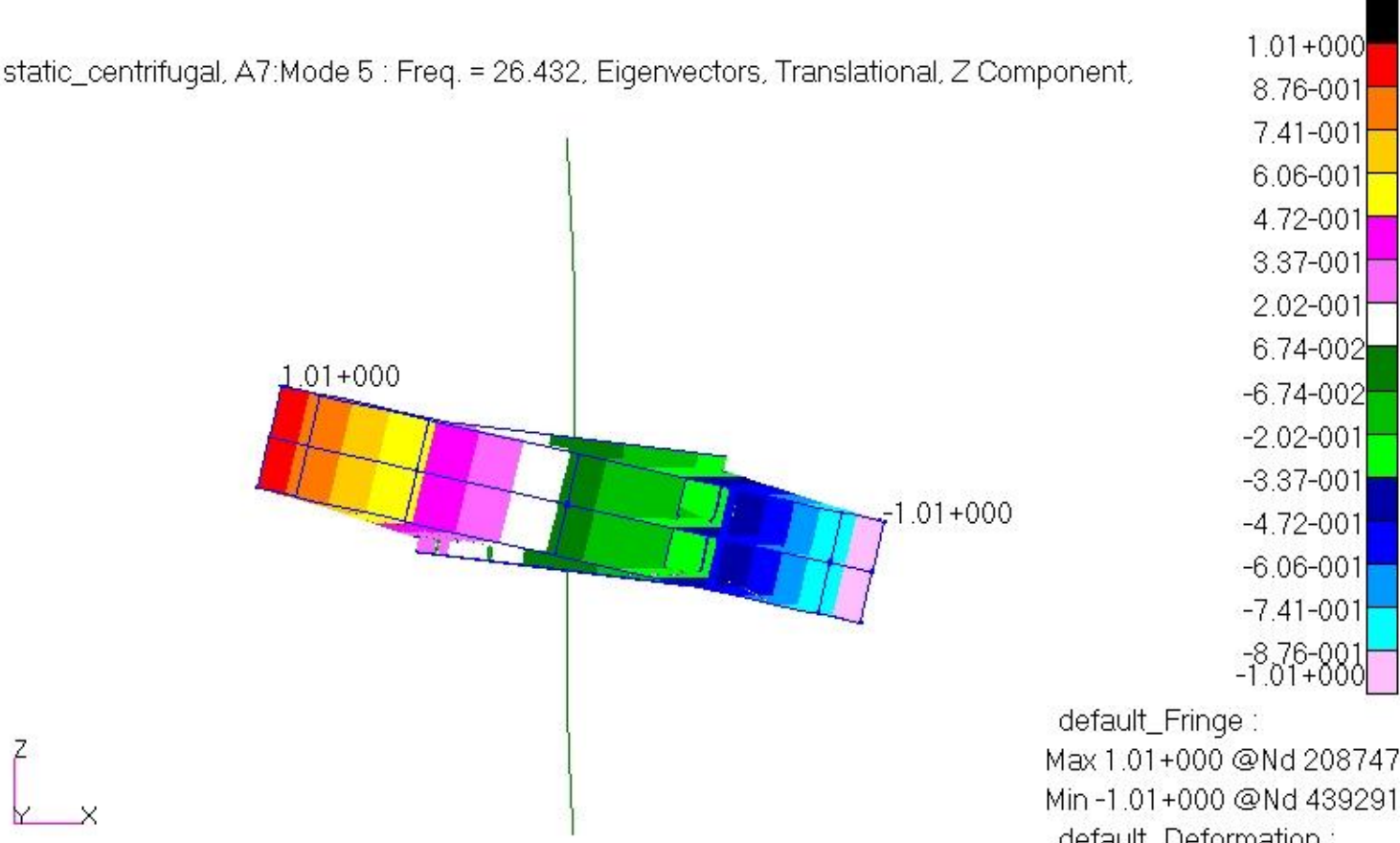

default_Fringe :

Max $1.01+000 @ N d 208747$ Min $-1.01+000 @ N d 439291$

default_Deformation :

Max1.03+000@Nd 223669

Figura 4.32 - Primeiro modo diametral (horizontal, em fase com o eixo)

Fringe: static_centrifugal, A7:Mode $6:$ Freq. $=40.031$. Eigenvectors, Translational, Magnitude ,

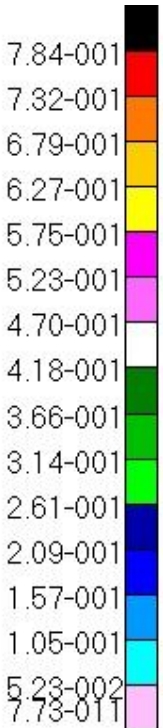

default_Fringe

Max 7.84-001@Nd 146820 Min 7.73-011@Nd 503639

default_Deformation : Max7.84-001@Nd 146820

Figura 4.33 - Primeiro modo circular nodal 
Fringe: static_centrifugal, A7:Mode $7:$ Freq. $=82.035$, Eigenvectors, Translational, $Z$ Component

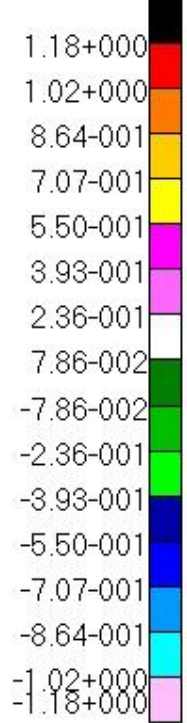

default_Fringe :

Max 1.18+000@Nd 208724 Min $-1.18+000 @ N d 93452$

default_Deformation :

Max1.19+000@Nd 93452

Figura 4.34 - Modo de duas linhas diametrais

Fringe: static_centrifugal, A7:Mode $9:$ Freq. $=125.29$. Eigenvectors, Translational, $Z$ Component,

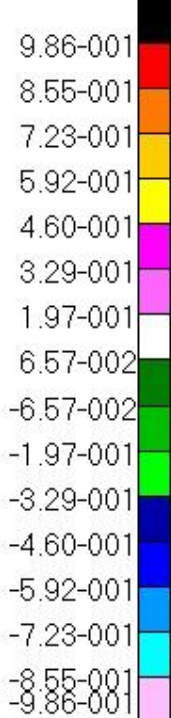

default_Fringe

Max9.86-001@Nd 234757 Min-9.86-001@Nd 465301 default_Deformation : Max 1.04+000@Nd 465372

Figura 4.35 - Modo diametral associado ao modo circular (vertical, fora de fase em relação ao eixo) 
Fringe: static_centrifugal, A7: Mode $10:$ Freq. $=125.55$, Eigenvectors, Translational, $Z$ Component,

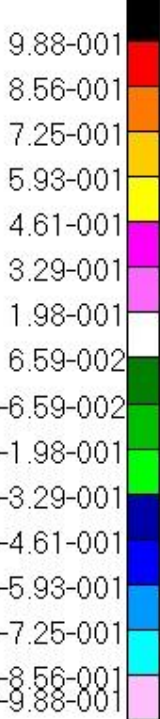

default_Fringe :

Max9.88-001@Nd 119485 Min -9.88-001@Nd 350029

default_Deformation

Max1.04+000@Nd 119556

Figura 4.36 - Modo diametral associado ao modo circular (horizontal, fora de fase em relação ao eixo)

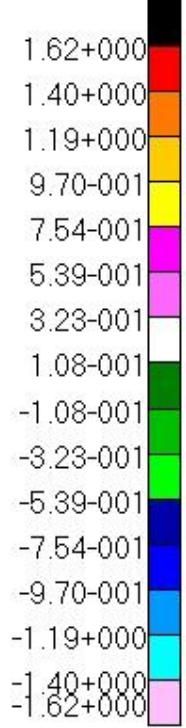

default_Fringe :

Max $1.62+000 @ N d 477693$ Min $-1.62+000 @ N d 247149$ default_Deformation : Max 1.62+000@Nd 247149

Figura 4.37 - Modo de três linhas diametrais 
Fringe: static_centrifugal, A7:Mode 13: Freq. $=136.96$. Eigenvectors, Translational, Magnitude,
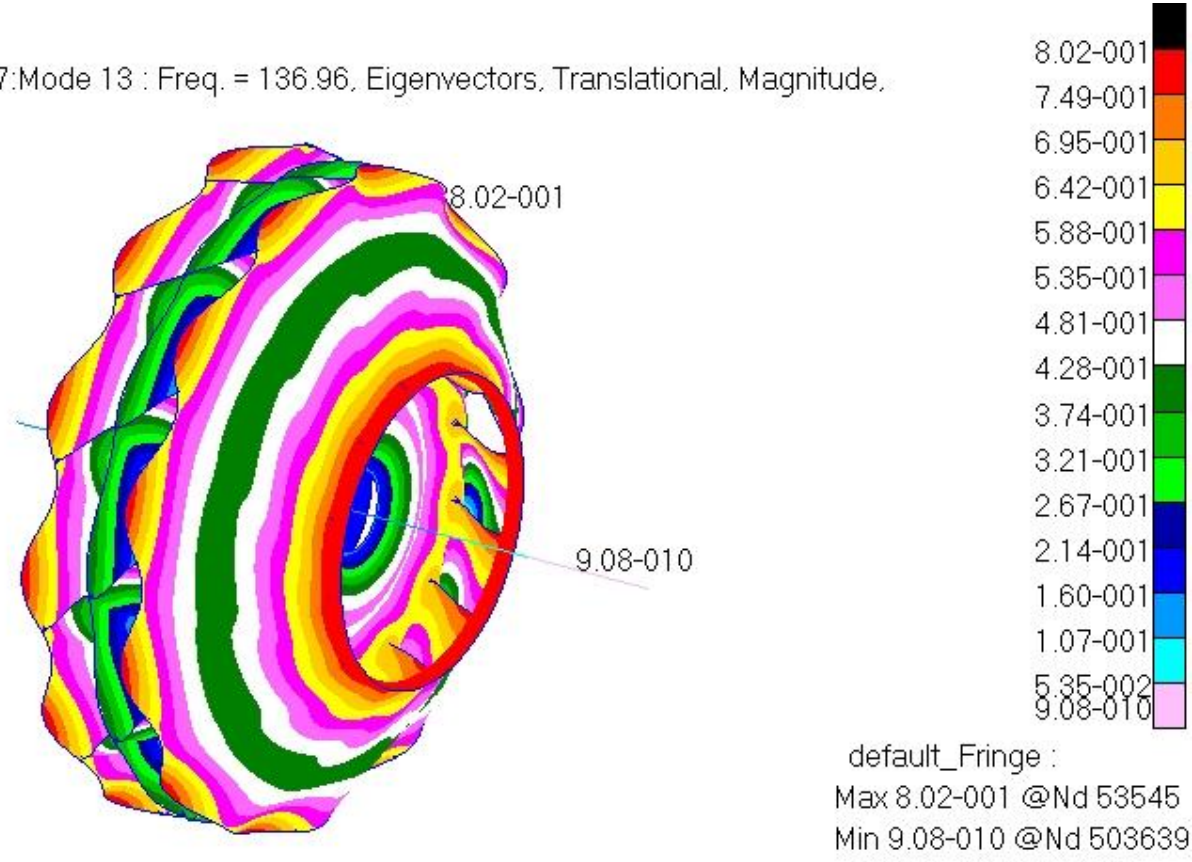

default_Fringe

Max8.02-001@Nd 53545 Min 9.08-010@Nd 503639 default_Deformation : Max8.02-001@Nd 53545

Figura 4.38 - Segundo modo circular nodal

Fringe: static_centrifugal, A7:Mode $16:$ Freq. $=164.23$, Eigenvectors, Translational, Magnitude
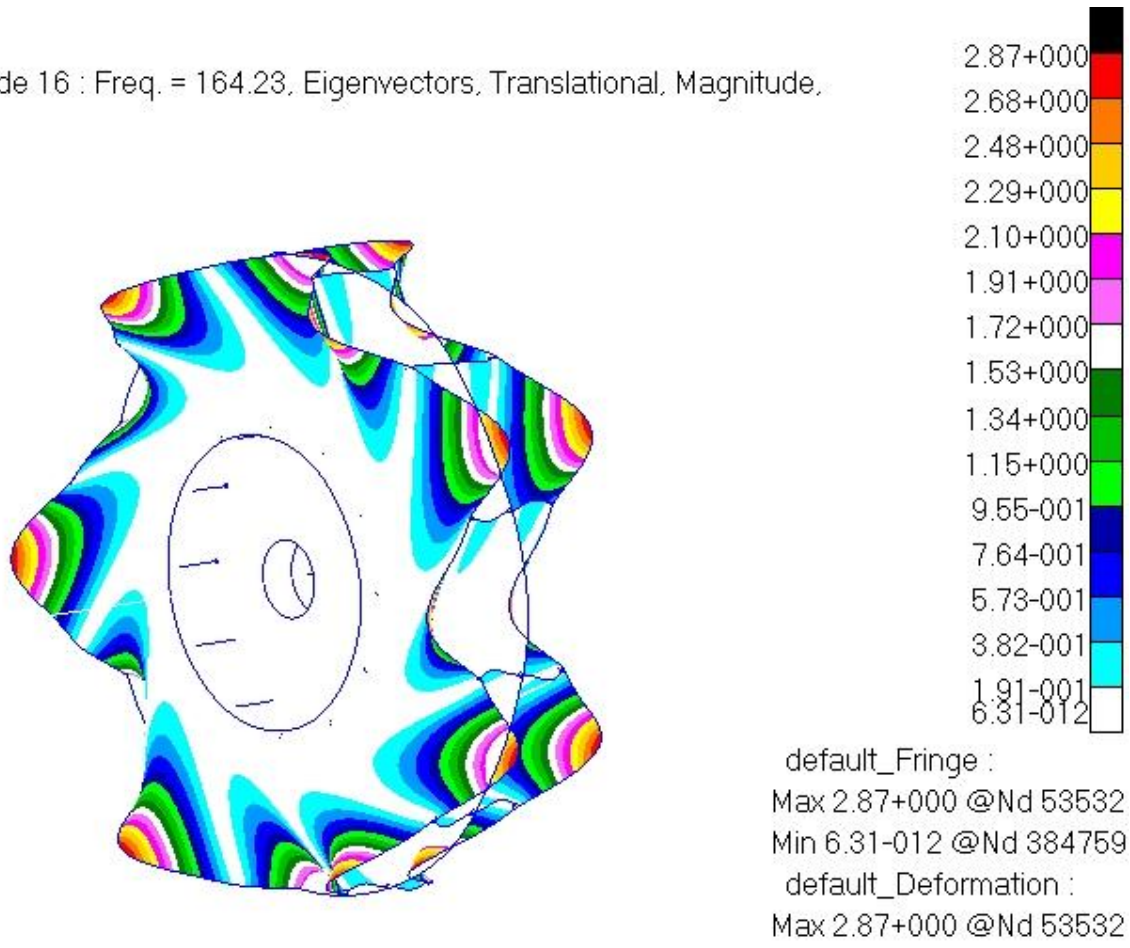

default_Fringe

Max 2.87+000@Nd 53532 Min 6.31-012@Nd 384759 default_Deformation Max 2.87+000@Nd 53532

Figura 4.39 - Ondulação dos discos laterais

Verifica-se, portanto, que as frequências naturais do impelidor estão acima da velocidade de operação do ventilador. A análise revela, ainda, a presença de modos de vibração caracterizados pela ondulação dos discos laterais entre as frequências 
de $162 \mathrm{~Hz}$ e $173 \mathrm{~Hz}$. Alguns destes modos não são simétricos, de modo que apenas alguns dos setores do impelidor - região compreendida entre palhetas adjacentes apresentam movimento ondulatório. Nos modos de vibração restantes, verifica-se a ondulação de todos os setores do impelidor, como indicado na Figura 4.39. Ressalte-se que estes modos são avaliados quanto à possibilidade de excitação aerodinâmica na frequência de passagem das palhetas. Entretanto, não é objetivo do presente trabalho estudar os modos excitados aerodinamicamente, motivo pelo qual as suas correspondentes frequências naturais não são indicadas na Tabela 4.6; com exceção do modo da Figura 4.39, apenas apresentado a título de ilustração. Estudos mais detalhados sobre as fases dos pulsos de pressão e dos movimentos de ondulação dos discos devem ser conduzidos nesta etapa, uma vez que estas excitações aerodinâmicas muitas vezes não são suficientes para iniciar um movimento vibratório.

Por fim, deve-se destacar que em ventiladores submetidos à variação de rotação, as investigações dos modos de vibração e das frequências naturais devem ser realizadas para cada rotação de operação, de modo a incorporar o correspondente efeito de enrijecimento centrífugo no cálculo das frequências naturais. Uma vez que o objetivo desta análise consiste apenas na ilustração da metodologia empregada para a análise de vibrações livres de ventiladores, neste ponto deve-se considerar que o ventilador em estudo possui velocidade constante. Portanto, a partir dos resultados obtidos é possível verificar a ausência de condições de ressonância do impelidor na rotação de operação do ventilador.

\subsection{ANÁLISE DE RESPOSTA EM FREQUÊNCIA DO IMPELIDOR}

Nesta etapa, desenvolve-se o modelo completo do impelidor centrífugo para a determinação das tensões dinâmicas em seus componentes. Os movimentos de translação e rotação, provenientes do cálculo de resposta ao desbalanceamento do rotor, são impostos ao cubo do impelidor centrífugo; seguindo a metodologia discutida na seção 3.2.2. 


\subsubsection{Modelo para análise dinâmica do impelidor centrífugo}

A elaboração do modelo para o cálculo de resposta do impelidor centrífugo é realizada segundo o procedimento descrito na seção 3.2.3. Assim, o cubo do ventilador, cujas dimensões são indicas na Tabela 4.1, é adicionado ao modelo construído para a análise de tensões estáticas. Elementos hexaédricos de 8 nós são empregados na malha do cubo.

O setor correspondente a $30^{\circ}$ do impelidor é então copiado doze vezes em torno do seu eixo de rotação, o que conduz ao modelo do impelidor completo, como mostra a Figura 4.40. A Figura 4.41 apresenta um detalhe do modelo em elementos finitos do impelidor centrífugo, com a indicação do cubo e dos elementos rígidos empregados para transferir os movimentos de base, do nó central para todos os nós pertencentes ao diâmetro interno do cubo.

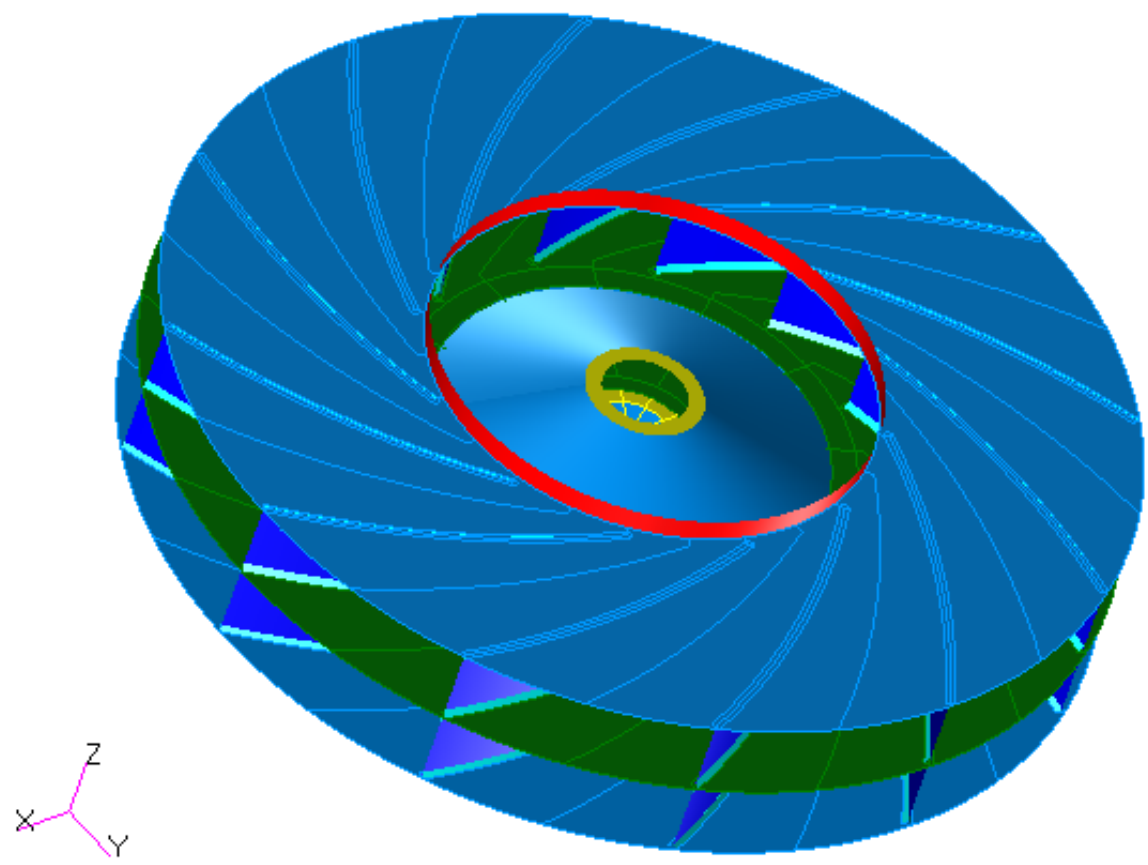

Figura 4.40 - Modelo completo do impelidor centrífugo analisado 


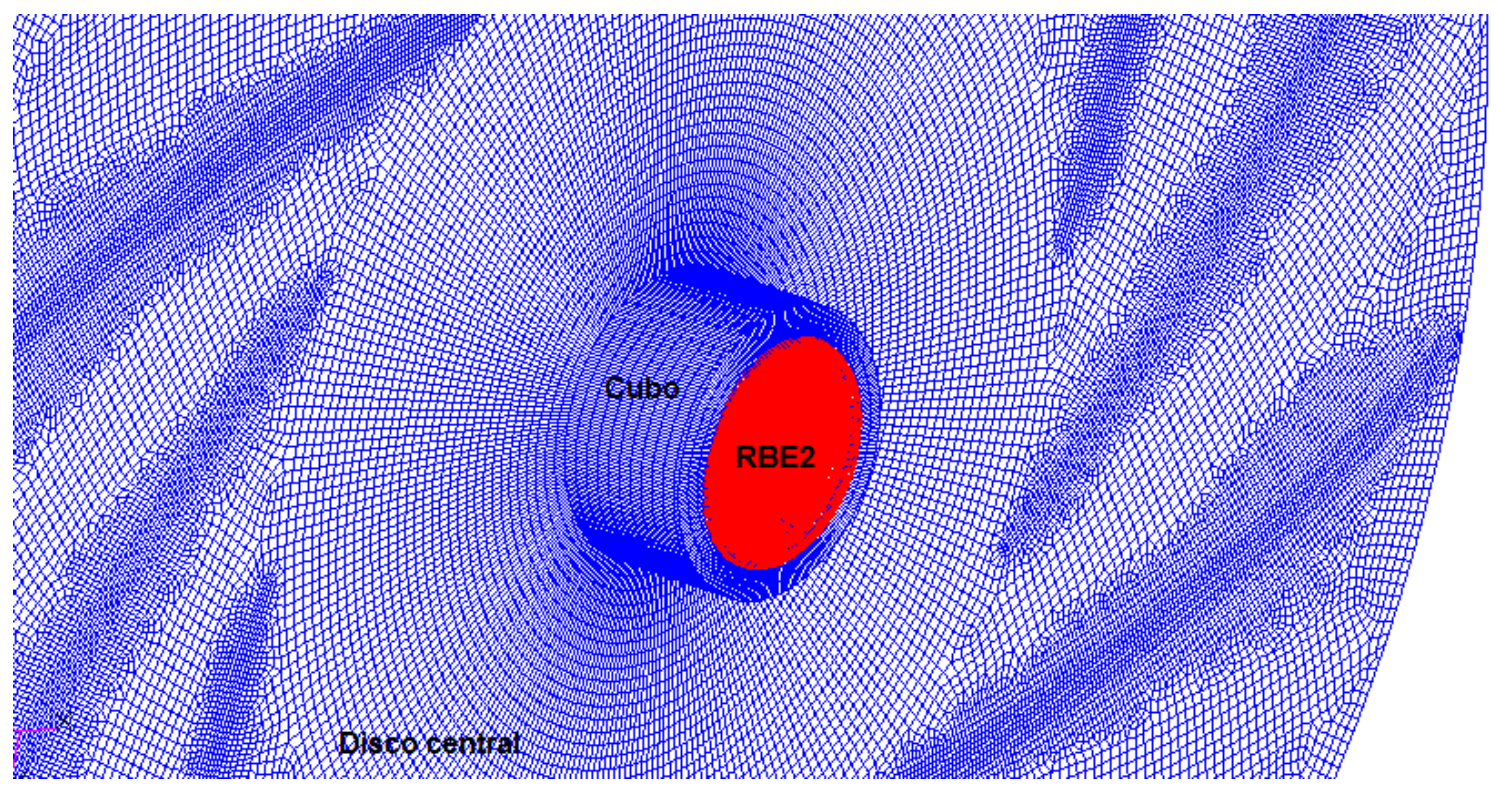

Figura 4.41 - Detalhe do cubo e do disco central do impelidor, com a indicação dos elementos rígidos utilizados

\subsubsection{Determinação das tensões dinâmicas e considerações acerca da superposição de efeitos}

Os movimentos de base correspondentes às translações e aos deslocamentos angulares no cubo do ventilador - determinados na análise de resposta em frequência do rotor - são obtidos a partir do gráfico apresentado na Figura 4.25. A análise da Figura 4.25 revela, ainda, que os deslocamentos angulares na rotação de operação do ventilador - $14.67 \mathrm{~Hz}$ ou 880 rpm - são muito pequenos na região do impelidor, o que pode ser explicado pela configuração do ventilador centrífugo em análise, em que o impelidor é posicionado de forma simétrica em relação aos mancais. Deste modo, os deslocamentos angulares podem ser desprezados para a análise das tensões dinâmicas. Contudo, a inclusão dos movimentos angulares no cubo do impelidor na análise de tensões dinâmicas pode se tornar relevante no estudo de ventiladores centrífugos de simples entrada, em que o impelidor encontra-se em balanço no eixo ou posicionado de forma assimétrica em relação aos mancais. 
A Tabela 4.7 transcreve os módulos dos movimentos de translação nas direções $Z$ e $Y$, observados na Figura 4.25. A título de simplificação, admite-se que estes movimentos estão defasados em $90^{\circ}$, ressaltando-se que, na realidade, os eixos da elipse correspondente à órbita do rotor não são exatamente paralelos aos eixos Y e Z. Assim, os valores de módulo e fase são especificados no software de elementos finitos para a avaliação das tensões dinâmicas. Procedimento análogo deve ser empregado caso sejam considerados movimentos de rotação no impelidor, oriundos do cálculo de resposta em frequência do rotor.

Tabela 4.7 - Movimentos de translação impostos ao modelo de elementos finitos. Os dados se referem à velocidade de operação do ventilador (14.67 Hz ou 880 rpm)

\begin{tabular}{ccc}
\hline Deslocamentos & Módulo $\left(10^{-6} \mathrm{~m}\right)$ & Fase (graus) \\
\hline $\mathrm{u}_{\mathrm{z}}$ & 38.62 & 0.0 \\
$\mathrm{u}_{\mathrm{y}}$ & 28.54 & 90.0 \\
\hline \hline
\end{tabular}

É importante ressaltar que o efeito do enrijecimento do impelidor na rotação de operação também é incorporado ao modelo para a análise de resposta. Os movimentos indicados na Tabela 4.7 são aplicados ao nó central e a resposta em frequência é calculada na rotação de operação do ventilador, isto é, $14.667 \mathrm{~Hz}$. Um amortecimento estrutural de $1 \%$ é considerado nas simulações.

Os módulos dos deslocamentos calculados na análise de resposta em frequência podem ser visualizados na Figura 4.42. A Tabela 4.8 apresenta as componentes complexas de deslocamento para um nó pertencente à extremidade de uma das palhetas, cujos valores estão em concordância com os resultados observados na Figura 4.42. A comparação destes deslocamentos com os deslocamentos impostos - indicados na Tabela 4.7 - revela que as respostas possuem aproximadamente o mesmo módulo das componentes de deslocamento impostas e que também estão defasadas em $90^{\circ}$, de modo que o comportamento apresentado pelo impelidor é essencialmente de corpo rígido. Pode-se verificar, através da análise de vibrações livres do impelidor, que as suas frequências naturais encontram-se consideravelmente acima da frequência correspondente à rotação de operação - a primeira frequência natural do impelidor é de $26.41 \mathrm{~Hz}$, correspondente 
ao primeiro modo diametral - o que justifica a ausência de grandes deslocamentos no impelidor.

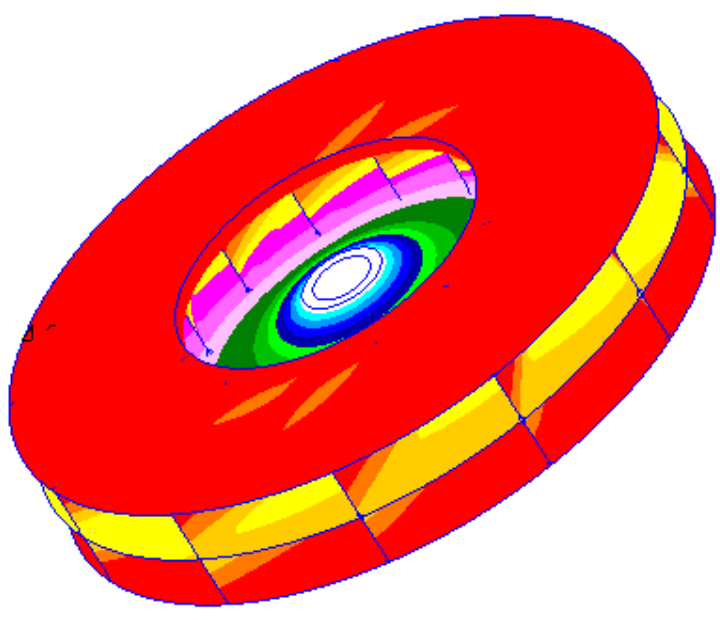

$4.82-002$

$4.82-002$

$4.81-002$

4.81-002

4.81-002

4.81-002

4.81-002

4.81-002

4.81-002

4.80-002

$4.80-082$

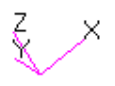

default_Fringe

Max4.82-002@Nd 135466

Min 4.80-002@Nd 78631

Figura 4.42 - Módulo dos deslocamentos no impelidor $\left(10^{-3} \mathrm{~m}\right)$, evidenciando o comportamento de corpo rígido

Tabela 4.8 - Deslocamentos calculados nas extremidades das palhetas

\begin{tabular}{cc}
\hline \hline Componentes & Deslocamentos $\left(10^{-6} \mathrm{~m}\right)$ \\
\hline$\delta_{z}$ & $38.79-0.009 i$ \\
$\delta_{y}$ & $-0.006+28.64 i$ \\
\hline \hline
\end{tabular}

É importante notar que, embora o MD Patran calcule corretamente os módulos e as fases das diferentes componentes de tensão no impelidor $\left(\sigma_{x x}, \sigma_{y y}\right.$ e $\tau_{x y}$ para um elemento de casca), as fases destas componentes não são consideradas na determinação das tensões de von Mises. Por este motivo, deve-se proceder com o cálculo manual das tensões de von Mises a partir das componentes complexas de tensão calculadas pelo MD Nastran. Ressalta-se, ainda, que este cálculo deve ser realizado para todos os nós do modelo de elementos finitos, uma vez que as representações gráficas da distribuição das tensões de von Mises no impelidor apresentadas pelo MD Patran não podem ser utilizadas como referência na localização das regiões do impelidor com tensões mais elevadas. 
Embora se verifique que para alguns nós do modelo as tensões de von Mises calculadas pelo pós-processador são aproximadamente iguais às determinadas pela equação (3.46), nota-se que em outros nós as diferenças percentuais podem ser superiores a $100 \%$, para mais ou para menos. Esta constatação reforça a necessidade do emprego do equacionamento discutido na seção 3.2.6 na avaliação das tensões dinâmicas de impelidores centrífugos. A título de ilustração, a Tabela 4.9 apresenta uma comparação entre os valores de tensão calculados pela equação (3.46) e os valores indicados pelo MD Patran para dois nós pertencentes ao disco central, em diferentes localizações: na região do diâmetro interno (nó 77047) e na região compreendida entre duas palhetas adjacentes (nó 129868).

Tabela 4.9 - Comparação entre as máximas tensões de von Mises calculadas pela equação (3.46) e os valores apresentados pelo MD Patran para dois nós do disco central

\begin{tabular}{cccc}
\hline \hline Identificação do Nó & $\begin{array}{c}\text { Máxima tensão de von } \\
\text { Mises calculada }(\mathrm{kPa})\end{array}$ & $\begin{array}{c}\text { Máxima tensão de von } \\
\text { Mises - Patran (kPa) }\end{array}$ & Diferença (\%) \\
\hline 77047 & 36.169 & 36.174 & 0.014 \\
129868 & 1.064 & 9.528 & 88.83 \\
\hline
\end{tabular}

Devido a esta limitação do pós-processador, foram elaboradas planilhas de cálculo para cada componente do ventilador (palhetas, discos, anéis e cones) e também para cada superfície destes componentes (Z1 e Z2), com o objetivo de determinar os valores máximos da tensão de von Mises no impelidor. Cada planilha de cálculo considerou como dados de entrada as partes real e imaginária das componentes de tensão de cada nó do modelo, conduzindo ao cálculo da máxima tensão de von Mises através da equação (3.46). A grande quantidade de nós do modelo de elementos finitos - que totalizam 426709 para os componentes analisados - conduz a arquivos de dados extensos e de difícil manipulação, reforçando a necessidade do desenvolvimento de um software auxiliar para contornar as limitações do pós-processador ou, opcionalmente, da busca de outros pós-processadores comercialmente disponíveis. A Tabela 4.10 exemplifica o cálculo da máxima tensão de von Mises em um nó do disco central. 
Tabela 4.10 - Exemplo de cálculo da máxima tensão de von Mises para um nó do disco central

\begin{tabular}{cccc}
\hline Componentes & Módulo $(\mathrm{kPa})$ & Fase (graus) & $\begin{array}{c}\text { Máxima tensão de von } \\
\text { Mises }(\mathrm{kPa})\end{array}$ \\
\hline$\sigma_{\mathrm{xx}}$ & 2.258 & 77.78 & \\
$\sigma_{\mathrm{yy}}$ & 21.258 & 89.47 & 36.169 \\
$\tau_{\mathrm{xy}}$ & 20.880 & 0.889 & \\
\hline \hline
\end{tabular}

A aplicação desta metodologia de cálculo para os nós do modelo de elementos finitos permite avaliar as máximas tensões de von Mises em cada um dos componentes do impelidor, apresentadas na Tabela 4.11. Na tabela também são indicadas as regiões dos componentes onde estes nós estão localizados.

Tabela 4.11 - Tensões dinâmicas nos componentes do impelidor na rotação de operação do ventilador $(880 \mathrm{rpm}$ ou $14.67 \mathrm{~Hz})$

\begin{tabular}{|c|c|c|c|}
\hline Componente & $\begin{array}{c}\text { Tensão de von Mises } \\
\text { Plano Z1 }(\mathrm{kPa})\end{array}$ & $\begin{array}{l}\text { Tensão de von Mises } \\
\text { Plano Z2 (kPa) }\end{array}$ & $\begin{array}{l}\text { Localização da máxima } \\
\text { tensão }\end{array}$ \\
\hline Palhetas & 21.8 & 20.4 & $\begin{array}{l}\text { Entrada da palheta } \\
\text { (ataque) }\end{array}$ \\
\hline Disco central & 36.2 & 36.2 & $\begin{array}{c}\text { Diâmetro interno, junto } \\
\text { ao cubo }\end{array}$ \\
\hline Discos laterais & 7.65 & 6.13 & Entrada da palheta \\
\hline $\begin{array}{l}\text { Anéis dos discos } \\
\text { laterais }\end{array}$ & 2.80 & 3.96 & Junto ao disco lateral \\
\hline Cones de rigidez & 46.8 & 44.1 & $\begin{array}{c}\text { Diâmetro interno, junto } \\
\text { ao cubo }\end{array}$ \\
\hline
\end{tabular}

A partir da Tabela 4.11, verifica-se que as tensões dinâmicas nos componentes do impelidor, na rotação de operação do ventilador, são da ordem de $\mathrm{kPa}$ e, portanto, consideravelmente menores que as tensões estáticas (da ordem de $\mathrm{MPa}$ ). Também é interessante notar que as regiões do impelidor com tensões dinâmicas mais elevadas estão localizadas nas proximidades das uniões soldadas. É o caso das palhetas, em que as máximas tensões dinâmicas ocorrem na borda de ataque na região correspondente à união com o disco central. Situação semelhante ocorre nos cones de rigidez e também no disco central, em que as máximas tensões dinâmicas são verificadas nos diâmetros internos, isto é, na união destes 
componentes com o cubo do impelidor. Estes resultados reforçam o interesse pela avaliação da vida em fadiga das uniões soldadas em impelidores centrífugos.

Os baixos níveis de tensão dinâmica calculados se justificam pelo movimento essencialmente de corpo rígido apresentado pelo impelidor, destacando-se que nenhum modo de vibração é excitado na rotação de operação e também que os movimentos de base impostos ao cubo do ventilador são extremamente pequenos (da ordem de $\mu \mathrm{m}$, como indica a Tabela 4.7). Consequentemente, a aplicação do Princípio da Superposição de Efeitos na combinação das tensões estáticas com as tensões dinâmicas, resulta, para o caso estudado, em distribuições de tensões muito semelhantes às apresentadas na seção 4.2 para cada componente do ventilador. Vale lembrar que estes resultados são particulares para o ventilador centrífugo de dupla-entrada estudado.

Embora níveis de tensão reduzidos tenham sido encontrados, verifica-se que o emprego desta metodologia pode ser de grande valia na análise de ventiladores que apresentem elevados deslocamentos na região do impelidor provenientes da resposta ao desbalanceamento; como, por exemplo, no caso da operação do equipamento ocorrer na proximidade da primeira rotação crítica do rotor. Adicionalmente, rotores de simples entrada - por apresentarem o rotor em balanço no eixo ou impelidores posicionados de forma assimétrica entre os mancais conduzem a deslocamentos angulares mais elevados na região do impelidor (quando comparados com ventiladores de dupla-entrada), o que pode contribuir para a verificação de tensões dinâmicas mais elevadas. Por fim, coincidências entre as frequências de excitação, como, por exemplo, a rotação de operação, com as frequências naturais do impelidor, também podem conduzir a maiores níveis de tensão dinâmica.

Se, por um lado, são verificados, na indústria, projetos que garantem a integridade estrutural do impelidor - seja através do emprego de fatores de serviço adequados para as tensões estáticas, seja através da consideração de margens entre as frequências de excitação e as frequências naturais do rotor e do impelidor, como evidenciado no exemplo estudado - por outro, a busca por maiores desempenhos implica em desafios no projeto estrutural estático e dinâmico destes equipamentos. Neste contexto, é interessante ilustrar a aplicação da metodologia proposta na avaliação do comportamento dinâmico de ventiladores centrífugos que eventualmente venham a operar na rotação crítica do rotor. 
A Figura 4.25 mostra que as maiores amplitudes de deslocamento na região do impelidor (nó 9 do modelo construído para a análise dinâmica do rotor) são verificadas na frequência de $21.86 \mathrm{~Hz}$, isto é, aproximadamente $1312 \mathrm{rpm}$, correspondente à primeira rotação crítica. Busca-se, neste ponto, avaliar a integridade estrutural do impelidor nesta rotação. Para esta avaliação serão consideradas as tensões estáticas e dinâmicas no impelidor analisado na velocidade de $21.86 \mathrm{~Hz}$. Neste ponto, é importante ressaltar algumas hipóteses iniciais necessárias para a realização desta avaliação, ressaltando-se a finalidade meramente ilustrativa do caso estudado. Evidentemente, a operação do ventilador em uma rotação superior a $880 \mathrm{rpm}$ exigiria um motor elétrico diferente do empregado originalmente, uma vez que a potência consumida por um ventilador centrífugo varia com o cubo da razão de velocidade. Também é interessante notar que a análise de dinâmica de rotores realizada na seção 4.3 admitiu que os coeficientes de rigidez e amortecimento são constantes na frequência. Análises mais rigorosas do comportamento dinâmico na rotação crítica do rotor devem considerar os coeficientes dos mancais correspondentes à velocidade de $21.96 \mathrm{~Hz}$. Além disso, o projeto dos mancais hidrodinâmicos também deve ser verificado para esta nova condição de operação.

Inicialmente, o modelo setorial do impelidor apresentado na seção 4.2 foi empregado para a análise das tensões estáticas na velocidade de $21.86 \mathrm{~Hz}$. A Tabela 4.12 mostra os resultados obtidos nas simulações. Como esperado, a razão entre as tensões estáticas calculadas nesta nova condição e as tensões apresentadas na Tabela 4.2 (para a velocidade de $14.667 \mathrm{~Hz}$ ) correspondem ao quadrado da razão de velocidade.

Tabela 4.12 - Tensões estáticas no impelidor na velocidade de $21.86 \mathrm{~Hz}$

\begin{tabular}{lcc}
\hline Componente & $\begin{array}{c}\text { Tensão de von Mises } \\
\text { Plano Z1 }\left(\mathrm{N} / \mathrm{mm}^{2}\right)\end{array}$ & $\begin{array}{c}\text { Tensão de von Mises } \\
\text { Plano Z2 }\left(\mathrm{N} / \mathrm{mm}^{2}\right)\end{array}$ \\
\hline Palhetas & 393 & 284 \\
Disco central & 193 & 193 \\
Discos laterais & 449 & 410 \\
Anéis dos discos laterais & 336 & 313 \\
Cones de rigidez & 222 & 178 \\
\hline \hline
\end{tabular}


Verifica-se, assim, que as tensões estáticas são inferiores à máxima tensão admissível, cujo valor considerado é de $488 \mathrm{~N} / \mathrm{mm}^{2}$, de modo que a integridade estrutural é assegurada do ponto de vista das tensões estáticas. Entretanto, esta avaliação também deve considerar a análise da dinâmica vibratória do impelidor, compreendida pela análise de vibrações livres e pela determinação das tensões dinâmicas provenientes dos movimentos de base no cubo do impelidor.

A análise de vibrações livres do impelidor estudado é realizada de maneira análoga à apresentada na seção 4.4. Deve-se destacar, contudo, a necessidade de incorporar ao modelo de elementos finitos o efeito de enrijecimento centrífugo correspondente à velocidade de passagem pela primeira rotação crítica, isto é, 21.86 $\mathrm{Hz}$. Esta consideração conduz a frequências naturais mais elevadas quando comparadas com as apresentadas na seção 4.4, o que está de acordo com a discussão realizada na seção 3.1.2. Uma comparação entre as quatro primeiras frequências naturais do impelidor nesta nova condição de velocidade $(21.86 \mathrm{~Hz})$ e as correspondentes frequências naturais na rotação de $14.67 \mathrm{~Hz}$ são apresentadas na Tabela 4.13.

Tabela 4.13 - Comparação das frequências naturais do impelidor em duas condições de enrijecimento centrífugo: $14.67 \mathrm{~Hz}$ e $21.86 \mathrm{~Hz}$

\begin{tabular}{|c|c|c|c|}
\hline $\begin{array}{l}\text { Descrição dos modos do } \\
\text { impelidor }\end{array}$ & $\begin{array}{l}\text { Frequências Naturais }(\mathrm{Hz}) \\
\text { Enrijecimento de } 14.67 \mathrm{~Hz}\end{array}$ & $\begin{array}{l}\text { Frequências Naturais }(\mathrm{Hz}) \\
\text { Enrijecimento de } 21.86 \mathrm{~Hz}\end{array}$ & $\begin{array}{c}\text { Diferença } \\
(\%)\end{array}$ \\
\hline $\begin{array}{l}1^{\circ} \text { modo diametral, em fase } \\
\text { com o eixo (vertical) }\end{array}$ & 26.41 & 31.31 & 15.65 \\
\hline $\begin{array}{l}1^{\circ} \text { modo diametral, em fase } \\
\text { com o eixo (horizontal) }\end{array}$ & 26.43 & 31.33 & 15.64 \\
\hline $1^{\circ}$ modo circular nodal & 40.03 & 42.24 & 5.23 \\
\hline $\begin{array}{l}\text { Modo de duas linhas } \\
\text { diametrais }\end{array}$ & 82.04 & 87.24 & 5.96 \\
\hline
\end{tabular}

Assim, nenhum modo de vibração do impelidor é excitado na passagem ou na operação na rotação crítica do rotor. A etapa seguinte na análise dinâmica do impelidor consiste na determinação das tensões dinâmicas devido aos movimentos de base no cubo do impelidor. Os deslocamentos na direção $Z$ e $Y$ na frequência de $21.86 \mathrm{~Hz}$ podem ser obtidos a partir da curva de resposta apresentada na Figura 4.25. A Tabela 4.14 transcreve o valor destes deslocamentos - e também das fases, 
consideradas as mesmas utilizadas na simulação anterior - utilizados como dados de entrada para a análise de resposta em frequência do impelidor.

Tabela 4.14 - Movimentos de translação na passagem pela primeira rotação crítica $(21.86 \mathrm{~Hz})$ impostos ao modelo de elementos finitos

\begin{tabular}{ccc}
\hline \hline Deslocamentos & Módulo $\left(10^{-3} \mathrm{~m}\right)$ & Fase (graus) \\
\hline $\mathrm{u}_{\mathrm{z}}$ & 0.8889 & 0.0 \\
$\mathrm{u}_{\mathrm{y}}$ & 2.3611 & 90.0 \\
\hline \hline
\end{tabular}

É importante notar que os valores indicados na Tabela 4.7 são da ordem de $\mu \mathrm{m}$, enquanto que os valores apresentados na Tabela 4.14 são da ordem de milímetros. Assim, os deslocamentos no impelidor na passagem ou na operação na primeira rotação crítica do rotor são consideravelmente maiores que os observados na rotação de $880 \mathrm{rpm}$. A imposição destes movimentos nas direções $Z$ e $Y$ do modelo de elementos finitos permite verificar os deslocamentos no impelidor, apresentados na Figura 4.43.

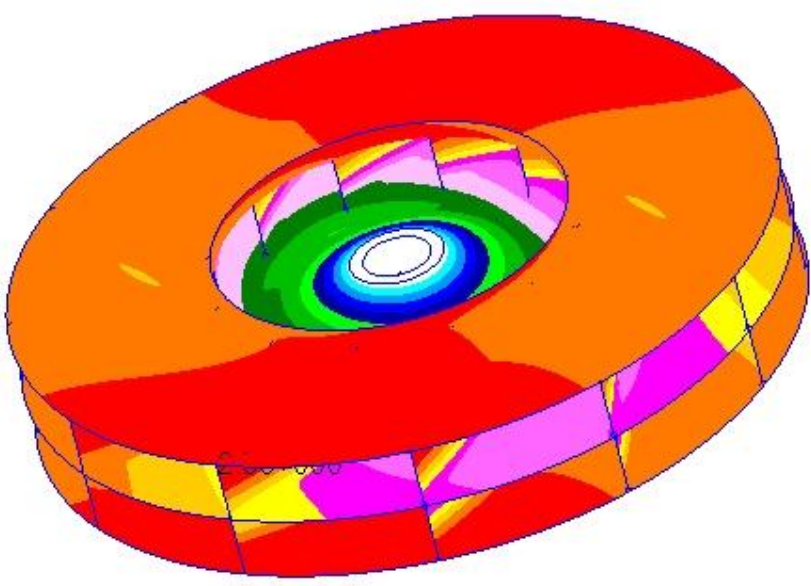

Figura 4.43 - Módulo dos deslocamentos no impelidor $\left(10^{-3} \mathrm{~m}\right)$ em $21.86 \mathrm{~Hz}$ 
A Tabela 4.15 indica as componentes complexas de deslocamento na extremidade de uma das palhetas do impelidor.

Tabela 4.15 - Deslocamentos calculados nas extremidades das palhetas na frequência de $21.86 \mathrm{~Hz}$

\begin{tabular}{cc}
\hline \hline Componentes & Deslocamentos $\left(10^{-3} \mathrm{~m}\right)$ \\
\hline$\delta_{z}$ & $0.8963-0.0014 i$ \\
$\delta_{y}$ & $0.0009+2.3847 i$ \\
\hline
\end{tabular}

Assim como os movimentos de base impostos, as componentes de deslocamento também estão defasadas em $90^{\circ}$. O módulo destes deslocamentos revela que o impelidor também apresenta comportamento de corpo rígido na passagem pela primeira rotação crítica do rotor. Estes resultados estão de acordo com a constatação de que nenhuma frequência natural do impelidor é excitada na rotação de $1312 \mathrm{rpm}(21.86 \mathrm{~Hz})$.

As tensões dinâmicas no impelidor nesta nova condição de operação devem ser obtidas de forma análoga à realizada para a rotação de $880 \mathrm{rpm}$. Portanto, a partir das componentes complexas de tensão obtidas no MD Nastran e do emprego da equação (3.46), calculam-se as máximas tensões de von Mises no impelidor. Os resultados obtidos são apresentados na Tabela 4.16.

Tabela 4.16 - Tensões dinâmicas nos componentes do impelidor na primeira rotação crítica do rotor (1312 rpm ou $21.86 \mathrm{~Hz}$ )

\begin{tabular}{lccc}
\hline Componente & $\begin{array}{c}\text { Tensão de von Mises } \\
\text { Plano Z1 }(\mathrm{MPa})\end{array}$ & $\begin{array}{c}\text { Tensão de von Mises } \\
\text { Plano Z2 (MPa) }\end{array}$ & $\begin{array}{c}\text { Localização da máxima } \\
\text { tensão }\end{array}$ \\
\hline Palhetas & 2.94 & 2.77 & $\begin{array}{c}\text { Entrada da palheta } \\
\text { (ataque) } \\
\text { Disco central }\end{array}$ \\
$\begin{array}{l}\text { Discos laterais } \\
\begin{array}{l}\text { Anéis dos discos } \\
\text { laterais } \\
\text { Cones de rigidez }\end{array}\end{array}$ & 1.94 & 4.93 & $\begin{array}{c}\text { Diâmo interno, junto } \\
\text { ao cubo } \\
\text { Entrada da palheta }\end{array}$ \\
\hline \hline
\end{tabular}


Verifica-se que as tensões dinâmicas no impelidor na primeira rotação crítica do rotor são da ordem de MPa, enquanto que as tensões dinâmicas obtidas na rotação de operação - Tabela 4.11 - são da ordem de kPa. Além disso, enquanto as tensões dinâmicas indicadas na Tabela 4.16 se referem aos nós dos elementos do modelo do impelidor, as tensões estáticas indicadas na Tabela 4.12 foram obtidas a partir da distribuição gráfica fornecida pelo pós-processador e se referem aos elementos de casca (e não propriamente aos nós destes elementos). Por este motivo, opta-se pela não sobreposição das tensões estáticas com as tensões dinâmicas. Esta sobreposição de efeitos pode ser viabilizada a partir do desenvolvimento de um software auxiliar que possibilite uma maior versatilidade no cálculo das máximas tensões de von Mises e no pós-processamento das mesmas; e pode se configurar como uma das sugestões para trabalhos futuros. A comparação das tensões estáticas indicadas na Tabela 4.12 e das tensões dinâmicas apresentadas na Tabela 4.16 permite constatar que, mesmo na operação do ventilador na primeira rotação crítica do rotor, o nível de tensões total não irá ultrapassar a máxima tensão admissível do impelidor considerada como critério de projeto, isto é, $488 \mathrm{~N} / \mathrm{mm}^{2}$.

Embora as simulações do ventilador centrífugo estudado indiquem que a passagem pela primeira rotação crítica não represente um risco à integridade estrutural do impelidor, algumas ressalvas devem ser feitas, uma vez que outros aspectos devem ser levados em consideração no dimensionamento dos ventiladores centrífugos. Ressalta-se mais uma vez, a finalidade ilustrativa dos exemplos apresentados neste capítulo.

As análises apresentadas não têm como objetivo a avaliação das tensões no cubo do ventilador centrífugo. Se, por um lado, as tensões estáticas neste componente são mais reduzidas e sua incorporação no modelo tem pouca influência nas tensões dos discos, palhetas, cones e anéis; por outro, o projeto estrutural do ventilador para aplicações com rotações mais elevadas deve envolver a verificação das tensões estáticas e dinâmicas também no cubo, ressaltando-se que as tensões estáticas crescem com o quadrado da variação de velocidade do ventilador. Acrescente-se $a$ isso o fato de que os materiais usualmente empregados para 0 cubo de ventiladores possuem limites de escoamento inferiores aos materiais utilizados para os demais componentes do impelidor. Estas particularidades devem ser incorporadas às análises estática e dinâmica em projetos mecânicos que visem 
a operação do ventilador em condições mais severas. Também é importante destacar a necessidade de modificar as expressões apresentadas na seção 3.2.6 cálculo da máxima tensão de von Mises em elementos de casca - para o estudo de elementos tridimensionais, caso seja de interesse a avaliação das tensões dinâmicas no cubo do ventilador centrífugo.

Outro aspecto que deve ser rigorosamente analisado caso seja de interesse operar o ventilador na rotação crítica do rotor, é o dimensionamento do eixo quanto à sua vida em fadiga. Na posição do impelidor, verifica-se uma força dinâmica devido ao seu desbalanceamento. Uma vez que a força de desbalanceamento é solidária ao movimento rotativo, esta implica em tensões estáticas no eixo do ventilador. Já as cargas devido ao peso próprio do rotor conduzem a tensões dinâmicas no eixo, uma vez que as reações nos apoios não são solidárias ao movimento rotativo. Assim, os eixos de ventiladores centrífugos são frequentemente analisados a partir do cálculo das tensões estáticas e dinâmicas, em especial nas mudanças de seção, com o auxílio do chamado Diagrama de Goodman. Uma vez que cada volta do eixo representa um ciclo na vida em fadiga, os eixos devem ser projetados para vida infinita. Sabe-se, entretanto, que a força de desbalanceamento é amplificada na medida em que o rotor se aproxima de suas rotações críticas. Deste modo, a análise do ventilador nesta condição deve considerar uma força de desbalanceamento amplificada no cálculo das tensões estáticas na avaliação da vida em fadiga do eixo. Contudo, estas verificações não são objetivo do presente trabalho.

Neste ponto, deve-se dar destaque à funcionalidade da metodologia apresentada, na medida em que esta é capaz de determinar as tensões dinâmicas máximas em cada componente do impelidor centrífugo; resultados que podem ser utilizados para análises de fadiga das uniões soldadas. Este aspecto é de grande interesse no projeto mecânico de ventiladores centrífugos, que em determinadas aplicações são submetidos a ciclos frequentes de liga e desliga ou a variações de velocidade durante a sua operação em campo. Destaca-se ainda a possibilidade de avaliar a integridade estrutural do impelidor a partir da sobreposição das tensões estáticas e das tensões dinâmicas não somente na região das uniões soldadas, mas em toda a extensão de seus componentes. É importante notar que a presente metodologia não visa substituir as análises tradicionalmente empregadas, mas sim 
fornecer elementos adicionais para o correto dimensionamento do impelidor a partir do estudo das tensões dinâmicas. 


\section{CONCLUSÕES E TRABALHOS FUTUROS}

A motivação para a realização deste trabalho foi a ausência de referências que tratem das particularidades da análise estrutural de ventiladores centrífugos e que reúnam, a um só tempo, os conhecimentos relativos à análise estática e dinâmica destes equipamentos. Não há literatura que discuta o cálculo de tensões dinâmicas em impelidores de ventiladores centrífugos, de modo que a dinâmica vibratória destes equipamentos é tradicionalmente analisada somente do ponto de vista da análise de vibrações livres. Com a conclusão deste trabalho, pretende-se ter contribuído para a alteração do panorama inicial, agregando-se ao estado da arte metodologias para a avaliação da integridade estrutural de ventiladores centrífugos através do cálculo das tensões estáticas e dinâmicas.

Alguns modelos para o cálculo analítico das tensões estáticas nos discos e palhetas de ventiladores centrífugos - discutidos no Capítulo 2 - são largamente empregados na indústria, que conta com a ampla experiência dos fabricantes de ventiladores centrífugos; e que percebe como inviável a realização de análises de elementos finitos para cada ventilador fabricado. Em contrapartida, foram identificadas situações nas quais são evidentes as fragilidades dos métodos analíticos: na análise de tensões em impelidores com discos e palhetas de geometrias mais complexas; na análise estrutural de equipamentos submetidos a temperaturas e rotações elevadas, fora da experiência prévia dos fabricantes; e na análise da vida em fadiga das soldas no impelidor, frequentemente submetidos a variações de velocidade e ciclos de ligamento e desligamento. Acrescente-se a isso que a busca crescente por ventiladores de maior desempenho aerodinâmico conduz ao emprego de impelidores com diâmetros e rotações elevados, implicando em tensões de grande magnitude no impelidor. Por estes motivos, o método dos elementos finitos mostra-se uma ferramenta essencial no projeto mecânico de ventiladores centrífugos.

O estudo da dinâmica vibratória de impelidores é tradicionalmente realizado a partir da análise de vibrações livres, discutida no início do Capítulo 3. Esta abordagem tem como objetivo determinar os modos de vibração $e$ as correspondentes frequências naturais do impelidor, e então avaliá-las segundo o 
conhecimento das fontes de excitação existentes. Discute-se ainda o efeito do enrijecimento centrífugo e evidencia-se a importância de incorporar este efeito aos modelos de elementos finitos para a análise dinâmica destes equipamentos. Adicionalmente à análise dinâmica dos impelidores, o trabalho aborda a análise dinâmica dos rotores de ventiladores centrífugos, cujo interesse reside na determinação das rotações críticas do ventilador e na avaliação da resposta dinâmica do rotor ao desbalanceamento. Neste ponto, apresenta-se o equacionamento para a modelagem de rotores de ventiladores centrífugos através do MEF, com a consideração de todos os elementos essenciais de uma análise de vibrações lineares de rotores.

Embora a literatura forneça elementos para o projeto dinâmico de máquinas rotativas, seja através da análise dos modos e frequências naturais do impelidor, seja através da análise de rotações críticas dos rotores, foi possível identificar a ausência de estudos que permitam o cálculo das tensões dinâmicas nos componentes dos impelidores. Buscou-se, assim, desenvolver uma metodologia para a determinação das tensões dinâmicas provenientes do desbalanceamento de ventiladores centrífugos. Ressalte-se, contudo, que a nova metodologia não visa substituir as análises tradicionalmente empregadas, e sim fornecer elementos adicionais para a verificação da integridade estrutural dos componentes do impelidor durante a sua operação em campo.

A metodologia apresentada neste trabalho é constituída de duas etapas principais: inicialmente, calcula-se a resposta ao desbalanceamento estático de rotores com eixos flexíveis e impelidores rígidos e indeformáveis, de modo a determinar os movimentos de translação e rotação na região do impelidor. Em seguida, os movimentos de base calculados são impostos a um modelo de elementos finitos do impelidor - neste ponto admitido flexível - cuja resposta em frequência conduz à distribuição das tensões dinâmicas em seus componentes. Como desdobramento desta análise, discute-se a sobreposição das tensões estáticas e das tensões dinâmicas a partir do Princípio da Superposição de Efeitos. Foi possível constatar que a nova metodologia assegura a linearidade dos sistemas combinados para cada rotação do ventilador, o que possibilita a aplicação deste princípio para a avaliação do nível de tensões total no impelidor.

O estudo de um ventilador centrífugo de dupla entrada no Capítulo 4 ilustra a metodologia para a determinação das tensões estáticas em impelidores centrífugos 
através do MEF e revela a possibilidade de se otimizar o projeto através da diminuição da espessura de seus componentes. Ressalte-se, contudo, o caráter particular do exemplo estudado, destacando-se, com base na experiência profissional do autor, a existência de projetos nos quais os níveis de tensão estática são extremamente elevados, muitas vezes próximos ao limite de escoamento do material. Nestes casos, análises rigorosas com a categorização das tensões no impelidor são conduzidas de modo a assegurar a integridade estrutural do equipamento.

A aplicação da metodologia para análise de resposta em frequência do impelidor estudado mostrou que o nível de tensões dinâmicas na sua rotação de operação é extremamente pequeno, constatação esta que pode ser compreendida através de duas características fundamentais do ventilador estudado: a existência de uma grande margem entre a primeira rotação crítica do rotor e a rotação de operação do ventilador, o que faz com que os deslocamentos na região do impelidor sejam de pequena magnitude; e a ausência de modos de vibração do impelidor que sejam excitados na rotação de operação do equipamento. Se, por um lado, estes aspectos refletem características comuns aos ventiladores centrífugos - cujo projeto dinâmico tem como premissa básica a obtenção de rotações críticas de rotor e de frequências naturais do impelidor consideravelmente maiores que a velocidade de operação do equipamento - por outro, verifica-se uma tendência de aplicação destes equipamentos em condições mais severas, como, por exemplo, no emprego de velocidades elevadas na proximidade ou correspondentes às rotações críticas do rotor; contribuindo, assim, para a elevação das tensões estáticas e dinâmicas. Por esse motivo, a metodologia desenvolvida também foi aplicada para o impelidor estudado na condição de operação na velocidade crítica do rotor, o que conduziu a níveis de tensão dinâmica consideravelmente mais elevados.

Fica então delineado, como campo para trabalhos futuros, um estudo sistemático de outros exemplos de ventiladores centrífugos, como, por exemplo, em ventiladores de simples entrada em balanço no eixo ou posicionados de forma assimétrica entre os mancais. Destaque-se também a necessidade do desenvolvimento, ou mesmo da investigação de outras opções comercialmente disponíveis, de softwares para o pós-processamento das tensões de von Mises que considerem as fases das diferentes componentes de tensão dinâmica. Nesse estudo também poderão ser incorporados elementos omitidos nas análises aqui 
apresentadas, como, por exemplo, a consideração de tensões dinâmicas provenientes do efeito gravitacional, bem como das excitações de origem aerodinâmica, aliadas à realização de ensaios experimentais para determinação das tensões dinâmicas; os quais - associados ao estudo da influência do valor de amortecimento estrutural empregado nas simulações de elementos finitos permitiriam validar os modelos empregados. Adicionalmente, podem ser incorporados à metodologia desenvolvida estudos detalhados da vida em fadiga das uniões soldadas de impelidores, bem como da vida em fadiga dos eixos quando da operação do ventilador na rotação crítica do rotor, de modo a fornecer mais elementos para a avaliação da integridade estrutural de ventiladores centrífugos submetidos a condições de operação severas. 


\section{REFERÊNCIAS}

AIR MOVEMENT AND CONTROL ASSOCIATION. AMCA 801-01: "Industrial Process/Power Generation Fans: Specification Guidelines". 2008.

AIR MOVEMENT AND CONTROL ASSOCIATION INTERNATIONAL, INC. ANSI/AMCA Standard 204-05: "Balance Quality and Vibration Levels For Fans", 2012.

AMERICAN PETROLEUM INSTITUTE. API 619: "Rotary-Type PositiveDisplacement Compressors for Petroleum, Petrochemical, and Natural Gas Industries". 2004.

AMERICAN SOCIETY OF MECHANICAL ENGINEERS. ASME Section VIII, Division 1 - Design and Fabrication of Pressure Vessels, 2011.

BATHE, K. J. Finite Element Procedures. Englewood Cliffs, New Jersey: Prentice Hall, 1996. 1037 p.

BELL, R.; BENHAM, P. P. Theoretical and Experimental Stress Analyses of Centrifugal Fan Impellers. The Journal of Strain Analysis for Engineering Design, vol. 13, n. 3, p. 141-147, Jul. 1978.

BOHL, W. Strömungsmaschinen 2 Berechnung und Konstruktion. Germany: Vogel, 1988. 284 p.

$\mathrm{BOHL}, \mathrm{W}$. Ventilatoren: Berechnung, Konstruktion, Versuch. Germany: Vogel, 1983. $266 \mathrm{p}$.

BONTE, M.H.A.; BOER, A; LIEBREGTS, R. Determining the von Mises stress power spectral density for frequency domain fatigue analysis including out-of-phase stress components. Journal of Sound and Vibration, vol. 302, issues 1-2, pp. 379-386, Abr. 2007.

BHOPE, D.V; PADOLE, P.M. Experimental and theoretical analysis of stresses, noise and flow in centrifugal fan impeller. Mechanism and Machine Theory, vol. 39, issue 12, p.1257-1271, Dec. 2004. 
BRITISH STANDARD INSTITUTION. BS 7608: Code of practice for fatigue design and assessment of steel structures, 1993.

BRITISH STANDARD INSTITUTION. PD 5500: "Specification for unfired fusion welded pressure vessels", Anexo A e K, 2009.

CHARRON, F.; DONATO, L.; FONTAINE, M. Exact calculation of minimum margin of safety from frequency response analysis stress results using yielding or failures theories. In: MSC WORLD USERS CONFERENCE, proceedings, p. 10, Maio 1993, Los Angeles.

CLOUGH, R. W.; PENZIEN, J. Dynamics of structures. New York: McGraw-Hill, 1975.

COMBESCURE, D; LAZARUS, A. Refined finite element modelling for the vibration analysis of large rotating machines: Application to the gas turbine modular helium reactor power conversion unit. Journal of Sound and Vibration, vol. 318, issues 45, p. 1262-1280, Dez. 2008.

COOK, R. D. Finite Element Modeling for Stress Analysis. New York: John Wiley \& Sons, INC., 1995. 320 p.

DEN HARTOG, J. P. Mechanical vibrations. New York: McGraw-Hill, 1956.

DEUTSCH, E. J. A method of stress analysis for shrouded discs. Aerospace Engng., vol. 21, n. 3, p. 24-30, 1962.

DEUTSCHES INSTITUT FÜR NORMUNG E.V. DIN 31690: Pedestal plain bearings; block plummer, German,1990.

EUROPEAN COMMITTEE FOR STANDARDIZATION. Eurocode 3: Design of steel structures, ENV 1993.

FLANIGAN, C. C. Accurate Enforced Motion Analysis Using MSC/Nastran Superelements. In: MSC/NASTRAN WORLD USERS CONFERENCE, proceedings, p. 20-24, June 20-24, 1994, Orlando, Florida.

GANS, H. D.; ANDERSON, W. J. Structural optimization including centrifugal effects. Finite Elements in Analysis and Design, vol. 7, n. 4, p. 317-324, 1991. 
GENTA, G. FENG, C. TONOLI, A. Dynamics behavior of rotating bladed discs: A finite element formulation for the study of second and higher order harmonics. Journal of Sound and Vibration, vol. 329, issue 25, p. 5289-5306, Dez. 2010.

GENTA, G.; Vibration of Structures and Machines. Practical Aspects. New York: Springer-Verlag, 1993.

GLESSNER, J.W; A method for analyzing stresses in centrifugal impellers. ASME paper, n. 54-A-167, 1967.

HAERLE, H. The strength of rotating discs. Engineering, n. 106, p.131-134, 1918.

HEARN, E,J; Mechanics of Materials - An Introduction to the Mechanics of Elastic and Plastic Deformation of Solids and Structural Materials. vol. 2, 3. ed. [S.I.]: Elsevier, 1997.

HITCHINGS, D. A finite element dynamics primer. [S.I]: NAFEMS, 1992. 258 p.

HOWDEN. Fabricante de ventiladores centrífugos. Disponível em: <http://www.howden.com>. Acesso em: 01 jul. 2009.

INTERNATIONAL ORGANIZATION FOR STANDARDIZATION. ISO1940-1: Mechanical Vibration - Balance quality requirements for rotors in a constant (rigid) state - Part 1: Specification and verification of balance tolerances, 2003.

INTERNATIONAL ORGANIZATION FOR STANDARDIZATION. ISO 14694: Industrial fans -Specifications for balance quality and vibration levels, 2003.

IRONS, J. Dynamic modelling of centrifugal fan rotors. In: 6th International Conference on Vibration in Rotating Machinery, IMechE, 1996.

IRRETIER, H. Free and Forced Vibrations of Turbine Blades. In: RIEGER, N. F (org.). Rotordynamics 2. Problems in Turbomachinery. Springer-Verlag Wien, New York, 1988.

JORGENSEN, R; Fan Engineering. 9. ed. Buffalo, New York: Howden Buffalo, Inc., 1999. 
JUVINALL, R. C. Engineering Considerations of Stress, Strain and Strength. 1. ed., [S.I]: McGraw-Hill, 1967.

LALANNE, M.; FERRARIS, G Rotordynamics Prediction in Engineering. Sussex: J. Willey \& Sons, 1990.

MACDONALD, K.A. MADDOX, S.J. New Guidance for fatigue design of pipeline girth welds. Engineering Failure Analysis, n. 10, p. 177-197, 2003.

MADDOX, S. J. Fatigue design rules for welded structures. Progress in Structural Engineering and Materials, vol.2, n.1, pp.102-109, 2000.

MEIROVITCH, L. Elements of vibration analysis. [S.I.]: McGraw-Hill, 1986.

MSC SOFTWARE CORPORATION. MSC Nastran 2008. Linear Static Analysis User's Guide. Disponível em: <www.mscsoftware.com>. Acesso em: 2 jan. 2012.

MSC SOFTWARE CORPORATION. Reference Manual. Part 6: Results Postprocessing. USA, 2010.

MSC SOFTWARE CORPORATION. Linear Static, Normal Modes, and Buckling Analysis Using MD Nastran and Patran. NAS120v Course Notes, 2009.

MSC SOFTWARE CORPORATION. Dynamic Analysis Using MD Nastran and Patran. NAS122 Course Notes, 2008.

MÜLLER, P. C.; SCHIEHLEN, W. O. Linear vibrations. [S.I.] Martinus Nijhoff Publishers, 1985.

NABI, M. S.; GANESHAN, N. Stress analysis of composite centrifugal fan impeller using the cyclic symmetric approach. Computers \& Structures, vol. 48, n. 5, 1993, p.781-785.

NELSON, H. D.; TALBERT, P. B. Rotordynamic Considerations. In: LOGAN, E.; ROY, R. (Org.) Handbook of Turbomachinery. 2. ed. New York: Marcel Dekker, 2003.

NICHOLAS, T. High cycle fatigue. A mechanic of materials perspective. [S.I] Elsevier, 2006. 
NICHOLAS, T. Critical issues in high cycle fatigue. International Journal of Fatigue, vol. 21, p. S221-S231, Set. 1999.

NORTON, R. L. Machine Design: An Integrated Approach. [S.I]: Prentice-Hall, 1998.

PESTEL, E. C.; LECKIE, F.A. Matrix methods in elastomechanics. New York: McGraw-Hill, 1964.

RADGEN, P. Market Study for Improving Energy Efficiency for Fans. Stuttgart: Fraunhofer IRB Verlag, 2002.

PONGE-FERREIRA, W. J. Método de ensaio e analise de características dinâmicas e velocidades criticas em impelidores de ventiladores centrífugos excitados aerodinamicamente. 1994. 223p. Dissertação (Mestrado) - Escola Politécnica, Universidade de São Paulo, São Paulo, 1994.

RAMAMURTI, V.; SUBRAMANI, D. A.; SRIDHARA, K. Free vibration analysis of a turbocharger centrifugal compressor impeller. Mechanism and Machine Theory, vol. 30, n. 4, p. 619-628, 1995.

RAMAMURTI, V.; BALASUBRAMNIAN, P. Steady State Stress Analysis of Centrifugal Fan Impellers. Computers \& Structures, n. 25, p.129-135, 1987.

RAO, J. S. YU, Y. D. SHIAU, T. N. Transient Response of Rotating Laminated Plates with Interfacial Friction Under Accelerating Conditions. Journal of Sound and Vibration, vol. 228, n. 1, p.37-50, 1999.

RAO, J. S. Rotordynamics. 1. ed. Nova Delhi: Wiley Eastern, 1983.

SAYER, R. J. Vibration Analysis of Centrifugal Fans. DoctorKnow Application Paper. 1999. Disponível em: <http://pt.scribd.com/doc/32261459/Vibration-Analysisof-Centrifugal-Fans>. Acesso em: 20 nov. 2011.

TIMOSHENKO, S. Strength of Materials. Part I. Elementary Theory and Problems. 3. ed. D. Van Nostrand Company, 1955.

TIMOSHENKO, S. Strength of Materials. Part II. Advanced Theory and Problems. 3. ed. D. Van Nostrand Company, 1956. 
TRAEXLER, J. F. Turbomachinery vibration. The Shock and Vibration Digest, v.9, n. 8, Ago. 1977.

VANCE, J.M; Rotordynamics Of Turbomachinery. Nova York: Wiley-Interscience, 1988, $400 \mathrm{p}$.

WEAVER, W.; TIMOSHENKO, S. P.; YOUNG, D. H. Vibration Problems in Engineering. 5. ed., Nova York: Wiley-Interscience, 1990.

XIONG, L. et al. Dynamic Response Analysis of the Rotating Blade of Horizontal Axis Wind Turbine. Wind Engineering, vol. 34, n. 5, p. 543-560, 2010.

YOUNG, W.; BUDYNAS, R. Roark's Formulas for Stress and Strain. New York: McGraw-Hill, 2002. 851 p.

ZACHARIADIS, D.C. Método para o cálculo da resposta dinâmica de estruturas à imposição de movimentos genéricos. Dissertação apresentada à Escola Politécnica da USP para obtenção do título de Mestre em Engenharia. São Paulo, 1986.

ZACHARIADIS, D. C. Estudo dos efeitos do desalinhamento angular de mancais hidrodinâmicos nas vibrações de rotores flexíveis. 2000. 185p. Tese (Doutorado) - Escola Politécnica, Universidade de São Paulo, São Paulo, 2000.

ZACHARIADIS, D. C. Unbalance Response of Rotors Supported on Hydrodynamic Bearings Placed Close to Nodal Points of Excited Vibration Modes. ASME Journal of Engineering for Gas Turbines and Power, vol. 128 n. 3, p.661-669, 2006.

ZHANG, Y. H.; MADDOX, S. J. Investigation of fatigue damage to welded joints under variable amplitude loading spectra. International Journal of Fatigue, vol. 31, p.138-152, 2009. 